\title{
IntechOpen
}

\section{Fire Safety and Management Awareness}

Edited by Fahmina Zafar and Anujit Ghosal

$$
\begin{aligned}
& 3 \sqrt{300} \\
& 4 \sqrt{5} \\
& 3 \sqrt{35}
\end{aligned}
$$





\title{
Fire Safety and Management Awareness
}

\author{
Edited by Fahmina Zafar \\ and Anujit Ghosal
}



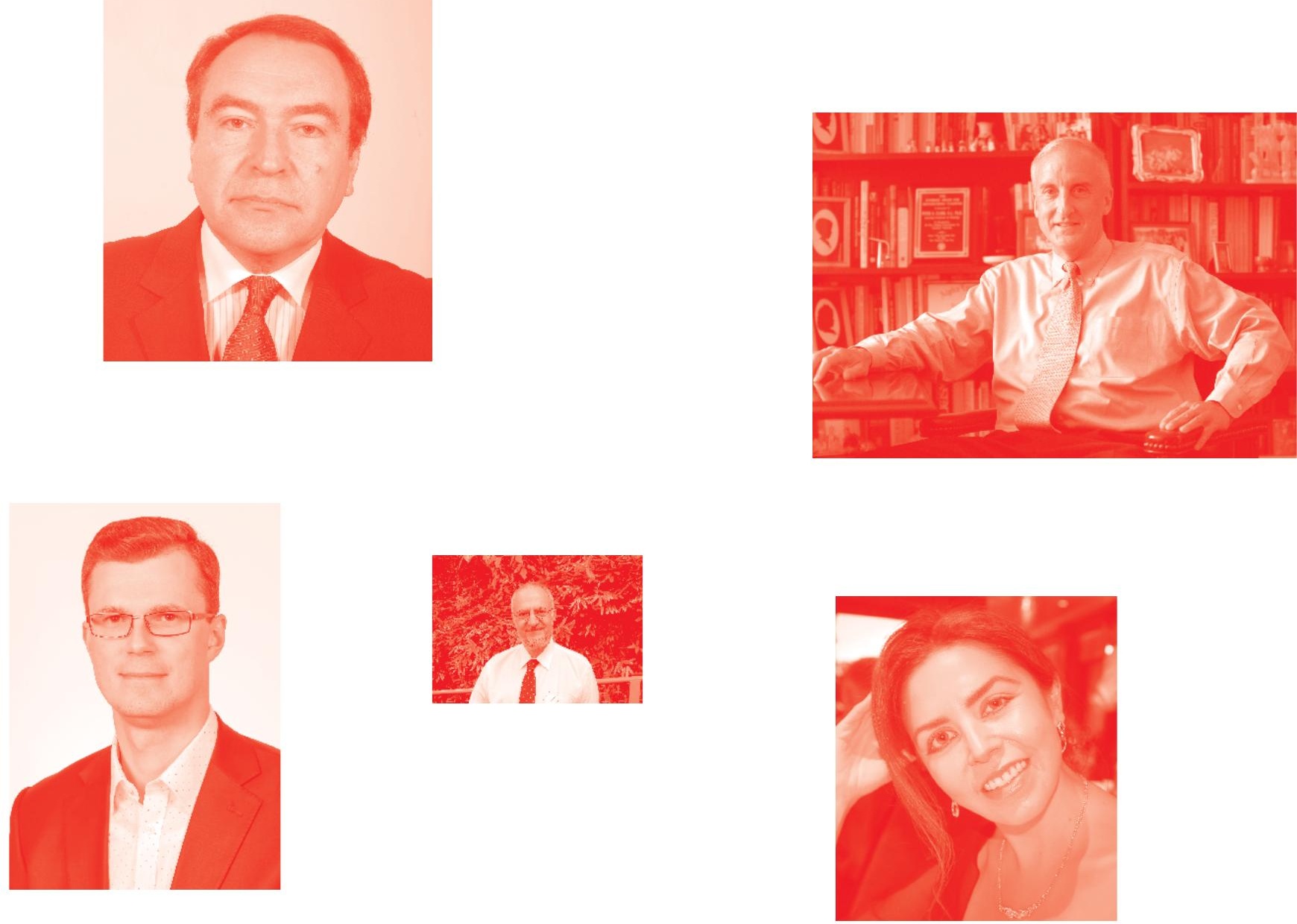

Supporting open minds since 2005
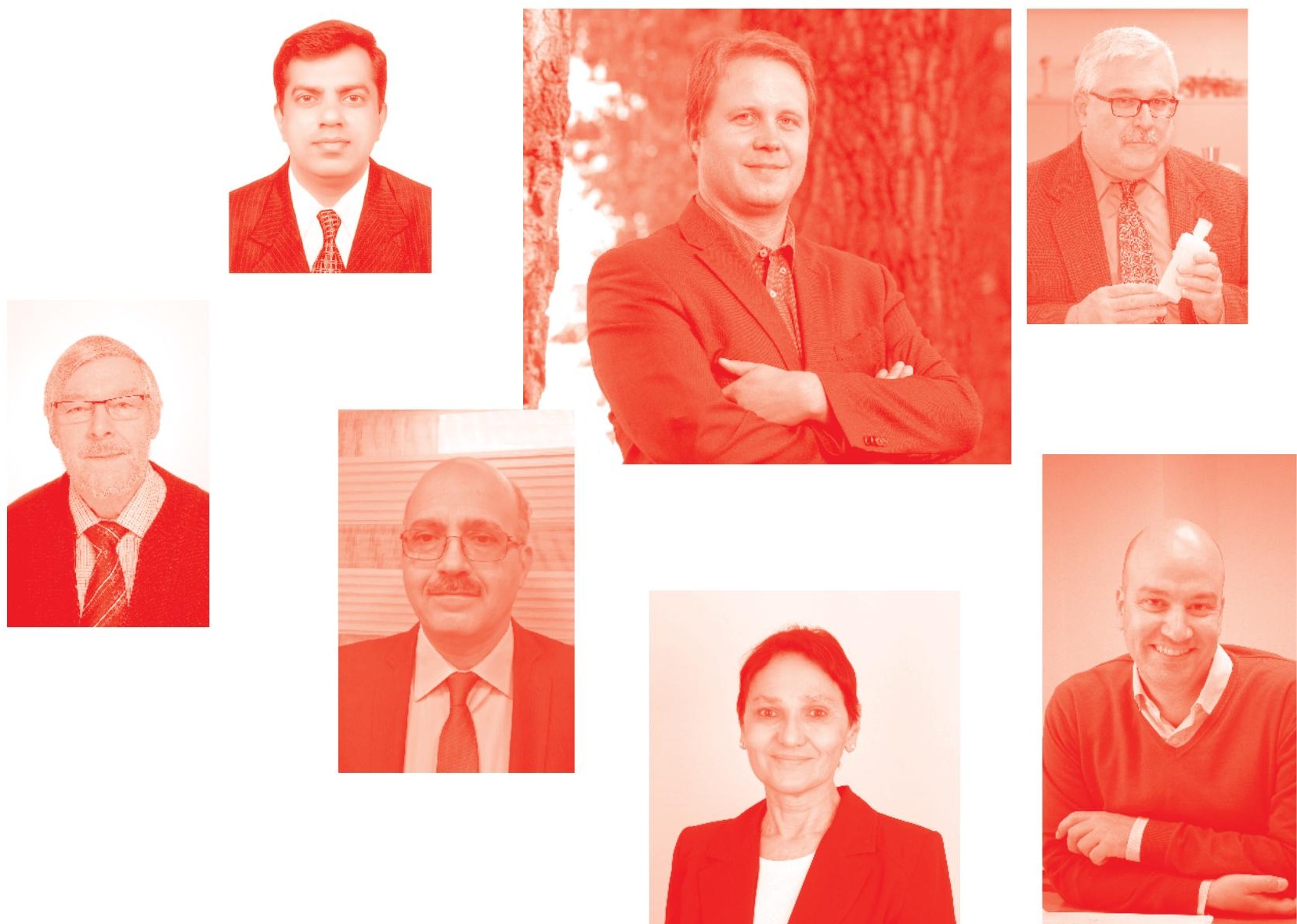
Fire Safety and Management Awareness

http: //dx . doi. org/10.5772/intechopen. 87859

Edited by Fahmina Zafar and Anujit Ghosal

\section{Contributors}

Rositsa Velichkova, Ivan Antonov, Svetlin Antonov, Kamen Grozdanov, Vancho Adjiski, Zoran Despodov, Rebecca Abney, Qin Ma, Agnes Iringova, Brady Manescau, Khaled Chetehouna, Aijuan Wang, Ilyas Sellami, Anujit Ghosal, Fahmina Zafar, Quentin Serra, Eric Florentin, Rachid Nait-Said, Fatiha Zidani

( ) The Editor(s) and the Author(s) 2020

The rights of the editor(s) and the author(s) have been asserted in accordance with the Copyright, Designs and Patents Act 1988. All rights to the book as a whole are reserved by INTECHOPEN LIMITED . The book as a whole (compilation) cannot be reproduced, distributed or used for commercial or non-commercial purposes without INTECHOPEN LIMITED's written permission. Enquiries concerning the use of the book should be directed to INTECHOPEN LIMITED rights and permissions department (permissions@intechopen.com).

Violations are liable to prosecution under the governing Copyright Law .

\section{(cc) BY}

Individual chapters of this publication are distributed under the terms of the Creative Commons Attribution 3.๑ Unported License which permits commercial use, distribution and reproduction of the individual chapters, provided the original author(s) and source publication are appropriately acknowledged. If so indicated, certain images may not be included under the Creative Commons license. In such cases users will need to obtain permission from the license holder to reproduce the material. More details and guidelines concerning content reuse and adaptation can be found at http : //www . intechopen . com/copyright-policy. html .

Notice

Statements and opinions expressed in the chapters are these of the individual contributors and not necessarily those of the editors or publisher. No responsibility is accepted for the accuracy of information contained in the published chapters. The publisher assumes no responsibility for any damage or injury to persons or property arising out of the use of any materials, instructions, methods or ideas contained in the book.

First published in London, United Kingdom, 2020 by IntechOpen

IntechOpen is the global imprint of INTECHOPEN LIMITED, registered in England and Wales, registration number: 11086078 , 5 Princes Gate Court, London, SW7 2QJ, United Kingdom Printed in Croatia

British Library Cataloguing-in-Publication Data

A catalogue record for this book is available from the British Library

Additional hard and PDF copies can be obtained from orders@intechopen. com

Fire Safety and Management Awareness

Edited by Fahmina Zafar and Anujit Ghosal

p. $\mathrm{cm}$.

Print ISBN 978-1-83962-425-4

Online ISBN 978-1-83962-426-1

eBook (PDF) ISBN 978-1-83962-427-8 


\section{We are IntechOpen, \\ the world's leading publisher of Open Access books}

\section{Built by scientists, for scientists}

\section{$5,100+$}

Open access books available

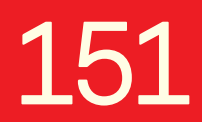

Countries delivered to

\author{
$126,000+$ \\ International authors and editors
}

Our authors are among the

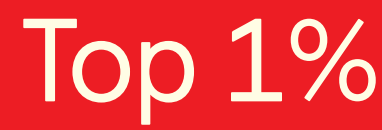

most cited scientists

Contributors from top 500 universities

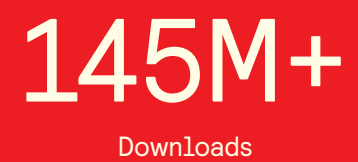

Downloads

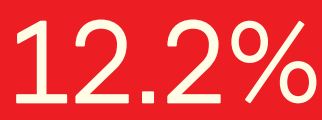

in Web of Science ${ }^{\mathrm{TM}}$ Core Collection (BKCI)

\section{Interested in publishing with us? \\ Contact book.department@intechopen.com}

Numbers displayed above are based on latest data collected.

For more information visit www.intechopen.com 



\section{Meet the editors}

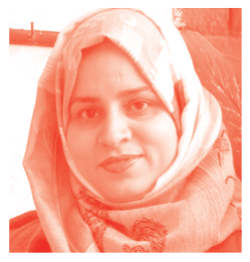

Dr. Fahmina Zafar is a senior researcher working at the Department of Chemistry, JMI, New Delhi, India, under the Women Scientists Scheme for Research in Basic/Applied Sciences, DST, India. Dr. Zafar received her PhD (2006) and MSc (1999) degree in Chemistry from JMI. She has worked as a postdoctoral fellow under UGC Kothari Postdoctoral Fellowship, and as a Scientist Pool, Research Associate, and Senior Research Fellow (CSIR) at the same department. She has more than 70 publications in peer-reviewed journals and books, and has presented more than 40 research papers in national and international conferences. Her research work involves the development of bio-based polymers, metallopolymers, organic-inorganic hybrids, coordination polymers, and nanocomposites for green environment in different fields including adsorption, antimicrobial, and corrosion-protective applications.

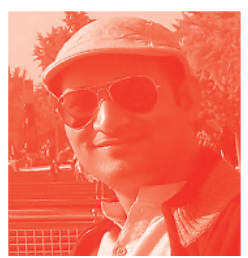

Dr. Anujit Ghosal is currently working as a young researcher at the School of Life Sciences, Beijing Institute of Technology, Beijing, China. He received his $\mathrm{PhD}$ degree (Chemistry) in 2015 and his M.Sc. degree (Materials Chemistry) in 2009 from Jamia Millia Islamia (J.M.I.), New Delhi, India, as well as his BSc degree with honours in Chemistry from Zakir Husain Delhi College, University of Delhi, Delhi, India in 2007. He has worked as a National Postdoctoral Fellow under a SERB fellowship in the School of Biotechnology, Jawaharlal Nehru University, New Delhi, India and served as an Assistant Professor for one year in Galgotias University, Greater Noida, UP, India. He has published in various international reputed refereed journals and participated in many national/international workshops. His research expertise involves polymer chemistry, hydrogels, magnetic nanomaterials, dye adsorption, drug delivery, and electrochemical corrosion. 



\section{Contents}

Preface

Section 1

Introduction

Chapter 1

Introductory Chapter: Fire Prevention Strategies

by Anujit Ghosal and Fahmina Zafar

Section 2

Effect of Variable Parameters

Chapter 2

Numerical Study on the Outdoor Wind Effects on Movement

Smoke along a Corridor

by Brady Manescau, Khaled Chetehouna, Quentin Serra,

Aijuan Wang and Eric Florentin

Chapter 3

Shifting Wildfire Trends and Management Implications for the Wildland Urban Interface in the Twenty-first Century

by Rebecca Abney and Qin Ma

Section 3

Advanced Protection Mechanism: Simulations

Chapter 4

Mathematical Modeling and Simulation of Development of the Fires in Confined Spaces

by Ivan Antonov, Rositsa Velichkova, Svetlin Antonov

and Kamen Grozdanov

Chapter 5

Methodology for Optimal Fire Evacuations in Underground

Mines Based on Simulated Scenarios

by Vancho Adjiski and Zoran Despodov 
Section 4

Safety Protocols with Case Studies

Chapter 6

A Case Study on the Fire Safety in Historic Buildings in Slovakia

by Agnes Iringová

Chapter 7

121

BLEVE Fireball Effects in a Gas Industry: A Numerical Modeling

Applied to the Case of an Algeria Gas Industry

by Brady Manescau, Khaled Chetehouna, Ilyas Sellami,

Rachid Nait-Said and Fatiha Zidani 


\section{Preface}

An important saying is "precaution is better than cure". The awareness of past and present adverse situations caused by fire outbreaks that have and are affecting living organisms directly or indirectly is mandatory for developing future preventive measures.

Fire is considered to be a natural calamity, but in recent years it is most likely caused by human error. Awareness and improvement in prevention protocols is of prime importance for sustainability. Human development and other unplanned activities have further increased fire tragedies. The increased population and economic burden have also led to the construction of more confined and populated buildings, small utility spaces as well as narrow exit routes. Literature surveys and case studies are symbolic proof of the destructive ability of man-made or natural fire eruptions worldwide.

Advanced fire or smoke sensors, use of particular construction material, evacuation plans for a sudden fire, installation of fire protection measures, and study of previous fire incidents are the keys to establishing awareness among professional and everyday people. In this regard, computation modelling and simulations have helped the analysts to prepare future housing projects or study previous fatal events in great depth. Under fixed parameters, recent technological advancements have made it possible to analyze and rectify the past or probable future fatal events caused by unwanted fire eruptions.

This book comprises seven chapters discussing few important aspects helpful in establishing safety against accidental fires and promoting awareness against them. The book discusses the improved construction strategies and ventilation designed to prevent accidents during emergency fires. Evacuation strategies and effects of external parameters (outdoor wind) on smoke are discussed using specific case modelling. Specific past events caused by fire have also been studied using numerical modelling to understand the disastrous scenario and improve the precautionary methods.

This book will be helpful to students, researchers, and other related professionals working in the field of fire prevention or management sections.

The efforts of all the authors, contributors, and technical staff of IntechOpen, with special thanks to Ms. Dajana Pemac, Author Service Manager, have greatly helped in finalizing the book compilation.

Fahmina Zafar

Jamia Millia Islamia, India

Anujit Ghosal

Beijing Institute of Technology,

China 

Section 1

\section{Introduction}





\title{
Introductory Chapter: Fire Prevention Strategies
}

\author{
Anujit Ghosal and Fahmina Zafar
}

\section{Brief introduction}

A few decades back, the incidents of fire were regarded as natural calamity and were treated as such with very little thought on other aspects. However, in-depth analysis of most of the recent accidental fire tragedies indicates the human fingerprints such as deforestation, cigarette, firecrackers, static fire in forest at night or other similar incidences [1-3]. The frequency and extent of loss in life or economic damages have been increasing along with the population growth. So, to check the catastrophic misfortunate instances of fire and controlling the after-effects, stringent rules must be followed [4-6]. Broadly, the rules can be divided in three categories as shown in the Figure 1.

In most of the places, fire safety and management protocols are common with slight modification based on the environmental conditions. These systems are adopted throughout the world, however, more strictly followed at flammable industries (oil, gas, paint, paper, etc.) while considered being little lenient at household vicinities $[7,8]$. The increased population with constant high pressure on the economic backbone of numerous countries has altered the previous protection protocols [9-11]. The high cost of living has resulted in a more congested neighborhood i.e. population density particularly in the urban areas is constantly increasing $[12,13]$. A collective approach is needed to avoid mistakes via., focusing on the fundamental area of management and planning. Figure 2 represents the basic blocks involved in planning and management section for any construction.

Any small mishap such as an electric short circuit, heating system malfunction, barbeques, candles, or similar incidences at one place will affect the entire or adjacent community other than environmental contamination. Apart from the prevention of fire incidence, defined safety measures can save lives after the occurrence of such accidental events. Various approaches have been followed for the management of fire preventions at the fundamental level. A few of them are presented below:

\section{i. Planning escape route}

ii. Routine inspections of doorways and exit passages

iii. Conducting regular practice drills for fire evacuations

iv. Maintenance of sprinklers or other extinguishers

v. Keep track of the exact number of occupants

vi. Avoid cluttering the areas which can inhibit the fire extinguish mechanisms.

vii. Recording alteration, submission, and safekeeping of building/factory blueprints 


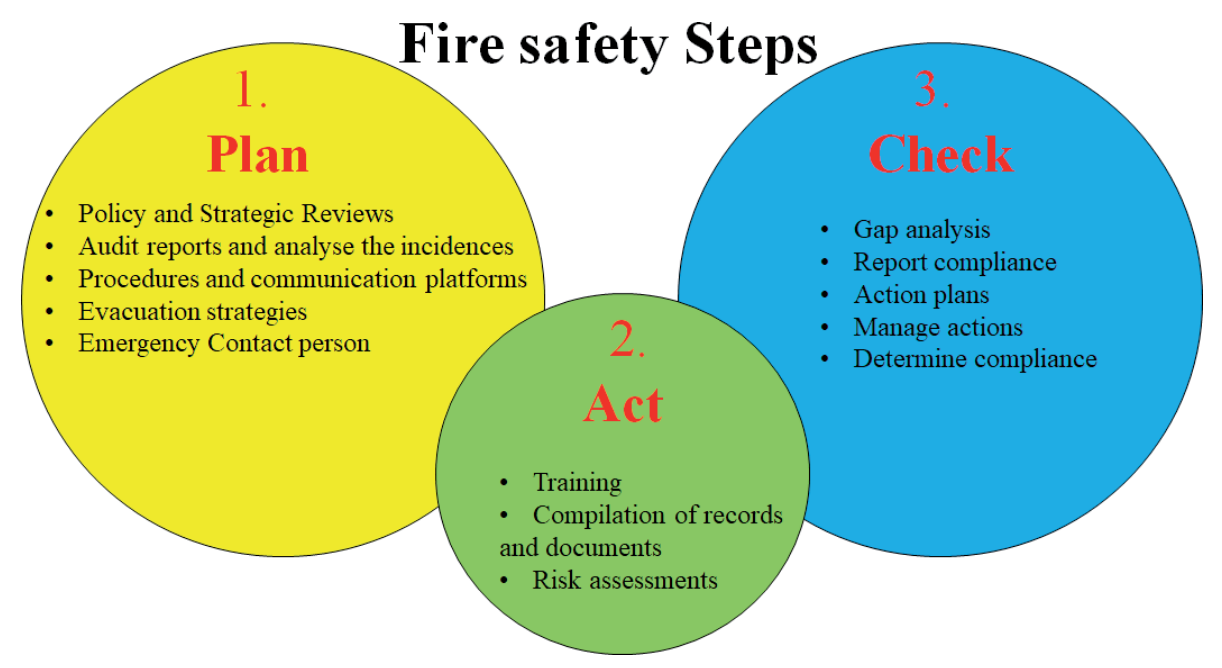

Figure 1.

Three broad categories of the fire protection activities.

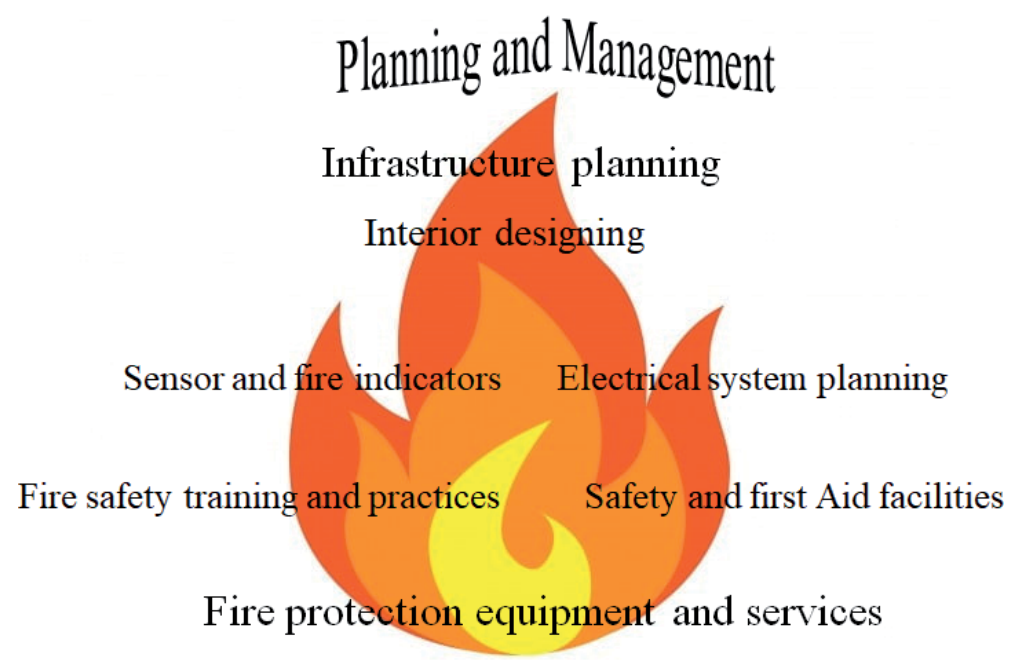

Figure 2.

Basics steps involved in fire protection of any construction.

\section{Comprehensive views}

Although numerous prevention and fire safety manuals have been developed but with modernization redefining fire prevention protocols with time is mandatory [14-16]. However, the process of change is ever dynamic for the inclusion of new information. Incorporation of the output from upcoming research studies for avoiding miss-managements during a fire outburst and remodeling the evacuation strategies are important. The architectural improvements which can further assist the evacuation process and ease the smoke exhaustion process should always be considered. The new engineering strategies based on recent active research should be adopted in the construction of housing societies, particularly in highly populated areas $[17,18]$. The implementation of fire safety protocol in pre-build structures 
via., virtual, mathematical, or numerical modeling and studies would improve the durability as well as safety of the area. Simulation of possible fire incidences or previous fire case-studies has been known to improve the overall understanding of the incidents and pre-planning strategies [19-21]. Development of such post evacuation strategies would minimize the materialistic loss as well as can zero the causalities under such events.

Other than the planning of construction and infrastructure skeleton, consideration of the use of specific materials in and around any place is also need to be checked [22]. Utilization of flammable materials such as plastics, oil based paints, use of cotton or storage of highly volatile chemicals seem to be a cause in many instances. Alternatively, non-flammable paints, coatings, fabrics, and construction materials like nanocomposite materials should be used [23-25]. Research on flame retardant materials and nanocomposites are also considered to be one of the alternatives against fire protection and evacuation management systems. Like coating over wooden furniture and cotton fabrics would render them less prone to fire and thus, can act as barrier during incidence of fire [26, 27]. Superhydrophobic and flame retardant tiles in kitchen and heating areas would result in reduction in possible accidents $[28,29]$. Further, designing of fire-fighting robots and other engineered bots are required to be brought in lime light for protection and prevention against tragedic incidences [30].

Finally, the strategies which can assist in improving pre, on-going, and post-fire incident management system are more pivotal in creating a fail-safe fire protection mechanism. The research encircling different views with building modeling, escape route planning in heritage buildings and mines, construction material used and prevention protocols are critical in safe keeping future generation including wild life as well as plants. The difficulties which are created due to the excessive urbanization and population boom in addition to poor engineering or planning of residence and work places particularly near forest or wood stock areas are to be addressed. Virtual in silico studies and numerical simulation in analyzing as well as recreating previous fire hazardous cases would provide additional benefits in visualization of the mistakes in following then existing protocols and to further improve fire safety measures.

\section{Acknowledgements}

Fahmina Zafar acknowledges Department of Science and Technology, New Delhi, India, for the Women Scientist Scheme (WOS) for Research in Basic/Applied Sciences, Rf\# SR/WOSA/CS-97/2016 and Department of Chemistry, Jamia Millia Islamia, New Delhi, India. 


\section{Author details}

Anujit Ghosal ${ }^{1,2 *}$ and Fahmina Zafar $^{2}$

1 School of Lifesciences, Beijing Institute of Sciences, Beijing, PRC

2 Department of Chemistry, Jamia Millia Islamia, New Delhi, India

*Address all correspondence to: anujit.ghosal@outlook.com

\section{IntechOpen}

(C) 2020 The Author(s). Licensee IntechOpen. This chapter is distributed under the terms of the Creative Commons Attribution License (http://creativecommons.org/licenses/ by/3.0), which permits unrestricted use, distribution, and reproduction in any medium, provided the original work is properly cited. (cc) BY 


\section{References}

[1] M.J. van Marle, R.D. Field, G.R. van der Werf, I.A.E. de Wagt, R.A. Houghton, L.V. Rizzo, P. Artaxo, K. Tsigaridis, Fire and deforestation dynamics in Amazonia (1973-2014), Global biogeochemical cycles, 31 (2017) 24-38.

\section{[2] A. Patrão, Human and Social}

Dimensions of Wildland Fire Management and Forest Protection.

[3] T. McDonald, Drought, fire, flood and COVID-complex systems and disruption, Ecological Management \& Restoration, 21 (2020) 73.

[4] W. Zeńczak, A. KrystosikGromadzińska, Improvements to a fire safety management system, Polish Maritime Research, 26 (2019) 117-123.

[5] H.M. Dijmarescu, Prometheus's Blind Spot: Invoking Rules and Political Histories of Fire, in, Northwestern University, 2020.

[6] Aspragathos N, Dogkas E, Konstantinidis $\mathrm{P}$, Koutmos $\mathrm{P}$, Lamprinou N, Moulianitis VC, et al. From pillars to AI technology-based Forest fire protection systems. In: Artificial Intelligence-Applications in Agriculture and Bio-System Engineering. London: IntechOpen; 2019

[7] Y. Khalil, A probabilistic visualflowcharting-based model for consequence assessment of fire and explosion events involving leaks of flammable gases, Journal of Loss Prevention in the Process Industries, 50 (2017) 190-204.

[8] C. Chen, G. Reniers, Risk assessment of processes and products in industrial biotechnology, (2018).

[9] W. Knorr, A. Arneth, L. Jiang, Demographic controls of future global fire risk, Nature Climate Change, 6 (2016) 781-785.
[10] M. McNamee, B. Meacham, P. van Hees, L. Bisby, W. Chow, A. Coppalle, R. Dobashi, B. Dlugogorski, R. Fahy, C. Fleischmann, IAFSS agenda 2030 for a fire safe world, Fire Safety Journal, 110 (2019) 102889.

[11] M. de Torres Curth, L. Ghermandi, V. Zimmerman, Living in a world of fire: the population dynamics of Mulinum spinosum in Northwestern Patagonia grasslands, Plant Ecology, (2020) 1-12.

[12] A.A. Sheeba, R. Jayaparvathy, Performance modeling of an intelligent emergency evacuation system in buildings on accidental fire occurrence, Safety science, 112 (2019) 196-205.

[13] A. Chakraborty, R. Devnath, Fire crisis Management-cesc's experience as Distribution Utility, Water and Energy International, 62 (2020) 15-21.

[14] T. Deave, A. Hawkins, A. Kumar, M. Hayes, N. Cooper, M. Watson, J. Ablewhite, C. Coupland, A. Sutton, G. Majsak-Newman, Evaluating implementation of a fire-prevention injury prevention briefing in children's centres: Cluster randomised controlled trial, PLoS One, 12 (2017) e0172584.

[15] M.-Y. Cheng, K.-C. Chiu, Y.-M. Hsieh, I.-T. Yang, J.-S. Chou, Y.-W. $\mathrm{Wu}, \mathrm{BIM}$ integrated smart monitoring technique for building fire prevention and disaster relief, Automation in Construction, 84 (2017) 14-30.

[16] Littlewood J. Smart Fire Performance-Assessment of Occupant Safety in Specialised Dwellings, in: International Conference on Sustainability in Energy and Buildings. Cham: Springer; 2018. pp. 435-444

[17] W. Węgrzyński, P. Sulik, The philosophy of fire safety engineering in the shaping of civil engineering development, Bulletin of the polish 
academy of sciences. Technical sciences, 64 (2016).

[18] E.K. Zavadskas, J. Antucheviciene, T. Vilutiene, H. Adeli, Sustainable decision-making in civil engineering, construction and building technology, Sustainability, 10 (2018) 14.

[19] D. Sahu, S. Kumar, S. Jain, A. Gupta, Experimental and numerical simulation studies on diesel pool fire, Fire and Materials, 40 (2016) 1016-1035.

[20] B. Lattimer, J. Hodges, A. Lattimer, Using machine learning in physicsbased simulation of fire, Fire Safety Journal, (2020) 102991.

[21] P. Ghasemi, A. Babaeinesami, Simulation of fire stations resources considering the downtime of machines: A case study, Journal of Industrial Engineering and Management Studies, 7 (2020) 161-176.

[22] E.J. Sugeng, M. de Cock, P.E. Leonards, M. van de Bor, Electronics, interior decoration and cleaning patterns affect flame retardant levels in the dust from Dutch residences, Science of The Total Environment, 645 (2018) 1144-1152.

[23] K. Shikinaka, M. Nakamura, R.R. Navarro, Y. Otsuka, Non-flammable and moisture-permeable UV protection films only from plant polymers and clay minerals, Green Chemistry, 21 (2019) 498-502.

[24] W. Guo, X. Wang, J. Huang, Y. Zhou, W. Cai, J. Wang, L. Song, Y. $\mathrm{Hu}$, Construction of durable flameretardant and robust superhydrophobic coatings on cotton fabrics for water-oil separation application, Chemical Engineering Journal, (2020) 125661.

[25] R. Olawoyin, Nanotechnology: The future of fire safety, Safety science, 110 (2018) 214-221.
[26] T. Ma, L. Li, Q. Wang, C. Guo, Construction of intumescent flame retardant and hydrophobic coating on wood substrates based on thiol-ene click chemistry without photoinitiators, Composites Part B: Engineering, 177 (2019) 107357.

[27] D. Lin, X. Zeng, H. Li, X. Lai, $\mathrm{T}$. Wu, One-pot fabrication of superhydrophobic and flame-retardant coatings on cotton fabrics via sol-gel reaction, Journal of colloid and interface science, 533 (2019) 198-206.

[28] S. Wi, S. Yang, U. Berardi, S. Kim, Assessment of recycled ceramicbased inorganic insulation for improving energy efficiency and flame retardancy of buildings, Environment international, 130 (2019) 104900.

[29] F. Zafar, E. Sharmin, Flame Retardants. London: IntechOpen; (2019). DOI: 10.5772/intechopen.82783

[30] S.S. Priyanka, R. Sangeetha, S. Suvedha, M.G. Vijayalakshmi, Android Controlled Fire Fighting Robot, Ineternational journal of innovative science Engg. and Technology, Volumn, 3 (2017). 
Section 2

Effect of Variable Parameters 



\title{
Numerical Study on the Outdoor Wind Effects on Movement Smoke along a Corridor
}

\author{
Brady Manescau, Khaled Chetehouna, Quentin Serra, \\ Aijuan Wang and Eric Florentin
}

\begin{abstract}
In this chapter, a numerical investigation is presented in order to highlight the effects of outdoor wind on smoke movements along a corridor in a compartment. For this, the Computational Fluid Dynamics (CFD) code, fire dynamics simulator (FDS), was used to model the reactive flows in interaction with outdoor wind. The wind velocity is taken between 0 and $12.12 \mathrm{~m} / \mathrm{s}$, based on the experimental result data come from the work of $\mathrm{Li}$ et al. was performed. From numerical data, it was found that smoke stratification state in the corridor depends on Froude number (Fr) and it can be divided into three cases: stable buoyant stratification $(\mathrm{Fr}<0.38)$, unstable buoyant stratification $(0.38 \leq \mathrm{Fr}<0.76)$, and failed stratification $(\mathrm{Fr} \geq 0.76)$. When $\mathrm{Fr} \geq 0.76$, smoke stratification is completely disturbed and smoke occupies the entire volume of the compartment, highlighting a risk of toxicity to people. Indeed, it was observed that the velocity of the outdoor wind influences strongly the concentration of $\mathrm{O}_{2}, \mathrm{CO}_{2}, \mathrm{CO}$, and visibility in the corridor and smoke exhaust. Moreover, for the input data used in the numerical modelling, the global sensitivity analysis demonstrated that the main parameters affecting the smoke temperature near the ceiling are the mass flux of fuel and the activation energy.
\end{abstract}

Keywords: outdoor wind, CFD, FDS, sensitivity analysis, corridor, smoke spread

\section{Introduction}

Since the end of the Second World War, the construction of buildings has experienced an increase in growth due to the increase in the world population and economic growth in recent decades. With many buildings, the problem of housing for people no longer arises. However, by making an inventory of the generally very high number of victims in building fires, these developments present numerous challenges for fire safety engineering. Indeed, for the past 75 years, there have been many fires in large buildings. There is for example, during April 15, 2019, the violent fire that started in the roof of the Notre-Dame de Paris cathedral, and it ravaged the roof and the frame by destroying the roof base and damaging the vault. In order to reduce the number of deaths and property damage, fire safety engineering has focused on understanding the different phenomena present in a building fire [1]. Among these phenomena, Paul et al. [2] and Hull et al. [3] showed that 
smoke is the main cause of death due to toxicity. Indeed, smoke plume can be hazardous for people in two different ways: the toxic gases in smoke, such as carbon dioxide, are a fatal hazard [2,3], and the smoke can make it difficult to rescue and evacuate people as it reduces visibility. In a compartment fire, it is therefore very important to know the characteristics of the smoke spread. The parameters that influence the smoke spread are mechanical ventilation and external atmospheric conditions. Generally, mechanical ventilation ensures smoke exhaust; however, external atmospheric conditions can disturb smoke flow. Moreover, smoke flows depend essentially on physical properties such as expansion, thermal pressure, thermal buoyancy, and wind effect. Variation in one of these parameters, such as the wind speed, can affect strongly smoke behavior [4, 5]. Considering this possibility, it is important to highlight the effects of external atmospheric conditions on smoke spread in a compartment.

Indeed, during a fire in a room, the presence of external wind through an opening contributes to disturbance of the smoke flow, which can impair the extraction process, thereby increasing the risk of death. In this context, many studies have been carried out in recent years to provide knowledge for fire safety engineering, including many full-scale $[6,7]$ and reduced scale $[8,9]$ experimental investigations.

At full scale, Tian et al. [6] showed that the more the wind velocity increases, the more the smoke temperature near the floor increases, in order to converge to the smoke temperature near the ceiling. Considering this, they highlighted that above a certain critical value of outdoor wind velocity, smoke stratification was disturbed, and smoke occupied the entire volume of the compartment. From scaling laws [10], small-scale experimental tests have been developed. Indeed, Li et al. [8] studied the influence of external wind velocity on the smoke flow in a small-scale facility. They showed that the driving forces of smoke flow through a high-rise building were modified according to the intensity of the external wind.

In addition to the experimental studies cited above, numerical simulations on smoke propagation in a compartment have also been conducted. For example, Li et al. [11] simulated smoke flows in a reduced scale (1:12) corridor under natural ventilation conditions using the CFD code FDS. In their work, they compared numerical data with experimental data and highlighted that FDS was able to simulate the temperature field and the level of smoke stratification for different heat release rates (HRR). In another example, Weng et al. [12] performed numerical simulations on the smoke flow in a subway tunnel fire equipped with an extraction system. Their results revealed that the temperature and the level of smoke stratification under the tunnel ceiling in the longitudinal direction increased with the HRR.

Considering the numerical studies presented above, it is shown that, using nice initial and boundary conditions, it is possible to make accurate simulations. Thus, in order to obtain accurate output results, it is necessary to define the input data correctly by carrying out a sensitivity analysis in order to find out the input parameters having the most influence on the output data. Two kinds of approach are classically used to achieve this: local and global approaches. For example, Batiot et al. [13] applied local and global sensitivity analysis on Arrhenius parameters in order to describe the kinetics of solid thermal degradation during fire phenomena, by determining four parameters (A, E, n, and $\nu$ ). They stressed the specific role of $\mathrm{A}$ and $\mathrm{E}$ on the equation and showed the role and the influence of these parameters in the differential equation used to model the mass loss rate of a solid fuel as a function of the temperature and time. In a second example, Xiao et al. [14] applied global sensitivity analysis to an environmental model named Level E. The sensitivity indices used the energy distribution of the model output over different frequency bands as the quantitative feature of the model output. 
Most of the numerical simulations that focused on the propagation of smoke in a ventilated or unventilated enclosure studied the level of smoke stratification as a function of the temperature profile and velocity. However, these numerical studies do not consider the effect of the external wind on smoke stratification in a corridor adjacent to a burning room with an opening. Using the data obtained by Li et al. [8], the aim of the present study was to highlight the ability of the fire dynamics simulator (FDS) to study smoke behavior according to the variation in outdoor wind velocity. This work, through a mesh resolution $[15,16]$, consists in reproducing the experimental conditions obtained in the work of $\mathrm{Li}$ et al. [8].

In this chapter, a CFD approach was proposed to evaluate the effects of outdoor wind on the smoke spread induced by an adjacent compartment fire. In order to highlight the influence of the input parameters used as initial conditions in the computational modelling, a global sensitivity analysis was performed. For this, Section 2 presents an overview of the global sensitivity analysis methodology with polynomial chaos expansion. Section 3 defines the physical and numerical modelling, Section 4 focuses on numerical results and global sensitivity analysis, and the conclusion is presented in Section 5.

\section{Sensitivity analysis methodology}

\subsection{Global sensitivity analysis}

The aim of sensitivity analysis is to quantify the influence of the variation of an input parameter on the variation of an output, also called quantity of interest. In the present study, the quantity of interest is the predicted smoke temperature near the ceiling $(X=5.4 \mathrm{~m}, \mathrm{Y}=0.5 \mathrm{~m}, \mathrm{Z}=85 \mathrm{~cm})$, filtered by a Savitzky-Golay algorithm (third-order) to eliminate high-frequency variations of temperature. It is expressed as a mapping of the input parameters $x_{i}$ for $i=1 \ldots r$, where $r$ is the number of parameters, and the dependence in time is omitted to simplify the notations as:

$$
\mathrm{T}=\mathcal{M}\left(\mathrm{x}_{1}, \ldots, \mathrm{x}_{\mathrm{r}}\right)
$$

Generally, there are two kinds of sensitivity analysis: local sensitivity analysis and global sensitivity analysis. The local sensitivity analysis is a simple approach in which the sensitivity indices are directly related to the derivatives of the quantity of interest with respect to each parameter [17-19]. It is called local because the local indices are only valid in a neighborhood of the nominal value [20]. While local approaches are restricted to the vicinity of the prescribed deterministic values, global sensitivity takes into account the entire domain of variation of each parameter.

To extend the approach in the case of larger variations of parameters, a probabilistic framework is adopted. Lacking knowledge on the probability density functions of the inputs, we assume that each of the parameters follows a uniform law with a $\pm 10 \%$ variation around its nominal value.

Of interest in this chapter are the Sobol sensitivity indices. These indices are often associated to an analysis of variance (ANOVA) decomposition, which consists in the decomposition of the model response into main effects and interactions [21]:

$$
\mathrm{T}=\mathcal{M}\left(\mathrm{x}_{1}, \ldots, \mathrm{x}_{\mathrm{r}}\right)=\mathrm{M}_{0}+\sum_{\mathrm{i}=1}^{\mathrm{r}} \mathrm{M}_{\mathrm{i}}\left(\mathrm{x}_{\mathrm{i}}\right)+\sum_{1 \leq \mathrm{i}<\mathrm{j} \leq \mathrm{r}}^{\mathrm{r}} \mathrm{M}_{\mathrm{ij}}\left(\mathrm{x}_{\mathrm{i}}, \mathrm{x}_{\mathrm{j}}\right)+\ldots+\mathrm{M}_{1, \ldots, \mathrm{r}}\left(\mathrm{x}_{1}, \ldots, \mathrm{x}_{\mathrm{r}}\right)
$$


The decomposition is unique if summands satisfy the properties [20]:

$$
\begin{gathered}
\mathrm{M}_{0}=\int \mathcal{M}\left(\mathrm{x}_{1}, \ldots, \mathrm{x}_{\mathrm{r}}\right) \mathrm{dx}_{1} \ldots . \mathrm{dx}_{\mathrm{r}} \\
\int \mathcal{M}\left(\mathrm{x}_{\mathrm{i}_{1}}, \ldots, \mathrm{x}_{\mathrm{i}_{\mathrm{s}}}\right) \mathrm{dx}_{\mathrm{i}_{1}} \ldots . \mathrm{dx}_{\mathrm{i}_{\mathrm{s}}}=0 \text { for } 1 \leq \mathrm{i}_{1}<\ldots<\mathrm{i}_{\mathrm{s}} \leq \mathrm{r}
\end{gathered}
$$

The variance of the model response according to variation of inputs can be derived as a sum of partial variances as follows:

$$
\operatorname{var}(T)=\mathrm{D}=\sum_{\mathrm{i}=1}^{\mathrm{r}} \mathrm{D}_{\mathrm{i}}+\sum_{1 \leq \mathrm{i}<\mathrm{j} \leq \mathrm{r}}^{\mathrm{r}} \mathrm{D}_{\mathrm{ij}}+\ldots+\mathrm{D}_{1, \ldots, \mathrm{r}}
$$

The partial variances $\mathrm{D}_{\mathrm{i}_{1}, \ldots, \mathrm{i}_{\mathrm{s}}}$ are defined by:

$$
D_{i_{1}, \ldots, i_{s}}=\int M_{i_{1}, \ldots i_{s}}\left(x_{i_{1}}, \ldots, x_{i_{s}}\right)^{2} d_{i_{1}} \ldots . d x_{i_{s}}
$$

Then, the Sobol indices can be derived according to:

$$
\mathrm{S}_{\mathrm{i}_{1}, \ldots, \mathrm{i}_{\mathrm{s}}}=\frac{\mathrm{D}_{\mathrm{i}_{1}, \ldots, \mathrm{i}_{\mathrm{s}}}}{\mathrm{D}}
$$

Crude Monte Carlo simulations or sampling-based techniques can be applied to obtain these indices, but the associated numerical is prohibitive for computationally demanding models such as those used in this chapter. To overcome this difficulty, the exact model provided by simulations was substituted by an analytical approximation, called metamodel, for which the computation of Sobol indices is exact and analytical. In this chapter, a polynomial chaos expansion was used as metamodel to derive the sensitivity indices.

\subsection{Polynomial chaos expansion}

The polynomial chaos (PC) expansion consists in the projection of the model $\mathrm{M}$ on the space spanned by a family of $\mathrm{N}_{\mathrm{p}}$ orthogonal polynomials:

$$
\mathcal{M}\left(\mathrm{x}_{1}, \ldots, \mathrm{x}_{\mathrm{r}}\right) \approx \tilde{\mathcal{M}}\left(\mathrm{x}_{1}, \ldots, \mathrm{x}_{\mathrm{r}}\right)=\sum_{\alpha \in \mathrm{A}_{\alpha}} \mathrm{Y}_{\alpha} \Phi_{\alpha}\left(\mathrm{x}_{1}, \ldots, \mathrm{x}_{\mathrm{r}}\right)
$$

where $A_{\alpha}$ is a finite set of vectors of positive integers $\alpha=\left(\alpha_{(1)}, \ldots, \alpha_{(r)}\right)$ such as $\operatorname{card}\left(\mathrm{A}_{\alpha}\right)=\mathrm{N}_{\mathrm{p}}$. Each of the multivariate polynomials $\Phi_{\alpha}$ can be expressed as a product of monovariate polynomials $\Psi_{\alpha_{(\mathrm{i})}}$ of order $\alpha_{(\mathrm{i})}$ :

$$
\Phi_{\alpha}\left(\mathrm{x}_{1}, \ldots, \mathrm{x}_{\mathrm{r}}\right)=\Psi_{\alpha_{(1)}}\left(\mathrm{x}_{1}\right) \times \ldots \times \Psi_{\alpha_{(\mathrm{r})}}\left(\mathrm{x}_{\mathrm{r}}\right)
$$

Legendre polynomials were used here because of the assumption of a uniform probability density function for each input parameter. To reduce the number of stochastic coefficients and thus the computational burden, a classical truncation criterion consists in prescribing the constraint: $\sum_{i=1}^{r} \alpha_{(i)} \leq p$, where $p$ is the maximum order allowed for each monovariate polynomial.

The interest in such a decomposition is that, due to orthonormal properties of the family of polynomials, the mean $\tilde{M}_{0}$, the variance $\tilde{D}$, the first-order Sobol 
indices $\tilde{\mathrm{S}}_{\mathrm{i}}$, and the total sensitivity indices $\tilde{\mathrm{St}}_{\mathrm{i}}$ of the metamodel can be computed as analytical functions of the chaos coefficients $\mathrm{Y}_{\alpha}[20]$ :

$$
\begin{gathered}
\tilde{\mathrm{M}}_{0}=\int \tilde{\mathrm{M}}\left(\mathrm{x}_{1}, \ldots, \mathrm{x}_{\mathrm{r}}\right) \mathrm{dx}_{1} \ldots \mathrm{dx}_{\mathrm{r}}=\mathrm{Y}_{\{0, \ldots, 0\}} \\
\tilde{\mathrm{D}}=\int\left(\tilde{\mathcal{M}}\left(\mathrm{x}_{1}, \ldots, \mathrm{x}_{\mathrm{r}}\right)-\tilde{\mathrm{M}}_{0}\right)^{2} \mathrm{dx}_{1} \ldots \mathrm{dx}_{\mathrm{r}}=\sum_{\alpha \in \mathrm{A}_{\alpha} \backslash\{0, \ldots, 0\}} \mathrm{Y}_{\alpha}^{2} \\
\tilde{\mathrm{S}}_{\mathrm{i}}=\frac{\sum_{\alpha \in \mathrm{A}_{\alpha}^{\{i\}}} \mathrm{Y}_{\alpha}^{2}}{\tilde{\mathrm{D}}} \text { with } \mathrm{A}_{\alpha}^{\{\mathrm{i}\}}=\left\{\left(\alpha_{(1)}, \ldots, \alpha_{(\mathrm{r})}\right) \text { such as }: \alpha_{(\mathrm{i})} \neq 0 \text { and } \alpha_{(\mathrm{j})} \neq 0 \text { for } \mathrm{j} \neq \mathrm{i}\right\} \\
\tilde{\mathrm{St}}_{\mathrm{i}}=\frac{\sum_{\alpha \in \mathrm{At}_{\alpha}^{\{i\}}} \mathrm{Y}_{\alpha}^{2}}{\tilde{\mathrm{D}}} \text { with } \mathrm{At}_{\alpha}^{\{\mathrm{i}\}}=\left\{\left(\alpha_{(1)}, \ldots, \alpha_{(\mathrm{r})}\right) \text { such as }: \alpha_{(\mathrm{i})} \neq 0\right\}
\end{gathered}
$$

To compute the chaos coefficients $\mathrm{Y}_{\alpha}$, intrusive and nonintrusive approaches can be used. The intrusive approach [22] consists in using PC expansion as an a priori function in the numerical solver. The development of a specific code is needed. It results in a single run of a very large problem. Here, we only consider nonintrusive techniques, in which the chaos coefficients are evaluated with repeated runs of a determinist program. Chaos coefficients can be evaluated by projection or by regression [23].

Here, we apply the second technique: it consists in searching the set of coefficients minimizing in the least-squares sense, the $\mathrm{L}_{2}$ distance between the model and the metamodel. This regression approach leads to:

$$
\left\{\mathrm{Y}_{\alpha}\right\}=\operatorname{argmin}\left(\frac{1}{\mathrm{Q}} \sum_{\mathrm{q}=1}^{\mathrm{Q}}\left(\mathcal{M}\left(\mathrm{x}_{1, \mathrm{q}}, \ldots, \mathrm{x}_{\mathrm{r}, \mathrm{q}}\right)-\sum_{\alpha \in \mathrm{A}_{\alpha}} \mathrm{Y}_{\alpha} \Phi_{\alpha}\left(\mathrm{x}_{1, \mathrm{q}}, \ldots, \mathrm{x}_{\mathrm{r}, \mathrm{q}}\right)\right)^{2}\right)
$$

The system is solved in a mean least-squares sense with a number $\mathrm{Q}$ of sampling points $\left(\mathrm{x}_{1, \mathrm{q}}, \ldots, \mathrm{x}_{\mathrm{r}, \mathrm{q}}\right)$ larger than the number of coefficients to be identified. Typically, in the literature, the number of sampling points is equal to twice the number of polynomial coefficients. In this study, the metamodel is computed using secondorder Legendre polynomials. This leads to $\mathrm{N}_{\mathrm{p}}=36$ stochastic modes, so that the number of sampling points is $\mathrm{Q}=72$. Roots of the third-order Legendre polynomial, $\Psi_{3}\left(\mathrm{x}_{\mathrm{i}, \mathrm{q}}\right)=0$, are chosen as sampling points. The results presented here were validated using the jackknife technique with 100 replications of a random subset of 70 samples.

\section{Numerical modelling}

\subsection{Governing equations}

The simulations were carried out using the CFD code fire dynamics simulator (FDS) version 6.5.3 [24]. It solves the Navier-Stokes equations using an explicit finite difference scheme. As a CFD code, FDS models the thermally driven flow with an emphasis on smoke and heat transport. It is a large eddy simulation (LES) model using a uniform mesh and has parallel computing capability using messagepassing interface (MPI) [25]. Reactive flows are modelled using a turbulence model based on a LES approach, a combustion model based on the eddy dissipation 
concept (EDC), and a thermal radiation model based on a gray gas model for the radiation absorption coefficient $[15,16]$.

The models are based on the numerical solving of Navier-Stokes equations.

These equations calculate mass, momentum, species, and energy conservation [25]:

$$
\begin{gathered}
\frac{\partial \rho}{\partial \mathrm{t}}+\frac{\partial}{\partial \mathrm{x}_{\mathrm{j}}}\left(\rho \mathrm{u}_{\mathrm{j}}\right)=0 \\
\frac{\partial}{\partial \mathrm{t}}\left(\rho \mathrm{u}_{\mathrm{j}}\right)+\frac{\partial}{\partial \mathrm{x}_{\mathrm{j}}}\left(\rho \mathrm{u}_{\mathrm{i}} \mathrm{u}_{\mathrm{j}}\right)=-\frac{\partial \mathrm{p}}{\partial \mathrm{x}_{\mathrm{i}}}+\rho \mathrm{g}_{\mathrm{i}}+\frac{\partial}{\partial \mathrm{x}_{\mathrm{j}}}\left\{\mu\left(\frac{\partial \mathrm{u}_{\mathrm{i}}}{\partial \mathrm{x}_{\mathrm{j}}}+\frac{\partial \mathrm{u}_{\mathrm{j}}}{\partial \mathrm{x}_{\mathrm{i}}}-\frac{2}{3} \delta_{\mathrm{ij}} \frac{\partial \mathrm{u}_{\mathrm{i}}}{\partial \mathrm{x}_{\mathrm{i}}}\right)\right\} \\
\frac{\partial \rho \mathrm{Y}_{\mathrm{k} *}}{\partial \mathrm{t}}+\frac{\partial}{\partial \mathrm{x}_{\mathrm{j}}} \rho \mathrm{u}_{\mathrm{j}} \mathrm{Y}_{\mathrm{k} *}=\frac{\partial}{\partial \mathrm{x}_{\mathrm{j}}}\left\{(\rho \mathrm{D})_{\mathrm{k} *} \frac{\partial}{\partial \mathrm{x}_{\mathrm{j}}} \mathrm{Y}_{\mathrm{k} *}\right\}+\dot{\omega}_{\mathrm{k} *}^{\prime \prime \prime} \\
\frac{\partial}{\partial \mathrm{t}}(\rho \mathrm{h})+\frac{\partial}{\partial \mathrm{x}_{\mathrm{j}}}\left(\rho \mathrm{u}_{\mathrm{i}} \mathrm{h}\right)=\frac{\mathrm{dp}}{\mathrm{dt}}+\dot{\mathrm{q}}^{\prime \prime \prime}+\lambda \frac{\partial^{2}}{\partial \mathrm{x}_{\mathrm{j}}^{2}} \mathrm{~T}+\sum \frac{\partial}{\partial \mathrm{x}_{\mathrm{j}}}\left\{\mathrm{h}_{\mathrm{k} *}(\rho \mathrm{D})_{\mathrm{k} *} \frac{\partial}{\partial \mathrm{x}_{\mathrm{j}}} \mathrm{Y}_{\mathrm{k} *}\right\}-\frac{\partial}{\partial \mathrm{x}_{\mathrm{j}}} \dot{\mathrm{q}}_{\mathrm{r}, \mathrm{j}}^{\prime \prime}
\end{gathered}
$$

where Eq. (14) represents the mass conservation equation, Eq. (15) represents the momentum conservation equation, Eq. (16) represents the species conservation equation, and Eq. (17) represents the energy conservation equation.

\subsection{Fire modelling}

The modelling was carried out using the Deardorff turbulence model and extinction model based on a critical flame temperature. The combustion model is based on the finite rate combustion using Arrhenius parameters (A: pre-exponential factor and Ea: activation energy). The fire source was modelled as a gas burner using butane as fuel with mass flux given by the experimental data [8]. The combustion heat of butane is $45182.83 \mathrm{~kJ} / \mathrm{kg}$.

\subsection{Computational domain and boundary conditions}

The experimental setup used as reference in the current numerical study represents a reduced scale (1:3) of a facility which contains a corridor and a fire room [8]. As shown in Figure 1, the dimensions of the corridor were $5.5 \mathrm{~m}$ (length) $\times 0.7 \mathrm{~m}$ (width) $\times 0.9 \mathrm{~m}$ (height) and the dimensions of the fire room were $2.0 \mathrm{~m}$ (length) $\times 1.7 \mathrm{~m}$ (width) $\times 1.0 \mathrm{~m}$ (height). The corridor and fire room were connected by a door whose dimensions were $0.7 \mathrm{~m}$ long by $0.3 \mathrm{~m}$ wide. The window in the fire room was opposite to the door and its dimensions were $0.5 \mathrm{~m}$ (width) $\times 0.5 \mathrm{~m}$ (height). The ceilings and floors of the corridor and fire room were made of steel plate with a thickness of $2.5 \mathrm{~mm}$.

As shown in Figure 1, the fire source was in the middle of the fire room, and it was defined as a gas burner using liquefied petroleum gas as fuel. The fuel supply rates of the gas burner were controlled and monitored by a flow meter. The HRR in the experiments was determined by multiplying the mass flow rate and the combustion heat of liquefied petroleum gas. The fire size can be scaled up to $96.2 \mathrm{~kW}$ of HRR, which corresponds to $1.5 \mathrm{MW}$ full-scale.

The wind can blow into the fire room through the window and the outdoor wind was generated by the fan and a static pressure box (cf. Figure 1). The velocity of the outdoor wind was adjusted by changing the AC frequency of the frequency converter. The velocity of the outdoor wind varied from 0 to $7.0 \mathrm{~m} / \mathrm{s}$ and the corresponding full-scale outdoor wind velocity range was $0-12.12 \mathrm{~m} / \mathrm{s}$ according to 


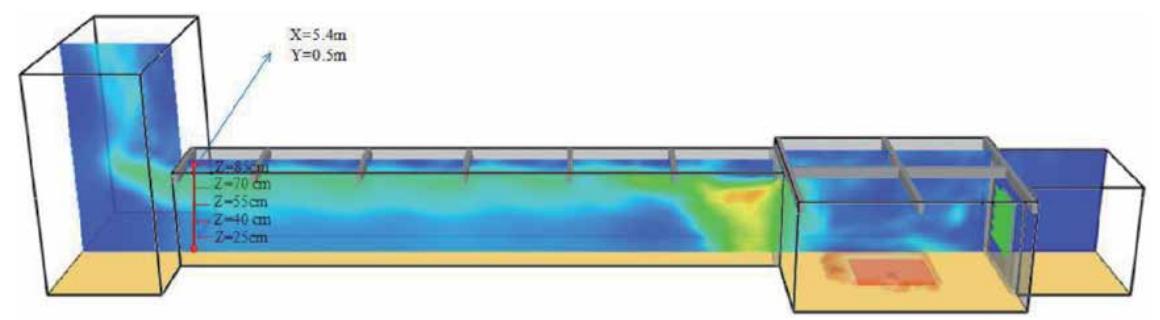

Figure 1.

Schematic view of the experimental corridor and fire room.

the scaling law of Froude modelling $[12,13]$. Varying the wind velocity, eight experiments were conducted at an HRR of $96.2 \mathrm{~kW}$, equaling $1.5 \mathrm{MW}$ at full-scale.

The experiments were carried out with ambient temperature ranging from 6 to $16^{\circ} \mathrm{C}$. K-type thermocouples with an accuracy of $\pm 1^{\circ} \mathrm{C}$ were used for the temperature measurements in the corridor and fire room. Hot wire wind speed meters were applied to measure the velocity of smoke.

In order to model the geometry and the boundary conditions of the setup used during the experimental tests [8], the walls of the corridor and fireroom were made of steel having a density of $7850 \mathrm{~kg} / \mathrm{m}^{3}$, a thermal conductivity of $46 \mathrm{~W} /(\mathrm{m} \cdot \mathrm{K})^{-1}$, a specific heat of $0.5 \mathrm{~kJ} /(\mathrm{kg} \cdot \mathrm{K})$, and an emissivity of 0.9 .

In simulations, the boundary condition at the window was modeled as an opening in the case without wind. With wind, a constant flow rate was set at the window using the velocity boundary used in the CFD code. In order to remain consistent with the experimental tests, a waiting time of $150 \mathrm{~s}$ was defined before activation of the outdoor wind velocity in the modelling. The simulations were performed in eight cases $(\mathrm{Vw}=0,1,2,3,4,5,6$, and $7 \mathrm{~m} / \mathrm{s}$, which correspond to $\mathrm{Vw}=0,1.73$, $3.46,5.20,6.93,8.66,10.39$, and $12.12 \mathrm{~m} / \mathrm{s}$ full-scale). Similarly, the simulation results were converted into full-scale data according to the Froude number.

The smoke temperature, smoke velocity, concentration of $\mathrm{O}_{2}$ and $\mathrm{CO}$, and visibility in the corridor were analyzed by setting different devices in the plane $(\mathrm{Y}=$ $0.5 \mathrm{~m})$, near the exit of the corridor $(X=5.4 \mathrm{~m})$, at different heights $(Z=85,70,55$, 40 , and $25 \mathrm{~cm}$ ). Moreover, other observations were carried out about the distribution of temperature, velocity, concentration of $\mathrm{O}_{2}$ and $\mathrm{CO}_{2}$, and visibility thanks to slice fields in the plane $\mathrm{Y}=0.5 \mathrm{~m}$.

\subsection{Mesh size resolution}

For numerical studies, it is important to choose the correct mesh size in order to obtain accurate simulation results. FDS provides a range of mesh sizes for mesh resolution. From a Poisson solver based on the fast Fourier transform (FFT), it is possible to obtain good numerical resolution by solving the governing equations. The mesh size was chosen in accordance with the recommendations made in the numerical studies $[15,16]$. An optimal mesh size should meet two requirements: good results in terms of accuracy and a short calculation time. The optimal mesh size of the domain is given by the nondimensional expression $\mathrm{D}^{*} / \partial \mathrm{x}$, where $\partial \mathrm{x}$ is the nominal mesh size and $\mathrm{D}^{*}$ is the characteristic fire diameter [24]. The characteristic fire diameter $D^{*}$ is determined using Eq. (18):

$$
\mathrm{D}^{*}=\left(\frac{\dot{\mathrm{Q}}}{\rho_{\infty \mathrm{c}_{\mathrm{p}} \mathrm{T}_{\infty} \sqrt{\mathrm{g}}}}\right)^{2 / 5}
$$


where $\mathrm{D}^{*}$ denotes the characteristic fire diameter, $\dot{\mathrm{Q}}$ the Heat Release Rate, and $c_{p}$ the specific heat.

Based on several experiments, the U.S. Nuclear Regulatory Commission recommends that the numerical range of $\mathrm{D}^{*} / \partial \mathrm{x}$ be between 4 and 16 for simulations to produce favorable results at a moderate computational cost, since the larger the value of $\mathrm{D}^{*} / \partial \mathrm{x}$ used in the simulation, the more accurate the simulation result. Hence, the range of mesh sizes can be obtained by the following equation $[15,16]$ :

$$
\frac{D^{*}}{16} \leq \delta_{x} \leq \frac{D^{*}}{4}
$$

After calculation, the range of mesh sizes was found to be: $(0.0625$ and $0.25 \mathrm{~m})$. Therefore, four different mesh sizes were used: 20, 10, 5, and $2.5 \mathrm{~cm}$.

Figure 2(a) and (b) presents the comparisons between experiment and FDS predictions for these four different meshes. The comparisons were carried out on the evolution of the smoke temperature and smoke velocity, both measured 70 $\mathrm{cm}$ above the ground and in the centerline of the corridor near the exit.

It can be seen that the numerical results obtained with mesh sizes of 5 and $2.5 \mathrm{~cm}$ converge with the experimental results, while the results of the 20 and $10 \mathrm{~cm}$ meshes diverge. Moreover, the $2.5-\mathrm{cm}$ mesh gives more accurate numerical results than the 5-cm mesh. As shown in Table 1, the relative gap (RG) of the calculation with the $2.5-\mathrm{cm}$ mesh $(3.85 \%)$ is slightly smaller than the calculation with a $5-\mathrm{cm}$ mesh $(6.83 \%)$. The relative gap (RG) is obtained by [26]:

$$
\mathrm{RG}=100 \times \frac{\sqrt{\sum_{\mathrm{i}=1}^{\mathrm{n}}\left(\mathrm{y}_{\mathrm{pre}, \mathrm{i}}-\mathrm{y}_{\exp , \mathrm{i}}\right)^{2}}}{\sqrt{\sum_{\mathrm{i}=1}^{\mathrm{n}}\left(\mathrm{y}_{\exp , \mathrm{i}}\right)^{2}}}
$$

where ypre is a predicted value, yexp is an experimental value, and $\mathrm{n}$ is the number of experimental points.

However, the calculation time with the $2.5-\mathrm{cm}$ mesh is 10 times longer than with the $5-\mathrm{cm}$ mesh. In addition, the relative gap of the $5-\mathrm{cm}$ mesh is close to that of the $2.5-\mathrm{cm}$ mesh. As it represents the best trade-off between precision and calculation time, the $5-\mathrm{cm}$ mesh was used for the following calculations, this choice is
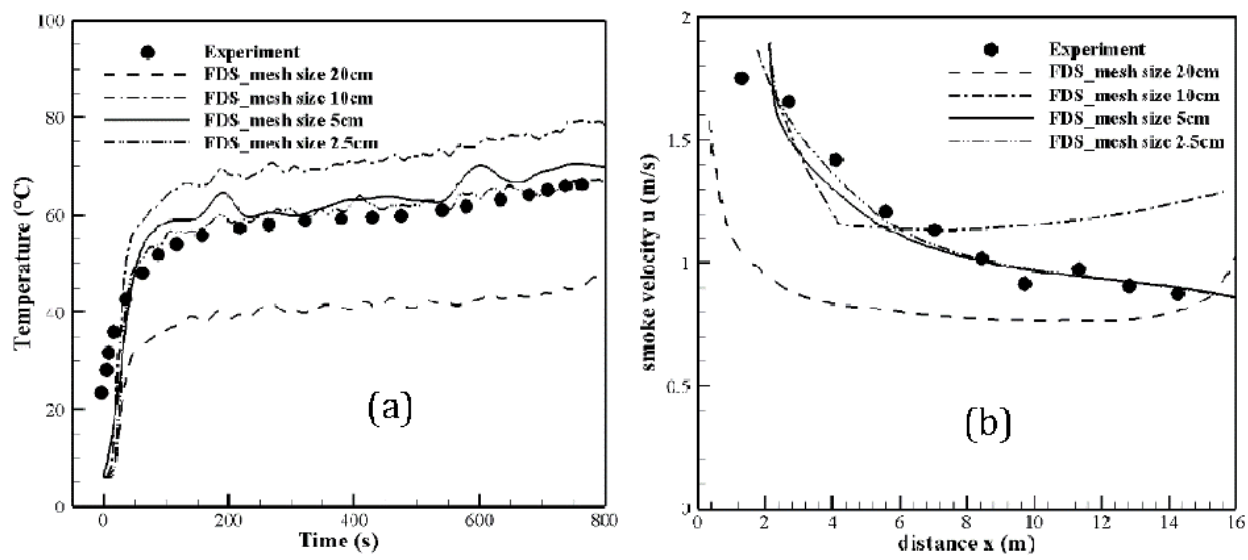

Figure 2.

The influence of grid cells on: (a) temperature at a height of $70 \mathrm{~cm}$; and (b) smoke velocity without wind at a height of $70 \mathrm{~cm}$. 
Numerical Study on the Outdoor Wind Effects on Movement Smoke along a Corridor DOI: http://dx.doi.org/10.5772/intechopen.92978

\begin{tabular}{|c|c|c|c|c|}
\hline \multirow[t]{2}{*}{ Numerical grid } & \multirow[t]{2}{*}{ Number of cells } & \multicolumn{2}{|c|}{ Relative gap (\%) } & \multirow[t]{2}{*}{ CPU time (h) } \\
\hline & & Temperature $\left({ }^{\circ} \mathrm{C}\right)$ & Smoke velocity $(\mathbf{m} / \mathbf{s})$ & \\
\hline Mesh size $20 \mathrm{~cm}$ & 1685 & 31.06 & 33.17 & 1.2 \\
\hline Mesh size $10 \mathrm{~cm}$ & 11865 & 19.76 & 16.91 & 4.4 \\
\hline Mesh size $5 \mathrm{~cm}$ & 94920 & 6.06 & 6.23 & 9.6 \\
\hline Mesh size $2.5 \mathrm{~cm}$ & 759360 & 3.80 & 3.85 & 92.2 \\
\hline
\end{tabular}

Table 1.

Results of different numerical grid mesh sizes.

reinforced by the suggestions of the various cases of validation of the FDS code proposed in the user guide [24].

With the 5-cm mesh, the total number of cells is 94920 and the simulation time is $1000 \mathrm{~s}$ with a time step of $0.010 \mathrm{~s}$. The calculations were carried out using 20 processors in the ARTEMIS cluster of the "Région Centre Val de Loire-France" and each computation took about $9.6 \mathrm{~h}$.

Figure 2(a) and (b) shows that the numerical results obtained with the 5-cm mesh are in agreement with experimental data as regards the evolution of smoke temperature and smoke velocity [8]. This indicates that with a 5-cm mesh, the boundary conditions can be satisfactorily modeled by FDS and that the interaction between wind and smoke flow can be reproduced.
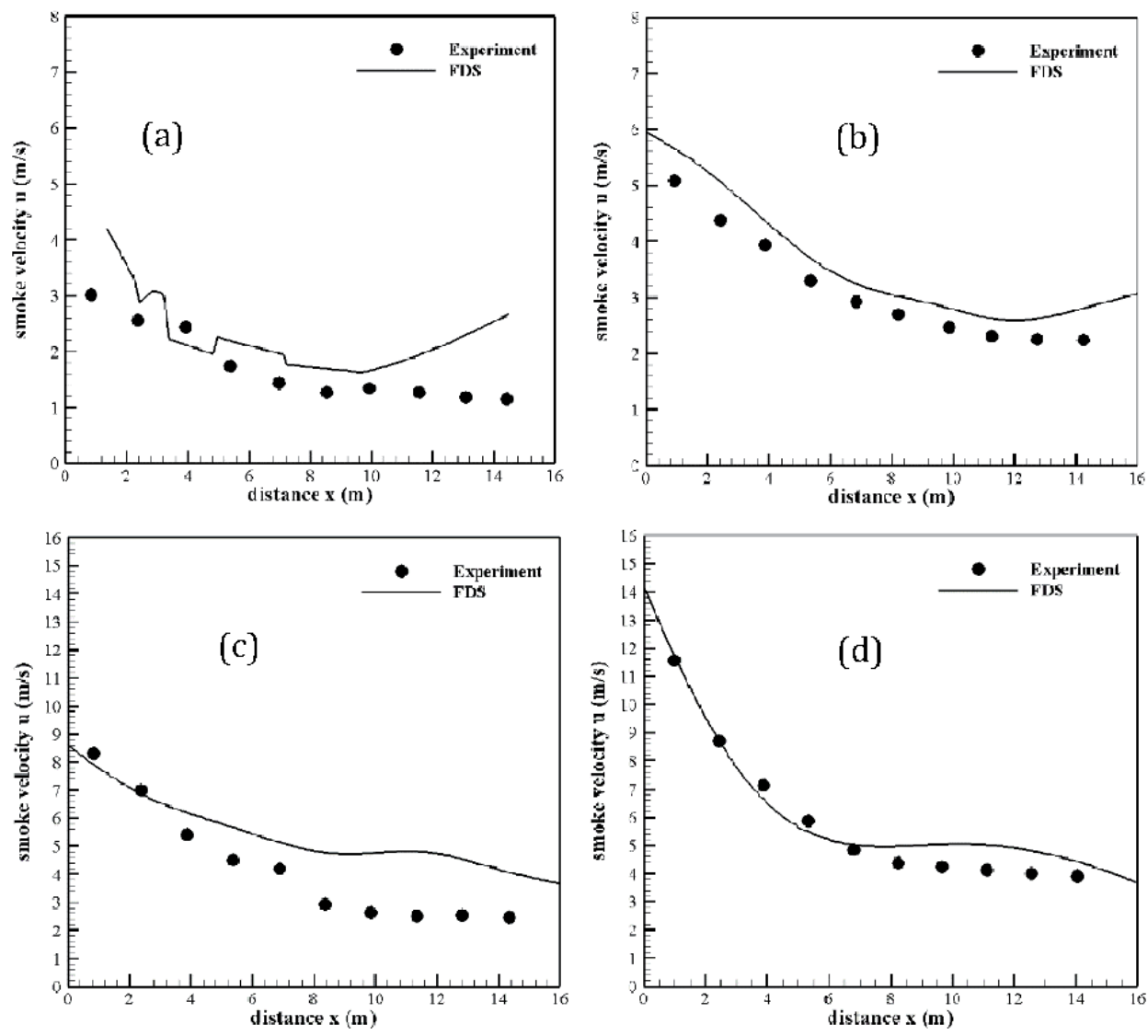

Figure 3.

Smoke velocity with: (a) $V w=1.73 \mathrm{~m} / \mathrm{s}$; (b) $V w=3.46 \mathrm{~m} / \mathrm{s}$; (c) $V w=6.93 \mathrm{~m} / \mathrm{s}$; and (d) $V w=12.12 \mathrm{~m} / \mathrm{s}$ at a height of $70 \mathrm{~cm}$ of FDS and experimental results [8]. 
Figure 3 plots the smoke velocity decays with different wind velocities: (a) $\mathrm{Vw}=$ $1.73 \mathrm{~m} / \mathrm{s}$; (b) $\mathrm{Vw}=5.20 \mathrm{~m} / \mathrm{s}$; (c) $\mathrm{Vw}=6.93 \mathrm{~m} / \mathrm{s}$; and (d) $\mathrm{Vw}=10.93 \mathrm{~m} / \mathrm{s}$ at $70 \mathrm{~cm}$ height. It can be seen that the predictions of the evolution of smoke velocities are similar to those of the experimental data [8]. Since the velocities were measured at a height of $70 \mathrm{~cm}$ in the experiments, these values are in fact averages.

Therefore, it is possible that for some values of the smoke velocity, the experimental data are underestimated or overestimated. In these conditions, predictions are overestimated at the start or at the end of the curves Figure 3(a) and (b). These small differences can be associated to the vortex waves that are not very well reproduced by the turbulence model. To try to improve it, a sensibility analysis can be performed on the different turbulence models [24]. However, good agreement between prediction and experiment is observed in the other pictures (Figure 3(c) and (d)).

It can be concluded from these different comparisons that the choice of a $5-\mathrm{cm}$ mesh is suitable and that it can deal with reactive flows with a good accuracy. Leakage was neglected during the modelling, as the amount of leakage in the experiment is unknown. It is possible, therefore, that some simulation results may be under- or overestimated. Overall, however, the predictions of the simulations are acceptable.

\section{Results and discussions}

In this part of the chapter, the numerical results with different wind velocities $(\mathrm{Vw}=1.73,3.46$, and $5.20 \mathrm{~m} / \mathrm{s})$ are discussed in terms of the effects of outdoor wind on smoke stratification and smoke extraction. A global sensitivity analysis was carried out in order to determine the effects of the input parameters on the output data. The target input parameters are mass flux (MF) of fuel, the material properties (conductivity $\lambda$, emissivity $\varepsilon$, density $\rho$, and specific heat $\mathrm{cp}$ ), and the Arrhenius parameters $(\mathrm{A}, \mathrm{Ea})$. The target output data are the smoke temperature near the ceiling.

\subsection{Outdoor wind effect on the smoke exhaust}

Figure 4 presents the smoke velocity field with (a) $\mathrm{Vw}=0 \mathrm{~m} / \mathrm{s}$; (b) $\mathrm{Vw}=1.73$ $\mathrm{m} / \mathrm{s}$; (c) $\mathrm{Vw}=3.46 \mathrm{~m} / \mathrm{s}$; and (d) $\mathrm{Vw}=5.20 \mathrm{~m} / \mathrm{s}$; in the cross-section $\mathrm{y}=0.5 \mathrm{~m}$ at $300 \mathrm{~s}$. The cross-section $\mathrm{y}=0.5 \mathrm{~m}$ is the plane in the middle of the corridor. In Figure 4(a), taking this plane at the height of $70 \mathrm{~cm}$, the maximum value of the smoke velocity is near the door and decreases with the distance from the door as shown in Figures 3 and 4. In addition, considering smoke stratification with a hot zone near the ceiling and a cold zone near the floor, it is observed that the buoyancy effects give the reverse observation. Near the floor, the smoke velocity increases with the distance, and using the vortex recirculation solved by the Deardorff turbulence model, the numerical solver can reproduce the vortex flow induced by the smoke flow.

From Figure 4, the maximum of smoke velocity in the corridor increases when the wind velocity increases. As mentioned previously, in these conditions, smoke exhaust can be disturbed. Outdoor wind can, however, contribute to the evacuation of smoke and fire extinction in that more smoke is extracted through the corridor when the wind velocity increases. It should nevertheless be mentioned that while ventilation and extraction systems play an important role in fire engineering [15], the efficiency of the smoke extraction system will be reduced and even be invalidated when the outdoor wind velocity is very high and the extraction system is installed in the windward surface of the compartment [21]. In this 
Numerical Study on the Outdoor Wind Effects on Movement Smoke along a Corridor DOI: http://dx.doi.org/10.5772/intechopen.92978
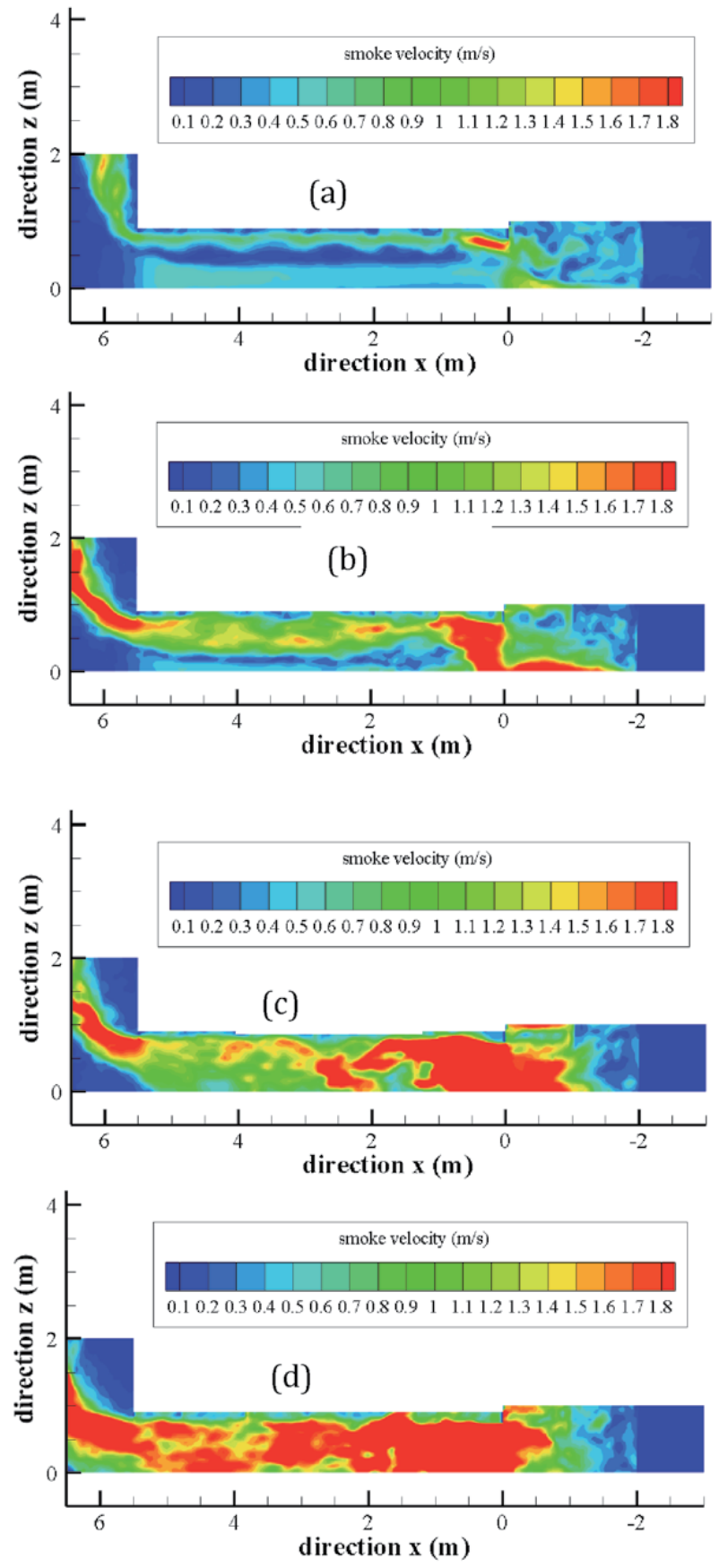

Figure 4 .

Simulation of the smoke velocity field with (a) $V w=0 \mathrm{~m} / \mathrm{s} ;(b) V w=1.73 \mathrm{~m} / \mathrm{s} ;$ (c) $\mathrm{Vw}=3.46 \mathrm{~m} / \mathrm{s}$; and (d) $V w=5.20 \mathrm{~m} / \mathrm{s}$ in the cross-section $y=0.5 \mathrm{~m}$ at $300 \mathrm{~s}$.

case, the extraction system cannot perform well, and smoke can spread along the entire compartment through the connected rooms. This situation is not acceptable for fire safety.

Figure 5 shows that when the outdoor wind velocity increases, the oxygen concentration increases and carbon dioxide concentration decreases. Figure 5 presents the influence of wind velocity on $\mathrm{O}_{2}$ concentration and $\mathrm{CO}_{2}$ concentration at a 

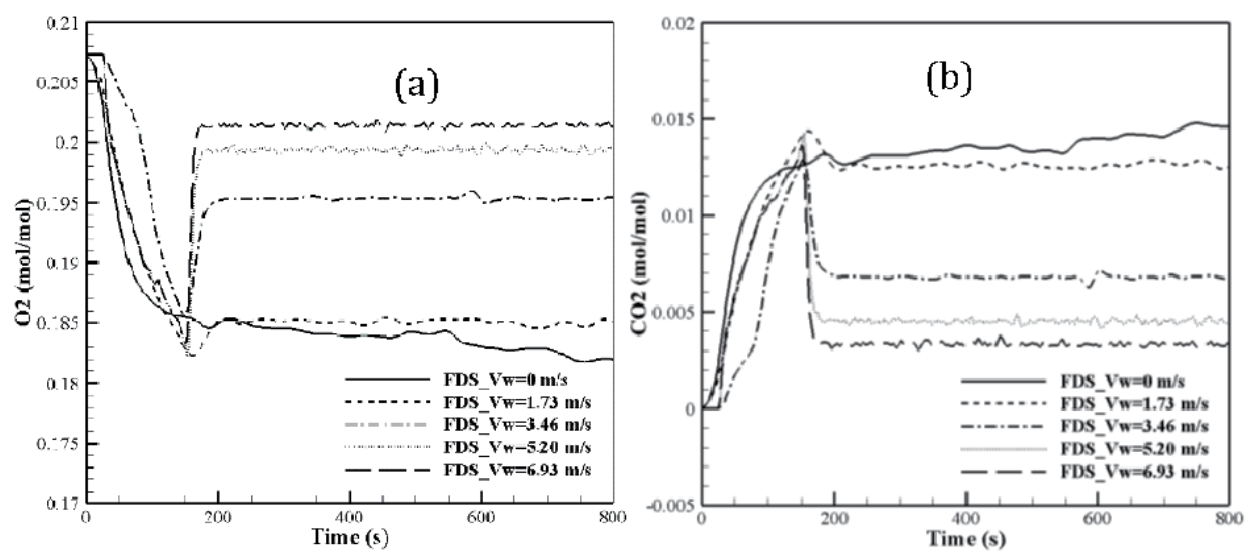

Figure 5.

Influence of wind velocity on: (a) $\mathrm{O}_{2}$ concentration; and (b) $\mathrm{CO}_{2}$ concentration at $85 \mathrm{~cm}$ height.

height of $85 \mathrm{~cm}$ (on the ceiling of the corridor), showing that the more wind velocity increases, the more oxygen concentration increases. After $300 \mathrm{~s}$, the oxygen concentration remains stable when the wind velocity varies from 0 to $6.93 \mathrm{~m} / \mathrm{s}$. The oxygen concentration at $300 \mathrm{~s}$ was therefore used to compare the different wind velocity cases.

When the wind velocity is $1.73 \mathrm{~m} / \mathrm{s}$, the $\mathrm{O}_{2}$ molar concentration increases only slightly compared to a situation without wind. When the wind velocity increases to $3.46 \mathrm{~m} / \mathrm{s}$, the $\mathrm{O}_{2}$ molar concentration increases strongly compared to the case without wind. For a wind velocity of $6.93 \mathrm{~m} / \mathrm{s}$, the $\mathrm{O}_{2}$ molar concentration increases to $20.2 \%, 1.8 \%$ higher than without wind. The rise in $\mathrm{O}_{2}$ concentration in the corridor also indicates that more smoke is extracted.

The more the wind velocity increases, the more the $\mathrm{CO}_{2}$ concentration decreases (Figure 5(b)). At a wind velocity of $6.93 \mathrm{~m} / \mathrm{s}$, the $\mathrm{CO}_{2}$ molar concentration decreases to $0.3 \%, 1 \%$ lower than without wind. The decline of the $\mathrm{CO}_{2}$ concentration in the corridor also contributes to people escaping from fires.

Using oxygen concentration field like the smoke velocity field in the Figure 4, the mean oxygen concentration in the corridor increases when the wind velocity increases, showing that a higher wind velocity can facilitate smoke exhaust.

It is also possible to highlight the influence of wind velocity on $\mathrm{CO}$ concentration and visibility. The evolutions of these latest are presented in Figure 6 at a height of $50 \mathrm{~cm}$. The height of $50 \mathrm{~cm}$ represents the average height of a person measuring 165 $\mathrm{cm}$ in a full-scale building. From Figure 6(a), CO concentration decreases with wind velocity.

The outdoor wind can thus be an advantage for diluting the CO concentration. Figure 6(b) shows that the more the outdoor wind velocity increases, the more the visibility increases. Thus, the more wind blows in, the more smoke is diluted. However, the visibility becomes homogenous in the enclosure due to disturbance in the smoke stratification. In a fire with a heat release rate larger than the one used in this study, the poor visibility can be unfavorable for the evacuation of people in the building.

Using the $\mathrm{CO}$ concentration field similarly to the smoke filed, the average concentration of $\mathrm{CO}$ decreases with the increase in wind velocity. There are two zones: a thin zone near the floor and a thick zone near the ceiling in the case of no wind.

The distribution of CO concentration in the corridor gradually becomes homogeneous as the wind velocity increases. Although in this study the $\mathrm{CO}$ concentration 


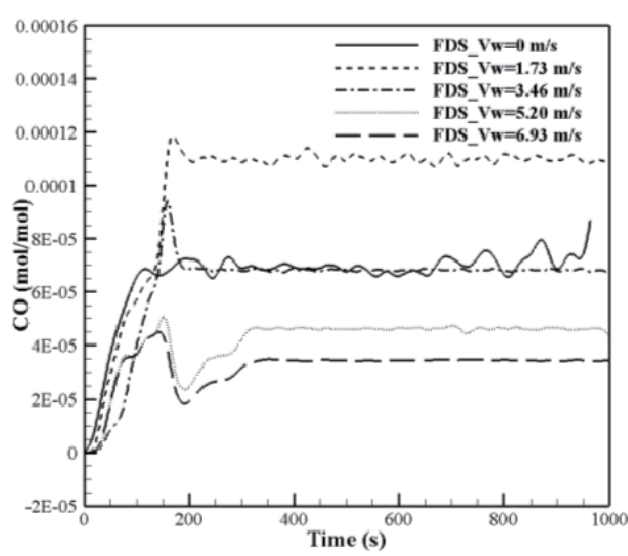

(a)

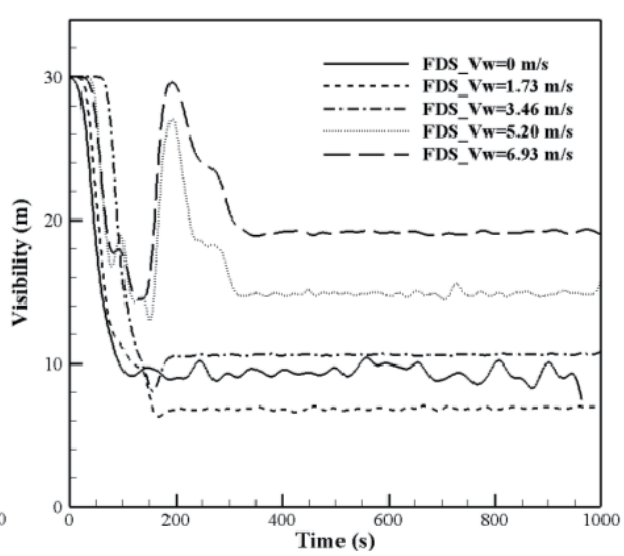

(b)

Figure 6.

Influence of wind velocity on: (a) CO concentration; and (b) visibility at $55 \mathrm{~cm}$ height at the exit of the corridor.

is so small that it would have little effect on people's health, the homogeneous distribution of $\mathrm{CO}$ concentration may cause serious problems when the heat release rate in the building is larger, producing more $\mathrm{CO}$.

Moreover, concerning the visibility, it is shown that the visibility of the lower area in the corridor is very high and the visibility of the upper area in the corridor is very low due to smoke stratification when there is no wind. For this, the visibility in the corridor gradually becomes homogeneous as the outdoor wind velocity increases and becomes better when the wind velocity reaches $5.20 \mathrm{~m} / \mathrm{s}$, indicating that the more smoke is exhausted, the more visibility is improved.

In other words, smoke can exit the corridor faster when the wind velocity increases. It can be said that to some extent, the outdoor wind is helpful for smoke exhaust and an advantage for the evacuation of people in fires as it can decrease the concentration of toxic gas and improve visibility in the environment. However, in these conditions, the outdoor wind becomes a disturbance for the extraction system, representing an unacceptable situation for fire safety.

\subsection{Outdoor wind effect on the smoke stratification and sensitivity analysis}

In $\mathrm{Li}$ et al. [8], it was shown that the more wind velocity increased, the more severely the smoke stratification was disturbed. This observation was obtained by comparing the smoke temperature near the floor (height $=25 \mathrm{~cm}$ ) and the smoke temperature near the ceiling (height $=85 \mathrm{~cm}$ ). The tests were performed for three velocities. The results showed that above a wind velocity of $3.46 \mathrm{~m} / \mathrm{s}$, the smoke temperatures near the floor and the ceiling were similar. This similarity was taken to imply that the smoke occupied the entire corridor volume, due to the absence of smoke stratification, and the numerical data used in the current study confirmed this observation.

Thanks to Figure 7, it is possible to make a comparison between the smoke temperature near the ceiling and near the floor. It is constated that the more wind speed increases, the more the smoke stratification is disturbed. Smoke stratification is represented by the stability between the hot zone and the cold zone. The hot zone is formed by hot smoke and the cold zone is formed by cold air. Smoke stratification in an enclosure is due to the temperature difference between these two zones. In addition, as shown in the literature [27-29], smoke stratification depends on the Froude number. Smoke stratification is very stable up to a critical Froude number 

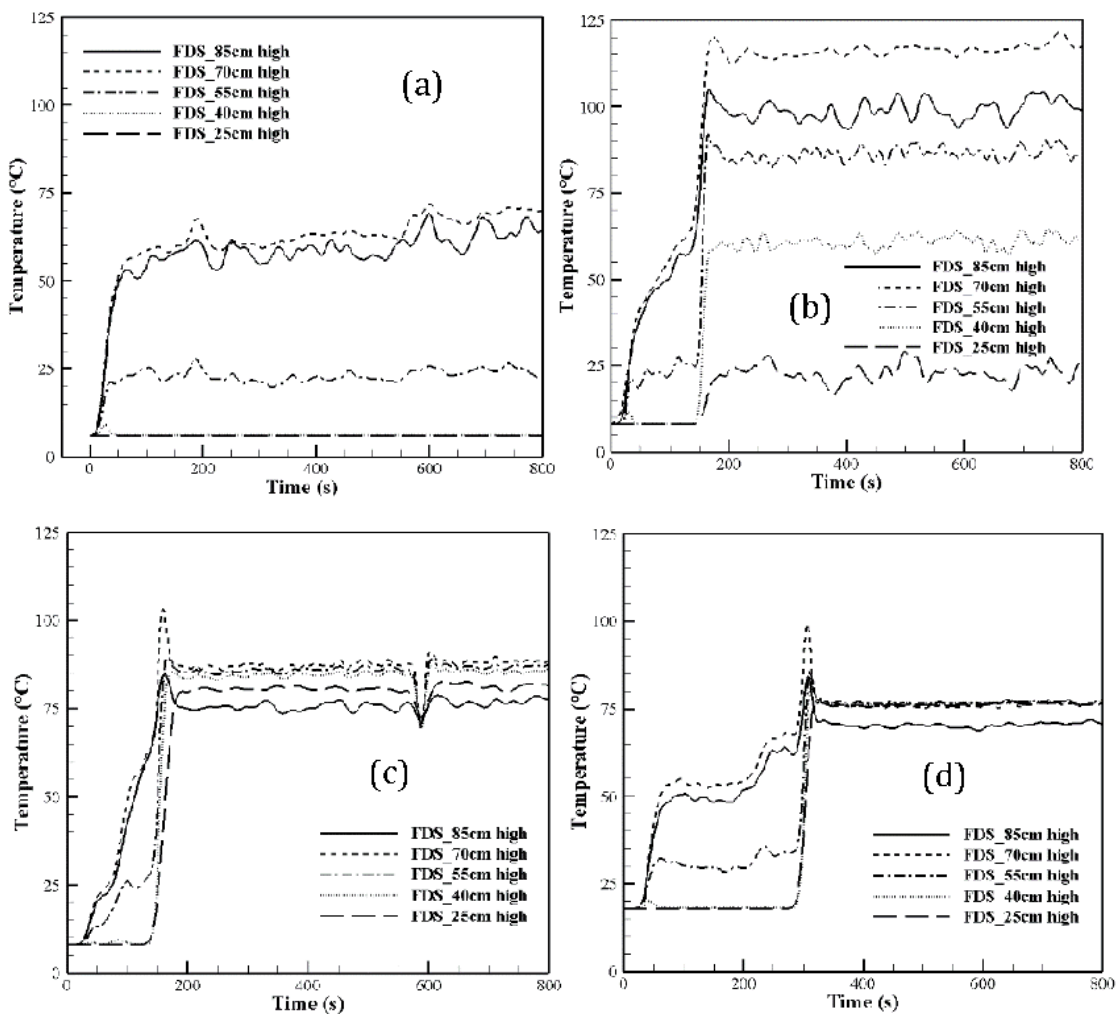

Figure 7.

Influence of wind velocity (a) $V w=0 \mathrm{~m} / \mathrm{s} ;$ (b) $V w=1.73 \mathrm{~m} / \mathrm{s} ;$ (c) $V w=3.46 \mathrm{~m} / \mathrm{s}$; and (d) $V w=5.20 \mathrm{~m} / \mathrm{s}$ on smoke temperature in different heights of the corridor.

and becomes disturbed when the Froude number is larger than this critical value. It is known that the Froude number can be associated to velocity. So, smoke stratification is related to the smoke velocity in an enclosure. In Figure 7(a), when the wind velocity is $0 \mathrm{~m} / \mathrm{s}$, the smoke temperature near the ceiling and floor are about 5 and $60^{\circ} \mathrm{C}$, indicating that smoke stratification is very stable. At a wind velocity of $1.73 \mathrm{~m} / \mathrm{s}$, the smoke temperature near the ceiling and floor are about 25 and $100^{\circ} \mathrm{C}$, respectively. In this condition, there are still two zones. In Figure $7(\mathbf{b})$, there is a slight perturbation of the temperature near the ceiling, indicating a slight disturbance in the smoke stratification. However, from a wind velocity of $3.46 \mathrm{~m} / \mathrm{s}$, the smoke temperature near the ceiling and floor are similar with an average of $80^{\circ} \mathrm{C}$. This means that above this velocity, there is no smoke stratification in the corridor and that smoke occupies the entire corridor. Under these conditions, there is a risk of toxicity for people. These observations confirm results reported in the literature [8] and highlight the ability of the CFD code to reproduce the effects of wind on the movement of smoke in an enclosure. Moreover, in these conditions, outdoor wind becomes a disturbance for smoke extraction, creating an unacceptable situation for fire safety.

The smoke temperature field with (a) $\mathrm{Vw}=0 \mathrm{~m} / \mathrm{s}$; (b) $\mathrm{Vw}=1.73 \mathrm{~m} / \mathrm{s}$; (c) $\mathrm{Vw}=$ $3.46 \mathrm{~m} / \mathrm{s}$; and (d) $\mathrm{Vw}=5.20 \mathrm{~m} / \mathrm{s}$ in the cross-section $\mathrm{y}=0.5 \mathrm{~m}$ at $300 \mathrm{~s}$ is shown in Figure 8. It can be clearly seen that when there is no outdoor wind, there is temperature stratification in the corridor. In addition, the temperature near the ceiling is much higher than the temperature near the floor. For a wind velocity of $1.73 \mathrm{~m} / \mathrm{s}$, smoke stratification is disturbed but still exists due to the presence of two zones, with a much smaller cold zone than hot zone. When the wind velocity is 
$3.46 \mathrm{~m} / \mathrm{s}$, smoke stratification almost disappears, as the smoke temperature is similar at the different heights and only the hot zone subsists. In this condition, smoke occupies the entire corridor. The phenomenon of temperature stratification in the corridor disappears completely when the wind velocity reaches $5.20 \mathrm{~m} / \mathrm{s}$ (Figure 8(d)), as also shown with the curves in Figure $7(d)$. These results also show that thanks to simulations performed by FDS, it is possible to demonstrate the fields of smoke movement in an enclosure with outdoor wind.
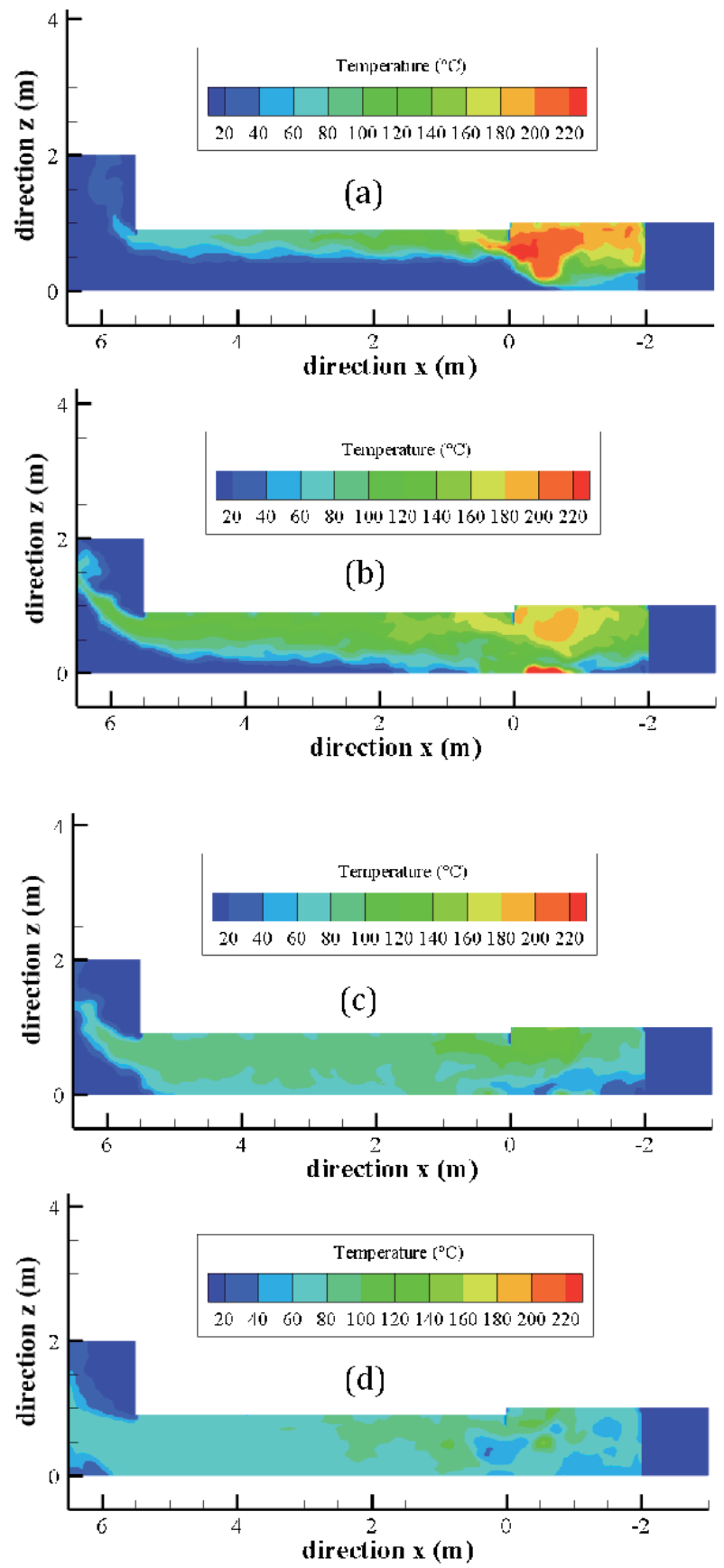

Figure 8.

Smoke temperature field with (a) Vw=o m/s; (b) Vw=1.73 m/s; (c) Vw=3.46 m/s; (d) Vw=5.20 m/s on the cross-section $y=0.5 \mathrm{~m}$ at $300 \mathrm{~s}$. 


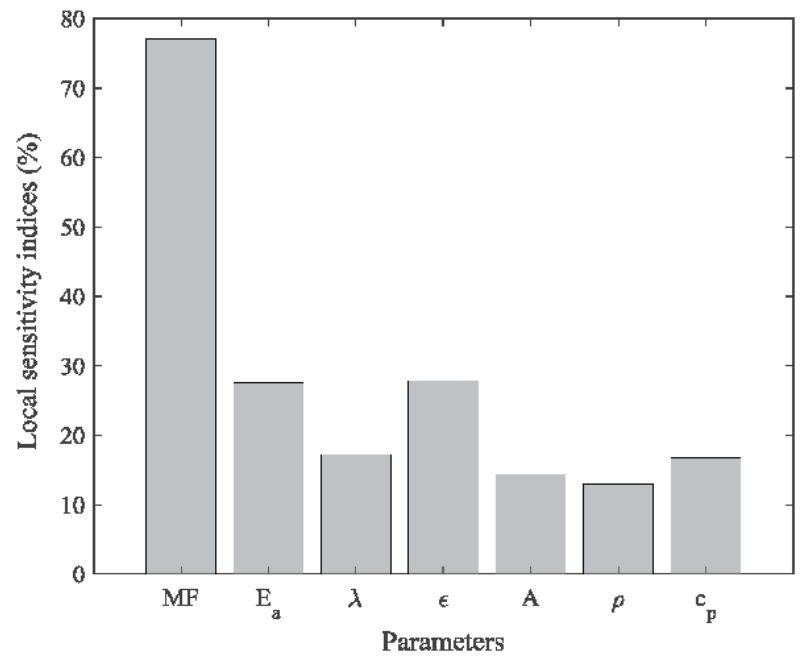

Figure 9.

Local sensitivity indices.

In addition, from a global sensitivity analysis, an investigation was carried out in order to highlight the relative importance of seven parameters: mass flux MF, activation energy Ea, conductivity $\lambda$, emissivity $\epsilon$, pre-exponential factor A, density $\rho$, and specific heat $\mathrm{cp}$. The aim was to determine whether, among these seven parameters, even a slight modification of the input parameter may cause a large variation in the response. The quantity of interest is the temperature near the ceiling. A tolerance interval of $\pm 10 \%$ was applied to each of the inputs so that for each of the inputs, a dimensionless random parameter is introduced. Its value depends on the realization $\theta$ and belongs to the interval $[-1,1]$.

In this context, the values of the random parameters $M F$ and $E_{a}$ depend on their mean value $\overline{\mathrm{MF}}$ and $\overline{\mathrm{E}_{\mathrm{a}}}$, on the tolerance interval $\pm 10 \%$, and on the random dimensionless parameter $\xi_{\mathrm{MF}}$ and $\xi_{\mathrm{E}_{\mathrm{a}}}$ (whose values depend on the observation $\theta$ ). For that, an analytical model is proposed to predict the time evolution of the quantity of interest for arbitrary values of mass flux (MF) and activation energy (Ea), such that:

$$
\begin{aligned}
\operatorname{MF}(\theta) & =\overline{\operatorname{MF}}\left(1+0.1 \xi_{\mathrm{MF}}(\theta)\right) \\
\mathrm{E}_{\mathrm{a}}(\theta) & =\overline{\mathrm{E}_{\mathrm{a}}}\left(1+0.1 \xi_{\mathrm{E}_{\mathrm{a}}}(\theta)\right)
\end{aligned}
$$

Indeed, using the smoke temperature as out data based on the methodology of the sensitivity analysis proposed by Chaos [20], Figure 9 shows that the mass flux of the fuel and the activation energy are the two parameters which are an important influence on the smoke temperature.

Moreover, Figure 9 presents the first-order sensitivity and the total sensitivity indices. Considering this influence, it is very important to define the values of the mass flux of the fuel and the activation energy with a good accuracy in order to over or underestimate the out data such as the temperature, heat flux, pressure, and the amount of species.

\section{Conclusion}

In this chapter, a CFD code, namely fire dynamics simulator (FDS), was employed to model the smoke spreading along a corridor induced by a 
compartment fire. The focus was on the effects of outdoor wind on the dynamics of smoke spreading based on experimental data. Simulations were carried out by varying wind velocity from 0 to $12.12 \mathrm{~m} / \mathrm{s}$. Good agreement between experimental data and prediction was found, enabling investigation of smoke stratification, smoke exhaust, and a global sensitivity analysis. The major findings include the following:

1. By analyzing the temperature distribution in the corridor, it was found that smoke stratification can be strongly affected by the outdoor wind. For wind velocities higher than the critical value of $3.46 \mathrm{~m} / \mathrm{s}$, smoke stratification is completely disturbed.

2. When the wind velocity is higher than the critical value (here $3.46 \mathrm{~m} / \mathrm{s}$ ), $\mathrm{O}_{2}$ concentration and visibility increase, while $\mathrm{CO}_{2}$ and $\mathrm{CO}$ concentration tends to decrease. It is shown that the magnitude of the outdoor wind can facilitate smoke exhaust in a compartment fire.

3. The results of a global sensitivity analysis indicate that it is essential to define the most influential input parameters correctly, namely the mass flux of the fuel and the activation energy. If not, large deviations in the outputs of the numerical results such as smoke temperature may occur due to variations, even slight ones, in the input parameters.

4. Based on the amplitude of the metamodel coefficients, a reduced metamodel has been proposed. A prediction with a confidence interval can be easily implemented, leading to close agreement with the numerical results.

Through this work, it is demonstrated that CFD FDS can provide information about the movement of smoke in a corridor. Besides, it can be coupled with a polynomial chaos-based sensitivity analysis, which enables the input parameters to be classified on quantitative grounds with a limited computational cost.

In addition, considering the importance of the effects of outside wind on reactive flows induced by a fire in a building, it is important to study other study configurations. In this context, it would be important to also study the role of the outside wind on the ignition of smoke rich in unburnt gas in the case of an under-ventilated fire. 


\section{Author details}

Brady Manescau $^{1 *}$, Khaled Chetehouna ${ }^{1}$, Quentin Serra ${ }^{2}$, Aijuan Wang ${ }^{1}$ and Eric Florentin ${ }^{2}$

1 INSA Centre Val de Loire, University of Orléans, PRISME, Bourges, France

2 INSA Centre Val de Loire, University of Orléans, University of Tours, LaMé, Bourges, France

*Address all correspondence to: brady.manescau@insa-cvl.fr

\section{IntechOpen}

(C) 2020 The Author(s). Licensee IntechOpen. This chapter is distributed under the terms of the Creative Commons Attribution License (http://creativecommons.org/licenses/ by/3.0), which permits unrestricted use, distribution, and reproduction in any medium, provided the original work is properly cited. (c) BY 


\section{References}

[1] Yu-Ting E, Zhou L. The Research on the current safety status of high-rise building at home and abroad. Procedia Engineering. 2016;135:574-577. DOI: 10.1016/j.proeng.2016.01.108

[2] Paul KT, Hull TR, Lebek K, Stec AA. Fire smoke toxicity: The effect of nitrogen oxides. Fire Safety Journal. 2008;43:243-251. DOI: 10.1016/j. firesaf.2007.10.003

[3] Hull TR, Brein D, Stec AA. Quantification of toxic hazard from fires in buildings. Journal of Building Engineering. 2016;8:313-318. DOI: 10.1016/j.jobe.2016.02.014

[4] Li M, Gao Z, Ji J, Li K, Sun J. Wind effects on flame projection probability from a compartment with opposing openings. Fire Safety Journal. 2017;91: 414-421. DOI: 10.1016/j. firesaf.2017.04.037

[5] Fan C, Zhang L, Jiao S, Yang Z, Li M, Liu X. Smoke spread characteristics inside a tunnel with natural ventilation under a strong environmental wind. Tunnelling and Underground Space Technology. 2018;82:99-110. DOI: 10.1016/j.tust.2018.08.004

[6] Tian X, Zhong M, Shi C, Zhang P, Liu C. Full-scale tunnel fire experimental study of fire-induced smoke temperature profiles with methanol-gasoline blends. Applied Thermal Engineering. 2017;116: 233-243. DOI: $10.1016 / \mathrm{j}$. applthermaleng.2017.01.099

[7] Zhong MH, Shi CL, He L, Shi JH, Liu C, Tian XL. Smoke development in full-scale sloped long and large curved tunnel fires under natural ventilation. Applied Thermal Engineering. 2016;108: 857-865. DOI: 10.1016/j.

applthermaleng.2016.07.141

[8] Li SC, Huang DF, Meng N, Chen LF, $\mathrm{Hu} \mathrm{LH}$. Smoke spread velocity along a corridor induced by an adjacent compartment fire with outdoor wind. Applied Thermal Engineering. 2017;111: 420-430. DOI: 10.1016/j. applthermaleng.2016.09.086

[9] Tang F, He Q, Mei F, Shi Q, Chen L, $\mathrm{Lu}$ K. Fire-induced temperature distribution beneath ceiling and air entrainment coefficient characteristics in a tunnel with point extraction system. International Journal of Thermal Sciences. 2018;134:363-369. DOI: 10.1016/j.ijthermalsci.2018.08.023

[10] Quintiere JG. Scaling and Dimensionless Groups. 2006. DOI: 10.1002/0470091150.ch12

[11] Li A, Zhang Y, Hu J, Gao R. Reduced-scale experimental study of the temperature field and smoke development of the bus bar corridor fire in the underground hydraulic machinery plant. Tunnelling and Underground Space Technology. 2014; 41:95-103. DOI: $10.1016 /$ j.tust. 2013.11.009

[12] Weng MC, Yu LX, Liu F, Nielsen PV. Full-scale experiment and CFD simulation on smoke movement and smoke control in a metro tunnel with one opening portal. Tunnelling and Underground Space Technology. 2014; 42:96-104. DOI: 10.1016/j. tust.2014.02.007

[13] Batiot B, Rogaume T, Collin A, Richard F, Luche J. Sensitivity and uncertainty analysis of Arrhenius parameters in order to describe the kinetic of solid thermal degradation during fire phenomena. Fire Safety Journal. 2016;82:76-90. DOI: 10.1016/j. firesaf.2016.03.007

[14] Xiao S, Lu Z, Wang P. Multivariate global sensitivity analysis for dynamic models based on wavelet analysis. Reliability Engineering and System 
Safety. 2018;170:20-30. DOI: 10.1016/j. ress.2017.10.007

[15] Sellami I, Manescau B, Chetehouna K, de Izarra C, Nait-Said R, Zidani F. BLEVE fireball modeling using fire dynamics simulator (FDS) in an Algerian gas industry. Journal of Loss Prevention in the Process Industries. 2018;54. DOI: 10.1016/j.jlp.2018.02.010

[16] Magnognou B, Garo JP, Coudour B, Wang HY. Risk analysis of unburnt gas ignition in an exhaust system connected to a confined and mechanically ventilated enclosure fire. Fire Safety Journal. 2017;91:291-302. DOI: 10.1016/ j.firesaf.2017.03.036

[17] Saltelli A, Ratto M, Tarantola S, Campolongo F. Sensitivity Analysis Practice: A Guide to Scientific Models. 2006. DOI: 10.1016/j.ress.2005.11.014

[18] Sobol IM. Sensitivity analysis for nonlinear mathematical models.

Mathematical Modeling and Computation. 1993;1:407-414. DOI: 10.18287/0134-2452-2015-39-4-459-461

[19] Crestaux T, Le Maître O, Martinez JM. Polynomial chaos expansion for sensitivity analysis. Reliability Engineering and System Safety. 2009;94:1161-1172. DOI: 10.1016/j.ress.2008.10.008

[20] Chaos M. Application of sensitivity analyses to condensed-phase pyrolysis modeling. Fire Safety Journal. 2013;61: 254-264. DOI: 10.1016/j.firesaf.2013. 09.016

[21] Yi L, Gao Y, Niu JL, Yang SJ. Study on effect of wind on natural smoke exhaust of enclosure fire with a twolayer zone model. Journal of Wind Engineering and Industrial Aerodynamics. 2013;119:28-38. DOI: 10.1016/j.jweia.2013.05.005

[22] Xiu D, Lucor D, Su C-H, Karniadakis GE. Stochastic modeling of flow-structure interactions using generalized polynomial chaos. Journal of Fluids Engineering. 2002;124:51. DOI: 10.1115/1.1436089

[23] Eldred M, Burkardt J. Comparison of non-intrusive polynomial chaos and stochastic collocation methods for uncertainty quantification. In: 47th AIAA Aerospace Sciences Meeting including the New Horizons Forum and Aerospace Exposition. Reston, Virigina: American Institute of Aeronautics and Astronautics; 2009. DOI: 10.2514/ 6.2009-976

[24] Mcgrattan K, Mcdermott R. Fire Dynamics Simulator User's Guide. 6th ed. 2016. DOI: 10.6028/NIST.SP.1019

[25] McGrattan K, Hostikka S, McDermott R, Floyd J, Weinschenk C, Overholt K. Fire Dynamics Simulator Technical Reference Guide Volume 1: Mathematical Model. NIST Special Publications. 1018-1. 1; 2017. DOI: 10.6028/NIST.SP.1018

[26] Menage D, Chetehouna K, Mell W. Numerical simulations of fire spread in a Pinus pinaster needles fuel bed. Journal of Physics Conference Series. 2012;395. DOI: 10.1088/1742-6596/395/1/012011

[27] Newman JS. Experimental evaluation of fire-induced stratification. Combustion and Flame. 1984;39:33-39

[28] Tang F, Li LJ, Dong MS, Wang Q, Mei FZ, Hu LH. Characterization of buoyant flow stratification behaviors by Richardson (Froude) number in a tunnel fire with complex combination of longitudinal ventilation and ceiling extraction. Applied Thermal Engineering. 2017;110:1021-1028. DOI: 10.1016/j.applthermaleng.2016.08.224

[29] Huang DF, Li SC. An experimental investigation of stratification characteristic of fire smoke in the corridor under the effect of outdoor wind. Journal of Wind Engineering and Industrial Aerodynamics. 2018;179:173-183. DOI: 10.1016/j.jweia.2018.05.021 


\title{
Shifting Wildfire Trends and Management Implications for the Wildland Urban Interface in the Twenty-first Century
}

\author{
Rebecca Abney and Qin Ma
}

\begin{abstract}
Anthropogenic climate change is projected to impact a significant proportion of ecosystems throughout the world. These shifts in climate are already impacting a diversity of wildland and urban ecosystems, and they are projected to increase wildfire frequency and severity in many regions. This projected increase is the result of the interaction of altered drought, precipitation, and temperature regimes. Understanding shifts in wildfire regimes is critical for managers at the wildlandurban interface that work to protect structures and human life. This chapter will explore how ongoing and future shifts in climate will drive alterations to natural fire regimes in the United States, with focus on implications for the wildland-urban interface.
\end{abstract}

Keywords: climate change, fire regime, urban-natural interface, wildfire

\section{Introduction}

Fire is a global phenomenon that has historically maintained the structure and function of a range of ecosystems. Many ecosystems are adapted to periodic fire events, known as fire regimes, that describe the interval and severity of fire in a particular system. However, human influences in the twentieth century have changed the frequency and severity of wildfire in many forested ecosystems and understanding these shifts of fire regimes has been a major topic of investigation for the past several decades. This research has elucidated the numerous, complex, and interactive environmental factors driving shifts in wildfire regimes. Annually, $450 \mathrm{mHa}$ of the Earth surface is burned due to wildfire [1], and the severity of wildland fires across the US has increased since the 1980s [2]. This is important because as the size, severity, and frequency of fires have changed, their influence on human infrastructure has become more damaging and costly.

The wildland-urban interface (WUI) is the boundary where human civilization and unmanaged lands meet. Currently, this interface occupies over $770,000 \mathrm{~km}^{2}$ in the US, and increases in area classified as WUI are driven by ongoing development that pushes urban environments further into wildland areas [3]. Increasing development into the WUI puts increasing numbers of structures, mainly residential homes, and human lives at risk to damage or loss via wildfire. Further, the 
infrastructure required by the WUI presents an additional source of ignitions in areas that are primed to burn. While trees exhibit traits of fire resistance $[4,5]$, houses, in particular older structures, burn with greater intensity and speed. For example, the 2018 Camp Fire in the Sierra Nevada of California burned quickly through the town of Paradise while leaving many standing trees scorched but not completely burnt. While this fire had many complex causes [6], the quick spread of the fire through the town was a reason that escape was made difficult despite a populous aware and prepared for the danger.

While these changes in fire regimes have exacerbated the damage in WUI, anthropogenic climate change is expected to intensify the risk by fire to WUIs. Across the US, climate change in the next century is projected to drive increases in wildfire severity in some areas, and increased wildfire incidence in other areas [7]. Shifts in wildfire patterns will be driven by shifts in precipitation timing and amounts, vegetation, temperature regimes, and drought conditions [8-11]. While changing climate patterns have been reasonably well characterized, wildfire regimes are more complex to predict due to the interconnected nature of the drivers and heterogeneous nature of ignition sources. It is critical to understand and provide more accurate predictions for shifts in wildfire frequency and severity, due to the loss of life, economic damage, related catastrophic environmental events, such as flooding or water quality damage. This is particularly important as human development into the wildland areas, which are more prone to wildfires, has increased significantly over the past half century.

\section{Shifting wildfire regimes}

Fire regimes integrate the tendency of vegetation to burn and the climate conditions that promote fire in a metric that describes the spatial and temporal nature of fire in a particular region. While there are several ways to calculate these metrics [12] a general calculation includes a measure of how frequently a fire occurs at a location (i.e., the average fire return interval) and the effect that fire has on vegetation (i.e., the severity of the fire). Variability in fire regimes is driven by differences in elevation, vegetation life history, drought and precipitation patterns, land-use, among other ecosystem-specific parameters $[13,14]$. Many animal and plant species have co-evolved with fire and are adapted to specific fire regimes [15]. Some densergrowing vegetation species are adapted to higher severity and stand-replacing burns, such as in the Northern Rockies, while other species are more adapted to lower and more moderate severity burns, such as in the southern Sierra Nevada.

The inherent complexity and spatial heterogeneity of fire regimes make it difficult to make general recommendations for fire management [15]. However, the implications of an expanding WUI and increasing trends of fire activity indicate a clear problem for fire management. This is compounded by the possibility that fire regimes may shift over time in response to anthropogenic driven changes in management, vegetation composition and density, and climate $[16,17]$.

\subsection{History of fire regimes in the US}

Historically, fire regimes were mostly driven by an ecosystem's vegetation, climate conditions, and human activities, which varied both spatially and temporally over the US. In the Northern Rocky Mountains, stand replacing fires are typical in pine forests of the region $[18,19]$. Fires in this ecosystem occur at relatively low frequency (longer return intervals), but when they do occur, they can burn large areas of forest ecosystems at high severity, e.g., the Yellowstone fire in 1988 [20-22]. 
In contrast, low-intensity fires occurred more frequently in the southwestern forests of New Mexico and Arizona, due to the dry and warm semi-arid climate and tree species that exhibited resistance to fires (e.g., Pinus ponderosa). Much of the southeast was historically occupied by longleaf pine (Pinus palustris, Figure 1A), which thrives in high frequency, low burn severity fire regimes [23]. Pre-European settlement, longleaf pine forests were managed by Native American populations, and post-settlement there was a significant decline in the land area of these forests [24]. Currently, they are managed via frequent prescribed fire and are often grown to produce pine straw [25]. While wildfires have been major drivers of the American landscape, natural ecosystems are continually adapting to fire regimes over time in response to shifts in vegetation, management, and climate. However, human activities, management, and climate change are also driving the interaction between fire and vegetation over the past several centuries.

The shift in fire regimes in the Sierra Nevada is an example of the interactive effects of human management and climate change. Prior to Euro-American settlement, natural lighting strikes and fire activities by Native Americans were the main causes of fire ignitions in the Sierra Nevada [26]. Forests were burned with mixed-severity fires that included both light to moderate burning of understory and crown fires at the interval of a decade or two. The small trees and ground fuels were killed and cleaned in fires periodically, leaving patches of large, mature trees that are more resistant to wildfires due to thick bark that is hard to burn, preventing fire from spreading to the canopy $[4,5]$. However, a combination of human influences changed the structure of these forests and made them more susceptible to frequent fires that spread through canopies. Early twentieth century logging practices preferentially selected for these larger trees, opening up space for denser thickets of small trees to colonize, leading to increases in forest density [27]. This change in structure was reinforced by widespread suppression of fires that historically cleared out undergrowth. Since the early twentieth century, fire suppression as a forest management technique was widely adopted after several large and severe wildfires
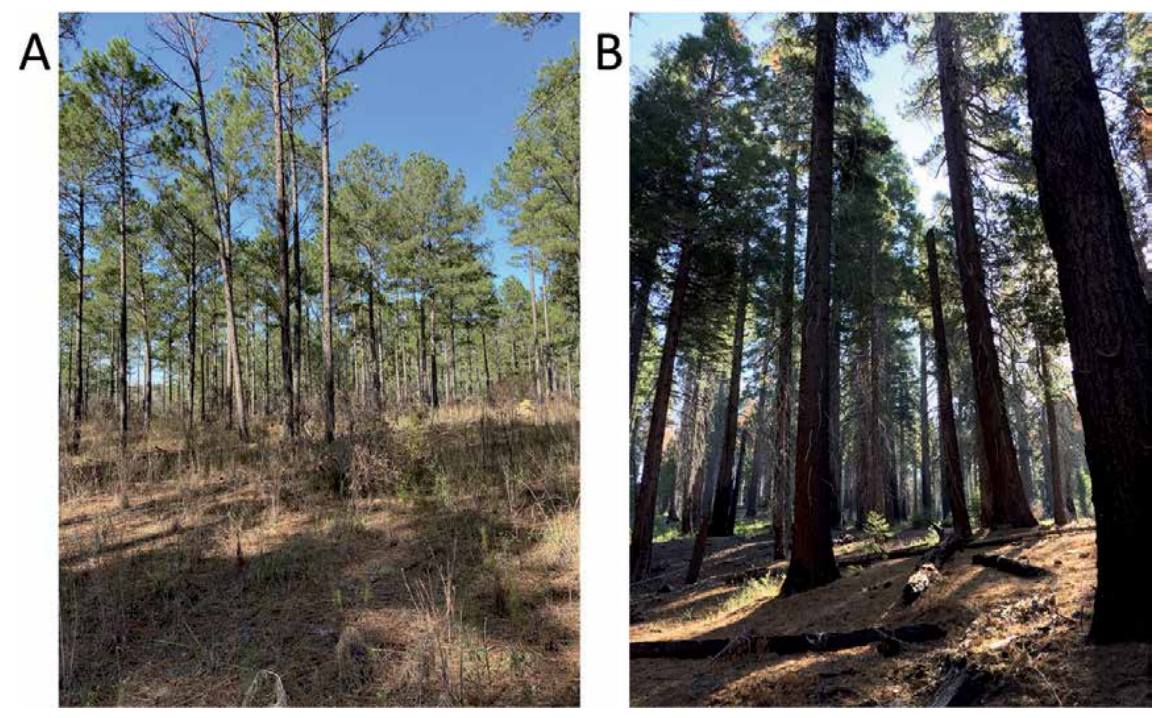

Figure 1.

Fire severity is in part controlled by the density of the fuels and fire return interval. In photo A, loblolly pine (Pinus palustris) plantation in Georgia is managed for pulpwood production with prescribed fire approximately every 3 years. This low severity, high frequency fire regime maintains an open canopy and lowdensity fuels. In photo B, a conifer forest in Yosemite National Park one-year post recovery after the Rim Fire. All photos are (c) R. Abney. 
in the Northern Rockies that killed many and destroyed a number of settlements. The fire suppression efforts were successful in excluding low-severity fires, and this management strategy reduced the fire frequency to the lowest frequency measured in the past 3000 years [28]. Consequently, the accompanying densification of forests due to the fire deficit has contributed to increasing numbers of devastating fires in late twentieth and twenty-first centuries [29]. This shift in fire regimes is the result of combined factors including (1) the reduction of regular fire usage, which were regularly conducted by Native Americans to reduce fuel loads and to encourage culturally important vegetation [30]; (2) legacy of decades of fire-suppression that densified undergrowth which lead to increased spread of fire; (3) removal of large trees, which are resilient to low-to-medium fires, due to industrialized timber logging; (4) the disappearing of gaps among trees, which could have stopped fire from spreading, but were filled with smaller and denser trees that can easily act as continuous fuel sources and (5) species change from those with fire adverse traits, to shade-tolerant ones [31]. The current fire regime that includes more high-severity, large fire size, is a significant challenge to forest managers and is a critical risk to the safety of human life and development in the WUI.

\subsection{Drivers of wildfire change}

Drivers of wildfire include three main categories: regional climate, fuel availability and condition, and ignition sources. In areas of low fuel density, sources of ignition drive fire occurrence; however, in higher population density areas, such as the WUI, fuel availability drives fire occurrence [32]. Climate influences fire occurrence by the timing and amount of precipitation, temperature, and wind speed. Wildfire season starts when all these climate features reach their thresholds. The intensity of drought and strength of wind as well as the length of wildfire season is highly related to the severity and risk of wildfires. Westerling et al. [17] found that an extended fire season, resulting from earlier spring warming and extended drought in late fall, increased the fire frequency and severity in the Western US. This trend is predicted to continue as climate gets warmer and drier with ongoing climate change [7]. In the eastern US, precipitation and temperature patterns form a different climate, and thus different fire seasons than the western US. Southwestern forests are influenced by late-summer precipitation stemming from the North American monsoon that end fire-season earlier in the year. The pacific north-west and the Northern Rockies are routinely colder and wetter, thus interannual fire season lengths are short in general.

The available fuel load in part determines the extent of wildfire, including what and how much can be burned. In areas with limited fuel loads, such as the shrubland and grassland in Southwestern US, fires can occur frequently but are usually low-severity burns. High severity burns often occur in forests with large and dense biomass, which can provide plentiful fuel sources for wildfires. The spatial continuity of fuels also plays a critical role in shifts in fire regimes. The combination of large trees and clearings in forest floor vegetation in historical frequent-fire Western forests constrained the spread of crown fires. Examples of this are found in ponderosa or giant sequoia groves. However, effective fire suppression until the 1980s has reduced the number of surface fires that would have removed the ground and understory fuels periodically. Small trees and undergrowth filled the gaps between trunks and created continuous fuels that could carry flames to tree crowns, which has in part lead to higher severity and larger fires in the Western US that are currently observed [33] (Figure 2). Thus, forest and fire management can change fire regimes by changing the quantity and structure of fuels. 


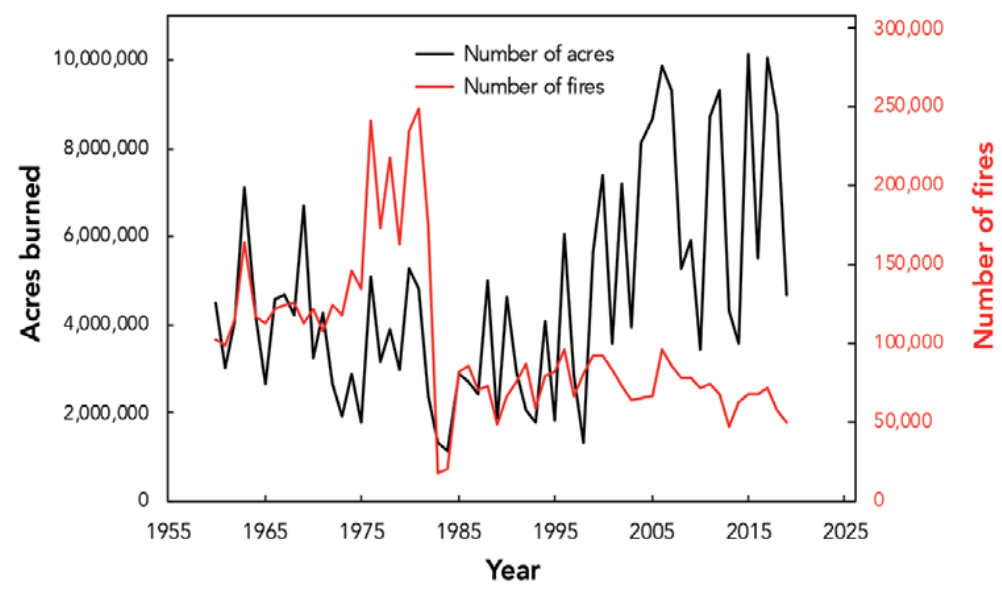

Figure 2.

The number of fires and land area burned in wildlands. Data are from the National Interagency Fire Center [2]. The number of fires has remained relatively constant since the 1980s, but the land area burned has increased, indicating that fires are becoming larger and more catastrophic.

Ignitions are a critical factor of wildfire regimes. Before the European settlement, lightning and Native American activities were the sources of ignition. As populations and permanent infrastructure expanded in the past century, sources of ignitions diversified, particularly in the WUI. While lightning is still an ignition source of large, severe wildfires in areas of lower population density such as in boreal forests and at higher latitudes [29], more fires are ignited by Anthropogenic sources, particularly as the WUI expands, such as sparks from power lines [34], accidental flares from camping fires [35], and deliberate arson [36].

The interactions among the three factors can change fire regimes in a positive feedback cycle. In areas with low population and human activities, sources of fire ignition increase fire occurrence, but in areas with high population density and frequent human activities, fuel availability drives the fire regime. In the meanwhile, shifts in climate can either increase or decrease the probability of fire occurrences in addition to the other two drivers.

\subsection{Shifts in wildfire management}

Prior to Native American settlement of North America, wildfires were unmanaged, and their severity and frequency were a result of the available fuel load and local climatic factors, namely precipitation, temperature, and drought conditions [37, 38]. North America was settled approximately 14,000 years ago [39], and there is considerable evidence for management of landscapes by Native Americans [40]. The exact magnitude of Native American burning is difficult to determine, due to methodological limitations in reconstructing historic fire frequencies [41], but the available evidence suggests that Native Americans utilized low severity burns in order to maintain prairie habitats and encourage growth of vegetation for cultural usage $[40,42]$. The reconstructed fire record of the western US suggests that much of the pre-European settlement wildfire regime was primarily dictated by large-scale climate patterns, rather than via human influence [28].

Around the turn of the twenty-first century, policies were introduced to encourage fire suppression, mainly wildland firefighting, in part as a response to fires in the Northern Rockies in 1910 and as a means to protect timber resources and human 


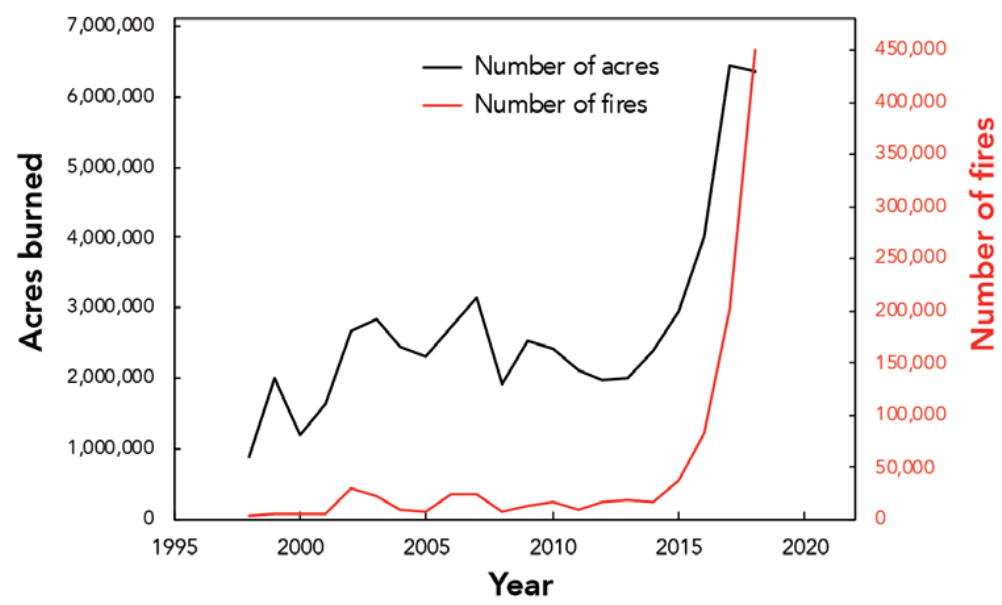

Figure 3.

Number of prescribed fires and acres burned in the United States from 1997 to 2018, data from the National Interagency Fire Center.

settlements $[43,44]$. These policies generally did not consider fire suppression via other management strategies (e.g., fuel load reductions, prescribed burning), which led to a significant increase in the density of American forests [43].

In the past several decades, scientific research indicated the role that fires play in natural ecosystems in shaping ecosystem dynamics, but also to prevent the large fuel loading that results in larger, more severe wildfires. Following this research and shifts in political perspectives, recent changes in legislation, namely the Healthy Forests Initiative (2002) and the Healthy Forests Restoration Act (2003) [44], have allowed for more prescribed burning (Figure 3). This rapid increase in the use of prescribed fire across the US is likely to lead to a shift back towards a more natural fire regime in some areas, although it is unlikely that the magnitude of prescribed burning would approach the extent of what would naturally occur.

Prescribed burning has been widely adopted in the southeastern US, which in recent decades has led to a decrease in wildfires, with some exceptions in drought years [45]. In the western US, prescribed burning has been slower to be more widely adopted as a management strategy due to a number of factors, including the larger proportion of public lands, more restrictive legislation, and concerns about emissions and air quality [46]. Across the US, considerable public weariness of prescribed fire has also been a major barrier to its widespread use [46], due to concerns about control of the burns and air quality.

\subsection{Predictions for future wildfire regimes}

Projections for future wildfire regimes indicate that some areas of the US will experience larger and more severe wildfires, while other areas will experience fewer and less severe wildfires. The accuracy of these projections will in part depend upon management techniques within fire-prone ecosystems, including the use of prescribed burning vs. fire suppression [16]. In their recent study, Parks, Miller [16] project significant decreases in wildfire severity in the western US, which they attribute to changes in fuel loads into the twenty-first century and water deficit conditions. In the southeastern US, projections indicate a slight increase in area burned, with considerable variability across different states [47]. 


\section{Wildfire in the wildland-urban interface}

The major concerns of wildfire in the WUI are the risk to human life, structures, and economic productivity. The WUI comprises $9 \%$ of the land in the US, which equates to $39 \%$ of all housing units [48]. Prior development increased the proportion of land classified as a WUI from 1970 to 2000 by 52\%, with future projections for ongoing increases in WUI lands [49].

One major consideration for management of wildfire risk at the WUI is understanding the drivers of shifts in wildfire regimes into the future. Some modeling work has predicted that shifts in fire regimes into the future will be more significant for wildfire occurrence at the WUI than expansion of WUI development [50]. However, with increasing areas classified as WUI, there are also increasing ignition sources for wildfires and developed lands that could suffer wildfire damage [3]. Some modeling work has shown that whether a residence has fire proofing, and the density of surrounding homes and vegetation all interact to control the severity and size of wildfire [51].

\subsection{Current and shifting attitudes towards fire in the wildland-urban interface}

Understanding attitudes concerning wildfire management at the WUI has drawn considerable research attention, because frequently public perception of the use of wildfire management techniques prevents their use [52-54]. Some of the major concerns are related to the cost of implementation of the management technique and direct impacts during implementation, such as decreased air quality during prescribed fire, and drawbacks of particular fire management techniques, including costs $[53,54]$. Public attitudes towards wildfire management at the WUI also depend upon local factors, including previous wildfire management strategies employed, trust in local agencies responsible for managing wildfire risk, and individual attitudes towards the management techniques $[53,55,56]$.

\subsection{Public awareness of shifting climates at the wildland urban interface}

As development has continued into the wildland-urban interface over the past several centuries, wildfire severity has increased [40]. Recent research has indicated that some populations are aware that future shifts in climate may lead to increased risk of wildfire and related property damage [57]. However, public perceptions of climate change have not significantly shifted in the past several decades, except along some partisan divides [58]. Regardless of public awareness of shifting wildfire risk into the future, areas of increased risk are facing increased insurance premiums and rates, as they already have in California [59].

\section{Management of wildfire in the wildland-urban interface}

\subsection{Current strategies for managing wildfire at the wildland-urban interface}

The main historic and current strategy to reduce the risk of wildfire has been fuel reduction $[3,54]$. In wildlands, prescribed fire, allowing natural fires to burn within designated boundaries, and mechanical treatments, such as thinning or mastication, are the main strategies that have been successfully used to reduce wildfire frequency and severity [60]. There is a need to develop or re-develop the natural fire regime, or shift towards a more frequent, lower intensity fire regime, particularly in the Western US [40]. 
Land managers of ecosystems that are highly prone to wildfire at the WUI will likely need to undertake a proactive management approach to protect human safety and infrastructure in the WUI [40]. A commonly utilized strategy at the WUI is the establishment of a "defensible space" around residences and other properties, which reduces vegetation and other burn hazards adjacent and up to $30 \mathrm{~m}$ away from buildings [61]. Buildings can also be constructed of combustion-resistant materials, although this strategy is more effective when combined with defensible space [62].

\subsection{Recommendations for strategies in consideration of future climate and fire regimes}

While many strategies have been identified to manage forests at the wildlandurban interface, they have not been widely adopted due to a combination of factors, including lack of funding and political willpower [63]. Current research has indicated the effectiveness of utilizing prescribed fire to reduce the frequency and severity [45]. Expanded and more frequent use of prescribed fire and other fuel reduction techniques in the WUI can serve to protect infrastructure from more catastrophic wildfire and act to re-establish a historic wildfire regime.

One of the major barriers to increasing use of fuel reduction management strategies is public perception of both the use of these techniques and the increased risk of wildfire with ongoing climate change. Future management strategies should continue to include strategies for managing public perception to increase acceptance and participation in fuel management at the WUI and to increase understanding of the diverse factors involved in managing forests for both prescribed fire and wildfire events [64]. Additionally, these strategies should continue to focus on informing the public about the efficacy of defensible spaces and improve development planning to ensure greater accessibility, improved use of defensible space, and better building design [61].

\subsection{Future research and ongoing uncertainty}

There is considerable current and ongoing research focused on enhancing fire condition predictors and managing strategies related to reducing the severity and frequency of wildfires $[16,17,65,66]$. Ongoing research in refining future climate predictions will generate considerably more certainty to predictions for future fire regimes. However, work in the area should focus more on the dynamics of wildfire at the WUI due to the critical resources that are at risk in those areas.

Many of the obstacles to implanting these management strategies are political in nature, with responsibility falling to local governments operating under limited funding and variable community support [63]. Some recent research has indicated that local differences in legal liability for prescribed burning lead to significant differences in the amount of land burned via prescribed fires [67]. While features of landscapes that make them prone to wildfire have been reasonably well-described, future research on mitigating the effects of wildfire in the WUI should consider the human dimension to management decision making [46]. Historically, human management has driven much of the increase in wildfire severity, and into the future, there will be a need for management strategies that reconcile natural fire regimes with protection of human life and property at the WUI.

\section{Conclusions}

Modern fire regimes are largely driven by anthropogenic activities and widely differ from pre-European and pre-Native American wildfire regimes. In the coming 
Shifting Wildfire Trends and Management Implications for the Wildland Urban Interface... DOI: http://dx.doi.org/10.5772/intechopen.93245

decades and century, projected climate shifts will drive corresponding shifts in wildfire occurrence and severity, with differing projections for different regions of the US. Development in the WUI needs to be informed for how to manage local shifts in wildfire regimes to mitigate the impacts of severe wildfire, and some of the ability of an area to respond is related to public perception of the risks of wildfire.

\section{Acknowledgements}

The authors would like to thank and acknowledge Joseph Crockett for comments on earlier versions of this book chapter.

\section{Conflict of interest}

The authors declare no conflict of interest.

\section{Author details}

Rebecca Abney ${ }^{1 *}$ and Qin $\mathrm{Ma}^{2}$

1 University of Georgia, Athens, GA, USA

2 Mississippi State University, Mississippi State, MS, USA

*Address all correspondence to: rebecca.abney@uga.edu

\section{IntechOpen}

(C) 2020 The Author(s). Licensee IntechOpen. This chapter is distributed under the terms of the Creative Commons Attribution License (http://creativecommons.org/licenses/ by/3.0), which permits unrestricted use, distribution, and reproduction in any medium, provided the original work is properly cited. (cc) BY 


\section{References}

[1] Randerson JT et al. Global burned area and biomass burning emissions from small fires. Journal of Geophysical Research Biogeosciences. 2012;117:G04012. DOI: 10.1029/2012JG002128

[2] National Interagency Fire Center. National Report of Wildland Fires and Acres Burned by State. 2015. Available from: https://www.nifc.gov/fireInfo/ fireInfo_statistics.html [cited 06 May 2015]

[3] Radeloff VC et al. Rapid growth of the US wildland-urban interface raises wildfire risk. Proceedings of the National Academy of Sciences. 2018;115(13):3314-3319

[4] Staver AC et al. Thinner bark increases sensitivity of wetter Amazonian tropical forests to fire. Ecology Letters. 2020;23(1):99-106

[5] Vines R. Heat transfer through bark, and the resistance of trees to fire. Australian Journal of Botany. 1968;16(3):499-514

[6] Melo RTM. We didn't start the fire... did we? Analyzing why California cannot seem to extinguish its worsening wildfire problem. Villanova Environmental Law Journal. 2020;31(1):5

[7] IPCC. In: Stocker TF, Qin D, editors. Climate Change 2013: The Physical Science Basis, Working Group I Contribution to the Fifth Assessment Report of the Intergovernmental Panel on Climate Change. Summary for Policymakers. 2013

[8] Fried JS, Torn MS, Mills E. The impact of climate change on wildfire severity: A regional forecast for northern California. Climatic Change. 2004;64(1-2):169-191
[9] Harrison SP, Marlon JR, Bartlein PJ. Fire in the earth system. In: Changing Climates. Earth Systems and Society. Netherlands: Springer; 2010. pp. 21-48

[10] Marlon JR et al. Long-term perspective on wildfires in the Western USA. In: Proceedings of the National Academy of Science; 2012

[11] Torn MS, Mills E, Fried J. Will climate change spark more wildfire damage. Confronting Climate Change In California. Berkeley, CA: Lawrence Berkeley National Laboratory; 1998. LBNL-42592

[12] Gill AM, Allan G. Large fires, fire effects and the fire-regime concept. International Journal of Wildland Fire. 2009;17(6):688-695

[13] Swetnam TW, Baisan CH. Historical fire regime patterns in the southwestern United States since AD 1700. In:

Fire Effects in Southwestern Forests:

Proceedings of the Second La Mesa Fire Symposium, Los Alamos, New Mexico; 1994

[14] Frost CC. Presettlement fire frequency regimes of the United States: A first approximation. In: Fire in Ecosystem Management: Shifting the Paradigm from Suppression to Prescription. Tall Timbers Fire Ecology Conference Proceedings; 1998

[15] Noss RF et al. Managing fireprone forests in the western United States. Frontiers in Ecology and the Environment. 2006;4(9):481-487

[16] Parks SA et al. How will climate change affect wildland fire severity in the western US? Environmental Research Letters. 2016;11(3):035002

[17] Westerling AL et al. Warming and earlier spring increase western 
US forest wildfire activity. Science. 2006;313(5789):940-943

[18] Hutto RL. Composition of bird communities following standreplacement fires in northern Rocky Mountain (USA) conifer forests. Conservation Biology. 1995;9(5):1041-1058

[19] Arno SF. Forest fire history in the northern Rockies. Journal of Forestry. 1980;78(8):460-465

[20] Christensen NL et al. Interpreting the Yellowstone fires of 1988. Bioscience. 1989;39(10):678-685

[21] Elfring C. Yellowstone: Fire storm over fire management. Bioscience. 1989;39(10):667-673

[22] Romme WH, Despain DG. Historical perspective on the Yellowstone fires of 1988. Bioscience. 1989;39(10):695-699

[23] Frost C. History and future of the longleaf pine ecosystem. In: The Longleaf Pine Ecosystem. New York, NY: Springer; 2007. pp. 9-48

[24] Van Lear DH et al. History and restoration of the longleaf pinegrassland ecosystem: Implications for species at risk. Forest Ecology and Management. 2005;211(1-2):150-165

[25] Haywood JD. Influence of pine straw harvesting, prescribed fire, and fertilization on a Louisiana longleaf pine site. Southern Journal of Applied Forestry. 2009;33(3):115-120

[26] Pyne S, Vale TR. Fire, native peoples, and the natural landscape. Restoration Ecology: Book Review. 2003;11(2):257-259

[27] Naficy C et al. Interactive effects of historical logging and fire exclusion on ponderosa pine forest structure in the northern Rockies. Ecological Applications. 2010;20(7):1851-1864

[28] Marlon JR et al. Long-term perspective on wildfires in the western USA. Proceedings of the National Academy of Sciences. 2012;109(9):E535-E543

[29] National Interagency Fire Center. Prescribed Fires and Acres by Agency. 2018. Available from: https://www.nifc. gov/fireInfo/fireInfo_statistics.html [cited 28 August 2018]

[30] Stewart OC. Forgotten Fires: Native Americans and the Transient Wilderness. Norman, OK: University of Oklahoma Press; 2002

[31] Earles JM, North MP, Hurteau MD. Wildfire and drought dynamics destabilize carbon stores of fire-suppressed forests. Ecological Applications. 2014;24(4):732-740

[32] Guyette RP, Muzika R-M, Dey DC. Dynamics of an anthropogenic fire regime. Ecosystems. 2002;5(5):472-486

[33] Hurteau MD et al. Climate change, fire management, and ecological services in the southwestern US. Forest Ecology and Management. 2014;327:280-289

[34] Mitchell JW. Power lines and catastrophic wildland fire in southern California. In: Proceedings of the 11th International Conference on Fire and Materials. Citeseer; 2009

[35] Lydersen JM, North MP, Collins BM. Severity of an uncharacteristically large wildfire, the Rim Fire, in forests with relatively restored frequent fire regimes. Forest Ecology and Management. 2014;328:326-334

[36] Prestemon JP, Butry DT. Wildland arson: A research assessment. In: Pye JM, Rauscher HM, Sands Y, Lee DC, Beatty JS, editors. Advances in Threat 
Assessment and Their Application to Forest and Rangeland Management. Gen. Tech. Rep. PNW-GTR-802. Vol. 802. Portland, OR: US Department of Agriculture, Forest Service, Pacific Northwest and Southern Research Stations; 2010. pp. 271-283

[37] Whitlock C, Shafer SL, Marlon J. The role of climate and vegetation change in shaping past and future fire regimes in the northwestern US and the implications for ecosystem management. Forest Ecology and Management. 2003;178(1-2):5-21

[38] Pausas JG, Paula S. Fuel shapes the fire-climate relationship: Evidence from Mediterranean ecosystems. Global Ecology and Biogeography. 2012;21(11):1074-1082

[39] Haynes G, Gary H. The Early Settlement of North America: The Clovis Era. Cambridge, England: Cambridge University Press; 2002

[40] Hessburg PF, Agee JK. An environmental narrative of inland Northwest United States forests, 18002000. Forest Ecology and Management. 2003;178(1-2):23-59

[41] Baker WL, Ehle D. Uncertainty in surface-fire history: The case of ponderosa pine forests in the western United States. Canadian Journal of Forest Research. 2001;31(7):1205-1226

[42] Gruell GE. Fire on the early western landscape: An annotated record of wildland fires 1776-1900. Northwest Science. 1985;59(2):97-107

[43] Busenberg G. Wildfire management in the United States: The evolution of a policy failure. Review of Policy Research. 2004;21(2):145-156

[44] Johnson JF, Bengston DN, Fan DP. US policy response to the wildfire fuels management problem: An analysis of the news media debate about the
Healthy Forests Initiative and the Healthy Forests Restoration Act. Journal of Environmental Policy \& Planning. 2009;11(2):129-142

[45] Addington RN et al. Relationships among wildfire, prescribed fire, and drought in a fire-prone landscape in the South-Eastern United States. International Journal of Wildland Fire. 2015;24(6):778-783

[46] Ryan KC, Knapp EE, Varner JM. Prescribed fire in North American forests and woodlands: History, current practice, and challenges. Frontiers in Ecology and the Environment. 2013;11(s1):e15-e24

[47] Prestemon JP et al. Projecting wildfire area burned in the SouthEastern United States, 2011-60. International Journal of Wildland Fire. 2016;25(7):715-729

[48] Radeloff VC et al. The wildlandurban interface in the United States. Ecological Applications. 2005;15(3):799-805

[49] Theobald DM, Romme WH. Expansion of the US wildland-urban interface. Landscape and Urban Planning. 2007;83(4):340-354

[50] Liu $\mathrm{Z}$ et al. Climate change and wildfire risk in an expanding wildland-urban interface: A case study from the Colorado front range corridor. Landscape Ecology. 2015;30(10):1943-1957

[51] Spyratos V, Bourgeron PS, Ghil M. Development at the wildland-urban interface and the mitigation of forest-fire risk. Proceedings of the National Academy of Sciences. 2007;104(36):14272-14276

[52] Gill AM, Stephens SL. Scientific and social challenges for the management of fire-prone wildland-urban interfaces. Environmental Research Letters. 2009;4(3):034014 
[53] Winter G, Fried JS. Homeowner perspectives on fire hazard, responsibility, and management strategies at the wildland-urban interface. Society \& Natural Resources. 2000;13(1):33-49

[54] Winter GJ, Vogt C, Fried JS. Fuel treatments at the wildland-urban interface: Common concerns in diverse regions. Journal of Forestry. 2002;100(1):15-21

[55] Winter G, Vogt C, McCaffrey S. Residents Warming up to Fuels Management: Homeowners, Acceptance of Wildfire and Fuels Management in the Wildland-Urban Interface. The public and Wildland Fire Management: Social Science Findings for Managers. Newtown Square, PA: U.S. Department of Agriculture, Forest Service, Northern Research Station; 2006. pp. 19-32

[56] McCaffrey S et al. Social science research related to wildfire management: An overview of recent findings and future research needs. International Journal of Wildland Fire. 2013;22(1):15-24

[57] Schulte S, Miller KA. Wildfire risk and climate change: The influence on homeowner mitigation behavior in the wildland-urban interface. Society and Natural Resources. 2010;23(5):417-435

[58] Egan PJ, Mullin M. Climate change: US public opinion. Annual Review of Political Science. 2017;20:209-227

[59] Dixon LS. Insurance for Wildfire Risk in California. RAND; 2018. CT-499 Testimony presented before a joint meeting of the California State Assembly and California State Senate Committees on Insurance on October 30, 2018

[60] Mell WE et al. The wildlandurban interface fire problem-current approaches and research needs. International Journal of Wildland Fire. 2010;19(2):238-251
[61] Syphard AD, Brennan TJ, Keeley JE. The role of defensible space for residential structure protection during wildfires. International Journal of Wildland Fire. 2014;23(8):1165-1175

[62] Syphard AD, Brennan TJ, Keeley JE. The importance of building construction materials relative to other factors affecting structure survival during wildfire. International Journal of Disaster Risk Reduction. 2017;21:140-147

[63] Stephens SL et al. Managing forests and fire in changing climates. Science. 2013;342(6154):41-42

[64] Dupéy LN, Smith JW. An integrative review of empirical research on perceptions and behaviors related to prescribed burning and wildfire in the United States. Environmental Management. 2018;61(6):1002-1018

[65] Pechony O, Shindell DT. Driving forces of global wildfires over the past millennium and the forthcoming century. Proceedings of the National Academy of Sciences. 2010;107(45):19167-19170

[66] Stephens S, Moghaddas J. Experimental fuel treatment impacts on forest structure, potential fire behavior, and predicted tree mortality in a California mixed conifer forest. Forest Ecology and Management. 2005;215(1-3):21-36

[67] Wonkka CL, Rogers WE, Kreuter UP. Legal barriers to effective ecosystem management: Exploring linkages between liability, regulations, and prescribed fire. Ecological Applications. 2015;25(8):2382-2393 

Section 3

\section{Advanced Protection Mechanism: Simulations}





\title{
Mathematical Modeling and Simulation of Development of the Fires in Confined Spaces
}

\author{
Ivan Antonov, Rositsa Velichkova, Svetlin Antonov \\ and Kamen Grozdanov
}

\begin{abstract}
The mathematical models of fire distribution in a confined space-in underground garages and in buildings-are described. Integral and computational fluid mechanics methods are used. The chapter presents the results of a fire simulation using the software Fluent. It uses Reynolds-type turbulence models of the Fire Dynamic Simulation or PyroSim graphical interface with a solution model describing a turbulence. For both cases, the pictures of the spread of fire and smoke over time in an atrium of an administrative building and a five-story building of the TUS were presented.
\end{abstract}

Keywords: fire simulation, FDS, garages, buildings, numerical simulation

\section{Introduction}

Mathematical modeling and numerical simulations of fires are an essential decisive part of the solution of important problems related to fire safety, analysis of the development of fires in the investigation of their consequences. The methods that are used must have the necessary accuracy and reliability, as close as possible to the physical picture of the processes.

The actual fire, as it is known, is an uncontrollable combustion process, complex enough and difficult for mathematical interpretation. This is due to its nonstationarity and three-dimensionality, which complicate the modeling of the heat and mass transfer processes observed in them. In the case of fires indoors of underground garages, buildings, and rooms, the development of the fire is accompanied by a change in the chronicle composition and parameters of the combustion products.

This chapter gives two different approaches in dealing with their complexity and implementation of solving the problem. On the other hand, an integrated, relatively simplified technical solution of a new system for preventing the spread of fires in underground garages is given, which is described in details in the chapter.

The second part deals with the basic mathematical apparatus used in CFDFluent and FDS software. The results of two fire simulations made by the authors through Fluent and FDS using the PyroSim GUI are presented [1, 2]. 


\section{Fire extinguishing system in large underground garages: integral methods for investigation}

In the present part, a simple method (from a technological point of view) is offered for solution of the complex problem. It is suggested to isolate the parked in the garage cars in pairs by which will be operating a thick curtain of water at arisen burning. The necessary insulation for solid noncombustible barriers are replaced at this way [3-6].

\subsection{Operating principal}

Referring to Figure 1, cars are placed to ensure the possibility between the pairs to have enough distance for the implementation of water curtains. In case of burning over the car is formed upward convective flow, because of differences of the density of the products of combustion and the environment. This stream is proportional to the lift force:

$$
d F_{A}=-\left[\int_{f}\left(\rho-\rho_{o k}\right) g d f\right] d x,
$$

where $f$ is the area of fire ignition and $d x$ is elementary stretch in the vertical direction.

The power of convective updraft is determined by the number of Archimedes:

$$
A r=\left(\frac{\rho_{o k}}{\rho}-1\right) \frac{g d_{h}}{u_{0}^{2}}
$$

where $d_{h}$ is the hydraulic diameter of the outbreak of fire and $u_{0}$ is the initial value of the velocity of the upward flow. The velocity is determined according to [6]:

$$
u_{0}^{2}=1,9 Q^{1 / 5} \text {, }
$$

where $Q, \mathrm{~kW}$ is the power of the fire.

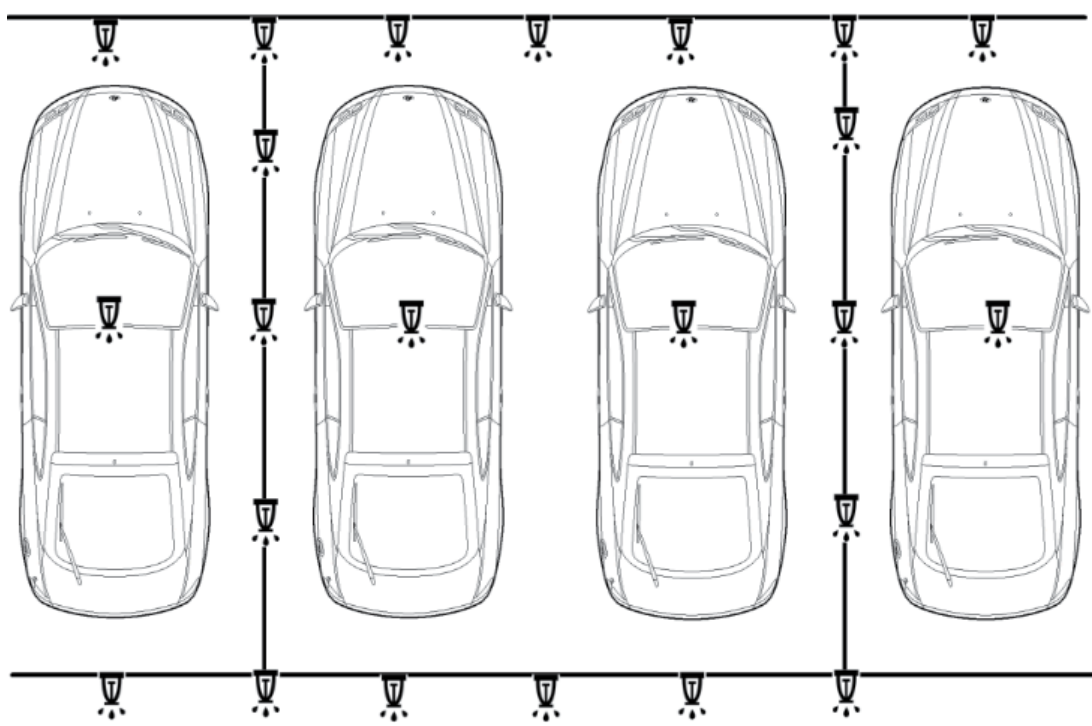

Figure 1.

Distribution of cars in the garages. 


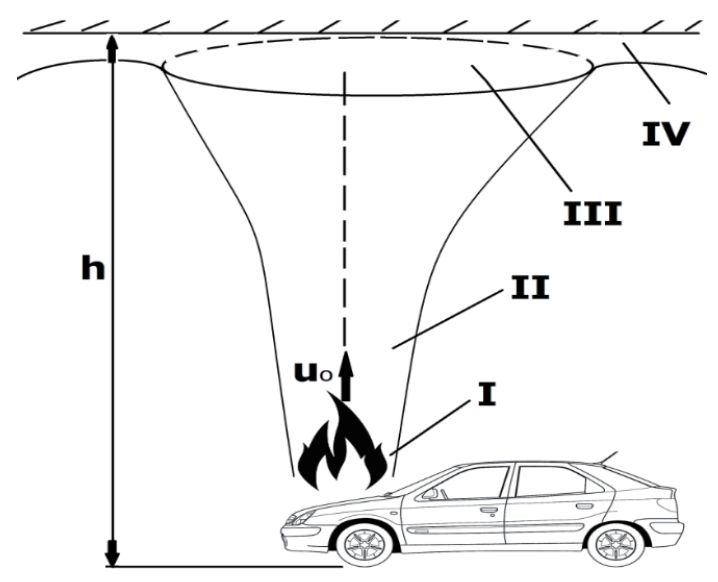

Figure 2.

Distribution of the fire.

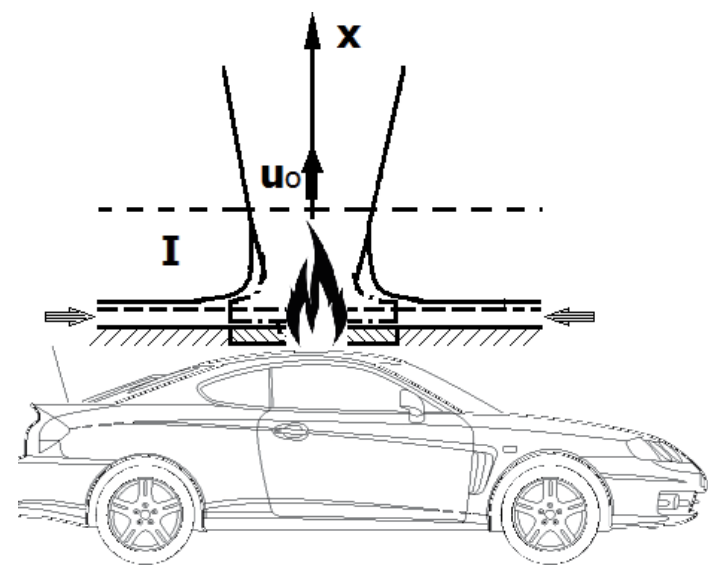

Figure 3.

Sketch of the convective flow.

The convective flow that is formed is shown in Figure 2. The conditional flow can be divided into the following areas: Convective flow is formed in zone I

(Figure 3). The ambient air enters the fire zone from all directions, which heats and reverses the direction vertically. The second zone is a free convective flow that continues until it reaches the ceiling of the room where the flow changes character (zone III). In this zone, the jet is transformed into a radially semi-enclosed stream and spreads over the garage ceiling (zone IV).

The system includes fire sprinklers-quick response and standard sprinklers. Convective flow is reaching the garage ceiling under the influence of its temperature and a quick response sprinkler is switched on and the burning car is flushed with a water spray. Thus begins the process of extinguishing a fire in the initial stages. Further, propagating as a radial semi-closed jet, it reaches the "standard" reaction sprinklers that are included on the water curtain $[7,8]$.

This stage is defined as the isolation of burning cars from the surrounding area and no other pairs are affected.

\subsection{Mathematical model of convective non-isothermal jet}

For the purpose of solving the task is used an integral method according to $[9,10]$. The used equations are as follows [11-13]: 
- for amount of movement

$$
\frac{d}{d x} \int_{0}^{b} \rho u^{2}\left(\pi y^{j}\right) d y=-g \int_{0}^{b}\left(\rho-\rho_{\text {oк }}\right)(\pi y)^{j} d y
$$

- to preserve enthalpy flow

$$
\frac{d}{d x} \int_{0}^{b} \rho \Delta h u y^{j} d y=0
$$

- for export of vertical upward mass flow

$$
\frac{d}{d x} \int_{0}^{b} u\left(\rho-\rho_{o \kappa}\right)(\pi y)^{j} d y=0
$$

A simple solution can be made as (5) of enthalpy is replaced by a linear dependence on the widening of the jet

$$
b=c x
$$

On the right-hand side of Eq. (4) is written the Archimedes buoyancy. The significance of included symbols is as follows: $u$ is the jet velocity; $y$ is the transverse coordinate; $\rho$ is the current density; $\rho_{o \kappa}$ is the density of the environment; and $\Delta h$ is the enthalpy of the stream. The exponent $\mathrm{j}$ signifies: at $\mathrm{j}=0$ a flat stream and $\mathrm{j}=1$ an axis jet. The coordinate $\mathrm{x}$ is directed vertically upward.

There is a correlation between density and temperature:

$$
\rho=\frac{p}{R T}
$$

where $p$ is the pressure of the environment, $R$ is the gas constant, and $T$ is the absolute temperature. Similarity to transverse distribution of the velocity and the density (temperature) are initiated [1,2], where solving Eqs. (4) and (6) leads to the parameters of the upward convective stream:

- the velocity of the upward stream

$$
u_{m}=B_{u}^{\prime \prime} D_{0}^{1 / 3} \Delta T_{n \imath}^{4 / 9} \bar{x}^{1 / 3}
$$

- the temperature difference

$$
\Delta T_{m}=T_{m}-T_{e n v}=B_{\Delta T}^{\prime \prime} D_{0}^{1 / 3} \Delta T^{8 / 9} \bar{x}^{5 / 3}
$$

where $D_{0}$ is the initial diameter of the heat source of fire (the burning car); $\Delta T_{1}=T_{f l}-T_{e n v} ; \bar{x}=\frac{x}{D_{0}}$; the constants $B_{u}^{\prime \prime}$ and $B_{\Delta T}^{\prime \prime}$ have values $B_{u}^{\prime \prime}=0.222\left[m^{3} K^{9 / 4}\right]$, $B_{\Delta T}^{\prime \prime}=0.71\left[m^{1 / 3} K^{9 / 8}\right]$. 
These values correspond to the case at $\bar{x}=\frac{x}{D_{0}} \geq 3 \div 3.5$. When adopted fire size created from a burning car $D_{0}=0.5 \mathrm{~m}$ and height $H=3 \div 4.5 \mathrm{~m}, \bar{x}$ of the garage will be always greater than the above values.

At the relatively short distance to the ceiling, the high power of fire (the accepted conditions are $Q=1500 \mathrm{~W}$ and $T=600 \mathrm{~K}$ ), the velocity and the temperature of the rising convective stream do not change significantly.

The initial velocity calculated by Eq. (3) is $u_{0}=8.2 \mathrm{~m} / \mathrm{s}$ and the time when the convective stream will reach the ceiling at different heights of the garage is given in Table 1.

This means that less than $1 \mathrm{~s}$ sprinklers over the burning car will be activated and extinguishing stream will flow over the burning car.

The expansion (increasing of thickness) of the jet in height can be determined by the expression:

$$
\frac{d b}{d x}=0.22 \frac{\rho_{0}+\rho_{o \kappa}}{2 \rho_{o \kappa}}
$$

where,

$$
b=\left[0.22 \frac{\rho_{0}+\rho_{o \kappa}}{2 \rho_{\text {oк }}}\right]
$$

The density of the jet in the opening section is defined by Eq. (8): at $R=$ $287 \mathrm{~J} / \mathrm{kgK}, T_{0}=600 \mathrm{~K}, p=10^{5} \mathrm{~Pa}$ in which for $\rho_{0}$ is received $\rho=0.58 \mathrm{~kg} / \mathrm{m}^{3}$. The density of the environment is $\rho_{e n v}=11.2 \mathrm{~kg} / \mathrm{m}^{3}$ at the same pressure and temperature $T_{e n v}=293 \mathrm{~K}$. At this density, the widening of the jet in the present case is

$$
b=0.163 x
$$

For a different height in the garage, the parameter $b$ is given in Table 2.

The last row in Table 2 is given the extension of the isothermal jet $\left(T_{0} \approx T_{\text {env }}\right)$. Obviously a slight extension of non-isothermal convective flow comparing with the isothermal.

Reaching the ceiling vertical, the convective stream is transformed into radial jet (Figure 4).

\begin{tabular}{ccccc}
\hline $\mathrm{h}, \mathrm{m}$ & 3 & 3.5 & 4 & 4.5 \\
\hline$\Delta t$ & 0.36 & 0.43 & 0.49 & 0.55 \\
\hline
\end{tabular}

Table 1.

$h$-height of the garage, $m ; \Delta \mathrm{t}$-time of the fire to reach the ceiling, $m$.

\begin{tabular}{lcccc}
\hline $\mathrm{h}(\mathrm{m})$ & 3 & 3.5 & 4 & 4.5 \\
\hline $\mathrm{b}_{1}(\mathrm{~m})$ & 0.501 & 0.507 & 0.652 & 0.73 \\
\hline $\mathrm{b}_{\text {sou }}(\mathrm{m})$ & 0.651 & 0.77 & 7.74 & 1.98 \\
\hline
\end{tabular}

Table 2.

$h$-height of the garage, $m ; b_{0}$-initial width of the radial jet, $m ; b_{1}$-width of the radial jet, $m$. 
Due to the weak widening of the jet and the short distance to the ceiling, the mass flow is not increased significantly because the temperature, density, and relatively low mileage ceiling have not changed. The jet has retained its temperature and density, and the velocity according to [14] may be determined:

$$
u_{\max }=0.88 u_{0}
$$

where for $u_{0}=8.2 \mathrm{~m} / \mathrm{s}$ it is $u_{\max }=7.2 \mathrm{~m} / \mathrm{s}$.

It is assumed that the starting size of the radial jet is equal to that obtained in Table 2, $b_{1}$, that is $D_{0}=b_{1}$.

Width of the radial jet $b_{0}$ is determined by the flow rate $Q$ at the intersection of the reverse flow. The flow rate is amount of initial flow rates $Q_{0}$ and increase its height due to suction of air from the environment. The flow rate of ejecting fluid is considered proportional to the square of the relative increase in the width of the jet $\left(\frac{b_{1}-b_{0}}{b_{0}}\right)^{2}$ and the distance $x$ divided by the duration of the process $\Delta t$.

$$
Q_{e j} \approx\left(\frac{b_{1}-b_{0}}{b_{0}}\right)^{2} \frac{x}{\Delta t}, \mathrm{~m}^{3} / \mathrm{s}
$$

In this, total flow rate is obtained as the sum of normal and ejecting flow rate:

$$
Q=Q_{0}+Q_{e j}, \mathrm{~m}^{3} / \mathrm{s}
$$

where $Q_{0}=u_{0} \frac{\pi d_{n}^{2}}{4}$, when $d_{n}=0.5 \mathrm{~m}$ and $u_{0}=8 \mathrm{~m} / \mathrm{s}$ we have:

$$
Q=Q_{0}+Q_{e j}=u_{0} \frac{\pi d_{n}^{2}}{4}+\left(\frac{b_{1}-b_{0}}{b_{0}}\right)^{2} \frac{x}{\Delta t}
$$

The flow rate of the respective heights $x=3 ; 3.5 ; 4 ; 4.5 \mathrm{~m}$ of the garage is shown in Figure 5 where it is defined by the relationship given in Eq. (12), respectively and in case of a leak by Eq. (13).

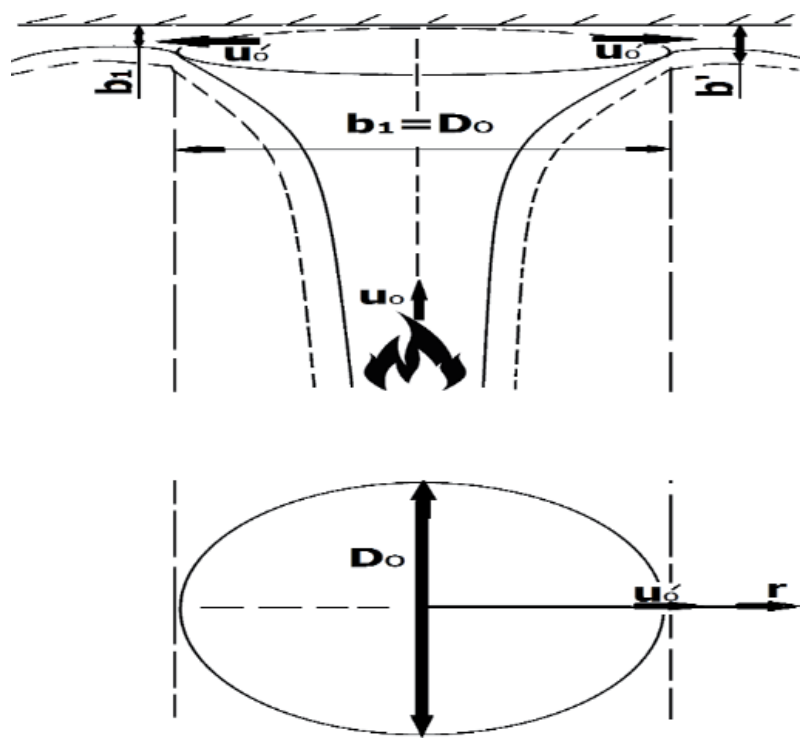

Figure 4 .

Sketch of radial jet. 
According to Figure 4, it is assumed $D_{0}=b_{1}$ that is already known and for flow rate in Eq. (16), the original width of the radial jet $b_{0}^{\prime}$ is calculated:

$$
b_{0}^{\prime}=\frac{Q}{\pi D_{0}} .
$$

The relationship $b_{0}(x)=f(x)$ is given in Figure 6 .

The cross-section of the radial jet as a function of $r$ is determined by the expression:

$$
S=2 \pi r b^{\prime}
$$

where $r$ is the current radius, $b^{\prime}$ is the width of the jet to the corresponding $r$.

Since the resulting stream is parietal and has parietal boundary layer whose thickness is approximately $0.1 b^{\prime}$, Eq. (19) can be recast in the form:

$$
S=2.2 r b^{\prime}
$$

The width $b^{\prime}$ is calculated by Eq. (12) and for the case in Eq. (13) by replacing $x$ with $r$, then we have:

$$
b^{\prime}=\left[0.22 \frac{\rho_{0}+\rho_{o k}}{2 \rho_{o k}}\right] r=c^{\prime} r ; c^{\prime}=0.22 \frac{\rho_{o}+\rho_{o k}}{2 \rho_{o k}},
$$

respectively, $b^{\prime}=0.163 r$.

When substituted in Eq. (19) we get the following:

$$
S=2.2 \pi c^{\prime} r^{2}
$$

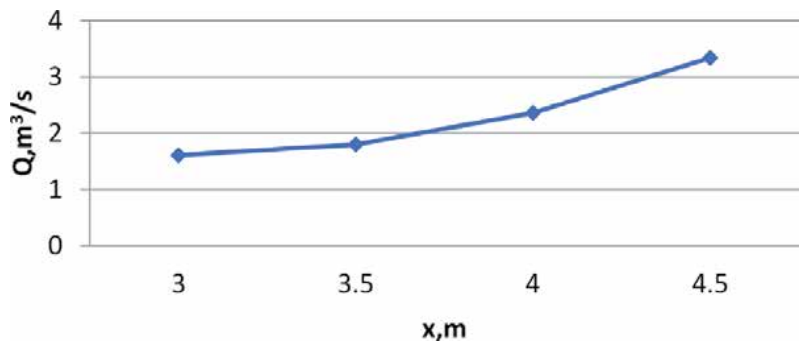

Figure 5 .

Change of the flow rate at different heights of the garage.

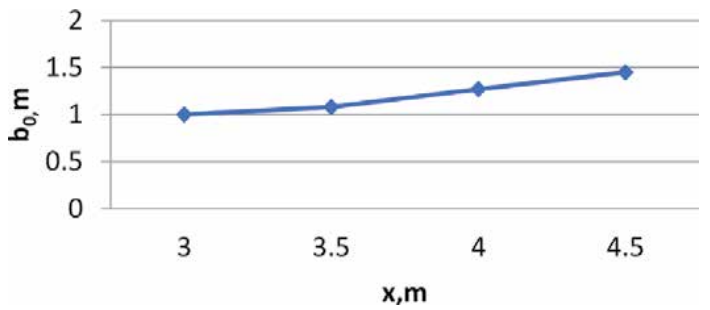

Figure 6.

Change of the initial weight at different heights of the garage. 
The average velocity of the ceiling of the room depending on $r$ is obtained by:

$$
u_{m}=\frac{Q}{S}
$$

respectively:

$$
u_{m}=\frac{Q}{2.2 \pi c^{\prime} r^{2}}, \mathrm{~m} / \mathrm{s}
$$

Parking average velocity depending on $r$ at the four heights is shown in Figure 7. Figure 8 shows the time to reach the appropriate distance:

$$
\Delta t=\frac{r}{u_{m}}, \mathrm{~s}
$$

This means that in the first $2 \mathrm{~s}$, all sprinklers at distance of $2 \mathrm{~m}$ away from the burning car will be triggered. For longer distances, the remote sprinklers will act at a condition if the temperature of the burning car does not decrease too quickly. For maximum calculated time of $7.7 \mathrm{~s}$ could not be expected too much decrease of the temperature, which leads to the conclusion that the ceiling temperature will be much greater than the starting temperature of "fast" sprinklers so that at $t_{p}=57^{\circ} \mathrm{C}$ or $\mathrm{T}=330^{\circ} \mathrm{K}$ will always remain less than the temperature of the wall jet which initial temperature is $600^{\circ} \mathrm{K}$.

With the removal from the water curtain, it is possible to turn on the other ceiling sprinklers that are in the range.

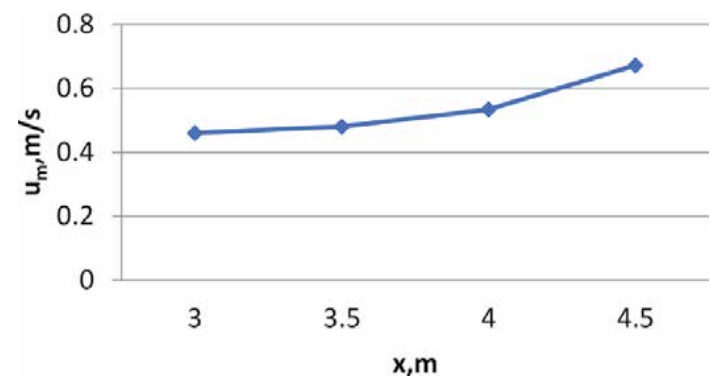

Figure 7.

Average velocity at different heights of garage.

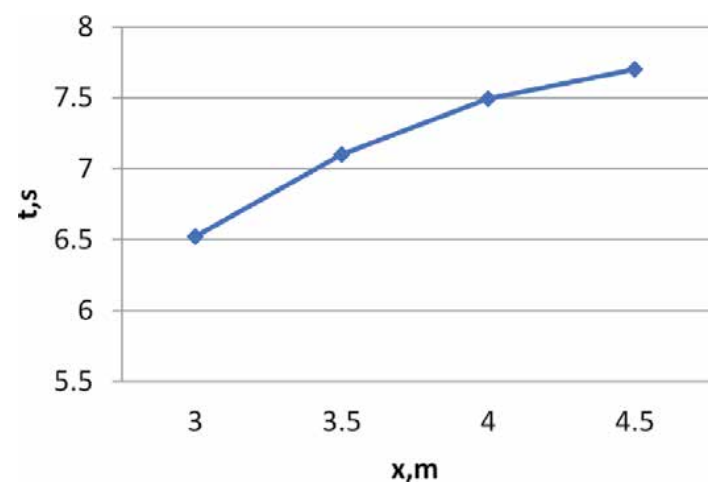

Figure 8.

Time to reach the sprinklers at different heights of garage. 
In the vicinity of the burning car to sprinkler curtain, a distance of $l \leq 2 \mathrm{~m}$ will trigger three (to five) fast sprinklers. At a longer distance, it will trigger maximum of three quick sprinklers of water curtain plus the main ones over the burning car and eventually those are lying in the range of $l=4 \mathrm{~m}$ ceiling sprinklers so that the number of activated sprinklers will increase [10].

To create a smokeless zone under a layer of smoke floating [14], air exhaust systems are designed and installed for smoke and hot gases. An exhaust ventilation system for smoke and hot gases is a scheme of safety equipment designed to perform a positive role in spin fire. The smoke is drawn in the direction of the noncarrier partition EI from a velocity of $2 \mathrm{~m} / \mathrm{s}$ to $5 \mathrm{~m} / \mathrm{s}$. Standard allowed velocity of $5 \mathrm{~m} / \mathrm{s}$, but it should be taken into consideration that this velocity would affect negatively and lead to the merging of streams of pure air.

From Abramovich [14], the density of the thermal load in the premises for the storage of combustible materials according to their purpose, is determined the heat capacity of the prevailing materials. The ventilation system to remove smoke and heat (VSRSH) has to reach its designed performance level within $60 \mathrm{~s}$ of receiving the command signal. Each VSRSH has to ensure receipt of sufficient fresh air that enters the room for the expense of the flue products.

\subsection{Thermal impact}

Heat transfer by convection and radiation is defined according to $[3,10]$. Thermal effects are expressed by the intensity of the heat flow $h_{n b t}, \mathrm{~W} / \mathrm{m}^{2}$ to the surface of the element is determined taking into account the heat transfer by convection and radiation, such as:

$$
h_{n b t}=h_{n b t, c}+h_{n b t, r}, \mathrm{~W} / \mathrm{m}^{2},
$$

where heat transfer by convection $h_{n b t, c}$ is given by the relationship

$$
h_{n b t, c}=\alpha_{c}\left(\theta_{g}-\theta_{m}\right), \mathrm{W} / \mathrm{m}^{2}
$$

radiation heat transfer $h_{n b t, r}$ is given by the dependence:

$$
h_{n b t, r}=\Phi \varepsilon_{m} \varepsilon_{f} \sigma\left[\left(\theta_{1} r+273\right)^{2}-\left(\theta_{m}+273\right)^{4}\right], \mathrm{W} / \mathrm{m}^{2}
$$

Convection component of the intensity of the heat flow is determined by:

$$
h_{n b t, t}=\alpha_{c}\left(\theta_{g}-\theta_{m}\right), \mathrm{W} / \mathrm{m}^{2}
$$

where $\alpha_{c}$ is the heat transfer coefficient by convection $\left[\frac{\mathrm{W}}{\mathrm{m}^{2}} \mathrm{~K}\right] ; \theta_{g}$ is the gas temperature near the exposed fire element $\left[{ }^{\circ} \mathrm{C}\right]$; and $\theta_{m}$ is the surface temperature of the element $\left[{ }^{\circ} \mathrm{C}\right]$.

The coefficient of heat transfer by convection $\alpha_{c}$ is determined by the nominal curves corresponding to "temperature-time." On indirectly heated surface elements, the intensity of heat flow $h_{n b t}$ is determined by Eq. (16) where $\alpha_{c}=4\left[\frac{\mathrm{W}}{\mathrm{m}^{2}} \mathrm{~K}\right]$. The coefficient of heat transfer by convection has value $\alpha_{c}=9\left[\frac{\mathrm{W}}{\mathrm{m}^{2}} \mathrm{~K}\right]$, considering that the effects of heat transfer by radiation are included.

Radiating components of net heat flux per unit surface area are defined as $h_{n b t, r}=$ $\Phi \varepsilon_{m} \varepsilon_{f} \sigma\left[\left(\theta_{1} r+273\right)^{2}-\left(\theta_{m}+273\right)^{4}\right], \mathrm{W} / \mathrm{m}^{2}$, where: $\Phi$ is the factor of configuration, 
$\varepsilon_{m}$ is the emitting surface element, $\varepsilon_{f}$ the transmission of fire, $\sigma=5.67 \times 10^{8}\left[\frac{\mathrm{wK}^{4}}{\mathrm{~m}^{2}}\right]$ is the constant of Stefan-Boltzmann, $\theta_{r}$ is the effective temperature of the radiation environment $\left[{ }^{\circ} \mathrm{C}\right]$, and $\theta_{m}$ is the surface temperature of the element $\left[{ }^{\circ} \mathrm{C}\right]$. Transmission of fire is equal to $\varepsilon_{f}=1$.

\subsection{Determination of the intensity of water curtain}

Because of the difficulties associated with the construction of fire walls, experiments are conducted so that these areas to be reduced to such proportions that the primarily split up do not disturb of the process. In many cases, such as in buildings of first degree of fire resistance, as already noted, firewalls did not provide the detriment of fire safety. In connection with this arises a need of using such fire barriers that could effectively limit the spread of fire and at the same time would give some freedom for internal layout of buildings with different functions, which is the case of the water curtain [15].

When calculating water curtains, the assumption must simultaneously satisfy the following conditions:

Structural parts of the building to withstand the effects of fire on one side and the passage of flames or hot gases to be prevented by the transfer of heat to the unexposed side. The ability of the structural parts of the building to withstand the effects of fire on one side and prevent the transfer of heat from the exposed to the unexposed side. The transfer is limited so that it does not ignite either the unexposed surface, or any other material in the immediate vicinity. The structural element is designed to serve as a barrier against the heat and to ensure the protection of people who are close to it.

The effectiveness of water curtains is assessed according to the amount of absorbed heat.

It is known that the dependence of the growth temperature of the source of radiation of maximum energy moves to the side of the shorter waves. This follows from the law of Vin:

$$
\lambda_{\max , T} T=0.29=\text { const }
$$

where $\lambda$ is the wavelength in $\mathrm{m}, T$ is the temperature at the surface of water curtain, ${ }^{\circ} \mathrm{K}$.

Good enough inter-phase and heat-absorbing surfaces have water drops of size $200 \times 10^{-6}$. It is considered that in the best case, sprinklers spray water of size less then $1000 \mu \mathrm{m}$.

\subsection{Required flow rate for air curtain}

The current has the following characteristics: density of the radiation heat flux is $1500 \mathrm{~W} / \mathrm{m}^{2}$; density of the irradiation protected material is $900 \mathrm{~W} / \mathrm{m}^{2}$; height of the hole-4 m; length of the hole- $6 \mathrm{~m}$; pressure of water in sprinkler-0.6 MPa (6 atm) and the radius of the water drops- $0.0006 \mathrm{~m}(600 \mu \mathrm{m})$.

Opacity density of the curtain:

$$
\delta=\frac{2.303 \log q_{u з \Omega}}{q_{\kappa p}}=0.51
$$

Thickness of the curtain: 


$$
R=\frac{\delta}{c}=\frac{0.51}{2.8}=0.182 \mathrm{~m}
$$

Flow rate of the water curtain for $1 \mathrm{~m}^{2}$ of lateral surface is defined by:

$$
Q=0.666 \mu \rho \frac{r R}{H} \sqrt{2 g h}=0.467 \frac{l}{s} \mathrm{~m}^{2}
$$

For the whole surface of the water curtain:

$$
Q^{H}=11.2 l / s
$$

Water curtains are constructed so that the entire hole is irrigated with finely dispersed water. For this purpose, sprinklers are placed over the hole and next to it. When they are placed at the top of the hole, it is possible for unprotected areas to remain through which it is possible for a penetration of hot gases to occur.

Sprinkler heads that are used to spray jets are spaced $0.5 \mathrm{~m}$ in protecting small holes and 1.25-1.5 $\mathrm{m}$ in protecting large holes. For sprinkler heads which are situated at a distance greater than $3 \mathrm{~m}$, it is required head pressure of the water 4-6 $\mathrm{mH}_{2} \mathrm{O}$.

\section{Numerical simulations: mathematical model of flow in a confined space}

The mathematical model is based on the equations used in the computational mechanics of fluids. These are the continuity equations, the Navier-Stokes equations in modification according to the Businex hypothesis $\left(\mu_{\mathrm{eff}}=\mu+\mu_{\mathrm{t}}\right)$, the energy equation (1st law of Thermodynamics), the Clapeyron equation for the gas mixture. Fire currents run at low speeds in the absence of detonation and explosions.

In the case of a fire without detonation, combustion, and explosions, it can be assumed: $\operatorname{div} \vec{V}=0, \frac{\partial u}{\partial x}+\frac{\partial v}{\partial y}+\frac{\partial w}{\partial z} \equiv 0$.

To these are added the equations for smoke propagation (smoke content) and for the optical density of the gas mixture.

Continuity equation:

$$
\frac{\partial \rho}{\partial t}+\frac{\partial(\rho u)}{\partial x}+\frac{\partial(\rho v)}{\partial y}+\frac{\partial(\rho w)}{\partial z}=J
$$

Equations for movements [9].

$$
\begin{aligned}
\rho \frac{\partial u}{\partial t}+\rho u \frac{\partial u}{\partial x}+\rho v \frac{\partial u}{\partial y}+\rho w \frac{\partial u}{\partial z}= & -\frac{\partial p}{\partial x}+\mu\left(\frac{\partial^{2} u}{\partial x^{2}}+\frac{\partial^{2} u}{\partial y^{2}}+\frac{\partial^{2} u}{\partial z^{2}}\right)+2 \frac{\partial}{\partial x}\left[\mu_{T} \frac{\partial u}{\partial x}\right] \\
& +\frac{\partial}{\partial y}\left[\mu_{T}\left(\frac{\partial u}{\partial y}+\frac{\partial v}{\partial x}\right)\right]+\frac{\partial}{\partial z}\left[\mu_{T}\left(\frac{\partial u}{\partial z}+\frac{\partial w}{\partial x}\right)\right] \\
\rho \frac{\partial v}{\partial t}+\rho u \frac{\partial v}{\partial x}+\rho v \frac{\partial v}{\partial y}+\rho w \frac{\partial v}{\partial z}= & -\frac{\partial p}{\partial y}+\mu\left(\frac{\partial^{2} v}{\partial x^{2}}+\frac{\partial^{2} v}{\partial y^{2}}+\frac{\partial^{2} v}{\partial z^{2}}\right)+2 \frac{\partial}{\partial y}\left[\mu_{T} \frac{\partial v}{\partial y}\right] \\
& +\frac{\partial}{\partial x}\left[\mu_{T}\left(\frac{\partial u}{\partial y}+\frac{\partial v}{\partial x}\right)\right]+\frac{\partial}{\partial z}\left[\mu_{T}\left(\frac{\partial v}{\partial z}+\frac{\partial w}{\partial x}\right)\right]
\end{aligned}
$$




$$
\begin{aligned}
\rho \frac{\partial w}{\partial t}+\rho u \frac{\partial w}{\partial x}+\rho v \frac{\partial w}{\partial y}+\rho w \frac{\partial w}{\partial z}= & -\frac{\partial p}{\partial z}+\mu\left(\frac{\partial^{2} w}{\partial x^{2}}+\frac{\partial^{2} w}{\partial y^{2}}+\frac{\partial^{2} w}{\partial z^{2}}\right)+2 \frac{\partial}{\partial z}\left[\mu_{T} \frac{\partial w}{\partial z}\right] \\
& +\frac{\partial}{\partial x}\left[\mu_{T}\left(\frac{\partial u}{\partial z}+\frac{\partial w}{\partial x}\right)\right]+\frac{\partial}{\partial y}\left[\mu_{T}\left(\frac{\partial v}{\partial z}+\frac{\partial w}{\partial y}\right)\right]
\end{aligned}
$$

Equations for heat exchange (1st law of Thermodynamics)

$$
\begin{aligned}
\rho C_{p}\left(\frac{\partial T}{\partial t}+u \frac{\partial T}{\partial x}+v \frac{\partial T}{\partial y}+w \frac{\partial T}{\partial z}\right)= & \frac{\partial}{\partial x}\left[\left(\lambda+\lambda_{t}+\lambda_{f}\right)+\frac{\partial T}{\partial x}\right]+\frac{\partial}{\partial y}\left[\left(\lambda+\lambda_{t}+\lambda_{f}\right)+\frac{\partial T}{\partial y}\right] \\
& +\frac{\partial}{\partial z}\left[\left(\lambda+\lambda_{t}+\lambda_{f}\right)+\frac{\partial T}{\partial z}\right]+q+\varepsilon
\end{aligned}
$$

where $c_{p}$ is the specific heat content at constant pressure; $\lambda$ is the coefficient of thermal conductivity; $\lambda_{i}$ is the coefficient of turbulent thermal conductivity; $\lambda_{p}$ is the coefficient of radiation thermal conductivity; and $q_{v}$ is the intensity of internal heat sources.

Here, $q_{v}$, can be represented by $q_{v}=q_{v c}+q_{v r}+q_{v b}$, where $q_{v k}$ is the intensity of internal convective heat sources; $q_{v b}$ is the intensity of internal combustion sources; and $q_{v r}$ is the intensity of internal sources due to radiation heat transfer.

Gas condition equation is given by:

$$
p=\rho T R,
$$

where $R$ is the universal gas constant.

Law for the conservation of the mass of the $i$ th gas that is a part of the mixture is

$$
\rho \frac{\partial \chi_{i}}{\partial t}+\rho u \frac{\partial \chi_{i}}{\partial x}+\rho v \frac{\partial \chi_{i}}{\partial y}+\rho w \frac{\partial \chi_{i}}{\partial z}=\frac{\partial}{\partial x}\left(\rho D \frac{\partial \chi_{i}}{\partial x}\right)+\frac{\partial}{\partial y}\left(\rho D \frac{\partial \chi_{i}}{\partial y}\right)+\frac{\partial}{\partial z}\left(\rho D \frac{\partial \chi_{i}}{\partial z}\right)+m_{i},
$$

where $D$ is the diffusion coefficient, representing the sum of the coefficient of gas diffusion $D_{i}$ and the coefficient of turbulent diffusion $D_{t}\left(D=D_{i}+D_{t}\right)$; $\chi$ is the mass concentration of the $i$ th gas; $m_{i}$ is the intensity of internal mass sources arising from the formation (disappearance) of molecules of a gas, a consequence of the ongoing chemical reactions of combustion in fires.

The law (equation) for preserving the optical density of smoke is of the form:

$$
\frac{\partial D_{o n}}{\partial t}+u \frac{\partial D_{o n}}{\partial x}+v \frac{\partial D_{o n}}{\partial y}+w \frac{\partial D_{o n}}{\partial z}=q_{D}
$$

where $D_{o n}$ is the smoke-generating capacity of the combustible material and $q_{D}$ is the intensity of the internal sources of optical density of the smoke formed by the ongoing reaction of combustion in a fire [3].

The thermophysical parameters of the mixture of gases involved and the result of combustion in a fire take into account the chemical composition of this mixture. It consists of oxygen, nitrogen, and combustion products - carbon monoxide, nitrogen, sulfur, etc., involved in the process combustible ingredients. They are defined as follows:

- density of the mixture 


$$
\rho=\sum_{i-1}^{n} \alpha_{i} \rho_{i}
$$

- gas constant

$$
R=\sum_{i-1}^{n} \chi_{i} R_{i}
$$

- specific heat capacity

$$
c_{p}=\sum_{i-1}^{n} \chi c_{p_{i}}
$$

where $\alpha_{i}$ is the bulk concentration of the $i$ th component and $\mathcal{H}_{i}$ is its mass concentration.

The values of these parameters are determined at constant pressure $(p=$ const). They can be considered as temperature dependent or considered permanent.

\subsection{A characteristic equation}

The characteristic equation summarizes the main partial differential equations, which are solved sequentially in software for each of the flow parameters. The type of equation is as follows:

$$
\frac{\partial}{\partial x}(\rho \Phi)+\operatorname{div}(\rho w \Phi)=\operatorname{div}(\operatorname{\Gamma grad} \Phi)+S,
$$

where $\Phi$ is the dependent variable-velocity components, enthalpy, concentration of the components of the gas medium, optical density of the smoke, respectively; $\Gamma$ is the diffusion coefficient for the corresponding $\Phi$; and $S$ is the source member. The values for Eq. (46) are given in [9].

\subsection{Modeling the turbulence using CFD}

Most often, a CFD-Fluent turbulence $k-\varepsilon$ model is applied. In this model, the coefficient of turbulent viscosity $v_{t}$ is represented by the Kolmogorov-Prandtl dependence, as the ratio of kinematic turbulent energy $k$ and the rate of dissipation $\varepsilon$ :

$$
v_{t}=C_{\mu} \frac{k^{2}}{\varepsilon}
$$

where

$$
k=\frac{1}{2} \sqrt{u^{\prime 2}+v^{\prime 2}+w^{\prime 2}} ; \quad \varepsilon=v \overline{\left[\left(\frac{\partial u}{\partial x}\right)^{2}+\left(\frac{\partial v}{\partial y}\right)^{2}+\left(\frac{\partial w}{\partial z}\right)^{2}\right]}
$$

\subsection{FDS turbulence modeling}

To close the system of equations at FDS, as in all other cases in turbulent flows, it is necessary to use appropriate models of turbulence. In this case, the large eddy 
simulation model [9] known in this type of task as the LES model is recommended as the most appropriate. The model is described in detail in [9].

The model of large eddy simulation is based on the following: large-scale vortices differ markedly in the course of transition from one current to another, with the small-scale structure changing slightly. The field of large-scale structures needs to be defined. Continuity of flow parameters is assumed using Leonard's so-called filtering function. For each flow parameter, $a=a+a^{\prime}$. Dissipative combustion processes such as viscous thermal conductivity, diffusion, and impurity transfer are modeled. What is special about the model is that the scale of the vortex structures is smaller than the size of the data network. The parameters $\mu, \lambda$, and $\mathrm{D}$ in the equations describing the process are replaced by expressions modeling their effect.

The strain rate tensor is used to determine $\mu$. Thermal conductivity and impurity diffusion are determined by:

$$
\begin{aligned}
& \lambda_{t}=\frac{\mu_{t} c_{p}}{p r_{t}} \\
& (\rho D)_{t}=\frac{\mu_{t}}{S_{0 t}} \\
& \mu_{t}=\rho v_{t}
\end{aligned}
$$

In the case of laminar heat transfer and diffusion, respectively:

$$
\begin{aligned}
& \lambda=\frac{\mu c_{p}}{p r} \\
& (\rho D)=\frac{\mu}{S_{0 t}}
\end{aligned}
$$

The process of combustion in the fire is most often implemented using the "Part of the mixture" approach. It is a scalar quantity characterizing the mass concentration of one or more components of a gas mixture at a given point in the flow. To reduce the volume of calculations, the significant memorized are two components of the mixture: mass concentration of unburned fuel and burned, respectively. Combustion products. Radiant heat transfer is calculated by the equations for the emission of sulfur-containing gases, which, in fact, implies a constraint on the problem. Large-scale models may also be used in certain cases. FDS equations use the FVM finite volume method. In addition to using the LES turbulence model, successful attempts have been made to apply the direct numerical modeling method described in [9]. FDS has been tested in a number of laboratories and institutions in the United States. The validation done shows the possibility of its application in many cases [16].

\section{Computer modeling and numerical simulations}

A detailed description of the Fluent (CFD) program interface is given in [17-19].

Development of fire in atrium space: The development of fire occurred in a certain object — the building shown in Figure 9 and Figure 10, located on Tsarigradsko shose Blvd., Sofia.

The arrangement of the air exchange in the atrium space in case of fire is shown in Figure 10. Atrium air exchange was implemented, showing zones with critical parameters of radiation, smoke, and fire. It is important to note that all of the above is possible only by knowing the respective velocity or temperature field of the air in the room [5]. 


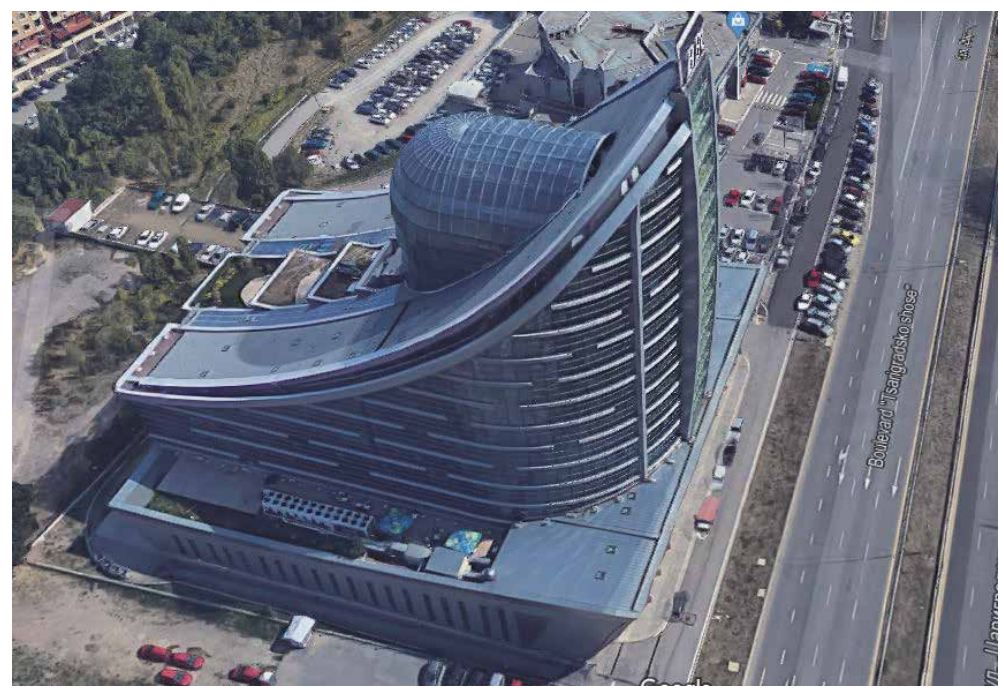

Figure 9.

Building with atrium subject to simulation study [20].

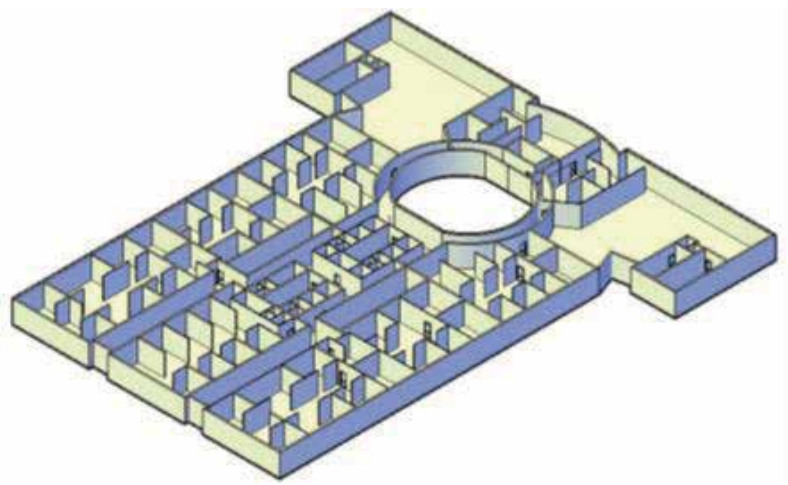

Figure 10.

Building fire development.

The geometric model so drawn shows the location of the fire, that is, hazard generator and flue gas outlet (smoke hatches).

In real fires, there is a degree transition zone between lower cold smoke and higher hot smoke.

The first smoke curtain signal may be calculated from the beginning of the transition zone formation. Thus, it can be assumed that forecasts using equations of this type depend on the exact application of the computer model.

After the 3D Atrium Model has been built (in the Gambit work environment), it is necessary to proceed with the "networking" procedure of the volume. Due to the large volume, it is not appropriate to use crosslinking of the elements in the same step.

For this reason, a fine mesh is selected at the site of fire generation and its departure from the room, while a larger one is used far from them.

In the present case, triangular elements were selected for the site of fire generation and the smoke hatches for the networking of persons with step $0.3 \mathrm{~m}$. For the other walls as well as the volume of the atrium, a step of $0.5 \mathrm{~m}$ is chosen.

Figure 11 shows the velocity field in the atrium in vector form. It can be seen from the figure that high velocities are observed at the site of smoke generation, both near the walls and the high part of the atrium. 
The temperature distribution in the volume of the atrium is shown in Figure 12. Areas with higher temperatures are clearly visible-near the source of smoke and the surrounding wall above it, and near the dome of the atrium.

Figure 13 shows the distribution of smoke in the atrium at various points in time for $120 \mathrm{~s}$ until equilibrium between the ascending and descending currents in the atrium is reached.

Figure 14 shows the change in turbulent kinetic energy in the atrium. What is striking is the fact that there is an intense transfer of substances from the outbreak of the fire along the wall of the atrium to the dome, and then it slowly subsides. When smoke reaches the floor of the room, the turbulent kinetic energy is approximately zero.

Modern computer programs for numerical modeling of processes related to the simulation of air exchange in atriums can alleviate some regulatory requirements for protected premises (atriums), which can lead to significant savings for investors. If necessary, openings may be left open in the premises. With the use of fire ventilation, they will not have a negative effect on the parameters of the fire. In large areas, flue products may only be contained above the fire. The ability to make new, more practical, and economical architectural decisions is increasing.

Application of the FDS environment for predicting and restoring the spread of fires and damage in the building [21, 22].

An analysis is made in the FDS environment to look at the basic features on which it is based. In analyzing the program, it should be emphasized that it is related to the numerical mechanics of the fluids and software products built on this basis. The same system of private differential equations is used, with the difference between the CFD and the FDS medium in the equations used to describe the turbulence. Fluent programs utilize turbulence models, which narrows their applicability in the study of fires in unlimited space. Large Eddy Simulation (LES) is used for FDS. This expands the applicability in the study of currents and fires in open space, as well as the effect of wind, etc. Weather conditions when solving problems.

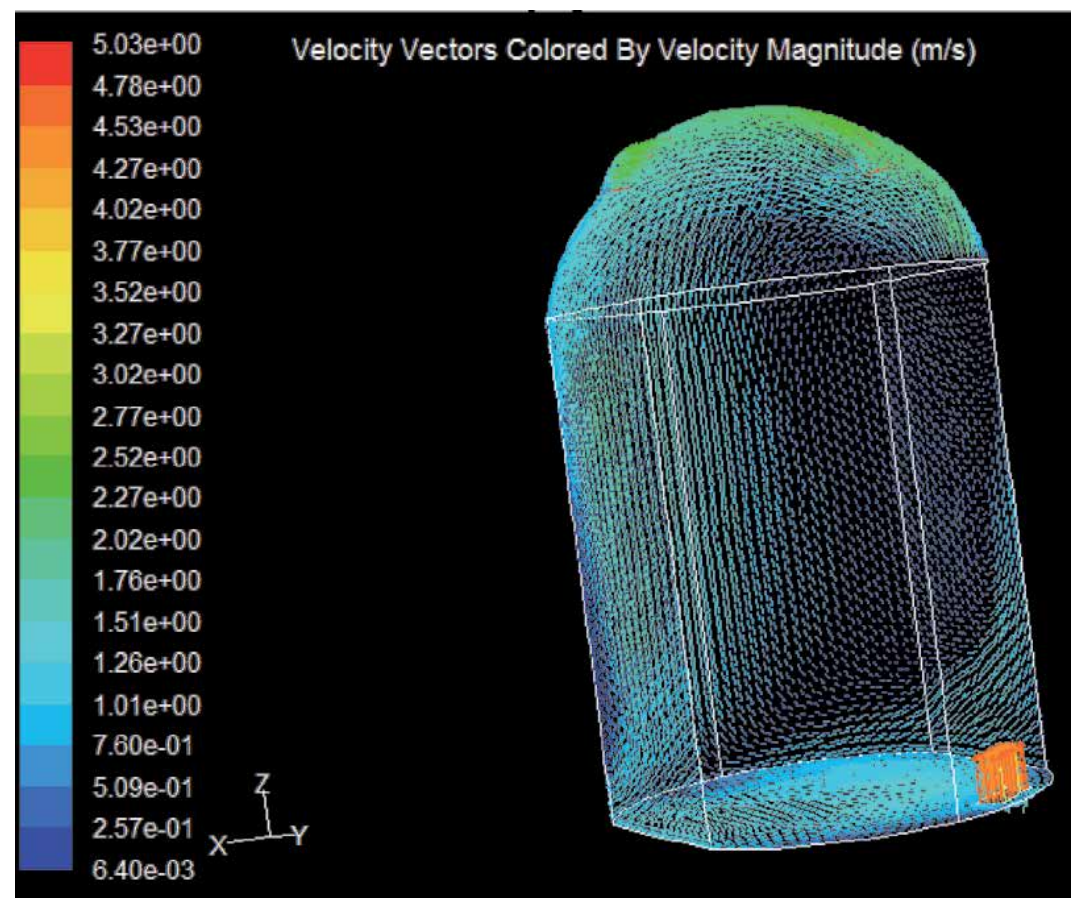

Figure 11.

The velocity field in atrium in vector form. 
Mathematical Modeling and Simulation of Development of the Fires in Confined Spaces DOI: http://dx.doi.org/10.5772/intechopen.91274

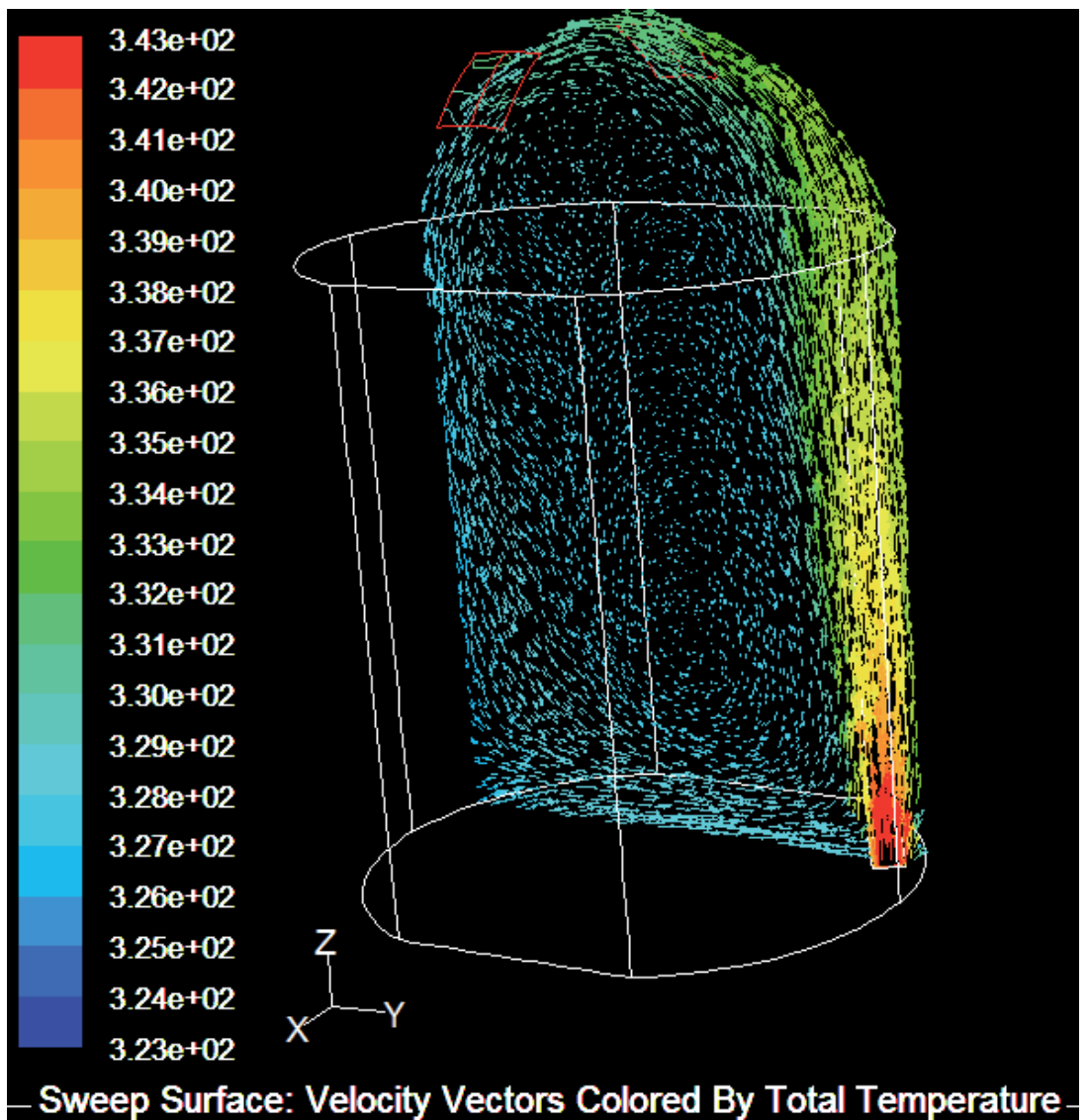

Figure 12.

The distribution of temperature in the volume of the atrium.

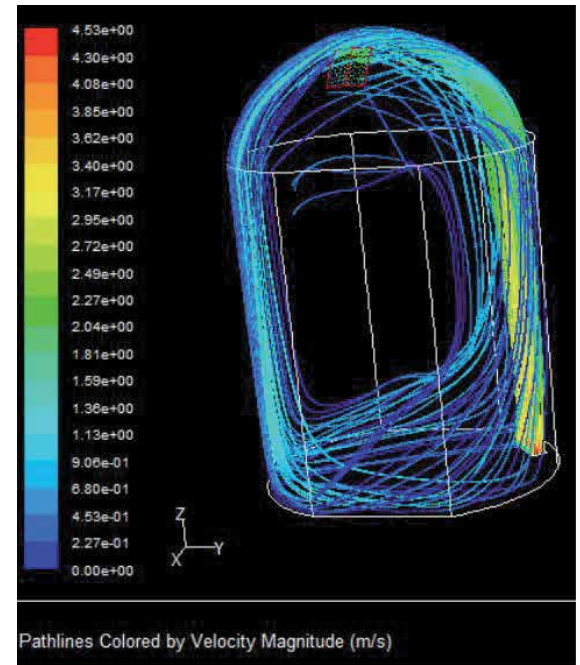

(a)

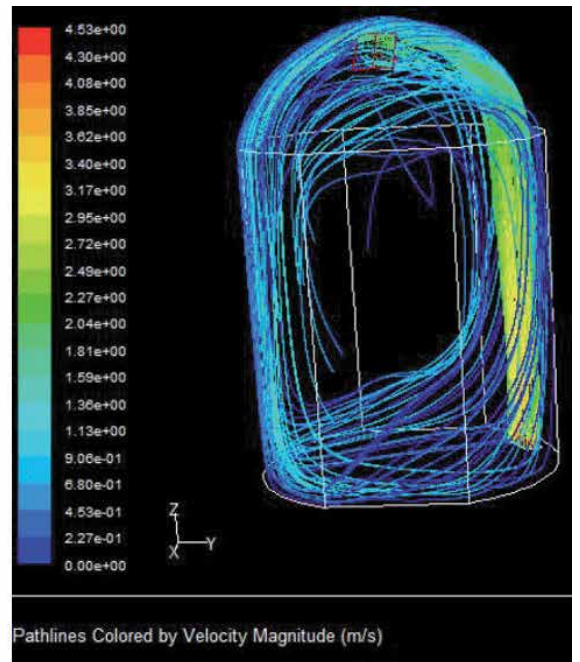

(b)

Figure 13.

The distribution of smoke in the atrium at different times. (a) $1320 \mathrm{~s}$, and (b) $1440 \mathrm{~s}$. 


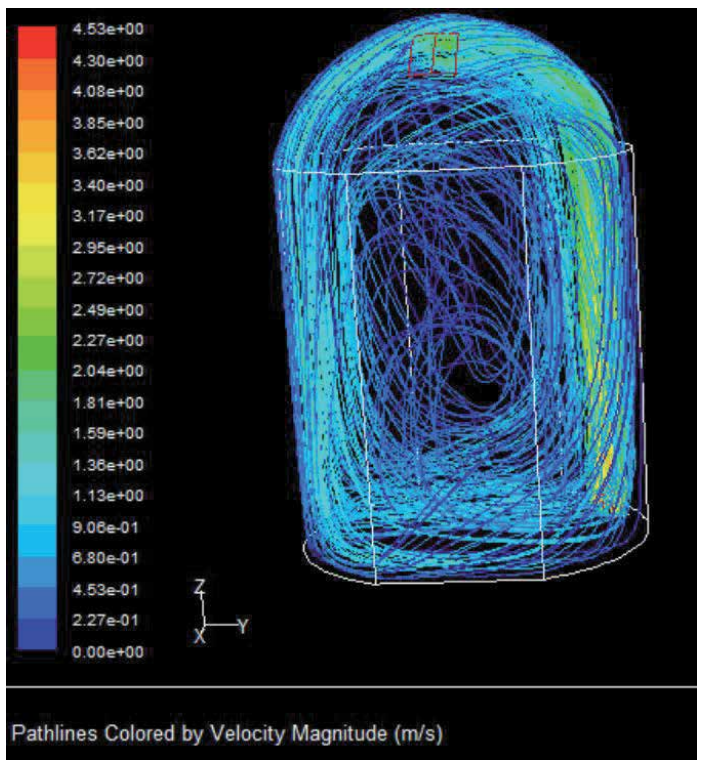

Figure 14.

Change in turbulent kinetic energy in the atrium.

The program is also used to analyze the spread of hazards in the work environment, both industrial and residential sites, as well as in the environment. This program allows to restore the development of fire in past events $[5,9,16]$.

\subsection{Closed-loop fire development modeling using the PyroSim (FDS) program}

This simulation product is applicable to the modeling of fire development and the determination of the evacuation and extinguishing route indoors. The software environment offers intuitive function menus (graphical user interface) and provides results for the propagation of flue gases, hydrocarbons, and other substances during a fire, as well as the temperature distribution along the cross section of the model's geometry. The program serves not only the prediction of the situation, but also the investigation of fire in the setting of the initial ignition zone, as well as training. The simulations in the program are based on the computational dynamics of fluids, and in particular, low-velocity convective currents. The capabilities of the software make it possible to investigate fires from cooking stoves to oil derivative stores (oil bases). The program is also applicable to simulation of flame-free processes, including building ventilation testing.

A detailed description of how to work with the PyroSim interface is given in [17].

Development of fire in a training building: The development of a fire in study building 2 of TU-Sofia is investigated. The fire is assumed to start from the ground floor-one of the laboratories (Figure 15).

Specific examples of the application of the PyroSim software product are shown in Figures 16-21 in a simulated fire in a training laboratory on the first floor of a technical building of the Technical University-Sofia. For the construction of the geometric model in Figure 16, the real barrier elements such as walls, doors, and windows, as well as the materials of which they are constructed with their respective melting/ignition temperatures, are taken into account.

Instantaneous flue gas images of the building are shown in Figure 17 (for 50s), Figure 18 (for 60s), and Figure 19 (for 440 s). It is clear that the smoke is spreading 


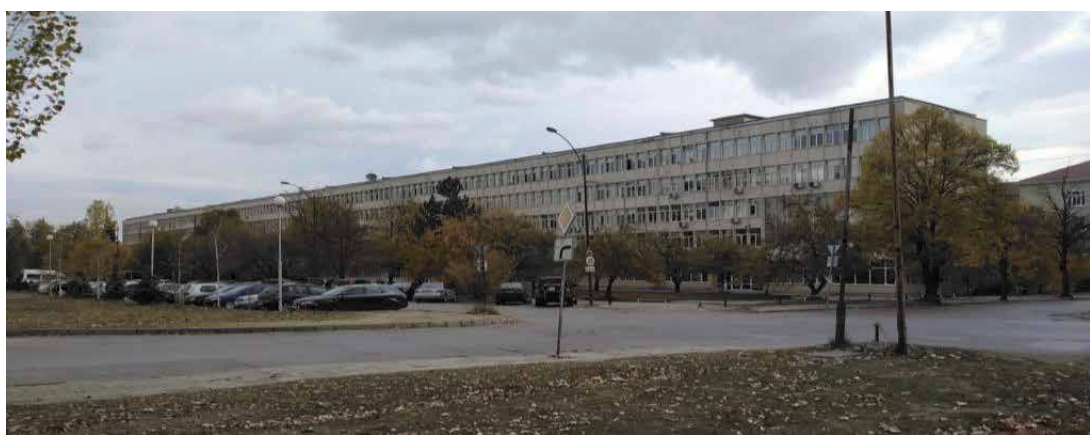

Figure 15.

Building 2 of TU-Sofia.

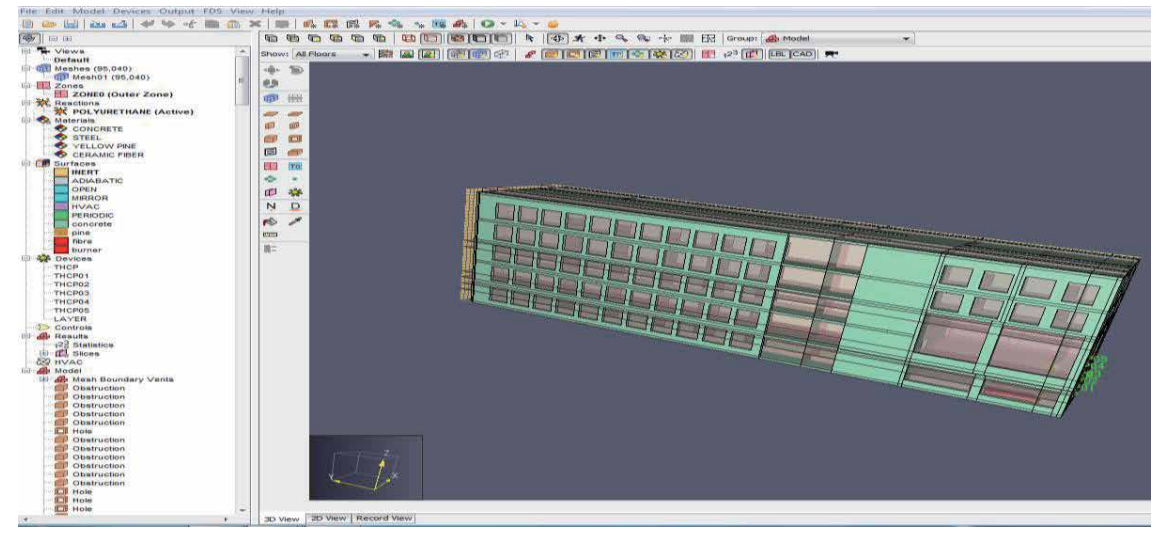

Figure 16.

Working environment for drawing the geometric model.

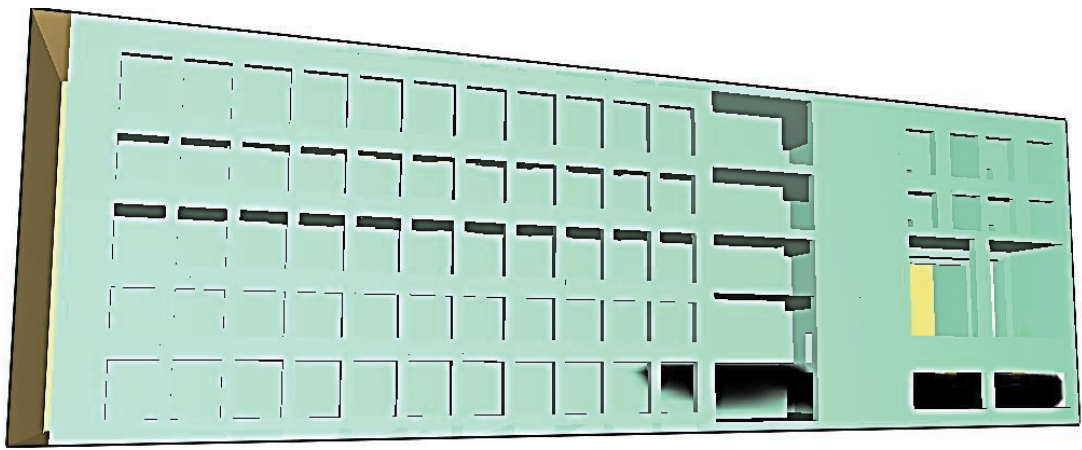

Figure 17.

Flue gas propagation in the building within 50 s of the simulation.

as fast as possible on one of the stairs, which is a kind of chimney (chimney) for this part of the building. For the same period of time, smoke spreads down the corridor on the first floor. Since there are no smoke barriers (doors) installed between the same staircase and the corridors on the floors, it will spread to all floors and will make it difficult to evacuate people in the building. Partition doors are placed on the next staircase (to the right of the model shown in Figures 18 and 19), which are intended to prevent the smoke from burning the floors in the direction from the staircase to the corridors, but in this case the flue gases will meet on both sides. The same barriers and 


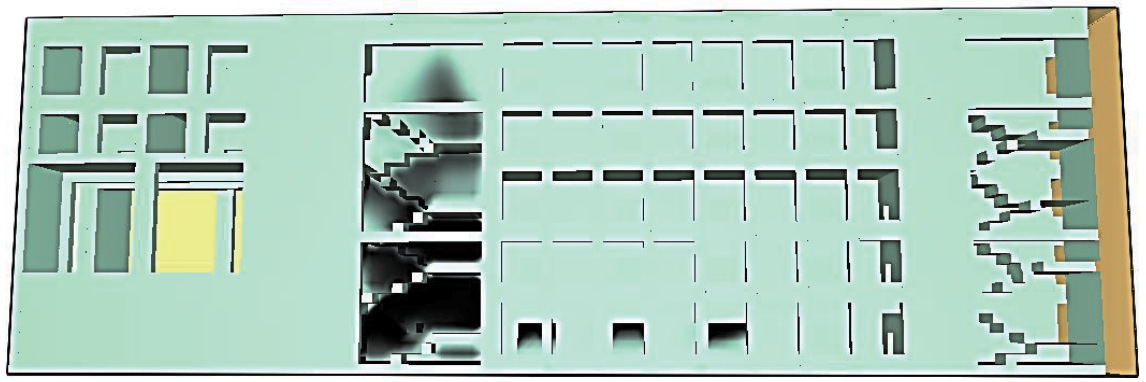

Figure 18.

Flue gas propagation in the building within 60 s of the simulation.

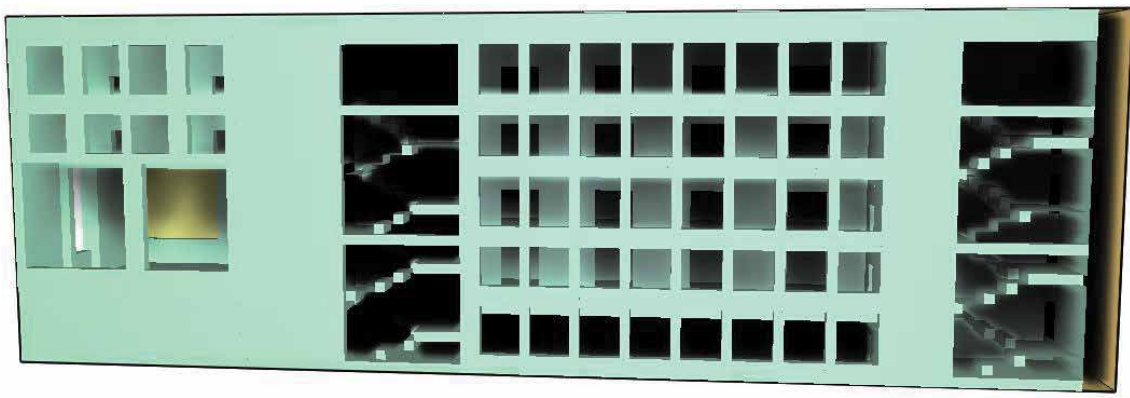

Figure 19.

Flue gas propagation in the building at 440 s of the simulation.

reduced visibility in this enclosure will cause additional evacuation difficulties, because people will not easily notice where the barrier on the second staircase is and are likely to collide with it glass shutter door, which is closed by a mechanical machine (mechanism), which is a prerequisite for an accident during the evacuation and may lead to an increase in the number of casualties in the building.
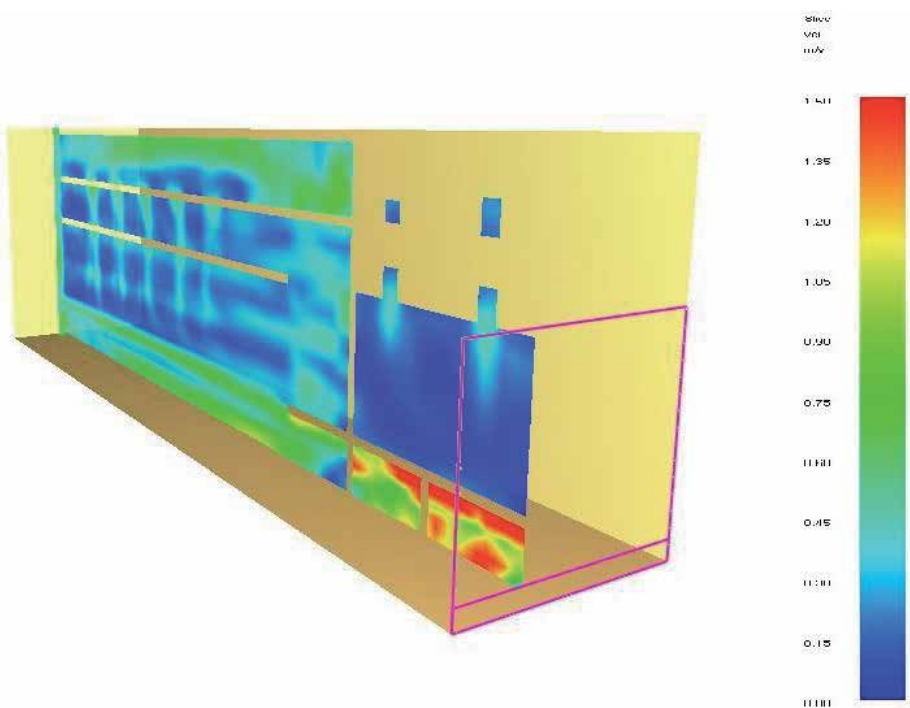

Figure 20.

Speed distribution for 3800 s of simulation. 


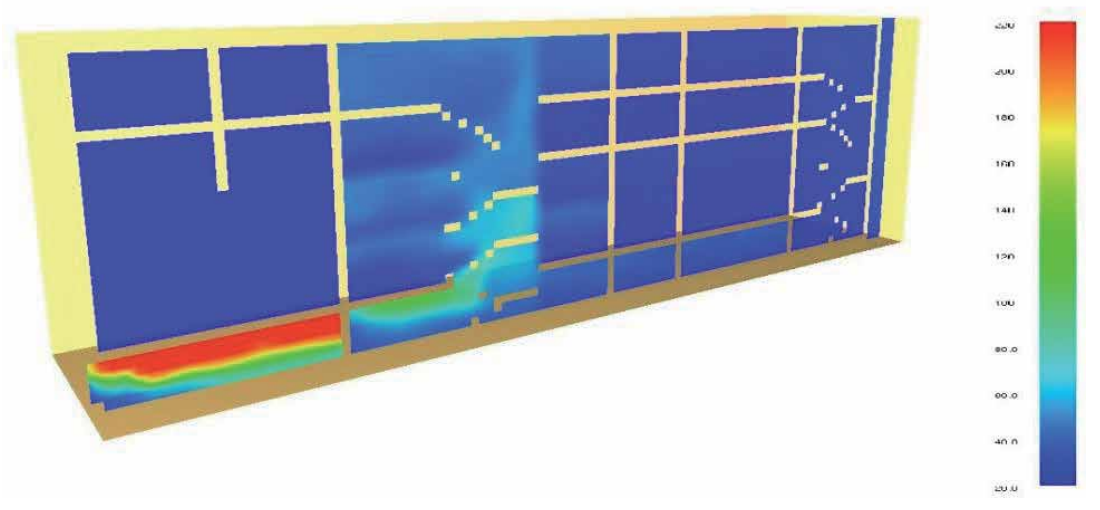

Figure 21.

Temperature distribution for the 480 th second of the simulation.

Figure 20 shows the velocity distribution along the vertical section of a building for $3800 \mathrm{~s}$ of the simulation. It is clear that the first and last floors of the building and the staircase adjacent to the burning room are affected at the beginning of the process, and then the other floors.

Figure 21 shows the temperature distribution along the vertical section of a building for the 480th second of the simulation. From here, it is reported that in the fire zone in the laboratory the temperature is above $200^{\circ} \mathrm{C}$, and at the site in the hallway in front of it, where the nearby staircase is, the temperature is above $120^{\circ} \mathrm{C}$. As the building climbs, the temperature drops to about $60^{\circ} \mathrm{C}$ until the third floor, indicating that there should be no escape route in this area without protective clothing. By linking the data from the previous figures, the instructions for the mandatory availability of respiratory protection may also be added, as this is also the main route for the distribution of flue gases.

The results of the simulation of a fire occurring in a particular building give preliminary information about the flaws in its design with respect to fire safety. If taken into account, placing barriers in the right places, as well as revising the evacuation route from the building would lead to increased security in the event of a disaster or accident and to removal all people without damage to their health.

\section{Conclusion}

The results obtained in this chapter are first and foremost a practical application that allows solving problems related to fire prevention and analysis in a restricted area.

The technical solution to limit the spread of fires is to use protective water curtains, as they isolate burning vehicles from the environment and thus prevent the transfer of fire to other vehicles in the underground garage. The solution can be applied to any particular similar object.

The results of the two simulations of fire in specific buildings indicate the possibility of Fluent and FDS-PyroSim software in analyzing fire spread, smoke, temperature, and harmfulness in confined spaces. As shown, these simulations can be used:

- in the case of designing buildings with fixed sprinklers and evacuation routes.

- in judicial analysis of the consequences of the fire by initiation of its development over time. 


\section{Author details}

Ivan Antonov, Rositsa Velichkova*, Svetlin Antonov and Kamen Grozdanov Technical Univesity of Sofia, Sofia, Bulgaria

*Address all correspondence to: rositsavelichkova@abv.bg

\section{IntechOpen}

(C) 2020 The Author(s). Licensee IntechOpen. This chapter is distributed under the terms of the Creative Commons Attribution License (http://creativecommons.org/licenses/ by/3.0), which permits unrestricted use, distribution, and reproduction in any medium, provided the original work is properly cited. (c) BY 


\section{References}

[1] Puzach SV, Chumachenko AP, Kozlov YI, Bubnov VM, Rodin BC. Method of calculation with a computer program for determining the actual limits of fire resistance and modeling of actions of fire extinguishing systems. In: Mechanical Ventilation and Smoke Removal During Fires. Moscow: VDPO; 2004

[2] PyroSim Example Guide. 2012. Available from: https://www.thunde rheadeng.com/pyrosim/tutorials/

[3] Antonov I, Velichkova R, Grozdanov K, Uzunova M. The possibility of replacing solid walls with water curtain applicable to a large underground garage. In: EFEA'2016, Belgrade, Serbia. 2016. DOI: 10.1109/EFEA.2016.7748805.

Available from: http://ieeexplore.ieee.org/ document/774880/; electronic ISBN: 978-1-5090-0749-3

[4] Antonov IS. About a modification of $k-\varepsilon$ model applicable to heat and mass transfer processes in two-phase turbulent flows. In: EMF'98 Science Conference Energy Efficiency and Environmental Protection. September 17-20, 1998, Sozopol, Proceedings. 1998. pp. 7-14

[5] CFD modeling of a large complex fire. Report 3120. Lund; 2000

[6] Drysdale D. An Introduction to Fire Dynamics. UK: Wiley; 2011

[7] Stoyanov V, Terziev A, Uzunova M. Numerical study of distribution of smoke and hazards in underground parking areas considering the operation of ventilation. In: 2014 3rd International Symposium on Environmental Friendly Energies and Applications (EFEA); St. Ouen. 2014. pp. 1-6

[8] Terziev A. Study of the fire dynamics in a burning car and analysis of the possibilities for transfer of fire to a nearby vehicle. In: 8th International
Conference on Thermal Equipment, Renewable Energy and Rural Development. E3S Web of Conferences TE-RE-RD 2019; Targoviste; Romania; 6 June 2019 through 8 June 2019; Vol. 112. 2019. Article number 01015; Code 151155

[9] Antonov I. Applied Fluid Mechanics. Sofia: Technical University of Sofia; 2016

[10] Marshall AM, di Marzo M. Modeling aspects of sprinkler spray dynamics in fires. Process Safety and Environmental Protection. 2004;82(2):97-104

[11] Launder BE, Spalding DB. Lectures on Mathematical Models of Turbulence. London: Academic Press; 1972

[12] Leonard A. Energy cascade in largeeddy simulation of turbulent fluid flows. Advances in Geophysics. 1975;18

(Part A):237-248

[13] Rodi W, Spalding DB. A twoparameter model of turbulence and its application to free jets. Warms and Stoffuberrtrag. 1970;3:585-595

[14] Abramovich GN. Theory of Turbulent Jets. Moscow; 2011. ISBN: 978-5-4365-0031-

[15] Velichkova R, Antonov I, Nikolov K, Grozdanov K, Uzunova M. Modeling of the occurrence of fire in closed cars garages. In: EFEA' 2016. DOI: 10.1109/ EFEA.2016.7748807. Available from: http://ieeexplore.ieee.org/document/ 7748807/. Electronic ISBN: 978-15090-0749-3

[16] Pichurov G, Stankov P, Ivanov M. Radial jet predictions based on computational fluid dynamics. In: Healthy Buildings 2006: Creating a Healthy Indoor Environment for People, Proceedings, Vol. 5. 2006. pp. 125-128. ISBN: 978-1-62276-998-8 
[17] Antonov SV, Antonov IV,

Grozdanov K. Modelling and Simulation of Fire. Sofia: Technical University of Sofia; 2018

[18] Antonov I, Terziev A. Tutorial on Applied Fluid Mechanics. Sofia: Technical University of Sofia; 2012

[19] Fluent Inc. Chapter 10. Modeling turbulence. UK: Fluent; 2001

[20] Grozdanov K. TS. Modeling of fire in auto accident with the purpose of event identification [PhD thesis]. Sofia; 2017

[21] FDS-SMV Official Website. Ford Dynamics Simulator and Smokeview. Available from: https://pages.nist.gov/ fds-smv/

[22] Puzach SV. Mathematical Modeling of Gas Dynamics and Heat and Mass Transfer in Solving Fire Safety Problems. Moscow: Russian Academy of Medical Science; 2003 


\title{
Methodology for Optimal Fire Evacuations in Underground Mines Based on Simulated Scenarios
}

\author{
Vancho Adjiski and Zoran Despodov
}

\begin{abstract}
The purpose of this chapter is to develop a methodology that will contribute in locating optimal evacuation routes in case of fire that are based on minimal carbon monoxide ( $\mathrm{CO}$ ) exposure during the evacuation procedures. The proposed methodology is tested using simulated fire scenarios from which CO concentration over time curve is extracted from all available evacuation routes and presented in a weighted form based on the accumulating effect of $\mathrm{CO}$ inhalation in the form of fractional effective dose (FED). The safety limits of the FED model on which the optimization process is based are determined using a model for the prediction of carboxyhemoglobin $(\mathrm{COHb})$ levels in human blood. The $\mathrm{COHb}$ model is associated with predicted clinical symptoms that are the basis for determining the level of incapacitation at which the mineworkers are incapable of completing their evacuation. Also in the process of improving the fire risk analysis, the proposed methodology enables the development of evacuation plans that are based on the results of modeled fire scenarios combined together with the results of the anticipated hazards generated by $\mathrm{CO}$ inhalation. The results presented in this chapter indicate a more precise approach in the process of planning the evacuation system inside the underground mines.
\end{abstract}

Keywords: underground mines, fire, safety, evacuation, optimization, simulation, modeling

\section{Introduction}

Fires are one of the most serious accidents that can occur in underground mines due to the restricted ability to evacuate quickly from the confined excavations that can be filled quickly with smoke and noxious fumes [1]. The behavior of underground mine fires is difficult to predict due to their dependence on multiple factors that are closely related to the amount of flammable material, ignition location, ventilation system arrangement, time of occurrence, etc. [2]. These uncertainties associated with mine fire scenarios can have unexpected impacts on the evacuation process, firefighting, and rescue strategies and also further complicate the process of design and implementation of fire protection systems. 
Developing effective evacuation plans in case of fire in underground mine is the most important and sometimes the only option for safe evacuation of all involved in the fire scenario. The wide range of possibilities in the process of improving the evacuation plans in case of fire has motivated many researchers to make new or to modify the existing methodologies or procedures for developing effective and optimal evacuation plans.

Ji et al. [3] developed a visual model to simulate the evacuation process of miners to determine the evacuation time, exit flow rate, and evacuation path and show that simulation is effective technology to establish safe evacuation system. Chen et al. [4] developed 3D CFD model to reconstruct the laneway conveyor belt fire scenes under two ventilating conditions to investigate the influence of smoke movement on miner evacuation behaviors. Wang et al. [5] through example demonstrated the use of their proposed framework for human error risk analysis of coal mine emergency evacuation and also the method to evaluate the reliability of human safety barriers. Wu et al. [6] conducted emergency evacuation simulation and visualized analysis of underground mine water bursting disaster scene, to achieve the simulation of the dynamic process of individual or group behavior and to provide platform for rational evacuation under the situation of mine disaster. Adjiski et al. [7-9] completed many different manuscripts and projects in the field of simulation and modeling of fire scenarios and evacuation plans in underground mines.

To the authors' best knowledge and the extensive search of literature, a lack of methodologies and systems that focus on developing evacuation plans in case of fire in underground mines is shown. Due to the large number of factors from which the effective evacuation process depends, this field of research requires continuous upgrading to address all challenges and also to provide optimal evacuation routes that sometimes represent the only option for preventing loss of human lives.

This chapter is an extension and upgrade of the previously published works from the same author and hopefully will contribute to the process that will improve the methodologies and systems for optimal fire evacuations in underground mines.

\section{Methodology for developing underground mine fire scenarios}

In underground mines, a fire can occur wherever flammable material is found, but predicting it at all possible locations is practically impossible. So by analyzing this list of fire locations that have potential flammable materials, it is down to those places that have the highest risk of fire occurrence [10]. The process of conducting fire risk assessment is very straightforward and does not need to be considered in any further detail in this research.

What is new in this study is the proposal of methodology for quickly and efficiently locating and generating fire scenarios ready for simulation on the basis of which optimal evacuation plans will be developed.

To identify possible locations for fire scenarios in underground mines, different approaches can be used, such as [2,9]:

- Fire risk assessment

- Historical records of fire incidents in the mine 
- Analysis of production plans

- Analysis of work processes and mechanization, etc.

The dynamics of mining activities to increase and fulfill production capacity generates a constant shift in production sites generally associated with mechanization that is likely to trigger a fire scenario. Due to this fact as a relevant indicator that realistically reflects and constantly updates, the list of possible fire locations would be a detailed analysis of daily or monthly production plans. This step involves a thorough analysis of the daily/monthly production plans that will detect any flammable materials mostly associated with the mechanization needed to achieve the required production capacity.

A case study of the "SASA"-R.N. Macedonia mine was used in order to conduct the necessary steps presented on Figure 1.

The steps shown in Figure 1 are based on a simple analysis of the production plans that can detect all workplaces with the appropriate work cycle together with the related mechanization which is often associated with fire scenarios.

To demonstrate the presented methodology, a 3D model of the underground ventilation network of the mine "SASA"-R.N. Macedonia is prepared on which all the necessary analysis and simulations will be performed (Figure 2). On the ventilation map, the possible fire locations along with the group of mineworkers identified using the proposed methodology on Figure 1 and also the possible exits from the underground mine are also marked.

The process of modeling fire scenarios is closely related to the degree of uncertainty when it comes to the input data, which largely depends on the size of the fire itself $[11,12]$. Examples of such input parameters that affect the fire models in underground mines are fire load, fire location, burn rate of materials, heat release rate, ventilation parameters, etc. Due to the stochastic nature of the input parameters related to the fire models, the appropriate results should be treated with caution.

From the large list of stochastic input parameters, the authors decided to elaborate only on the process of obtaining fire load inputs, which largely depends on

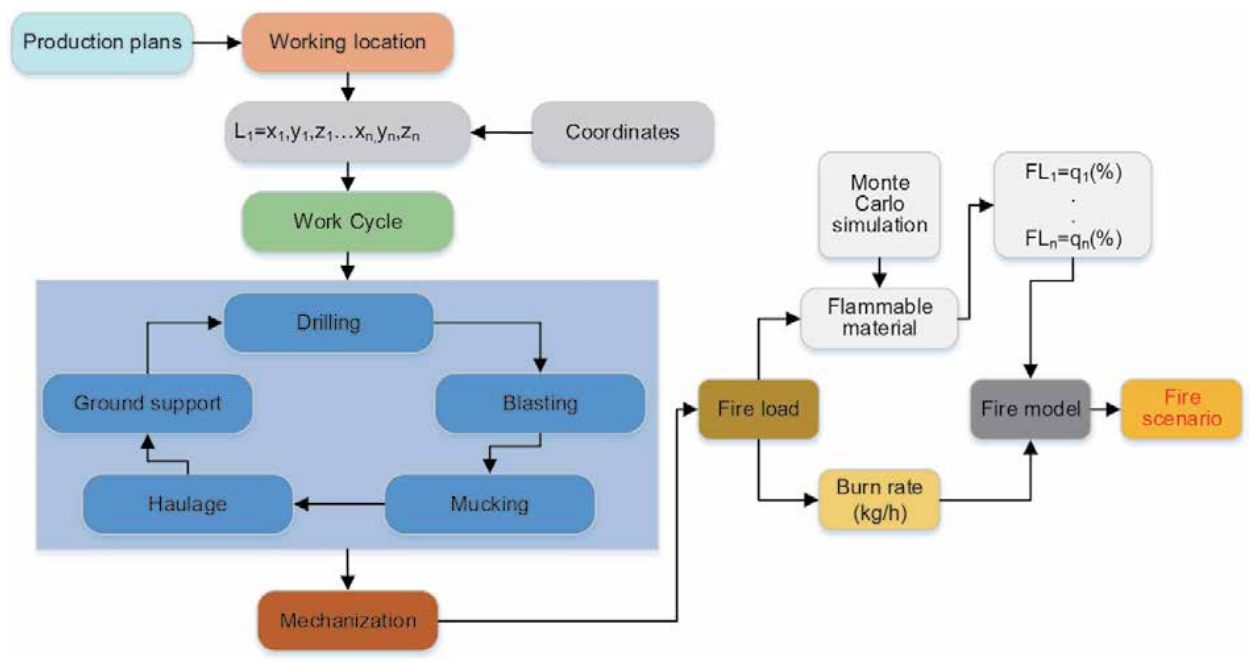

Figure 1.

Methodology for developing and locating fire scenarios in underground mines. 


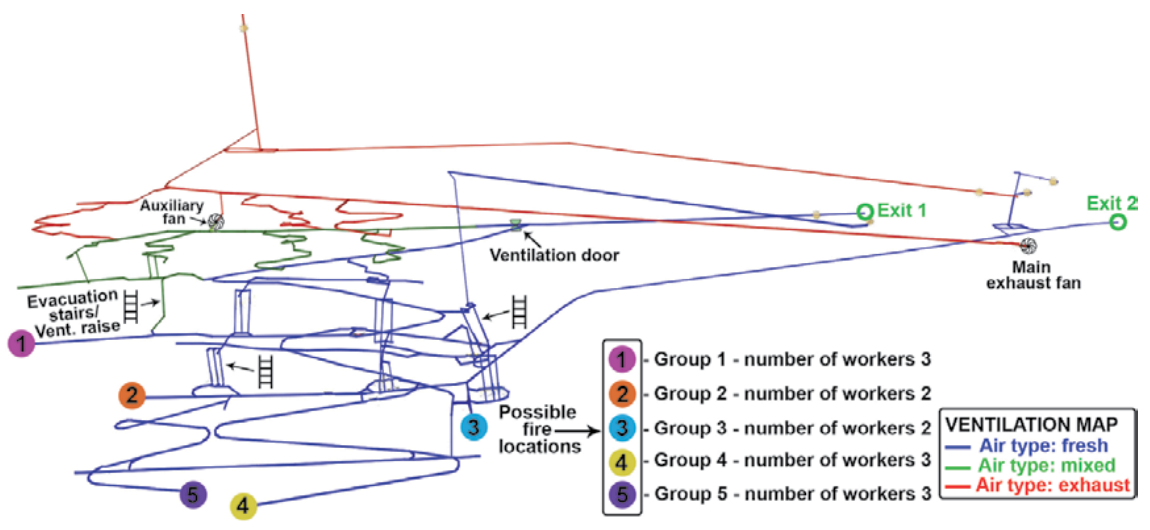

Figure 2.

Ventilation map of the "SASA" mine with marked possible fire locations, group of mineworkers, and exits.

the severity of the fire scenario itself. The process of modeling fire load inputs that are closely related to the inability to accurately determine the type and quantity of flammable material covered by a fire scenario is done using the Monte Carlo simulation technique. The reason for selecting and analyzing the fire load parameter is because of its immense contribution in generating the amount of toxic gases from which the complexity of the evacuation process depends. The reason for choosing the Monte Carlo simulation technique is because of its speed and simplicity of implementation and also the ability to generate a large amount of input data sampled randomly from their respective distributions [13-15].

The process of developing this model that incorporates the Monte Carlo simulation technique associated with the normal distribution defined by mean $=50$, and standard deviation $=15$, has been previously explained by the same author, and the entire methodology and reasons for selecting the highlighted parameters can be found here [16].

What is new in this research is the development of a database that includes all fire scenarios in a predetermined location using the abovementioned methodology on Figure 1.

All fire scenarios are analyzed in terms of impact from the fire load input parameters on the evacuation process, that is, how different distribution of combustible materials from the same mechanization (or other composition of combustible materials) will impact the evacuation process.

The introduction of this database aims to select fire scenarios of the same type but with different fire load distribution, from which we can analyze the effects on the evacuation process. The results of this analysis can be used to improve the design of fire systems and evacuation plans and to test them for their effectiveness in different conditions.

From the simple analysis of the monthly production plan of "SASA" mine, we have extracted all work sites for ore exploitation and development of mining facilities with the appropriate work cycle together with the related mechanization. To present the methodology, we will only analyze fire scenarios generated by only one mechanization and present the optimal evacuation route for only one group of workers.

For the purposes of this analysis, we will present the results of the fire scenarios generated by the mechanization Scooptram ST7, located at the possible fire location 3 , from where we will simulate the fire scenarios and calculate the optimal evacuation route for group 1 (Figure 2). 


\begin{tabular}{cccc}
\hline & Tire $[\mathrm{kg}]$ & Diesel fuel $[\mathrm{L}]$ & Hydraulic fluid $[\mathrm{L}]$ \\
\hline Scooptram ST7 & $238 * 4$ (tires) $=952$ & 190 & 111 \\
\hline
\end{tabular}

Table 1.

Approximate fire load calculation for the fire scenario from Scooptram ST7.

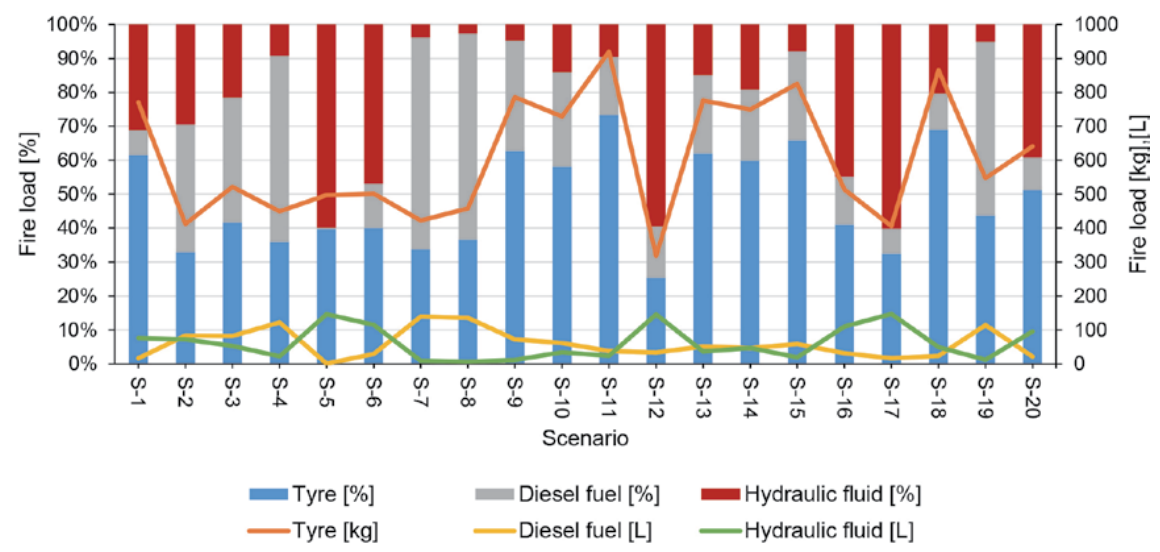

Figure 3 .

Generated scenarios along with the corresponding fire load distribution obtained from the Monte Carlo simulation model.

The inputs in the next steps of the proposed methodology are the approximate values of the total fire load for the selected mechanization. To simplify the process of determining this data, we used the technical manual of the Scooptram ST7, from which we approximated the quantities for the tire, hydraulic fluid, and diesel fuel which will be threatened as total fire load (Table 1). Regardless of the fact that the amount of diesel fuel is stochastic in nature, and is dependent on a number of factors, to simplify the model, we will consider it a known value, and we will treat it in a further expansion of the research.

Following the analysis of the approximate amount of fire load, the next step is to model them using the previously mentioned Monte Carlo simulation technique, along with the necessary data for its normal distribution defined by mean and standard deviation [16].

For the purpose of this study using the Monte Carlo simulation model, we have generated 20 scenarios with different fire load distribution, which will give variations in the results from the fire scenarios, and we will analyze their impact on the evacuation process (Figure 3).

\section{Modeling and simulation of fire scenarios in underground mines}

The purpose of fire models is to describe fire characteristics, such as heat release rate, the burning rate of material, smoke, generating toxic gases, etc., and the results of simulating these models will be as good as the inputs $[9,17]$. In order to create a relevant fire model in underground mines, it must be based on an accurate ventilation model. This interconnection and accuracy of the fire and ventilation models will depend on the movement of smoke and toxic gases through the mine facilities from which the evacuation process is based.

Various case studies previously published from the same author are based on the modeling of fire scenarios in a number of different mine ventilation layouts [7-9]. 
For this study, i.e., for simulating fire models across the 3D ventilation network, we used the VentSim software along with VentFIRE ${ }^{\mathrm{TM}}$ module that are interconnected because they belong to the same software package. With the help of VentSim software a 3D ventilation network with all working parameters is developed, while the VentFIRE ${ }^{\mathrm{TM}}$ module is used for simulation and calculation of the fire scenarios previously generated with the Monte Carlo simulation model.

The theoretical and the working principle of the VentSim software together with the VentFIRE ${ }^{\mathrm{TM}}$ module can be found here [18]. Fire models in some cases are analyzed by CFD software for the purpose of comparison between the results obtained from simpler computational methods. Due to the size and complexity of the underground mines, it should be emphasized that CFD analysis can only be used to represent a small section of the mine. The results of such CFD analyses that require a large number of computations which will generate only results related to the immediate proximity of the fire scenario cannot realistically represent the full image generated by the fire model $[8,19]$. The functionality of the methodology presented in this chapter is based on the modeling and simulation of fire scenarios whose results can fully represent each time interval of the movement of smoke and fire gases through the whole ventilation network from which the evacuation process entirely depends.

In the process of modeling fire scenarios in VentFIRE ${ }^{\mathrm{TM}}$ module in addition to the fire load data presented in Figure 3, which was generated with the Monte Carlo simulation model, specific data are also required for each material which is presented in Table 2. For the purpose of providing this data, laboratory tests or fire databases containing such information may be used [20,21].

The results of the fire models obtained by the VentFIRE ${ }^{\mathrm{TM}}$ module are in the form of a dynamic representation of the real-time fire progression and utilize a graphic visualization of the spread and concentration of combustion products and all the fire-related data throughout the ventilation system (Figure 4).

Monitoring points that are strategically placed throughout the ventilation network allow the extraction of data in the form of concentrations over time for all fire-related data. In this study, for the evaluation of the evacuation plans, only the $\mathrm{CO}$ concentration over time curve will be analyzed throughout the ventilation network. The results from the monitoring points will serve for realistic mapping of the $\mathrm{CO}$ inhalation throughout the evacuation route for anyone affected by the fire scenario. Figure 5 shows the $\mathrm{CO}$ concentration measured from the monitoring point at the location for the fire scenario S-1.

\begin{tabular}{lccc}
\hline & Tire & Diesel fuel & Hydraulic fluid \\
\hline Density $\left[\mathrm{kg} / \mathrm{m}^{3}\right]$ & 1150 & 832 & 760 \\
\hline Simplified chemical hydrocarbon formula & $\mathrm{C}_{4} \mathrm{H}_{6}$ & $\mathrm{C}_{12} \mathrm{H}_{23}$ & $\mathrm{C}_{36} \mathrm{H}_{74}$ \\
\hline Heat of combustion $[\mathrm{M} / \mathrm{kg}]$ & 44 & 45 & 48 \\
\hline Burning rate of material $\left[\mathrm{kg} / \mathrm{m}^{2} * \mathrm{~s}\right]$ & 0.062 & 0.045 & 0.039 \\
\hline $\mathrm{O}_{2}$ consumed $[\mathrm{kg} / \mathrm{kg}]$ & 3.62 & 3.33 & 3.57 \\
\hline Yield $\mathrm{CO}_{2}[\mathrm{~kg} / \mathrm{kg}]$ & 0.9 & 3.2 & 3.3 \\
\hline Yield $\mathrm{CO} \min [\mathrm{kg} / \mathrm{kg}]$ & 0.13 & 0.019 & 0.1 \\
\hline Yield CO max $[\mathrm{kg} / \mathrm{kg}]$ & 0.23 & 0.21 & 0.24 \\
\hline Yield soot $[\mathrm{kg} / \mathrm{kg}]$ & 0.1 & 0.059 & 0.1 \\
\hline
\end{tabular}

Table 2.

Input fire characteristics data for the fire load. 
Methodology for Optimal Fire Evacuations in Underground Mines Based on Simulated Scenarios DOI: http://dx.doi.org/10.5772/intechopen.91213

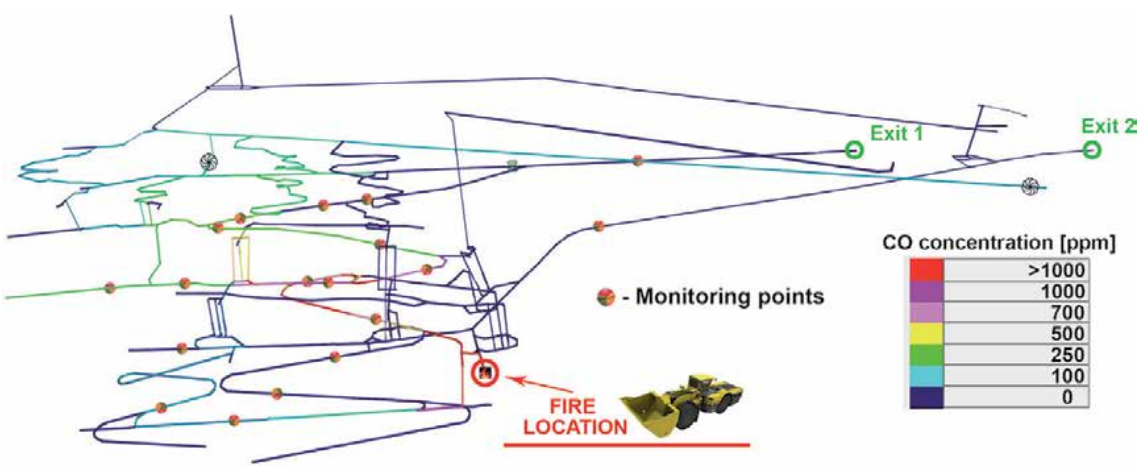

Figure 4 .

Screenshot from the fire scenario $S-1$ at 30 minutes from the fire ignition.

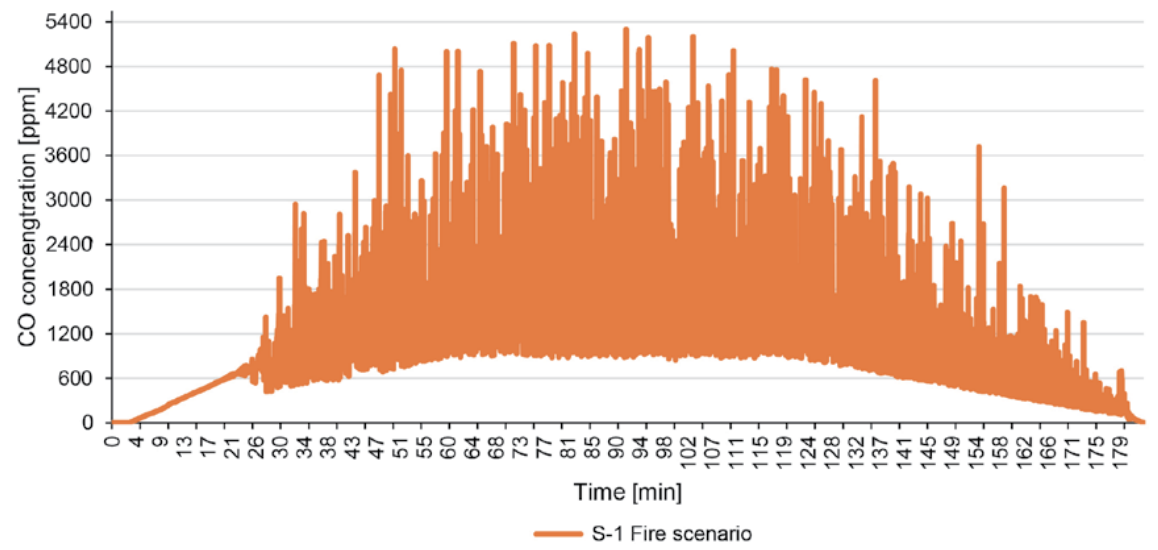

Figure 5 .

$C O$ concentration over time curve at the fire scenario $S-1$ location.

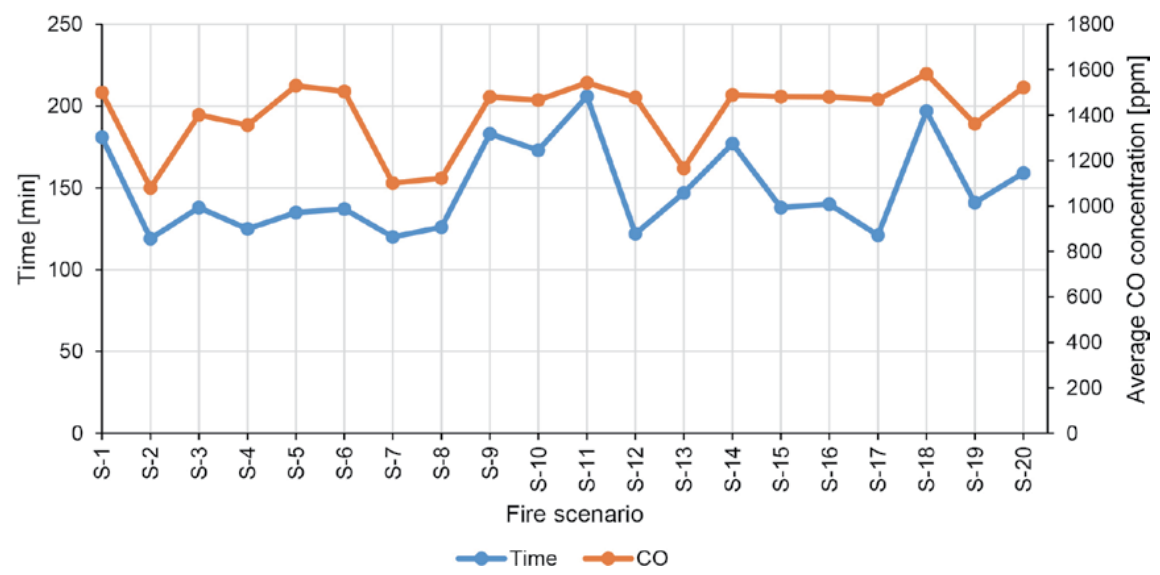

Figure 6.

Average values of $\mathrm{CO}$ concentration at fire location and total time duration of the fire for all scenarios generated by the Monte Carlo simulation model.

Figure 6 shows the average values of $\mathrm{CO}$ concentration vs. total duration time for all fire scenario variants generated by the Monte Carlo simulation model, measured from the fire location. 
These results highlight the impact of different fire load distribution, thus providing additional data for analysis during the process for determining the optimal evacuation routes.

\section{Methodology for determining the optimal evacuation routes based on simulated fire scenarios}

\subsection{Life safety assessment during evacuation based on fractional effective dose (FED) from CO inhalation}

Statistical underground mine fire evidence shows that most injuries and deaths are not caused by direct contact with the fire but by way of smoke and toxic gases inhalation [22].

While the fire scenario may be confined to a localized underground mine area, the smoke produced will rise and with the help of the ventilation system may spread rapidly through the mine.

The spread of smoke and toxic gases through the underground mine network will cause difficulties in the evacuation process, and therefore, there is a need for an effective methodology for planning and developing of optimal evacuation routes.

Purser [23] gives extensive review of smoke and toxic gases hazards, including exposure thresholds that can cause incapacitation and even death.

In underground mine fires, the most common asphyxiate is $\mathrm{CO}$, and its effects of incapacitation depend from the gas concentrations and the durations of exposure.

The evacuation management system must be designed and evaluated against a set of criteria to ensure safe evacuation of the mineworkers, which can be achieved by analyzing the fire environments using modeling and simulation.

The proposed method in this book chapter involves the determination of accumulating exposure effect at regular discrete time increments to get the cumulative dosage in terms of FED for the total period of exposure. The exposure doses are calculated as a fraction of incapacitation at every time increment, and the value of $\mathrm{FED}=1.0$ represents the state of incapacitation in which mineworkers are incapable of completing their own evacuation.

Purser [24] suggests mathematical model for estimating toxic hazard from inhalation of CO from fire scenario in terms of time to incapacitation or death in form of FED and is given as follows:

$$
\begin{gathered}
\mathrm{FED}_{\text {Toxicity }}=\mathrm{FED}_{\mathrm{CO}} * \mathrm{~V}_{\mathrm{CO}_{2}}+\mathrm{FED}_{\mathrm{O}_{2}} \\
\mathrm{FED}_{\mathrm{CO}}=\sum_{\mathrm{t}_{1}} \frac{\mathrm{K} *[\mathrm{CO}]^{1,036}}{\mathrm{D}} \Delta \mathrm{t} \\
V_{\mathrm{CO}_{2}}=\frac{\exp \left(0,1903 * \% \mathrm{CO}_{2}+2,0004\right)}{7,1} \\
\mathrm{FED}_{\mathrm{O}_{2}}=\sum_{\mathrm{t}_{1}}^{\mathrm{t}_{2}} \frac{1}{\exp \left(8,13-0,54\left(20,9 \%-\% O_{2}\right)\right)} \Delta \mathrm{t}
\end{gathered}
$$

where CO (carbon monoxide) is the average concentration (ppm) over the time increment $\Delta \mathrm{t}$ in minutes, $\mathrm{K}$ and $\mathrm{D}$ are constants which depend on the activity of the person (Table 3), $\% \mathrm{CO}_{2}$ is the carbon dioxide concentration, and $\left(20,9-\% \mathrm{O}_{2}\right)$ is the oxygen vitiation over the time increment $\Delta \mathrm{t}$. 
Methodology for Optimal Fire Evacuations in Underground Mines Based on Simulated Scenarios DOI: $h t t p: / / d x$. doi.org/10.5772/intechopen.91213

\begin{tabular}{lcl}
\hline Activity & K & D \\
\hline At rest & $2,81945 * 10^{-4}$ & 40 \\
\hline Light work & $8,2925 * 10^{-4}$ & 30 \\
\hline Heavy work & $1,6585 * 10^{-4}$ & 20 \\
\hline
\end{tabular}

Table 3.

Values for different activity levels for the constants $K$ and $D$.

\begin{tabular}{ll}
\hline COHb (\%) & Clinical symptoms \\
\hline $0,4-1$ & Normal value for nonsmokers \\
\hline $2,5-4$ & Decreased exercise performance in patients with angina \\
\hline $5-10$ & $\begin{array}{l}\text { Shortness of breath on vigorous exertion, possible tightness across forehead, statistically } \\
\text { significant diminution of visual perception, manual dexterity, or ability to learn }\end{array}$ \\
\hline $11-20$ & $\begin{array}{l}\text { Atypical dyspnea, throbbing headache, dizziness, nausea, confusion and decreased } \\
\text { exercise tolerance, dilatation of skin vessels }\end{array}$ \\
\hline $21-30$ & $\begin{array}{l}\text { Severe headache, pulsation in sides of head, impaired thinking, disturbed vision, fainting, } \\
\text { easy fatigability, disturbed judgment }\end{array}$ \\
\hline $31-40$ & Severe headache, dizziness, respiratory failure, coma, intermittent convulsions \\
\hline $41-50$ & $\begin{array}{l}\text { Brain damage, lethargy, seizures, syncope, death from severe cellular hypoxia if exposure } \\
\text { is prolonged }\end{array}$ \\
\hline $51-60$ & Same as above, coma, convulsions, Cheyne-Stokes respiration \\
\hline$>70$ & Slowing and stopping of respiration and death within short period \\
\hline
\end{tabular}

Table 4.

Approximate clinical symptoms associated with the blood COHb (\%) level [26].

One of the limitations of this model is the lack of a clear safety margin between the values of the FED in which the transition in the evacuation process from safe to unsafe zone begins. As previously stated, for the evacuation to be considered safe, the FED value should be $<1$. The question here is how much less than 1 ?

To improve the methodology in this regard, additional model is introduced that will allow to link the entire evacuation timeline with another parameter in the form of $\mathrm{COHb}$ prediction in the blood as a result of the $\mathrm{CO}$ inhalation generated by the fire scenario.

\subsection{Model for predicting carboxyhemoglobin $(\mathrm{COHb})$ concentration as a result of CO inhalation}

The overwhelming hazard in fires is the COHb buildup in the blood as a result of exposures to $\mathrm{CO}$. Inhaled $\mathrm{CO}$ acts on the human body by competing with oxygen to combine with hemoglobin molecules in the blood, forming COHb rather than normal oxyhemoglobin $(\mathrm{O} 2 \mathrm{Hb})$ [25]. Exposure to a large concentration of $\mathrm{CO}$ is lethal, and the signs and symptoms produced are directly related to the percentage of COHb in the blood (Table 4).

The most widely used mathematical model (Coburn-Forster-Kane (CFK)) was implemented in order to predict $\mathrm{COHb}(\%)$ blood level from $\mathrm{CO}$ exposure on mineworkers during the underground mine fire scenario. 
Previous research by several authors validated both linear and nonlinear CFK model against observations made on subjects exposed to variable $\mathrm{CO}$ concentrations, and the consensus is that the model predictions works quite well. The CFK nonlinear model is given by the following Equation [27]:

$$
\begin{aligned}
{[\mathrm{COHb}]_{\mathrm{t}}=\frac{1}{\mathrm{~A}\left(\frac{\mathrm{AC}}{[\mathrm{COHb}]_{0}}\right)} } & +(1-\mathrm{C}) \mathrm{V}_{\mathrm{CO}} \mathrm{B}+(1-\mathrm{C}) \mathrm{P}_{1, \mathrm{CO}} \\
\mathrm{A} & =\frac{\mathrm{PO}_{2}}{\mathrm{M}\left[\mathrm{O}_{2} \mathrm{Hb}\right]} \\
\mathrm{B} & =\frac{1}{\mathrm{D}}+\frac{\mathrm{P}}{\mathrm{V}_{\mathrm{a}}} \\
\mathrm{C} & =\mathrm{e}^{\left(-\frac{\mathrm{tA}}{\mathrm{V}_{\mathrm{b}} \mathrm{B}}\right)}
\end{aligned}
$$

where:

$\mathrm{M}-$ Haldane constant, ratio of the affinity of $\mathrm{Hb}$ for $\mathrm{CO}$ to that of $\mathrm{O}_{2}=240$.

$\left[\mathrm{O}_{2} \mathrm{Hb}\right]$-oxyhemoglobin concentration $=0,2 \mathrm{ml} \mathrm{ml}^{-1}$ blood.

$[\mathrm{COHb}]_{\mathrm{t}}$-carboxyhemoglobin concentration at time $\mathrm{t}$ in $\mathrm{ml} \mathrm{CO}$ per $\mathrm{ml}$ blood.

$[\mathrm{COHb}]_{0}$-initial concentration of carboxyhaemoglobin in blood

( $\% \mathrm{COHb}=0,5 \%$ for nonsmokers; $\% \mathrm{COHb}>2 \%$ for $80 \%$ of smokers; $\% \mathrm{COHb}=10 \%$ for heavy smokers).

$\mathrm{PO}_{2}$ - partial pressure of oxygen in lung capillaries $=13,3 \mathrm{kPa}$.

$\mathrm{V}_{\mathrm{CO}}$-endogenous $\mathrm{CO}$ production rate $=0,007 \mathrm{ml} \mathrm{min}^{-1}$.

$\mathrm{D}$-diffusion capacity of the lungs for $\mathrm{CO}=225 \mathrm{ml} \mathrm{min}^{-1} \mathrm{kPa}$ (in reality this is not a constant but is altered by a number of factors including exercise).

$\mathrm{P}-$ Barometric pressure - saturated vapor pressure of water at $37^{\circ} \mathrm{C}=95,1 \mathrm{kPa}$.

$\mathrm{V}_{\mathrm{b}}$-blood volume $5500 \mathrm{ml}$.

$\mathrm{P}_{1, \mathrm{CO}}$ - partial pressure of CO in inspired air $=0,0101 \mathrm{kPa}$ (adopted for the purposes of this model).

$\mathrm{V}_{\mathrm{a}}$-alveolar ventilation rate $=6000 \mathrm{ml} \mathrm{min}^{-1}$.

$\mathrm{t}$-duration of exposure [min].

The limitations in the CFK model are located with the physiological variables needed as input to the model which are difficult to measure, such as blood volume, endogenous production of CO, and the pulmonary diffusing capacity [28].

For the purpose of this study, an Excel model based on the CFK equation is built to predict the individual's $\mathrm{COHb}$ formation (\%), as a result from $\mathrm{CO}$ inhalation. For simplification purposes the abovementioned physiological variables are set as default values (as defined in the equation).

The proposed model for predicting $\mathrm{COHb}(\%)$ with appropriate clinical symptoms (Table 4) connected with the FED model can better determine the threshold in which the evacuation will be considered safe.

\subsection{Model for the conversion of the factors that influence the speed of evacuation}

To be able to calculate the optimal evacuation routes in underground mines, details about the tunnels' parameters should be provided. Each fire scenario generates factors that influence the complexity and the speed of the evacuation itself.

Based on extensive literature review, two factors are located that have most influence on the evacuation speed, and these factors are generalized in the form of tunnel slope and smoke visibility [7, 29-31]. The model framework is shown in Figure 7. 


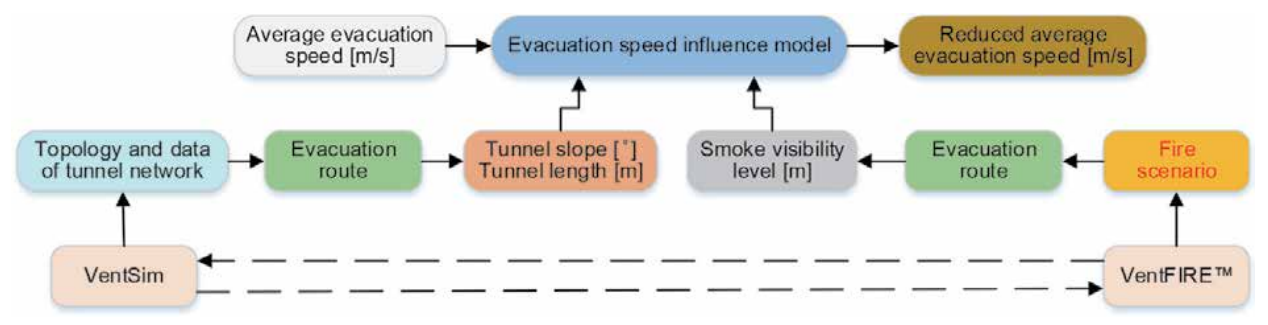

Figure 7.

Methodology for implementation of the evacuation speed influence model.

These factors that influence mineworkers' escape speed can increase the exposure time from the fire scenario and thus present very important factors to be considered in the process of determining optimal evacuation routes.

We defined the mineworkers' normal evacuation speed by $v_{0}$, and under the influence of the above factors, the evacuation speed will be $v_{f}$.

The tunnel slope influences the mineworkers' evacuation (and also walking) speed, and the greater the slope the more influence it will have on the process.

The tunnel slope influence under climbing situation is given by the following Equation [31]:

$$
\mathrm{k}_{\mathrm{ts}}=\frac{\mathrm{mgv}_{0} \sin \theta_{\mathrm{s}}}{\mathrm{P}_{0}}+\cos \theta_{\mathrm{s}}
$$

where $\mathrm{m}$ is the standard human mass $[\mathrm{kg}], \mathrm{g}$ is the gravity acceleration $\left[\mathrm{m} / \mathrm{s}^{2}\right]$, and $\theta_{\mathrm{s}}$ is the tunnel's angle of slope in degrees.

When mineworkers pass down slope tunnels, we will assume no influence on their speed, and the model will treat this as normal evacuation speed $\mathrm{v}_{0}$ (i.e., $\mathrm{k}_{\mathrm{ts}}=1$ ).

The smoke generated by the fire scenario is a major factor in determining tunnel visibility. This visibility factor has important effects on the evacuation speed of the mineworkers who are escaping.

Based on the reviewed literature, two threshold values hold a central function during an evacuation in a smoke-filled environment [30, 32]. The first threshold value is the visibility level at which evacuees in general can be expected to start reducing their evacuation speed. This value based on the reviewed experiments of the data presented from the literature was set to 3 meters as corresponding visibility threshold value [30, 33, 34].

The second threshold value is the visibility level at which the mineworkers can be assumed to be evacuating with their slowest speed. Based on the reviewed literature, the slowest speed during an evacuation in a smoke-filled environment is similar to movement in complete darkness which can be expected to be about $0,2 \mathrm{~m} / \mathrm{s}$ [30]. In this analysis, the value for the slowest speed of evacuation will also be applied when the mineworkers will move through the evacuation stairs in the ventilation raise.

Practically, in the process of calculating the reduction of evacuation speed based on the smoke visibility level, the model is set in the following way:

- All individuals in the group are assumed to be evacuating with the same speed.

- Visibility levels $>3 \mathrm{~m}$ : mineworkers' evacuation speed is represented by $1,2 \mathrm{~m} / \mathrm{s}$ 


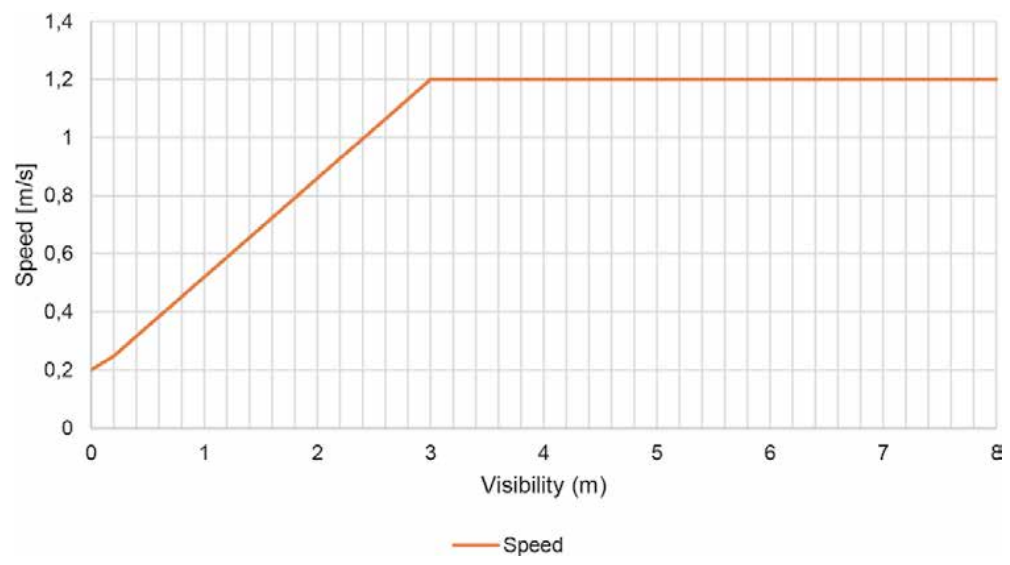

Figure 8.

Representation of relative reduction of speed in a smoke-filled environment according to the model.

- Visibility levels $\leq 3 \mathrm{~m}$ : mineworkers' evacuation speed is represented by a relative reduction of $0,34 \mathrm{~m} / \mathrm{s}$ per meter visibility in a smoke-filled environment down to the previously defined minimum speed of $0,2 \mathrm{~m} / \mathrm{s}$.

The correlation in this model is described by the following equation and by Figure 8 [30]:

$$
w=\min (1 ; \max (0,2 ; 1,2-0,34 *(3-V)))
$$

where $\mathrm{w}$ is the evacuation speed $[\mathrm{m} / \mathrm{s}]$ and $\mathrm{V}$ the visibility $[\mathrm{m}]$.

\section{Results and discussion}

Determining the optimal routes for evacuation in the case of underground mine fire makes the difference between life and death. In this book chapter, we established a methodology for calculating the optimal routes for evacuation in case of underground mine fire based on simulated scenarios. The methodology shown in Figure 9 provides the necessary steps to assess the potential fire scenarios and to generate the necessary data on the basis of which all evacuation routes will be evaluated and the optimization process implemented.

The methodology consists of three parts, i.e., developing underground mine fire scenarios, modeling and simulation of fire scenarios, and determining the optimal evacuation routes based on the generated results. The parts of the presented methodology and the procedures for their implementation are presented in detail above.

For the purpose of this study, a case study of the "SASA"-R.N. Macedonia mine was used for determining the optimal routes for evacuations.

To present all the steps that the methodology is consists of, we will present the results obtained from only one fire location from which we will calculate the optimal evacuation routes for only one group of workers for all of the 20 fire scenarios generated by the Monte Carlo simulation model.

The results from the Monte Carlo simulation (Figure 3) are used as input fire load data for modeling and simulating fire scenarios in the VentFIRE ${ }^{\mathrm{TM}}$ module through the mine ventilation network (Figure 2). Following the simulation of all 20 fire scenarios from the same fire location, all possible evacuation routes for group 1 have been identified (Figure 10). 


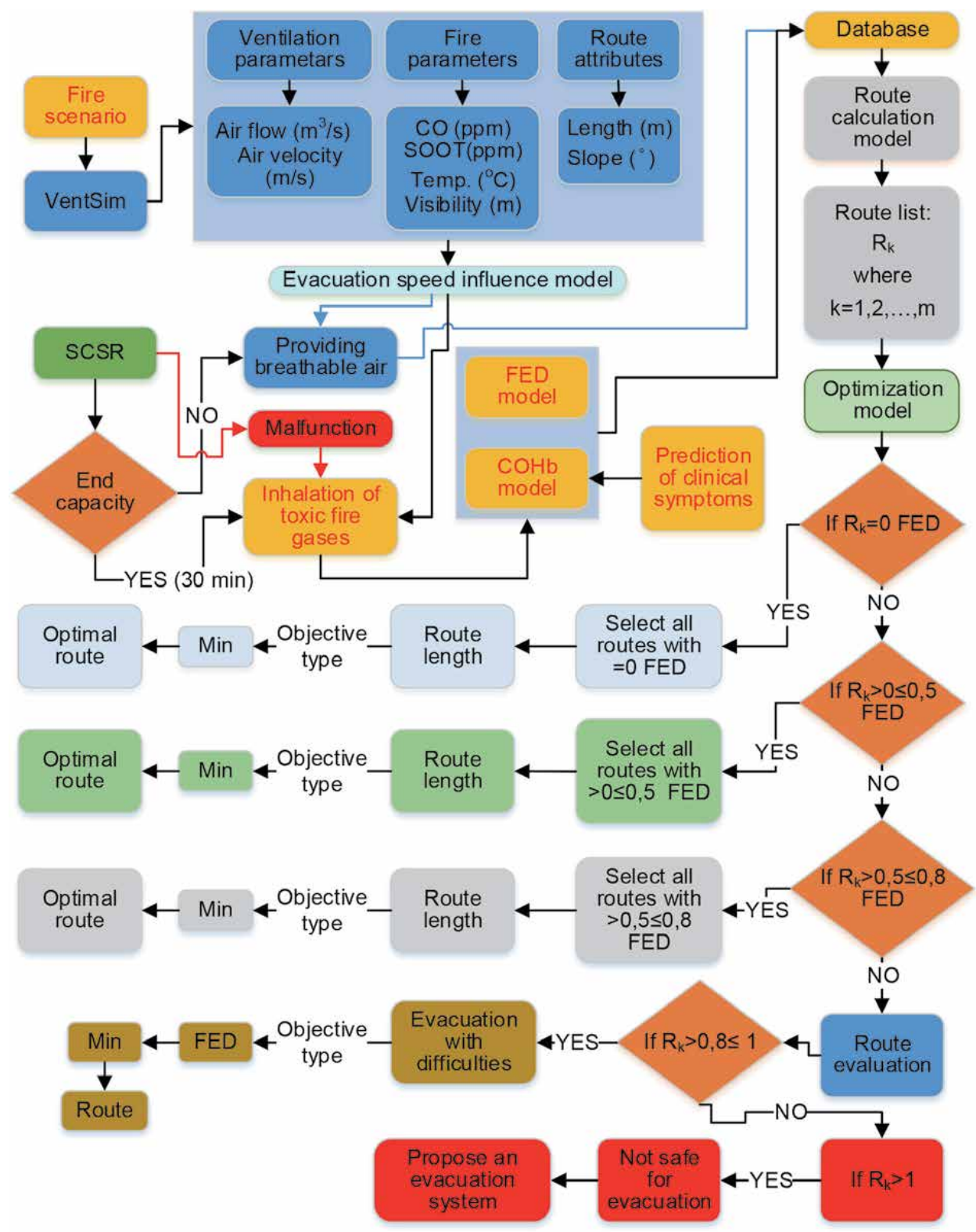

Figure 9.

Proposed methodology implementation framework.

In the process of calculating all the parameters needed to determine the optimal evacuation routes, we will take into account the self-contained self-rescuer (SCSR). The use of SCSR in underground mining is a legal obligation in almost all countries around the world, so its introduction into the process of determining the optimal evacuation routes is a very important factor. The SCSR is a portable device that is used in underground mines to provide breathable air for the mineworkers when the surrounding atmosphere is filed with contaminants after emergency situation.

Extensive research on fire reports provides the fact that sometimes this first line of defense from smoke inhalation in the form of SCSR fails to function properly due to technical problems or due to insufficient training of the mineworkers [35].

Because of this fact in this study, we will make two parallel analyses to calculate the 


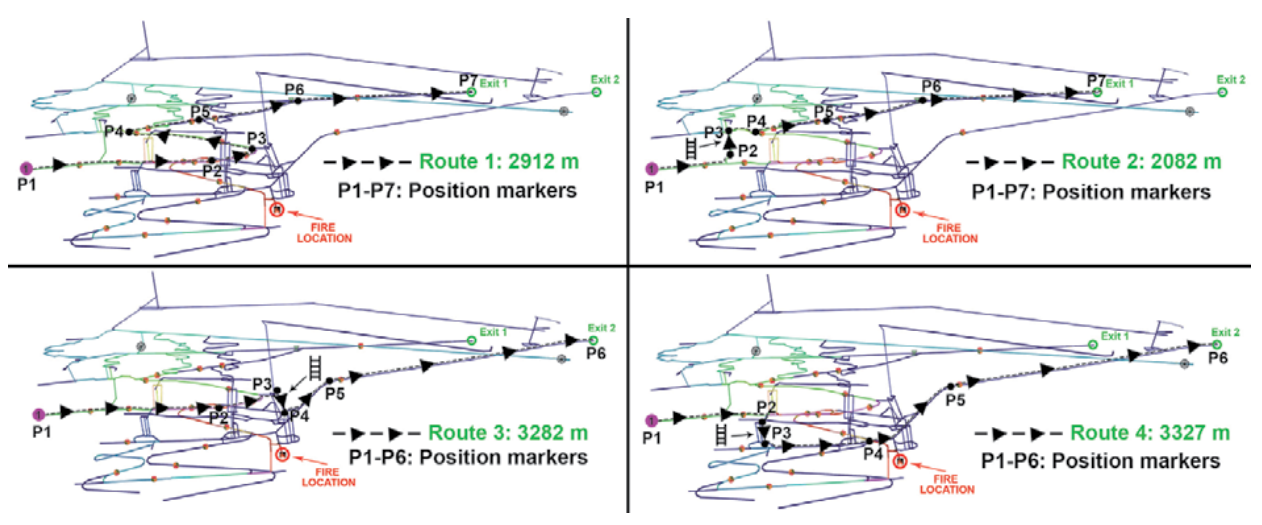

Figure 10.

Identification of possible evacuation routes for group 1 for all generated fire scenarios.

\begin{tabular}{cccccccc}
\hline Position & $\begin{array}{c}\text { Section } \\
\text { length } \\
{[\mathbf{m}]}\end{array}$ & $\begin{array}{c}\text { Visibility } \\
{[\mathbf{m}]}\end{array}$ & $\begin{array}{c}\text { Slope } \\
{\left[{ }^{\mathbf{0}}\right]}\end{array}$ & $\begin{array}{c}\text { Reduction of } \\
\text { evacuation speed } \\
\text { (from visibility } \\
\text { and slope) }[\mathbf{m} / \mathbf{s}]\end{array}$ & $\begin{array}{c}\text { Average } \\
\text { CO } \\
(\mathbf{p p m})\end{array}$ & $\begin{array}{c}\text { Evacuation } \\
\text { time in } \\
\text { section }[\mathbf{s}]\end{array}$ & $\begin{array}{c}\text { Cumulative } \\
\text { time }[\mathbf{s}]\end{array}$ \\
\hline P1-P2 & 667 & 5 & 0 & 1,2 & 448 & 556 & 556 \\
\hline P2-P3 & 232 & 2 & 6 & 0,4 & 881 & 580 & 1136 \\
\hline P3-P4 & 495 & 4,6 & 6,1 & 0,3 & 514 & 1650 & 2786 \\
\hline P4-P5 & 524 & 12 & 5,71 & 0,29 & 480 & 1807 & 4593 \\
\hline P5-P6 & 199 & 25 & 5,8 & 0,55 & 0 & 362 & 4955 \\
\hline P6-P7 & 792 & 25 & 1 & 0,66 & 0 & 1200 & 6155 \\
\hline
\end{tabular}

Table 5 .

Results for group 1, evacuated along route 1 for scenario $S-1$.

optimal evacuation routes in which we will introduce the use of a SCSR with a capacity of 30 minutes and the possibility of its non-functionality. By introducing this parameter in the form of functionality and non-functionality of SCSR, we can provide a detailed analysis that can predict the evacuation routes under different conditions.

To elaborate on the proposed methodology, we will present in details the results of scenario S-1.

After the development of the underground mine fire scenarios and their modeling and simulation inside the VentFIRE ${ }^{\mathrm{TM}}$ module, all the necessary data for the optimization process is gathered.

For the purpose of this analysis, an average evacuation speed of $1,2 \mathrm{~m} / \mathrm{s}$ is assumed. The average evacuation speed will be affected by the tunnel slope and smoke visibility.

To calculate the impact on the average speed inside the evacuation process, An Excel model was built based on Eqs. 9 and 10. The results from the simulated fire scenario $\mathrm{S}-1$, which are required as inputs for the $\mathrm{FED}, \mathrm{COHb}$, and route calculation models, are shown in Tables 5-8.

In the calculation process for the $\mathrm{CO}$ exposure over the entire evacuation route, we will include the SCSR in its two previously mentioned forms. To calculate the exposure from $\mathrm{CO}$ for each of the possible evacuation routes, the results shown in Tables 5-8 are used as inputs to the FED and the COHb model. The results from the $\mathrm{CO}$ exposure based on FED and COHb models build inside Excel are shown in Figures 11-14. 
Methodology for Optimal Fire Evacuations in Underground Mines Based on Simulated Scenarios DOI: http://dx.doi.org/10.5772/intechopen.91213

\begin{tabular}{cccccccc}
\hline Position & $\begin{array}{c}\text { Section } \\
\text { length } \\
{[\mathbf{m}]}\end{array}$ & $\begin{array}{c}\text { Visibility } \\
{[\mathbf{m}]}\end{array}$ & $\begin{array}{c}\text { Slope } \\
{\left[{ }^{\mathbf{0}}\right]}\end{array}$ & $\begin{array}{c}\text { Reduction of } \\
\text { evacuation speed } \\
\text { (from visibility } \\
\text { and slope) }[\mathbf{m} / \mathbf{s}]\end{array}$ & $\begin{array}{c}\text { Average } \\
\text { CO } \\
(\mathbf{p p m})\end{array}$ & $\begin{array}{c}\text { Evacuation } \\
\text { time in } \\
\text { section [s] }\end{array}$ & $\begin{array}{c}\text { Cumulative } \\
\text { time }[\mathbf{s}]\end{array}$ \\
\hline P1-P2 & 347 & 5,1 & 0 & 1,2 & 448 & 289 & 289 \\
\hline P2-P3 & 80 & 5,3 & 75 & 0,2 & 450 & 400 & 689 \\
\hline P3-P4 & 135 & 4,7 & 1,4 & 1 & 524 & 135 & 824 \\
\hline P4-P5 & 524 & 12 & 5,71 & 0,29 & 480 & 1807 & 2631 \\
\hline P5-P6 & 199 & 25 & 5,8 & 0,55 & 0 & 362 & 2993 \\
\hline P6-P7 & 797 & 25 & 1 & 0,65 & 0 & 1226 & 4219 \\
\hline
\end{tabular}

Table 6.

Results for group 1, evacuated along route 2 for scenario $S-1$.

\begin{tabular}{cccccccc}
\hline Position & $\begin{array}{c}\text { Section } \\
\text { length } \\
{[\mathbf{m}]}\end{array}$ & $\begin{array}{c}\text { Visibility } \\
{[\mathbf{m}]}\end{array}$ & $\begin{array}{c}\text { Slope } \\
{\left[{ }^{\mathbf{0}}\right]}\end{array}$ & $\begin{array}{c}\text { Reduction of } \\
\text { evacuation speed } \\
\text { (from visibility } \\
\text { and slope) }[\mathbf{m} / \mathbf{s}]\end{array}$ & $\begin{array}{c}\text { Average } \\
\mathbf{C O} \\
(\mathbf{p p m})\end{array}$ & $\begin{array}{c}\text { Evacuation } \\
\text { time in } \\
\text { section }[\mathbf{s}]\end{array}$ & $\begin{array}{c}\text { Cumulative } \\
\text { time }[\mathbf{s}]\end{array}$ \\
\hline P1-P2 & 667 & 5 & 0 & 1,2 & 448 & 556 & 556 \\
\hline P2-P3 & 340 & 2 & 6 & 0,34 & 881 & 1000 & 1556 \\
\hline P3-P4 & 80 & 25 & 75 & 0,2 & 0 & 400 & 1956 \\
\hline P4-P5 & 462 & 25 & 0 & 1,2 & 0 & 385 & 2341 \\
\hline P5-P6 & 1689 & 25 & 0 & 1,2 & 0 & 1408 & 3748 \\
\hline
\end{tabular}

Table 7

Results for group 1, evacuated along route 3 for scenario $S-1$.

\begin{tabular}{cccccccc}
\hline Position & $\begin{array}{c}\text { Section } \\
\text { length } \\
{[\mathbf{m}]}\end{array}$ & $\begin{array}{c}\text { Visibility } \\
{[\mathbf{m}]}\end{array}$ & $\begin{array}{c}\text { Slope } \\
{\left[{ }^{\mathbf{0}}\right]}\end{array}$ & $\begin{array}{c}\text { Reduction of } \\
\text { evacuation speed } \\
\text { (from visibility } \\
\text { and slope) }[\mathbf{m} / \mathbf{s}]\end{array}$ & $\begin{array}{c}\text { Average } \\
\text { CO } \\
(\mathbf{p p m})\end{array}$ & $\begin{array}{c}\text { Evacuation } \\
\text { time in } \\
\text { section }[\mathbf{s}]\end{array}$ & $\begin{array}{c}\text { Cumulative } \\
\text { time }[\mathbf{s}]\end{array}$ \\
\hline P1-P2 & 461 & 5,1 & 0 & 1,2 & 448 & 384 & 384 \\
\hline P2-P3 & 80 & 14 & 75 & 0,2 & 344 & 400 & 784 \\
\hline P3-P4 & 426 & 22 & 0 & 1,2 & 0 & 355 & 1139 \\
\hline P4-P5 & 671 & 25 & 0 & 1,2 & 0 & 559 & 1698 \\
\hline P5-P6 & 1689 & 25 & 0 & 1,2 & 0 & 1408 & 3106 \\
\hline
\end{tabular}

Table 8.

Results for group 1, evacuated along route 4 for scenario $S-1$.

All of the gathered results from the models are stored and arranged in the database. The next step of the proposed methodology is to filter the results inside the database through a route calculation model that will sort out all the evacuation routes according to the level of $\mathrm{CO}$ exposure, i.e., the results obtained from the FED and $\mathrm{COHb}$ model.

The purpose of the route calculation model is to generate a list of all evacuation routes, which will include the data for route length and cumulative $\mathrm{CO}$ exposure in the form of a FED through the evacuation process. 


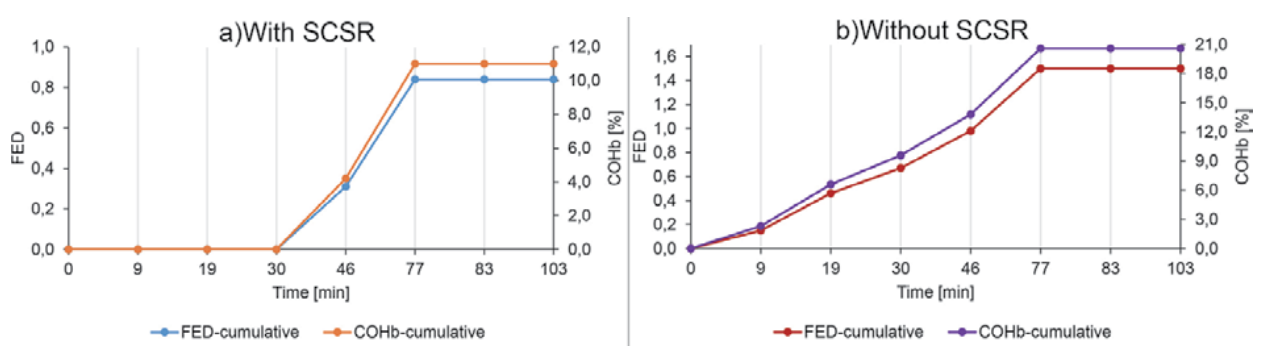

Figure 11.

Results from the FED and COHb models, for inhalation of $\mathrm{CO}$ during evacuation along the route 1.

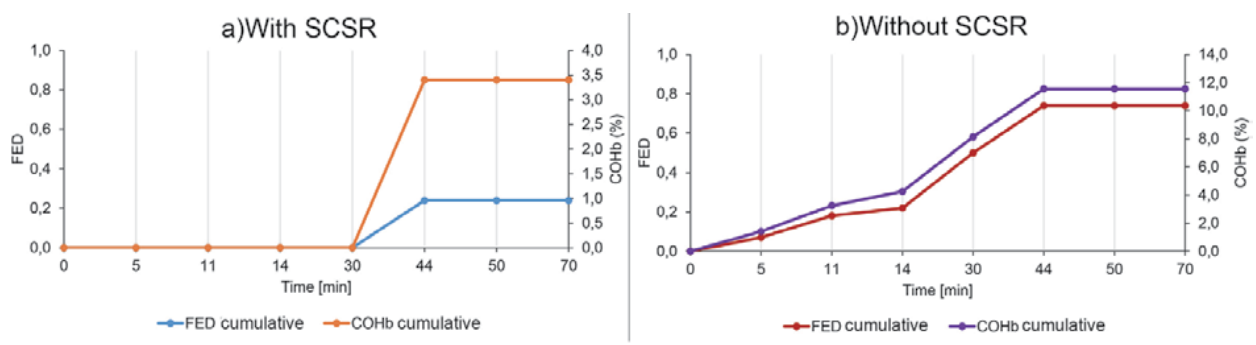

Figure 12.

Results from the FED and COHb models, for inhalation of CO during evacuation along the route 2.

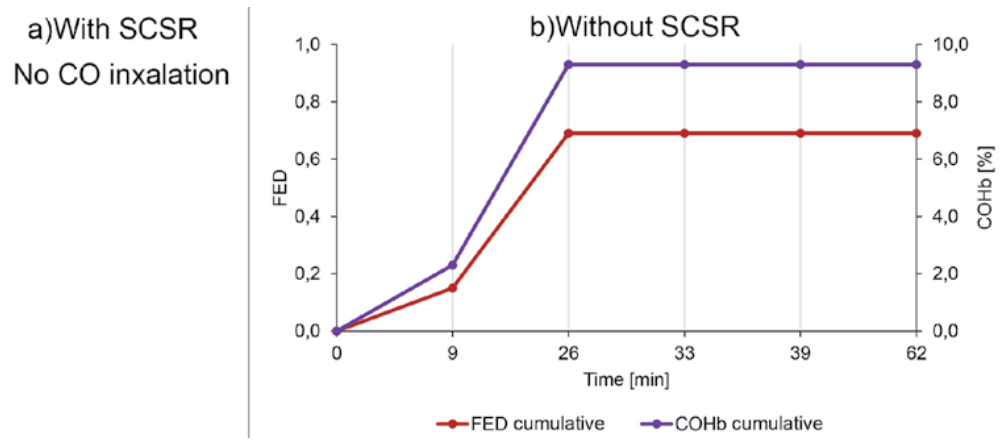

Figure 13.

Results from the FED and COHb models, for inhalation of $\mathrm{CO}$ during evacuation along the route 3.

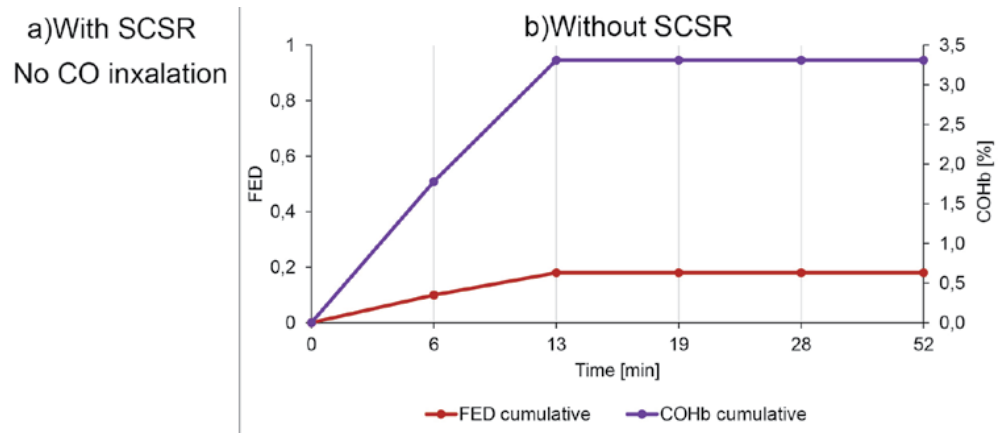

Figure 14.

Results from the FED and COHb models, for inhalation of CO during evacuation along the route 4. 
The first step in the optimization model is to group the evacuation routes into five categories:

1. Group 1 of evacuation routes with a value of FED $=0$

2. Group 2 of evacuation routes with a value of FED $>0 \leq 0,5$

3. Group 3 of evacuation routes with a value of FED $>0,5 \leq 0,8$

4. Group 4 of evacuation routes with a value of FED $>0,8 \leq 1$

\section{Group 5 of evacuation routes with a value of FED $>1$}

The values of the FED parameter on which the grouping is based are determined using the $\mathrm{COHb}$ model from which $\mathrm{COHb}(\%)$ concentrations in the blood are predicted for the same $\mathrm{CO}$ exposure which in turn are related to the clinical symptoms presented in the Table 4.

After grouping the routes into the abovementioned categories, they are filtered through a decision support process that applies the parameter optimization objectives. The optimization model is set so that there is no data in the first group to continue to the next one until the last group is reached.

For the routes in the first group in which the level is set to FED = 0, the model will select the shortest route in length which will represent the optimal evacuation route.

The same optimization process is also set for the second and the third group in which the level is set to FED $>0 \leq 0,5$ and FED $>0,5 \leq 0,8$ accordingly. The reason why this three groups are separated is to give an advantage in the optimization process to the routes with less CO exposure than on those with shorter lengths.

For the routes in the fourth group in which the level is set to FED $>0,8 \leq 1$, the model will select the route with the minimum $\mathrm{CO}$ exposure presented in the form of FED. In this group, clinical symptoms of $\mathrm{CO}$ exposure predict conditions that can cause difficulties during the evacuation process, and because of this, the optimization is set based on the FED parameter with minimal value. The evacuation routes selected in this group should be treated with caution, and they should be thoroughly analyzed for opportunities to install additional evacuation support systems in certain critical locations.

For the routes in the fifth group in which the level is set to FED $>1$, the model will treat all routes as unsafe for evacuation. If the proposed methodology in this study does not generate data which will fall into the first four groups, then an additional analysis should be performed using the developed ventilation model that shows the movement of smoke and toxic gases through the underground mining facilities. These results could serve to plan the action strategy for the rescue teams

\begin{tabular}{lcc}
\hline & FED & Route length [m] \\
\hline Route 3 (rank 1) & 0 & 3282 \\
\hline Route 4 (rank 2) & 0 & 3327 \\
\hline Route 2 (rank 3) & 0,24 & 2082 \\
\hline Route 1 (rank 4) & 0,84 & 2912 \\
\hline
\end{tabular}

Table 9.

Ranked evacuation routes from the optimization process for scenario S-1 with the use of a SCSR. 
or for a suggestion of additional systems that could help in the evacuation process for those affected by the fire scenario.

Table 9 shows the results from the optimization methodology for scenario S- 1 in which the routes are sorted by their ranking, taking into account the use of a SCSR.

Considering the use of a SCSR, the optimal evacuation route for scenario S-1 is route 3 which has the best rating according to the present methodology.

Table 10 shows the results from the optimization methodology taking into account the possibility of malfunction of the SCSR for scenario S-1.

The optimal evacuation route for scenario S-1 in which we assumed the malfunction of the SCSR is route 4 which according to the present methodology has the best rating.

\begin{tabular}{lcc}
\hline & FED & Route length [m] \\
\hline Route 4 (rank 1) & 0,18 & 3327 \\
\hline Route 2 $($ rank 2) & 0,74 & 2082 \\
\hline Route 3 (rank 3) & 0,69 & 3282 \\
\hline Route 1 (rank 4) & 1,5 & 2912 \\
\hline
\end{tabular}

Table 10.

Ranked evacuation routes from the optimization process for scenario S-1 without the use of SCSR.

\begin{tabular}{|c|c|c|c|c|c|c|}
\hline \multirow[b]{2}{*}{ Scenario S-2 } & \multicolumn{3}{|c|}{ Optimal route with SCSR } & \multicolumn{3}{|c|}{ Optimal route without the use of SCSR } \\
\hline & Route 3 & $\mathrm{FED}=0$ & Length $=3282 \mathrm{~m}$ & Route 2 & $\mathrm{FED}=0,421$ & Length $=2082 \mathrm{~m}$ \\
\hline Scenario S-3 & Route 3 & $\mathrm{FED}=0$ & Length $=3282 \mathrm{~m}$ & Route 4 & $\mathrm{FED}=0,115$ & Length $=3327 \mathrm{~m}$ \\
\hline Scenario S-4 & Route 3 & $\mathrm{FED}=0$ & Length $=3282 \mathrm{~m}$ & Route 4 & $\mathrm{FED}=0,112$ & Length $=3327 \mathrm{~m}$ \\
\hline Scenario S-5 & Route 3 & $\mathrm{FED}=0$ & Length $=3282 \mathrm{~m}$ & Route 4 & $\mathrm{FED}=0,175$ & Length $=3327 \mathrm{~m}$ \\
\hline Scenario S-6 & Route 3 & $\mathrm{FED}=0$ & Length $=3282 \mathrm{~m}$ & Route 4 & $\mathrm{FED}=0,168$ & Length $=3327 \mathrm{~m}$ \\
\hline Scenario S-7 & Route 3 & $\mathrm{FED}=0$ & Length $=3282 \mathrm{~m}$ & Route 2 & $\mathrm{FED}=0,439$ & Length $=2082 \mathrm{~m}$ \\
\hline Scenario S-8 & Route 3 & $\mathrm{FED}=0$ & Length $=3282 \mathrm{~m}$ & Route 2 & $\mathrm{FED}=0,432$ & Length $=2082 \mathrm{~m}$ \\
\hline Scenario S-9 & Route 3 & $\mathrm{FED}=0$ & Length $=3282 \mathrm{~m}$ & Route 4 & FED $=0,165$ & Length $=3327 \mathrm{~m}$ \\
\hline Scenario S-10 & Route 3 & $\mathrm{FED}=0$ & Length = $3282 \mathrm{~m}$ & Route 4 & $\mathrm{FED}=0,161$ & Length $=3327 \mathrm{~m}$ \\
\hline Scenario S-10 & Route 3 & $\mathrm{FED}=0$ & Length = $3282 \mathrm{~m}$ & Route 4 & $\mathrm{FED}=0,159$ & Length $=3327 \mathrm{~m}$ \\
\hline Scenario S-11 & Route 3 & $\mathrm{FED}=0$ & Length $=3282 \mathrm{~m}$ & Route 4 & $\mathrm{FED}=0,174$ & Length $=3327 \mathrm{~m}$ \\
\hline Scenario S-12 & Route 3 & $\mathrm{FED}=0$ & Length $=3282 \mathrm{~m}$ & Route 4 & $\mathrm{FED}=0,163$ & Length $=3327 \mathrm{~m}$ \\
\hline Scenario S-13 & Route 3 & $\mathrm{FED}=0$ & Length = $3282 \mathrm{~m}$ & Route 2 & $\mathrm{FED}=0,448$ & Length $=2082 \mathrm{~m}$ \\
\hline Scenario S-14 & Route 3 & $\mathrm{FED}=0$ & Length $=3282 \mathrm{~m}$ & Route 4 & $\mathrm{FED}=0,170$ & Length $=3327 \mathrm{~m}$ \\
\hline Scenario S-15 & Route 3 & $\mathrm{FED}=0$ & Length $=3282 \mathrm{~m}$ & Route 4 & $\mathrm{FED}=0,169$ & Length $=3327 \mathrm{~m}$ \\
\hline Scenario S-16 & Route 3 & $\mathrm{FED}=0$ & Length $=3282 \mathrm{~m}$ & Route 4 & $\mathrm{FED}=0,162$ & Length $=3327 \mathrm{~m}$ \\
\hline Scenario S-17 & Route 3 & $\mathrm{FED}=0$ & Length $=3282 \mathrm{~m}$ & Route 4 & $\mathrm{FED}=0,156$ & Length $=3327 \mathrm{~m}$ \\
\hline Scenario S-18 & Route 3 & $\mathrm{FED}=0$ & Length = $3282 \mathrm{~m}$ & Route 4 & $\mathrm{FED}=0,171$ & Length $=3327 \mathrm{~m}$ \\
\hline Scenario S-19 & Route 3 & $\mathrm{FED}=0$ & Length = $3282 \mathrm{~m}$ & Route 4 & $\mathrm{FED}=0,144$ & Length $=3327 \mathrm{~m}$ \\
\hline Scenario S-19 & Route 3 & $\mathrm{FED}=0$ & Length = $3282 \mathrm{~m}$ & Route 4 & $\mathrm{FED}=0,173$ & Length $=3327 \mathrm{~m}$ \\
\hline
\end{tabular}

Table 11.

Optimal evacuation route for every fire scenario generated by the Monte Carlo simulation model. 
Table 11 Shows every optimal evacuation route for group 1 based on the fire scenarios generated by the Monte Carlo simulation model. As previously mentioned the simulation process in the VentFIRE ${ }^{\mathrm{TM}}$ module is done from the same fire location for each of the generated scenarios.

\section{Conclusion and future aspects}

A methodology for determining optimal evacuation routes in case of underground mine fire has been developed based on the results from simulated fire scenarios. The presented methodology can be consistent with the actual situation of the mine because the development of the fire scenarios is based on the risk analysis generated from the current production plans, and the simulation of the developed scenarios are performed on the ventilation network from the mine.

To address the stochastic nature of the fire scenarios, the methodology implements the Monte Carlo simulation technique to emphasize the fact related to the inability to accurately determine the input parameters for the fire modeling process. From the large list of stochastic input parameters that can have a noticeable effect on the fire scenarios itself, the authors decided to elaborate only on the process of obtaining fire load inputs, from which the size of the fire depends and thus the amount of generated toxic gases. The results of the proposed methodology point to the fact that by treating the stochastic input parameters presented in this chapter in the form of a fire load, the generated conditions influenced the process of determining the optimal evacuation routes.

The Monte Carlo simulation model with the above-defined parameters which follows the normal distribution is implemented on a case study from "SASA"-R.N. Macedonia mine. After the analysis with the proposed methodology, a fire scenario generated by the mechanization Scooptram ST7 is located which represents the total fire load. The stochastic model is set to generate 20 variations from the fire load that are treated as separate scenarios in the process of determining the optimal evacuation routes.

The process of modeling and simulation of the generated fire scenarios is done with the VentFIRE ${ }^{\mathrm{TM}}$ module which uses the ventilation network to calculate the movement of the smoke and toxic gases from which the evacuation process depends.

The fire parameters obtained from the simulated scenarios are used to calculate the optimal evacuation routes for each of the generated scenarios.

The proposed methodology as the main factors influencing the evacuation process treats the inhalation of $\mathrm{CO}$ through the evacuation route presented in the form of FED and COHb, factors in the form of tunnel slope, and smoke visibility that affect the speed of evacuation and also the SCSR.

In the analysis presented in this chapter, differences in optimal routes for evacuation were located only in the conditions of SCSR malfunction. The results presented in Table $\mathbf{1 1}$ highlight the importance of this additional analysis that is possible only by creating multiple variants of one fire scenario which is actually the underlying purpose of the proposed methodology. In the conditions of using the SCSR, the proposed methodology has determined and confirmed route 3 as optimal for evacuation in all variants of the generated fire scenarios. The results obtained from the conditions of SCSR malfunction located the changes in the optimal evacuation between routes 2 and 4 depending on the variable conditions that determined all the fire scenarios. This approach of analyzing fire scenarios offers certainty in the process of confirming the optimal route as well as locating possibilities for its change depending on the variable fire conditions. 
In order to further improve the methodology, we need to expand our research by introducing the other stochastic variables that may have impact on the evacuation process such as the physical status of mineworkers that is related to age, gender, exercise ability, and response ability.

This research provides a convenient methodology for improving the accuracy of determining the optimal evacuation routes which significantly can increase the safety in underground mines.

\section{Acknowledgements}

This work was financially supported by the Faculty of Natural and Technical Sciences-Mining Engineering, "Goce Delchev” University, Shtip, R.N. Macedonia.

\section{Author details}

Vancho Adjiski* and Zoran Despodov

Faculty of Natural and Technical Sciences, Mining Engineering, Goce Delchev University, Shtip, R.N. Macedonia

*Address all correspondence to: vanco.adziski@ugd.edu.mk

\section{IntechOpen}

(C) 2020 The Author(s). Licensee IntechOpen. This chapter is distributed under the terms of the Creative Commons Attribution License (http://creativecommons.org/licenses/ by/3.0), which permits unrestricted use, distribution, and reproduction in any medium, provided the original work is properly cited. (c) BY 


\section{References}

[1] Conti R, Chasko L, Wiehagen W. Fire Response Preparedness for Underground Mines. Pittsburgh, PA: National Institute for Occupational Safety and Health-NIOSH; 2005. pp. 1-19

[2] Hansen R. Design fires in underground mines. In: Studies in Sustainable Technology 2010:02. Västerås: Mälardalen University; 2010. pp. 7-54

[3] Ji J, Zhang J, Chen J, Wu S. Computer simulation of evacuation in underground coal mines. Mining Science and Technology (China). 2010;20(5):677-681. ISSN: 1674-5264. DOI: 10.1016/S1674-5264 (09)60261-1

[4] Chen P, Guo S, Wang Y. Human evacuation affected by smoke movement in mine fires. International Journal of Coal Science \& Technology. 2016;3(1):28-34. DOI: $10.1007 /$ s40789-015-0100-3

[5] Wang L, Wang Y, Cao Q, Li X, Li J, $\mathrm{Wu} \mathrm{X}$. A framework for human error risk analysis of coal mine emergency evacuation in China. Journal of Loss Prevention in the Process Industries. 2014;30(2014):113-123. ISSN: 0950-4230. DOI: 10.1016/j.jlp.2014. 05.007

[6] Wu Q, Xu H, Du Y, Zhang X, Zhao Y. Emergency evacuation simulation system and engineering application for water bursting disaster in mine. Journal of China Coal Society. 2017;42(10):2491-2497

\section{[7] Adjiski V, Mirakovski D,}

Despodov Z, Mijalkovski S. Simulation and optimization of evacuation routes in case of fire in underground mines. Journal of Sustainable Mining. 2015; 14(3):133-143. DOI: 10.1016/j.jsm. 2015.10.001
[8] Adjiski V. Possibilities for simulating the smoke rollback effect in underground mines using CFD software. GeoScience Engineering. 2014;2014(2):8-18. DOI: $10.2478 /$ gse2014-0008

[9] Adjiski V, Despodov Z, Mirakovski D, Mijalkovski S. Fire risk assessment and computer simulation of fire scenario in underground mines. Studies in Engineering and Technology. 2015;2(1):54-60. DOI: 10.11114/set. v2i1.825

[10] Adjiski V, Despodov Z, Serafimovski D. Prototype model for fire safety system in underground mining. American Journal of Mining and Metallurgy. 2017;4(1):62-67. DOI: 10.12691/ajmm-4-1-6

[11] Li X, Hadjisophocleous G, Sun X. Sensitivity and uncertainty analysis of a fire spread model with correlated inputs. Procedia Engineering. 2018; 211 (2018):403-414. DOI: 10.1016/j. proeng.2017.12.029

[12] Guanquan C, Jinhui W. Study on probability distribution of fire scenarios in risk assessment to emergency evacuation. Reliability Engineering and System Safety. 2012;99:24-32. DOI: 10.1016/j.ress.2011.10.014

[13] Kong D, Johansson N, Hees P, Lu S, Lo S. A Monte Carlo analysis of the effect of heat release rate uncertainty on available safe egress time. Journal of Fire Protection Engineering. 2013; 23(1):5-29. DOI: 10.1177/104239151 2452676

[14] Lindström T, Lund D. A Method of Quantifying User Uncertainty in FDS by Using Monte Carlo Analysis.

Report 5309. Sweden: Department of Fire Safety Engineering and Systems Safety, Lund University; 2009. pp. 15-36 
[15] Salem AM. Use of Monte Carlo simulation to assess uncertainties in fire consequence calculation. Ocean Engineering. 2016;117:411-430. DOI: 10.1016/j.oceaneng.2016.03.050

[16] Adjiski V, Zubicek V, Despodov Z. Monte Carlo simulation of uncertain parameters to evaluate the evacuation process in an underground mine fire emergency. The Southern African Institute of Mining and Metallurgy. 2019;119(11):907-917. DOI: 10.17159/ 2411-9717/701/2019

[17] Gillies S, Wu HW. Case studies from simulating mine fires in coal mines and their effects on mine ventilation systems. In: Aziz N, editor. Coal 2004: Coal Operators' Conference, University of Wollongong \& the Australasian Institute of Mining and Metallurgy. 2004. pp. $111-125$

[18] Ventsim Visual ${ }^{\mathrm{TM}}$ User Guide. Ventsim Software by Chasm Consulting. Capalaba, QLD, Australia; 2014

[19] Adjiski V, Mirakovski D, Despodov Z, Mijalkovski S. CFD simulation of the brattice barrier method for approaching underground mine fires. Mining. Science. 2016;23: 161-172. DOI: $10.5277 /$ msc162313

[20] Hansen R, Ingason H. Heat release rate measurements of burning mining vehicles in an underground mine. Fire Safety Journal. 2013;61:12-25. DOI: 10.1016/j.firesaf.2013.08.009

[21] Roh JS, Ryou HS, Kim DH. Critical velocity and burning rate in pool fire during longitudinal ventilation. Tunneling Underground Space Technology. 2007;22(3):262-271

[22] Hansen R. Literature survey-fire and smoke spread in underground mines. In: MdH SiST 2009:2. Västerås: Mälardalens Högskola; 2009. pp. 7-67
[23] Purser DA. Modelling toxic and physical hazard in fire. Fire Safety Science. 1989;2:391-400. DOI: 10.3801/ IAFSS.FSS.2-391

[24] Purser DA. Toxicity assessment of combustion products. In: SFPE

Handbook of Fire Protection

Engineering. 3rd ed. Quincy, MA:

National Fire Protection Association (NFPA); 2002. pp. 2-83

[25] Dirks KN, Sturman A, Johns MD. Using health impacts to assess atmospheric carbon monoxide models. Meteorological Applications. 2006; 13(1):83-87. DOI: $10.1017 /$ S1350482705002057

[26] Chaloulakou A, Fili N, Spyrelis N. Occupational exposure to $\mathrm{CO}$ concentrations in enclosed garages: Estimation of blood COHb levels. In: Environmental Pollution, Proceedings of the 5th International Conference, Thessaloniki, Greece. 2000. pp. 934-940

[27] Coburn RF, Forster RE, Kane PB. Considerations of the physiological variables that determine the blood carboxyhæmoglobin concentrations in man. The Journal of Clinical Investigation. 1965;44:1899-1910. DOI: 10.1172/JCI105296

[28] Adjiski V, Despodov Z, Serafimovski D. System for prediction of carboxyhemoglobin levels as an indicator for on-time installation of selfcontained self-rescuers in case of fire in underground mines. GeoScience Engineering. 2019;65(4):23-37. ISSN: 1802-5420. DOI: $10.35180 / g s e-$ 2019-0021

[29] Ronchi E, Gwynne SMV, Purser DA. The impact of default settings on evacuation model results: A study of visibility conditions vs occupant walking speeds. In: Advanced Research Workshop - Evacuation and Human Behaviour in Emergency SituationsSantander, Spain. 2011. pp. 2-15 
[30] Fridolf K, Nilsson D, Frantzich H, Ronchi E, Arias S. Walking speed in smoke: Representation in life safety verifications. In: 12th International Performance-Based Codes and Fire Safety Design Methods Conference, Oahu, Hawaii. 2018. pp. 1-6

[31] Guangwei Y, Dandan F. Escaperoute planning of underground coal mine based on improved ant algorithm. Mathematical Problems in Engineering. 2013;2013:32-46. DOI: 10.1155/2013/ 687969

[32] Ruixin Z, Rongshan N, Hongze Z, Yanqiang F. Experimental study on the escape velocity of miners during mine fire periods. Mathematical Problems in Engineering. 2018;2018:1-12. DOI: 10.1155/2018/9458785. Article ID: 9458785

[33] Fridolf K, Frantzich H, Ronchi E, Nilsson D. The relationship between obstructed and unobstructed walking speed: Results from an evacuation experiment in a smoke filled tunnel. In: 6th International Symposium on Human Behavior in Fire. Cambridge. 2015. pp. 537-548

[34] Fridolf K, Ronchi E, Nilsson D, Frantzich H. Movement speed and exit choice in smokefilled rail tunnels. Fire Safety Journal. 2013;59:8-21. DOI: 10.1016/j.firesaf.2013.03.007

[35] McAteer D. The Sago Mine Disaster. Buckhannon, West Virginia; 2016. p. 110. Available from: www.wvgov.org 

Section 4

\section{Safety Protocols with Case Studies}





\title{
A Case Study on the Fire Safety in Historic Buildings in Slovakia
}

\author{
Agnes Iringová
}

\begin{abstract}
This chapter deals with the issue of fire safety in historic buildings that undergo functional change, restoration, replacement of construction, facade or installation renovation. It analyzes the current technical state in relation to microclimate and fire safety in historic buildings in Slovakia. It pays attention to the legislative framework for building conservation in the Slovak Republic considering its impact on the reconstruction and restoration of historic buildings. It assesses approaches and methods for fire safety solutions in historic buildings depending on the extent of their modification-intervention in the layout, function and construction. It presents solution procedures and knowledge in terms of application of fire safety requirements in historic buildings using model examples in accordance with the Slovak legislation.
\end{abstract}

Keywords: fire safety, restoration, historic buildings, legislation, model examples

\section{Introduction}

The successful restoration or renovation of a historic building depends on the integration of new operational requirements into the existing premises without the necessity of changing its original structure, layout and appearance. It is important for the building conservation to preserve the building's originality after its renovation and provide better microclimate and safety standard. The extent of the construction changes is connected with the extent of changes to fire safety solution. Restoration of a historic building can be defined as a set of layout and construction modifications implemented into the building structures in such a way that the building's original height and ground plan can be preserved. The construction interventions modify the building's technical parameters such as layout, load-bearing capacity, thermal and acoustic protection and fire safety. The building proceeding in the Slovak Republic related to the above-mentioned changes follows Act No. 50/1976 Coll. on town planning and building code.

Restoration of a historic building can be as follows: (a) an exact restoration, based on the detailed documentation of the building's original condition;

(b) analogous restoration, based on the verifiable similarity or sameness with a better preserved building; and (c) hypothetical restoration, based on a substantiated, scientifically formulated hypothesis (assumption), giving the base for rebuilding a destroyed or disappeared building or its part.

Nowadays, most original historic buildings are not suitable for the occupation; they do not meet either hygiene or static, thermal and fire protection requirements. As for the restoration of a historic building, it is important to pay attention to the 
choice and optimization of building materials and the optimization of the building's functional use in terms of fire safety.

In these cases, the fire safety measures should be the result of a compromise among the fire protection, building conservation, building law and quality requirements for the building's new function. Fire safety in historic buildings is applied using passive and active fire protection of spaces and structures.

\section{Analysis of the current fire safety in historic buildings in Slovakia}

Based on the data from fire and rescue corps from 2013 to 2017, there are 2450 buildings of historic significance in Slovakia. Nowadays, the fire safety in historic buildings of great national and cultural importance (e.g. castles, cathedrals, mansions, etc.) where many rare museum exhibits are located is provided by electric fire signalization (EFS) equipment, fire extinguishers, internal and external fire cocks and firefighting measures applied in the building's operation. These measures are related to the fire training of employees who stay in the building during the operation. Each employee is trained how to eliminate fire in its initial phase, evacuate persons and exhibits and call the firefighters.

As stated in the Act of the Slovak Ministry of Interior No. 199/2009 on fire protection as amended, the building's operator is obliged to work up, keep and maintain the fire documentation according to the current condition and ensure it is respected. Each owner or administrator of a listed building should determine a qualified person who will be responsible for respecting all operational and organizational measures related to fire safety in a building and will keep and update the fire documentation. Trained persons provide and take regular prophylactic fire inspections of firefighting equipment.

Fire brigades regularly carry out training exercises in significant listed buildings to check their firefighting skills, means and methods and the accessibility of fire equipment in buildings. Despite the above measures, the real fire protection in most historic buildings in Slovakia is weak, and fire alarm systems are not located in all buildings. As Fire and Rescue Service Report 2018 states, there were 40 fires in such heritage buildings in the last 10 years. The most common cause was negligence, technical failure or deliberateness combined with the fire risk at the time of the building's operation.

Analysis of fire safety in listed buildings is primarily focused on firefighting equipment in terms of its location, availability and functionality as well as on staff readiness to use it effectively [1]. The most common deficiencies found during the fire inspections or in analyses of fire causes in such buildings are as follows:

- Missing or non-functional electrical fire alarm

- Non-functional hand fire extinguishers or their bad location in terms of accessibility at the time of fire

- Missing, capacity-insufficient or unmaintained fire hydrants

- Access roads badly rideable for the fire brigade due to insufficient road width and reinforcement or badly designed crossroads

- Employees inadequately trained for firefighting and missing fire documentation determining evacuation plans for employees, visitors or exhibits 
- Insufficient maintenance of public spaces in terms of fire spread, location and storage of flammable materials in the immediate vicinity of the building

- Improper handling with the heat or ignition source, that is heaters, welding kits and handling with an open fire, where smoking is prohibited, etc.

- Technical defects in electrical installations or other equipment

- Incendiarism, vandalism

It is not always possible to prevent fire in a building despite the implementation of fire-protective and operational measures, especially in unforeseeable natural disasters. In general, if fire safety measures are kept at all levels of protection, it is supposed that the building does not collide with fire. If fire safety measures are missing, neglected or non-functional at the time of fire, it often causes big artistic and architectural losses.

Here is the example of fire in the castle of Krásna Hôrka from 2012. The fire progress is shown in Figure 1b. Fire was caused by children who carelessly handled free flame near the castle hill. They threw a burning object into dry grass that ignited. As there was strong wind, fire spread rapidly onto the combustible castle roofs covered by wooden shingles (see Figure 1a). The castle consists of three buildings. The original upper castle dates from the fourteenth century; the middle and lower castles were built later by the original owners. The castle housed a permanent display of period works of art giving basic information on the castle and its original owners. There were original exhibits with a high museum value. The original roof structure consisted of timber trusses covered with wooden shingles and took the area of about $5000 \mathrm{~m}^{2}$. The lower and middle castle has vaulted ceilings; the upper castle has steel-bearing ceiling structure with a wooden flap. The castle has stone and brick external walls.

Fire safety in the castle before fire included passive fire protection, roof space had no accidental fire load, and timber truss members were treated with fire coating

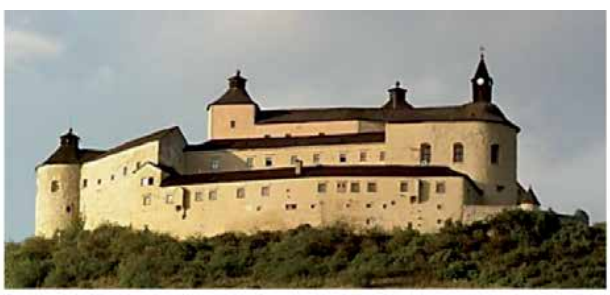

a

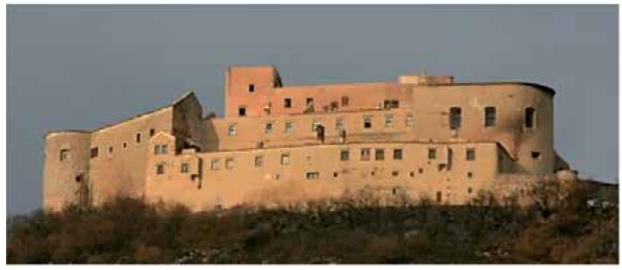

c

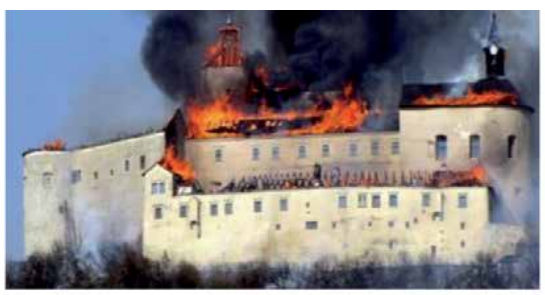

b

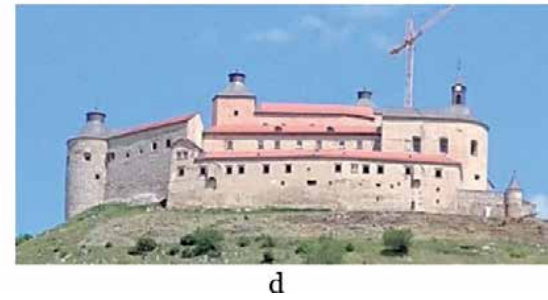

Figure 1.

The castle of Krásna Hôrka before fire, during fire, after fire and at the present time. (a) Original castle timber roofs before fire in 2012; (b) fire in the castle in 2012; (c) the castle after fire in 2012; $(d)$ the castle at the present time. 
in 2000, and active fire protection-electric fire signalization-is installed in the roof space [2].

The Gothic tower contained a water reservoir of about $66 \mathrm{~m}^{3}$; the upper castle contained fire-water hose systems and wall hydrants. Powder fire extinguishers were installed in all spaces. Although the castle was protected at the time of fire by both passive and active fire protection, its protection was not sufficient considering the outside source of fire, climatic conditions and burning rate of dried roof timber.

The fire lasted for about 3 days in terms of the quantity of timber structures and unfavorable natural conditions-strong wind. The roofs burned down (see Figure 1c). The firefighting was slowed down due to the road that was badly accessible for the fire brigade - there is only one access road leading to the castle. The water source was far from the burning area, and it was not possible to use the water reservoir in the castle.

The fire affected mainly the Gothic castle that was restored in 1982. The part of the ceiling fell down; some exhibits such as swords and other historical weapons were destroyed. The interior exhibits in the lower and middle castle and the Francis Museum survived without harm. Overall, $90 \%$ of all historic exhibits were saved. The castle building suffered fire damage especially on its construction, and the total damage was estimated at approx. 8.05 million $€$.

Nowadays, the castle's restoration is coming to an end. All roofs, including loadbearing and truss structures, were built as replicas of the original structures, taking into account the forms they had at the time of the last major castle's style alternation after fire in 1817 (1818). The original wooden shingle roof is replaced by burnt ceramic roofing, and the bastions have metal roofing (see Figure 1d). In this case, fire was caused by negligence and climatic conditions.

\section{Past and contemporary legislative regulations for fire safety solutions in historic buildings in Slovakia}

\subsection{Legislative regulations in the past}

No legislative standards were applied to the construction of buildings in terms of fire protection in the Middle Ages. The fire protection criteria in buildings with timber load-bearing structures were set out in the regulation issued probably by William I. Conqueror (1028-1087). All fireplaces in buildings were required to be put out at night and in the absence of persons. Furthermore, this regulation was supplemented by the requirement to cover the fireplace to prevent air access to the hot ash [3]. It is known from history that after the fire outbreak in the settlement, the consequences were global and fatal for inhabitants due to the combustible roofs and limited possibilities of firefighting at the time. For this reason, the past legislation focused on the fire protection in buildings due to the high risk of easy and rapid fire spreading from building to building.

The oldest legislation valid in our territory for the royal free cities, as well as the towns and villages of higher importance with an authorized municipal office that deserved to be added to the royal free cities, was "Fire Regulations for the Kingdom of Hungary" issued in Presburg in 1788. This regulation was divided into four chapters:

1. How to prevent the occurrence of fire-related to the rules for construction of chimneys and internal fireplaces

2. How to detect fire early if it occurs_-signals generated by bells 
3. How to extinguish fire as quickly as possible-each settlement was obliged to have a public water reservoir, pond, lime trees planted on four sides of neighboring farm houses, etc.

\section{How to prevent harmful consequences that may occur after fire}

Growth in the manufacturing sector in the late nineteenth century brings the use of technique for firefighting. Fire protection starts to be provided by professional fire brigades. Non-combustible building materials-reinforced concrete, burnt ceramic blocks, etc.-are used for the construction of buildings that have natural protection against fire spreading within the building as well as from one building to another. The timber load-bearing elements of ceilings were protected by plasters and embankments made of non-combustible materials. Wooden shingles, straw and reed on the roofs were replaced by ceramic roofing. The timber trusses were separated from chimneys and treated with fire-resistant coatings to reduce their flammability. There was no fire risk in the roof spaces with trusses; they were separated from vertical shafts.

\subsection{Contemporary legislative regulations for fire safety solutions in historic buildings in Slovakia}

The obligatory regulation for fire protection currently valid in Slovakia is Act No. 314/2001 as amended and implementary regulation issued by the Slovak Ministry of the Interior No. 121/2002 Coll. on fire prevention, as amended. The implementary regulation No. 94/2004 as amended specifies requirements for the project solution. The restoration of historic buildings takes into account mainly all society's requirements for the preservation of their original appearance and material solutions considering adequate fire safety. Legislation valid for the restoration of historic buildings in Slovakia is Act No. 49/2002 on the heritage protection as amended, issued by the Slovak National Council and followed by the implementary regulations. Details on the performance of monument research are specified in the implementary regulation No. 253/2010 Coll. issued by the Slovak Ministry of Culture. It determines, based on monumental survey, the conditions for methods and extent that can be used in the remediation of existing historic buildings. Survey conclusions are one of the bases for the design and extent of construction work as well as the choice of materials used in the renovation. The requirements and conditions for the restoration of historic buildings in terms of fire safety are limited due to the specific conditions. The restoration and renovation of buildings in Slovakia follows the criteria specified in Slovak Standard STN 730834 on construction changes.

In terms of fire safety, the building's alternation is the only alternation resulting in a higher fire risk, number of persons, replacement of load-bearing structures and installations within the affected spaces. The extent of fire safety measures is determined by the extent of changes in the building's construction or operation [4]. The alternations of buildings can be divided into three categories:

The first category includes alternations without the functional change resulting in the higher fire risk. There are only minor repairs to the original structures done without changing their reaction to fire and modernization of installation systems in buildings.

The second category includes alternations to the functional use of the building's part or the entire building that will change the fire risk, fire resistance requirements for the fire-separating structures, number of people and related evacuation plan. Such alternations to the buildings are related to the fire compartmentation, fire 
protection, changes in ventilation system, fire separation of evacuation routes and requirements for the installation of firefighting equipment.

The third category includes restorations of buildings, changing the use, useful area and fire height. This is related to the buildings where more than $50 \%$ of the total floor area in the fire section changed is found in the building's extension or superstructure [1]. In such cases, the fire safety measures are required to be done completely as in the new buildings, and their assessment is also in accordance with the legislation applicable to the new buildings.

The building's functional change often brings the exchange of a building's owner or manager whose criteria for the heat-moisture regime in the indoor environment are higher. As a result of this change, there is a requirement to increase building's thermal protection if the building conservationists give the permit. Thermal protection in historic buildings is done at least to eliminate microclimate deficiencies, optimally considering the building's energy efficiency and sustainability in terms of its environmental impact [5].

If listed buildings are restored, the fire safety solution must contain an expert opinion analyzing the specific building's conditions and determining requirements for its fire safety depending on the boundary conditions such as functional use, design, layout in the vertical direction, occupancy, number and quality of emergency routes, availability of access roads and firefighting water. The fire safety solution should take into account at least the following requirements: the operations with the high fire load and fire factor higher than 1.1, except theaters, exhibition halls, museums and areas for visitors, cannot be situated in the listed buildings whose original function of spaces is modified.

The fire alarm systems are required to be installed in the unique historic spaces, e.g. spaces containing murals, unique historic collections, unique structures or elements made of flammable materials.

The fire safety reassessment is required to be done if alternations to historic buildings result in their restoration or renewal.

\section{Theoretical analysis of physical, design and layout determinants affecting the restoration of historic buildings in terms of fire safety}

Historic buildings were usually constructed using a combination of combustible and non-combustible materials. The most used building material was wood-in roof structures, ceilings and stairs. It was used in the past as a single building material to construct buildings of folk architecture in Slovakia. Historic buildings usually contain composite construction systems. The cellars and basements had stone or masonry walls, and ceilings had ceramic vaults. The above-ground floors had peripheral walls that were built using a combination of non-combustible masonry made of burnt and non-burnt bricks or stone and combustible wood-beamed ceilings. The ceilings were either visible or covered with plaster usually applied to the reed mats. Roof load-bearing structures contained roof trusses with wooden purlins statically independent on the last floor ceiling. Depending on the building's ground plan dimensions, the purlin or collar systems were mostly used for small spans in folk architecture; a combination of standing saddles and hanging trusses or strut frames was used for larger spans, e.g. mansions, castles or churches.

The roof space was usually naturally ventilated and had no functional use. The attic was accessible via wooden or stone single or spiral stairs due to the repairs and maintenance. The wooden ceilings and trusses as well as the dimensions of their members were based primarily on the spans they covered and empirical and technical possibilities of the builders at the time of construction. Due to the 
technical possibilities of the joints affecting the load-bearing capacity of the purlin system, the wooden members were dimensioned with a significant static reserve. The wooden members were usually joined by mortising or lapping, and their fire resistance was achieved by partial walling [6].

The fire safety degree is determined on the basis of fire load density with dependence on the ventilation parameter, fire risk, building's fire height and combustibility of used building elements according to Table 8 STN 730802/10. The degree of fire safety in building structures (DFSB) value is the basis for determining fire safety requirements of load-bearing and fire-separating structures given in Table 12 STN 730802/10. These requirements are compared to the current fire resistance of the existing structures.

The fire resistance of the original structures can be taken from the table in STN 730821 or calculated according to Eurocodes depending on their static stress.

\subsection{Fire resistance of load-bearing and fire-separating structures}

Fire resistance is the ability of building structures to withstand the effect of fire. It is defined by the time during which the structures can be exposed to fire without damaging their function. The fire structures can be divided into loadbearing and non-load-bearing, in terms of their function, and fire-separating or interior load-bearing, in terms of their location in a fire compartment. If the fire-separating structure is load-bearing and located at the frontier between fire compartments, it must meet the criteria of load-bearing capacity (R), integrity (E) and thermal insulation (I) at the time of fire. If the load-bearing structure within the fire compartment is a post, it must meet the $\mathrm{R}$ criterion at the required time. The stability of fire structures along the building's height must not depend on the stability of structures with lower fire resistance on lower floors. The fire resistance of fire-separating structures is determined by a test or calculation. The design and assessment of fire resistance of building structures follow a set of standardsEurocodes EN 1991-1-2, EN 1992-1-2, EN 1993-1-2, EN 1994-1-2, EN 1995-1-2, EN 1996-1-2 and EN 1999-1-2.

The fire resistance of building structures is calculated using the design procedure in terms of the requirement for the result accuracy and specific boundary conditions of a fire compartment. First, thermal analysis of a fire compartment is done, then the heat transfer into the structure and temperature development within the structure is determined, and finally the fire-separating structure is analyzed. Detailed analyses of the temperature in a fire compartment are determined by dynamic simulations and end-element methods. Simpler procedures are used to determine the temperature in a fire compartment by parametric temperature curves or nominal temperature curves. The resulting fire resistance determined according to the nominal standard curves is the standard fire resistance (Figure 2).

The heat transfer within the structure for detailed solutions is determined by the end-element method; for less detailed solutions, it is determined by incremental or direct methods. Direct methods used for heat transfer are conservative and valid only to a limited extent and can be used to assess only particular elements of a fire-separating structure. The calculation is based on room temperature [7-9]. Fire resistance verification of a fire-separating structure can be done by the three following views:

Time-clearly expresses the reliability reserves of the structural element:

$$
t_{f i, d} \geq t_{f i, r e q u}
$$

where $t_{f i, d}$ is the design time of fire resistance and $t_{f i, r e q u}$ is the required time of fire resistance. 


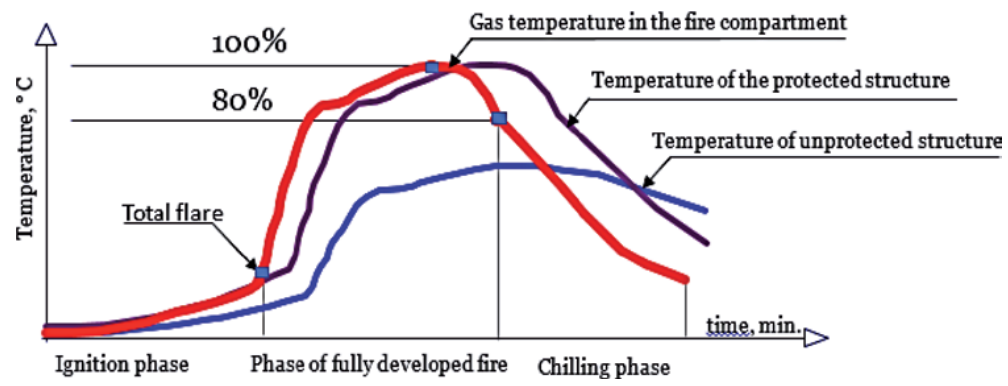

Figure 2.

Surface temperature on fire-separating structures without surface fire protection and with fire-protective lining during standard fire [10].

Load-bearing capacity - the easiest in terms of calculation because the method is similar to the assessment at the room temperature:

$$
\mathrm{R}_{\mathrm{fi}, \mathrm{d}, \mathrm{t}} \geq \mathrm{E}_{\mathrm{fi}, \mathrm{d}, \mathrm{t}}
$$

$\mathrm{R}_{\mathrm{fi}, \mathrm{d}, \mathrm{t}}$ is the design value of load-bearing capacity of a member in fire during the time $t$ and $E_{f i, d, t}$ is the design value of fire load effects during the time $t$.

Temperature:

$$
\theta_{\mathrm{d}} \geq \theta_{\mathrm{cr}, \mathrm{d}}
$$

where $\theta_{\mathrm{d}}$ is the design value of material temperature and $\theta_{\mathrm{cr}, \mathrm{d}}$ is the design value of critical material temperature.

Simplified assessment of structural elements in terms of their fire resistance is given in tables in STN 730821: 1973, which is currently valid for the assessment of building structures during construction changes. The fire resistance values of building structures are given in particular tables considering building materials and static load of the structures-walls, columns and ceilings [11].

\subsection{Fire resistance assessment of existing fire-separating structures in a model solution}

The following model example shows a fire safety solution used in the restoration of a folk house situated in the village of Vel'ké Leváre. The folk house is dated to the Hutterian culture period. It was restored with the intention of preserving its original layout including the original constructions and elements. The building has a combined structural system - the brick external walls, wooden beam ceiling and collar beam truss. It was necessary to optimize the boundary conditions of the given solution so that the consequences of a functional change regarding the current constructions could be minimal. The museum display showing the original culture was situated in the restored space after the original supporting elements, roof covering and original wall and floor surfaces had been replaced or repaired. The external wall is combined stone with bricks. There are wooden ceilings with visible beams supported by a wooden beam. This beam is embedded into the perimeter walls, and its center is supported by a column. The wooden truss has a two-level collar beam.

The building's functional use was changed in terms of fire safety-it became a museum, that is its original residential function was changed into an exhibition one. The fire load increased but only on the first floor. The required value of the 
fire safety degree was not changed compared to the original one. The attic spaces used as living rooms serve today only to show the original truss construction. Considering the fire height of $0 \mathrm{~m}$ and the combined building's construction, the required fire safety degree is $\mathrm{I}$, that is the same as in the original functional use.

The fire resistance requirement for the original load-bearing and fire-separating structures was not changed after the functional change of the restored spaces. The fire resistance requirement for the load-bearing ceiling members and perimeter wall is given according to STN 73082 and is dependent on the average fire load, that is the sum of the accidental and permanent fire load, coefficients of ventilation, flammability factor and use and type of firefighting equipment. In terms of the calculated fire load pv $=66 \mathrm{~kg} / \mathrm{m}^{2}$, the fire resistance requirement for the fire-separated structures is REI 30 (building envelope and roof), and the fire resistance requirement for loadbearing structures of a non-compact ceiling in an assessed fire compartment is R 30 .

\subsection{Fire resistance of the external wall in a model solution}

The external wall is made of stone and brick and has a variable thickness of $530-630 \mathrm{~mm}$. The required fire resistance for this model solution is REI $30 \mathrm{~min}$.

In accordance with the values given in Table 1A STN 730821, the real fire resistance of the perimeter wall is well above the required value (Table 1).

As the dimensions of the assessed wooden ceiling members and column in a model solution are different from the members given in the standard, their real fire resistance is calculated according to EN 1996-1-2: 2004 Eurocode 6: Design of masonry structures, Section 1.2 general rules-fire resistance design of masonry structures.

In specific cases, the fire resistance of fire-separating structures can be determined by a calculation according to EN 1996-1-2: 2004 Eurocode 6: Design of masonry structures, Section 1.2 general rules-fire resistance design of masonry structures.

\subsection{Fire resistance of the wooden ceiling in a model solution}

There is a wooden beamed ceiling above the ground plan in the model example. The ceiling material and structure are visible (see Figure 3 ).

The ceiling beams are supported by a wooden beam. The wooden beam is fastened on the load-bearing peripheral walls and supported by a wooden column (see Figure 4).

The real fire resistance for load-bearing and fire-separating structures was calculated according to the methodology given in STN EN 1991-1-2: 2004; the

\begin{tabular}{lc}
\hline Type of a structural member & Thickness [mm] \\
$\begin{array}{l}\text { Fire } \\
\text { resistance } \\
\text { REI }\end{array}$ & 240 \\
\hline $\begin{array}{l}\text { Masonry walls made of solid bricks perforated up to 15\% of the } \\
\text { volume, built on mortar of 4-CSN 2430 class, loaded and non-loaded } \\
\text { with double-sided plaster }\end{array}$ & 180 \\
\hline $\begin{array}{l}\text { Wooden beams loaded in bending, unprotected from three sides } \\
\text { Unprotected wooden columns loaded in buckling at } \lambda=75, \text { see CSN } \\
731701\end{array}$ & $200 / 200$ \\
\hline
\end{tabular}

Table 1.

Fire resistance of the fire-separating structures according to STN 730821 [12]. 
fire resistance of wooden members was calculated according to STN EN 1995-1-2 (Eurocode 5) depending on their mechanical stress [13, 14].

The real fire resistance for load-bearing and fire-separating structures is primarily dependent on their mechanical load during fire and fire load density caused by building's operation. Determination of fire resistance for structures in a fire compartment depends on the typical fire load density per unit of floor area (qf, d), burning rate coefficient, fire risk coefficients and fire protection coefficients. Estimated fire duration in the assessed fire compartment is determined after considering the influence of structures, ventilation and active firefighting equipment.

The fire resistance of wooden members affected by fire (wooden beam ceiling, column and girder) was specified using the effective cross-section method [15]. The methodology is based on the assumption that the first phase of burning wooden elements causes the surface burning and forms a carbonized layer. Such element becomes partially thermo-insulated by further thermal stress, which prolongs its fire resistance. The charring thickness is determined by the fire duration to which the element is exposed and by the charring rate. This interface or the location of the carbonized line in most coniferous and deciduous trees corresponds to the isothermal position of $300^{\circ} \mathrm{C}$. After obtaining an effective cross-section, the element is assessed according to [16]. The method of reduced properties works with the residual cross-section (obtained after reading the carbonized layer) taking into account the changed strength and stiffness material properties based on the modified coefficient. In light of this assessment, all wooden load-bearing members in the assessed fire section of the museum met the required fire resistance without additional structural modifications.

The assessment of ceiling supporting members in terms of static load at a room temperature is given in Table 2. Table 3 gives the assessment of supporting ceiling members in terms of static and fire load during a standard fire [17].

For material characteristics the following are considered: $\mathrm{k}_{\mathrm{fi}}$, coefficient of solid timber, $\mathrm{k}_{\mathrm{fi}}=1.25 ; \mathrm{k}_{\mathrm{mod}, \mathrm{fi}}$, modification factor for fire, $\mathrm{k}_{\mathrm{mod}, \mathrm{fi}}=1.0$; and $\gamma_{\mathrm{M}, \mathrm{fi}}$, partial factor for timber in fire, $\gamma_{\mathrm{M}, \mathrm{fi}}=1.0$. For the calculation of charring depth, the following are considered: $\beta_{\mathrm{n}}$, notional design charring rate under standard fire exposure, $\beta_{\mathrm{n}}=0.8 \mathrm{~mm} / \mathrm{min}$ (for solid timber); $\mathrm{k}_{0}$, coefficient for non-protected
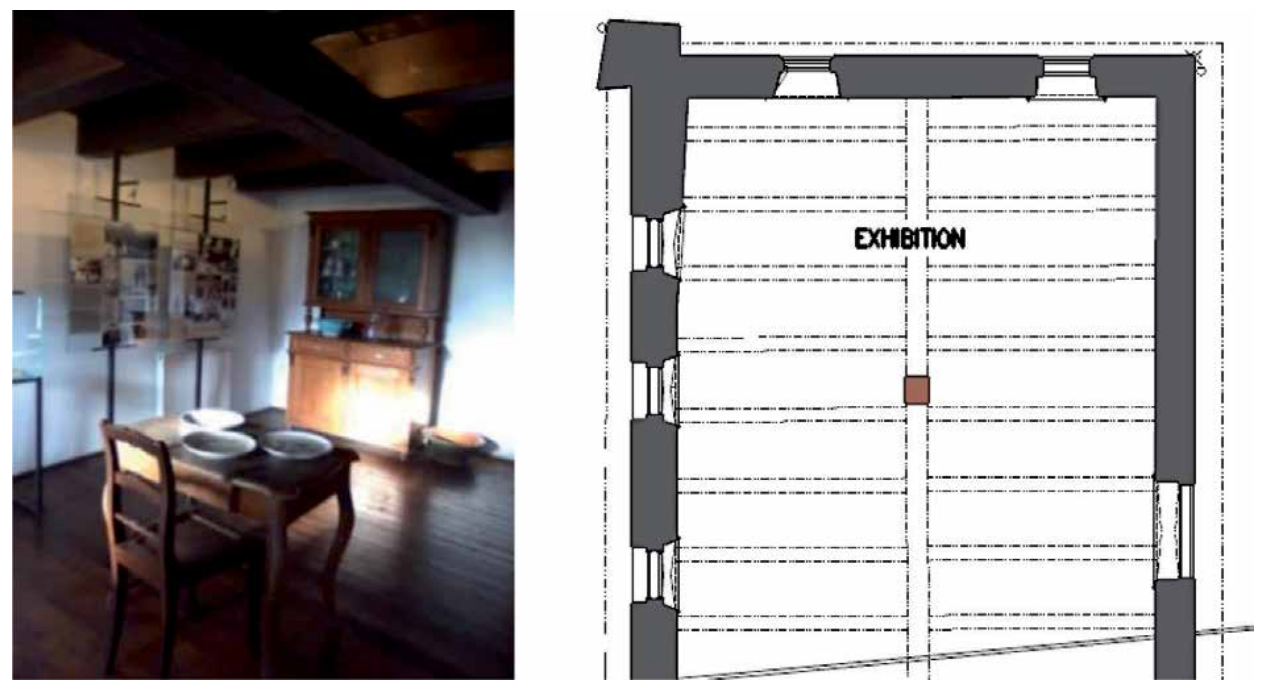

Figure 3.

Layout and visible ceiling in a model solution (left) and ground plan with assessed wooden truss (right). 

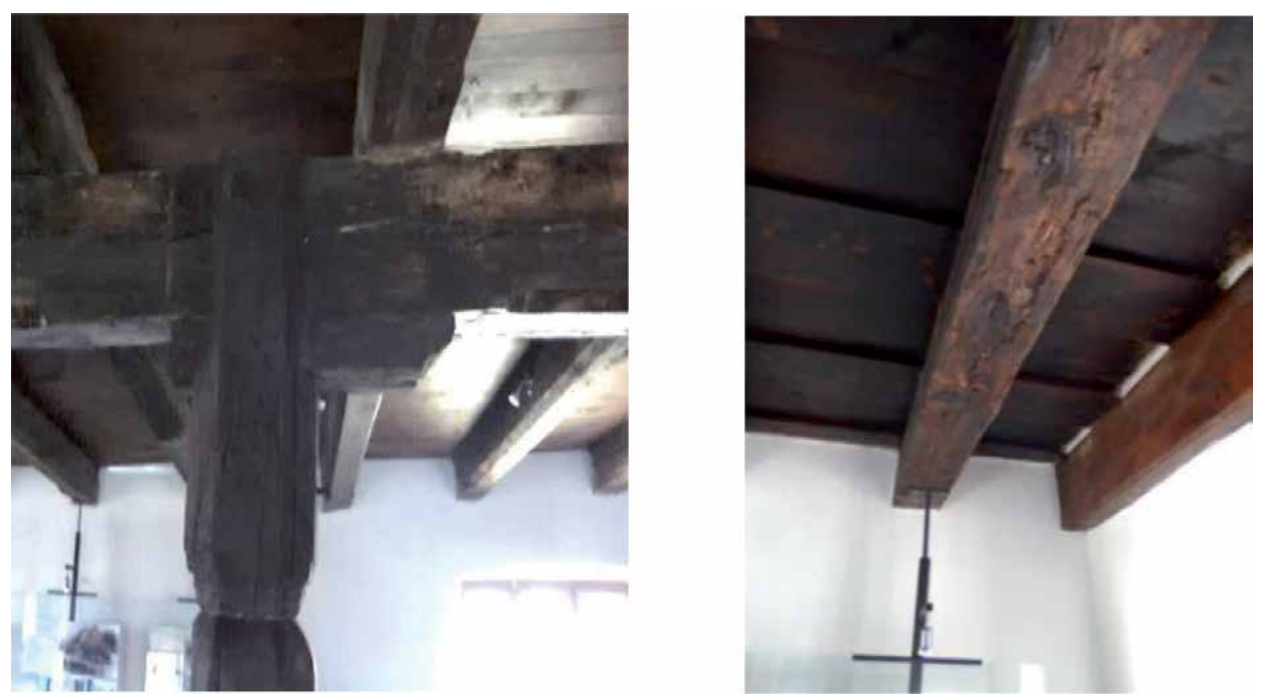

Figure 4.

Supporting using a wooden beam and column (left) and ceiling wooden beam with a wooden decking (right).

\begin{tabular}{cccccccc}
\hline No & Member & $\mathbf{b}[\mathbf{m m}]$ & $\mathbf{h}[\mathbf{m m}]$ & $\begin{array}{c}\mathbf{M}_{\mathrm{y}, \mathrm{Ed}} \\
{[\mathbf{k N m}]}\end{array}$ & $\begin{array}{c}\mathbf{M}_{\mathbf{z}, \mathrm{Ed}} \\
{[\mathbf{k N m}]}\end{array}$ & $\begin{array}{c}\mathbf{N}_{\mathrm{Ed}} \mathbf{1} \\
{[\mathbf{k N}]}\end{array}$ & $\begin{array}{c}\boldsymbol{\eta f i} \\
{[-]}\end{array}$ \\
\hline 1 & Ceiling beam & 200 & 250 & 6.35 & 0.63 & 0.53 & 0.6 \\
\hline 2 & Roof girder & 300 & 270 & 14.64 & -0.16 & 15.8 & 0.6 \\
\hline 3 & Column & \multicolumn{2}{c}{$\mathrm{d}=230^{2}$} & 0.11 & 1.30 & 55.50 & 0.6 \\
\hline
\end{tabular}

where: $\eta f i$-reducing factor for combined load. As simplification it is possible to use the value 0.6 (according to STN EN 1995-1-2).

${ }^{1}$ Positive sign (+) means tensile force; negative sign (-) means compression force.

${ }^{2}$ The average column diameter at its narrowest spot.

Table 2.

Parameters of static load of wooden ceiling supporting members at the room temperature.

surfaces, $\mathrm{k}_{0}=1.0$; and $\mathrm{d}_{0}$, layer thickness with assumed zero strength and stiffness, $\mathrm{d}_{0}=7 \mathrm{~mm}$.

The structures assessed in terms of table values given in STN 730821 (see

Tables 3 and 5) as well as values determined by a calculation in dependence on the current boundary conditions - static load and material characteristics of woodmeet the required fire resistance value [16].

\section{Solution methods}

If the restoration of listed buildings is designed, its preparatory phase analyzes the current fire risk in the building. The fire risk analysis examines the current fire risk and the extent of fire-technical and organizational measures [5].

\subsection{Analysis of fire risk}

The fire risk assessment can be divided into four phases:

Analysis of the current building solution in terms of fire safety-includes assessment of current or planned layouts, flammability of structures and materials, number of 


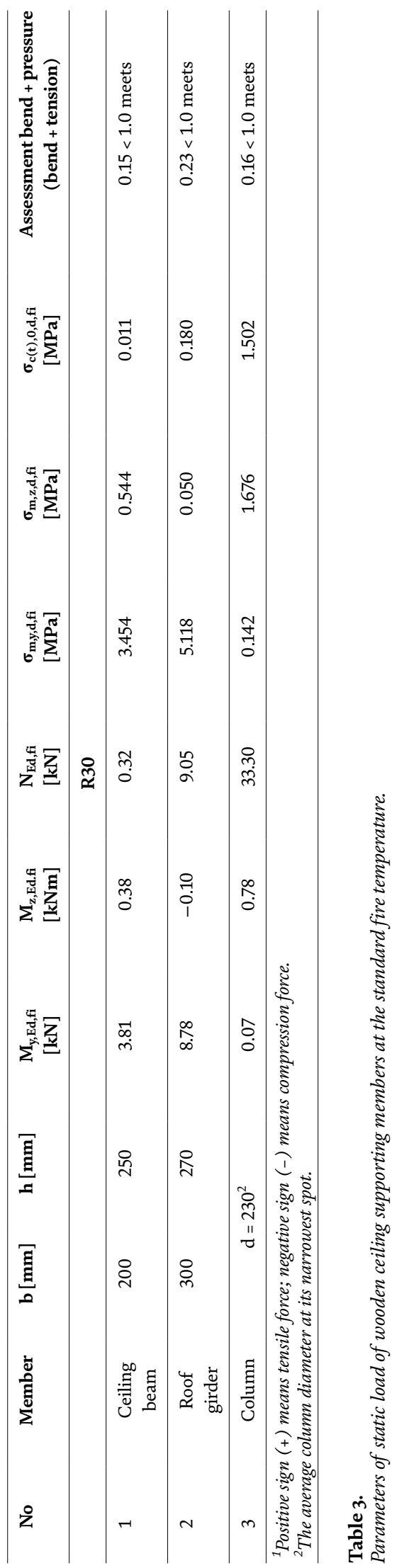


A Case Study on the Fire Safety in Historic Buildings in Slovakia

DOI: http://dx.doi.org/10.5772/intechopen.91241

\begin{tabular}{|c|c|c|c|c|c|c|}
\hline \multicolumn{5}{|c|}{ Densities in mega-joules per square meter } & \multirow{3}{*}{$\begin{array}{c}\text { Pn conversion } \\
\text { from } E K(16,75) \\
80 \% \text { fractile }\end{array}$} & \multirow{3}{*}{$\begin{array}{c}\text { Pn value from } \\
\text { Table A1 in STN } \\
730802\end{array}$} \\
\hline \multirow[t]{2}{*}{ Occupancy } & \multirow{2}{*}{$\begin{array}{c}\text { Mean } \\
\left(\mathrm{MJ} / \mathrm{m}^{2}\right)\end{array}$} & \multicolumn{3}{|c|}{ Percent fractile ${ }^{*}$} & & \\
\hline & & 80 & 90 & 95 & & \\
\hline Dwellings & 780 & 870 & 920 & 970 & 52 & 40 \\
\hline Hospitals & 230 & 350 & 440 & 520 & 21 & 20 \\
\hline Hotel rooms & 310 & 400 & 460 & 510 & 24 & 30 \\
\hline Offices & 420 & 570 & 670 & 760 & 34 & 40 \\
\hline Shops & 600 & 900 & 1100 & 1300 & 54 & 90 \\
\hline Museums & 300 & 470 & 590 & 720 & 28 & 60 \\
\hline Libraries & 1500 & 2250 & 2550 & --- & 134 & 120 \\
\hline Schools & 285 & 360 & 410 & 450 & 22 & 25 \\
\hline \multicolumn{7}{|c|}{$\begin{array}{l}\text { Conversion factors: } 1 \mathrm{MJ} \approx 0.948 \mathrm{BTU}, 1 \mathrm{~m}^{2} \approx 10.8 \mathrm{ft}^{2} \text {. } \\
\text { The percent fractile is the value that is not exceeded in that percent of the rooms or occupancies. }\end{array}$} \\
\hline
\end{tabular}

Table 4.

Comparison of the fire load density values in different occupancies according to the data given in EN 1991-1-2 and Table A1 STN 730802.

staircases and their location in relation to the center of gravity of evacuated persons, ventilation of staircases and disposition possibilities of their fire separation, evacuate conditions for person and historic articles depending on the building's functional use in fire as well as the accessibility and safety of staircases for firefighters. It also assesses the possibilities of fire spreading in the building's open spaces, e.g. central representative staircases, open galleries, internal atriums, unsealed crawl spaces in ceilings, etc. The analysis determines the construction and division of the building into smaller units-fire compartments, location of fire doors and the way of their closing and risk of fire spreading to adjacent buildings.

Analysis of the current operational solution in terms of fire prevention-includes an assessment of the building's functional use considering the accidental fire load with regard to the fire resistance of the existing load-bearing structures and the number of persons in terms of the capacity of existing evacuation routes. It also contains assessment of internal organizational measures that should minimize the causes of fire such as regular inspections of electrical installations and appliances, technical equipment, chimneys, etc.

Analysis of the current fire detection system-includes an assessment of the function and location of the automatic fire detection system. If there is no such system installed in the building (this is the common situation in historic buildings in Slovakia), it is necessary to verify the organizational measures ensuring fire detection, that is to ask authorized employees to be helpful and use their senses. This includes regular inspections in the building by its guard. If there is no guard in the smaller buildings, the inspection is done by authorized employees at the end of working hours.

Analysis of the fire equipment availability in case of fire-finds out the location of portable fire extinguishers, their capacity and extinguishing agent. It analyzes the availability of internal firefighting water and wall fire hydrants as well as their position and functionality. It also verifies the location, capacity and functionality of external firefighting water sources, that is external hydrants, water tanks and natural water sources that can be used by fire brigades. It analyzes organizational measures related to fire extinguishing such as staff training, firefighting documentation, identification of emergency routes and access roads. After determining the 


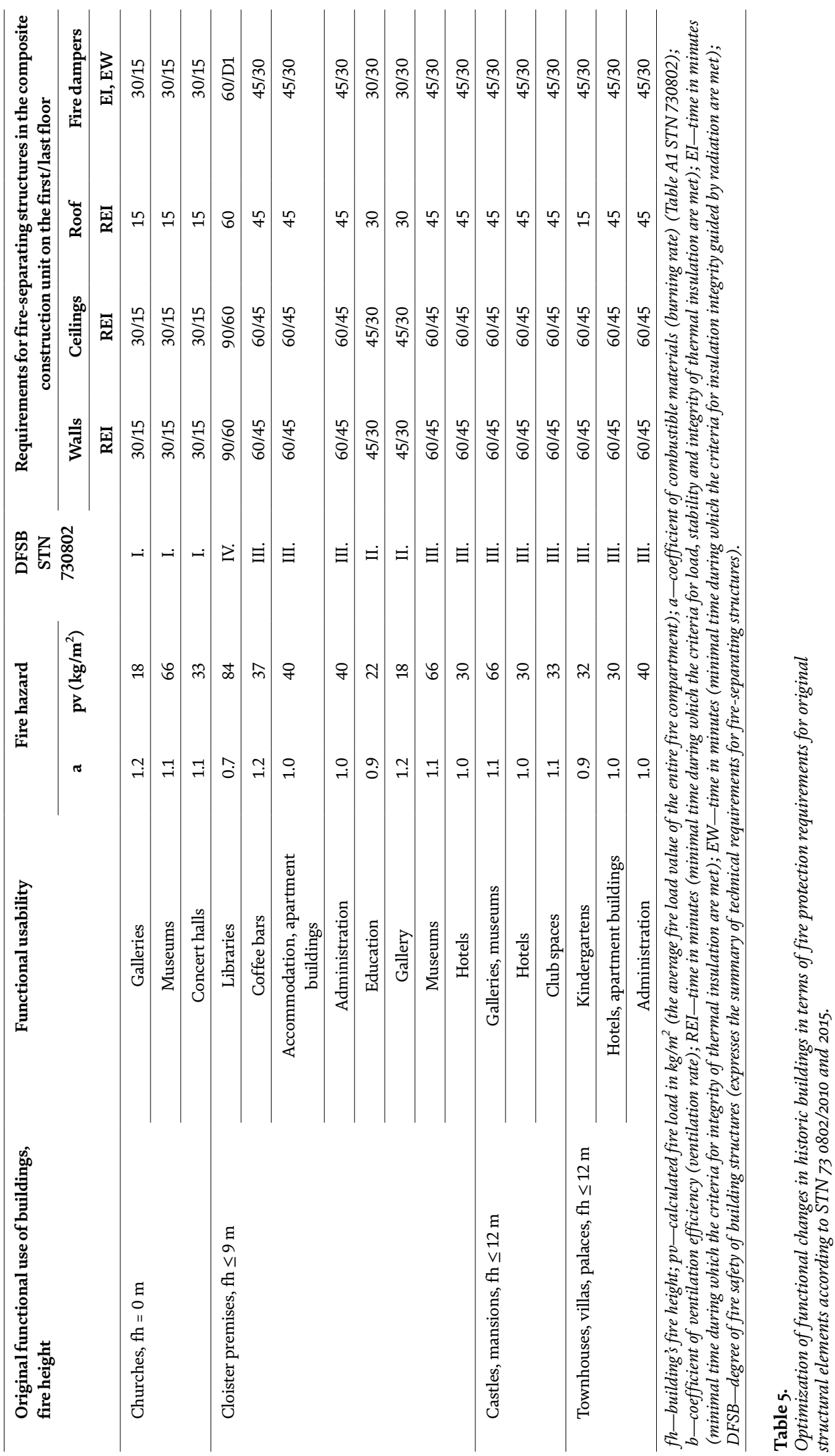


current fire safety measures in the building, the restoration or functional change is optimized in such a way that the planned alternation would not reduce the current building's fire safety.

\subsection{Fire safety design}

The fire safety in buildings is generally a combination of passive and active measures ensuring the following points for each fire section during the fire:

- Retain the carrying capacity and stability of load-bearing structures and firefighting partitions at the required time.

- Reduce the development and spread of fire and smoke within the building.

- Reduce the spread of fire toward the surrounding buildings through windows, roofs and burning other structures.

- Enable safe evacuation of persons from the building.

- Enable effective and safe intervention of fire brigades.

The building solution for a historic building whose original function is planned to be changed contains mostly:

- Fire compartmentation of the building excluding concentrated fire load and reducing the open layouts going through more floors

- Detection of the fire risk resulting from the building's operation

- Fire resistance assessment of existing fire separation structures considering the fire risk, fire height and combustibility of load-bearing and fire separation structures including the possible solution for their additional fire protection

- Construction of protected emergency routes if it is possible; if not, it is necessary to reduce the building's occupancy

- Ensuring the accessibility of sufficient source of firefighting water and hand fire extinguishers

- Construction of the safe intervention routes including access roads and boarding areas

If there are some barriers on the access roads to the building such as castle hills or impassable entrance gates, it is necessary to determine a set of construction and fire-technical measures using active elements of fire protection, e.g. stationary fire extinguishing equipment.

\subsection{Fire compartmentation}

If it is possible in terms of building's operation, it should always be divided into several smaller fire compartments to minimize fire damage and increase the occupants' safety during evacuation and fire intervention. If there are no complications 
during the fire intervention and the fire brigade arrive in the first phase of fire, then there is minor material damage found usually in the fire-affected part of the building.

The separate fire compartments always include emergency routes, gathering areas, rooms with a high fire load, warehouses and technical rooms.

The fire separation of an existing staircase from adjacent spaces with vertical fire load divides the building into more floors that are simultaneously fire compartments. They reduce the spread of thermal radiation and smoke within the building and relatively safe evacuation [18]. The staircases are separate fire compartments without fire risk; their layout, ventilation and air exchange frequency depend on the time required for evacuation of persons.

The separate fire compartments should be all spaces with installations-airconditioning engine rooms, boiler rooms, switch rooms, installation shafts as well as storage areas, deposits, etc.

If the spaces are modified for housing, accommodation, hospital or meeting, they must be divided into the fire compartments. Each dwelling unit must be a separate fire compartment; the same is valid for bed sections in hospital, hotel rooms or meeting rooms and museums, exhibition halls, theaters, etc. Any room or fire compartment containing more than 200 people is considered to be a meeting room. There are no exceptions allowed, and it is always necessary to reach an agreement between the fire safety requirements and building conservation.

The multistory fire sections require higher fire resistance of building structures than single-story ones, as the fire load is concentrated on the first floor. If fire occurs, it is supposed that the entire building will burn at the same time. The building structures are required to withstand thermal stress without breaking their stability and integrity throughout the fire of the entire building, that is longer than the single-story fire compartment. Finance that are saved by reducing the fireseparating structures such as doors, ceilings, etc. are usually used to ensure the fire resistance of the existing structures if they are composite and combustible. Such solutions absolutely do not respect property protection and safety of persons in the building. If fire damage is to be minimized, the building must be divided into fire compartments. The maximum area of fire compartments depends on the combustibility of the structure, number of floors and coefficient of combustible substances.

\subsection{Fire risk}

The fire safety solution in historic buildings whose original function is changed depends on the extent of construction modifications and planned functional use of the original spaces. If the functional use of historic buildings is planned to be changed, the real fire risk related to the planned operation should be taken into account. The fire risk is specified for each fire compartment. Its value depends on the combustibility and heating capacity of materials used in particular spaces depending on their functional use, coefficient of combustible substances, ventilation and active fire safety equipment. It is calculated from the relation:

$$
\text { qf, d = qf, k.m. } \mathrm{qq} 1 \delta \mathrm{q} 2 \delta \mathrm{nJ} / \mathrm{m}^{2}
$$

where $\mathrm{qf}, \mathrm{k}$ is the fire load density per floor area unit $\mathrm{MJ} / \mathrm{m}^{2} ; \mathrm{m}$ is the burning rate coefficient; $\delta q 1$ is the fire danger; $\delta q 2$ is the fire danger; and $\delta q n$ is the function

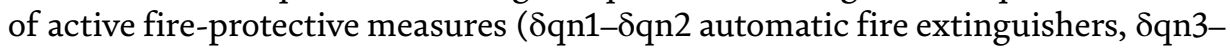

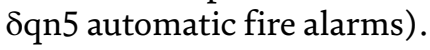

The fire load density expresses the probable fire intensity in the fire compartment or its part. 


\subsection{Fire load}

Fire load can be determined by a calculation from relation (5) or from statistical values; examples for selected types of operations are given in Table 1 (source EN 1991-1-2 and comparison with parameters STN 920201-1).

Fire load $Q$ in a fire compartment is defined as the total energy that can be released in fire occurrence. One part of the total energy will be used to heat the space (walls and internal gas); the rest of the energy will be released through openings-building elements such as wall and ceiling linings. The building content such as furniture is the fire load. Fire load $Q$ divided by the floor area gives the fire load density qf. Typical fire load density in EC 1 is defined by the equation [10]:

$$
\mathrm{qf}, \mathrm{k}=\frac{1}{A f} \cdot \sum_{i}^{\infty}(\psi i . m i . H u i . M i)
$$

where $\mathrm{Mi}$ is the mass of material $\mathrm{i}[\mathrm{kg}]$; Hui is the net heating value of material $\mathrm{i}[\mathrm{MJ} / \mathrm{kg}]$; $\mathrm{mi}$ is the factor describing combustible properties of material $\mathrm{i}$; $\Psi \mathrm{i}$ is the factor assessing protected fire load of material $i$; and Af is the floor area of the fire compartment $\left[\mathrm{m}^{2}\right]$.

HuiMi represents the total amount of energy that is contained in material $i$ and released if combustion process is complete. Factor " $\mathrm{m}$ " is a non-dimensional factor between 0 and 1 representing combustion efficiency: $m=1$ corresponds to complete combustion, and $\mathrm{m}=0$ if materials do not contribute to fire. The value of $\mathrm{m}=0.8$ is suggested for standard materials; the value of $\mathrm{Hu}=17.5 \mathrm{MJ} / \mathrm{kg}$ is suggested for wood, resulting in $14 \mathrm{MJ} / \mathrm{kg}$ for (m.Hu).

Common building designs supposing the use of similar material quantities with the same heating capacity in installations can work with the statistical value of typical fire load density, as defined in EN 1991-1-2; if the designs are done in Slovakia, they follow Table A1 STN 730802. The value of accidental fire load stated in this standard is the weight of wood in $\mathrm{kg}$ calculated per unit of the floor area of fire compartment in $\mathrm{m}^{2}$, whose heating capacity is the same as heating capacity of all combustible materials in this area. Table 4 shows the data comparison.

The functional change of the original spaces changes the fire risk and number of persons. The change of building's fire height, e.g. by roof extension, changes the original building's fire height, fire protection requirements and evacuation plans. An increasing number of persons in the building change the requirements for the capacity and ventilation of emergency routes as well as the fire resistance of fire separation structures. Therefore, it is very important for the investment plan (as for space function and useful floor area extension) to be optimized in such a way that the original boundary conditions would not be changed fundamentally in terms of fire safety and would not require additional significant alternations to the building structures affecting their historic value.

The fire resistance requirements for building constructions specified in STN 730802 are directly dependent on calculated fire load, building's fire height and combustibility of constructions used in a building. It is optimal to prefer operations with a calculated fire load up to $50 \mathrm{~kg} / \mathrm{m}^{2}$ if the function of restored buildings containing mostly composite construction systems was changed. This value considers the operational fire load, surface finishes, effect of ventilation and fire-technical equipment. Classrooms, hotel rooms, coffee bars, offices or galleries are classified as spaces with medium fire load (medium fire development) (see Table 5).

Calculated fire load is determined by the relations:

$$
\mathrm{pv}=(\mathrm{pn}+\mathrm{ps}) \cdot \mathrm{a} \cdot \mathrm{b} \cdot \mathrm{c}\left(\mathrm{kg} / \mathrm{m}^{2}\right)
$$


which depends on: pn-accidental fire load from furnishings given in Table A1 STN 730802 [19]; ps—stable fire load from windows, doors, floor and wall coverings given in Table A1 STN 730802; and a-coefficient of combustible materials (burning rate),

$$
\mathrm{a}=(\mathrm{an} \cdot \mathrm{pn}+\mathrm{a} \cdot \mathrm{ps}) / \mathrm{pn}+\mathrm{ps}
$$

where an is given in Table A1 STN 730802, as is 0.9 and b is the coefficient of ventilation efficiency (ventilation rate),

$$
\mathrm{b}=\mathrm{S} \cdot \mathrm{k} / \text { So } \cdot \sqrt{\text { ho }}
$$

where $\mathrm{S}$ is the floor area of fire compartment; So is the total window area in fire compartment; ho is the average window height in fire compartment; $k$ is the coefficient determined according to Section 4.5.4. STN 730802; and $\mathrm{c}$ is the factor of fire safety equipment efficiency,

$$
\mathrm{c}=\mathrm{c} 1 \cdot \mathrm{c} 2 . \mathrm{c} 3 \cdot \mathrm{c} 4
$$

where $\mathrm{c} 1$ is the coefficient of fire detection (see Table 2 STN 730802); $\mathrm{c} 2$ is the coefficient of fire brigade intervention (see Tables 3 and 4 STN 730802); c3 is the coefficient of fixed fire extinguishing system (see Table 5 STN 730802); and c4 is the coefficient of automatic fire sprinklers (see Table 6 STN 730802)

Table 5 gives the calculated fire load of a typical fire compartment considering the most common use of space in historic buildings whose function was changed during their use. Model examples considered medium ventilation effect with the coefficient value $b=1$. As the most historic buildings do not contain active fire safety equipment, all calculations considered the coefficient value $\mathrm{c}=1$. Subsequently, DFSB is determined depending on the calculated fire load value, combustibility of structures in the fire compartment and the building's fire height (see Table 8 STN 730802). DFSB expresses the summary of technical requirements for fire-separating structures; required minimum fire resistances of fire-separating structures are taken from Table 12 STN 730802.

If building conservation and finance costs are taken into account, it is not possible to carry out every functional change in listed buildings. The building can be classified as unsuitable if fire safety cannot be ensured with reasonable economic and operational costs. The new functional use must not reduce the existing fire safety. In general, listed buildings renovated by using only technical solutions cannot have any functional use. It is optimal for listed buildings to have as low fire risk as possible in terms of fire safety and subsequent fire safety measures [20].

\section{Evacuation}

People evacuated from a burning building are endangered by toxic gases released during combustion, flame, high temperature, smoke and lack of oxygen. The safe evacuation depends on the building's division into fire compartments using fire-separating structures. Their design is based on the assumption that fire will occur in a fire compartment so people present in other fire compartments will not be exposed to fire. The building's division into fire compartments is done in such a way that the life and health loss would be minimal or none. Fire-separating structures in fire compartments should prevent fire and its products from spreading. Separate fire compartments always form protected emergency routes. 
Fire compartmentation in historic buildings is often limited due to the building conservation. This fact has a major impact on the safe evacuation. Open staircases, galleries and non-solid ceiling structures help fire spreading within such buildings. Thermal radiation, toxic gases and smoke are spread throughout the building. The fire intensity and time are increased by combustible materials in built-in ceilings, columns, staircases, wall facings and insulations of technical installations. This affects the safety and speed of people's movement within the affected fire compartment on unprotected emergency routes.

Safety and fluency of evacuation in historic buildings with original layout and functional use is often limited by:

- Open staircases-unprotected emergency routes with limited evacuation time and no other evacuation staircase

- Partially protected existing narrow spiral or ladder stairs limiting the speed of people's movement that can be used by a limited number of persons during evacuation

- Missing exits from stairs leading to an open area outside the building

- Limited number of exits leading to an open area through locked doors without automatic opening during fire in single-story buildings

- Missing other emergency routes-an absence of other staircases or alternative escape possibilities through windows, ladders, etc.

- Insufficient capacity of escape lanes-inwards opening doors narrowing the escape lane and slowing the people's movement speed

These circumstances cause the time for evacuation to be longer, people's safety to be lower and the risk for firefighting brigade to be higher.

The fire development and spreading is a function of time, that is time is crucial for evacuation of people or historic exhibits. Fluent evacuation is conditioned by the number and quality of emergency routes in terms of ventilation, slope, width and number of evacuated persons. Their ventilation and number depend on the building's fire height and the number of evacuated persons. There should be at least two emergency routes available for evacuation in every space; there is significantly better chance of people's survival in spaces directly affected by fire. Evacuated persons can use the emergency route that is less affected by fire.

Staircases are used to evacuate people between floors in buildings. According to STN 730802 and the time required for safe evacuation, staircases can be divided into unprotected, partially protected and protected emergency routes.

Unprotected routes are open staircases and those located within the fire compartment. Partially protected routes are staircases with fire-separating structures preventing the heat and smoke from spreading and those that are not adequately ventilated. Internally enclosed staircases without natural ventilation are the most common. Protected routes are staircases with fire-separating structures preventing the heat and smoke from spreading and natural or artificial ventilation. Routes of type A with natural or forced ventilation with a maximum evacuation time of 6 min are sufficient for historic buildings with the fire height up to $22.5 \mathrm{~m}$. The ventilation requirement is ten times the air change per hour. 


\subsection{Solution example of a model building's restoration in terms of evacuation}

The change of building's functional use and fire load usually results in an increasing number of persons in building compared to the original solution. The evacuation conditions are also changed if the building's fire height is changed, e.g. due to the addition of one or two floors into the attic. Since both cases fundamentally affect the evacuation conditions, it is necessary to check the original emergency routes and modify so that they would be suitable for the new number of evacuated persons or longer emergency route.

Here is the solution example of a model building. The new owner of a manor house changed the building's functional use and fire height by adding a floor into the unused attic space. The manor house is a typical baroque building with a U-shaped ground plan. The manor house had originally three above-ground floors with a mansard roof. The building once served as a residence of a noble family. After restoration, it will serve as a hotel. There are social spaces containing inner halls, smaller salons, restaurants, kitchen and sanitary operational background on the ground floor and first floor. Hotel rooms with technical and operational facilities are located on the upper floors (see Figure 5).

Each side wing contains one double-wing staircase that was originally open and classified as unprotected at the time of evacuation. Designed building's alternation by hotel rooms built in the attic changed building's fire height and extended staircases beyond the allowable dimensional limits defined in Table 16 STN 730802. It was necessary to alter existing staircases in the side wings. The staircases on each floor were fire-separated from the other fire-loaded spaces and ventilated through existing windows facing the inner courtyard (see Figure 5).

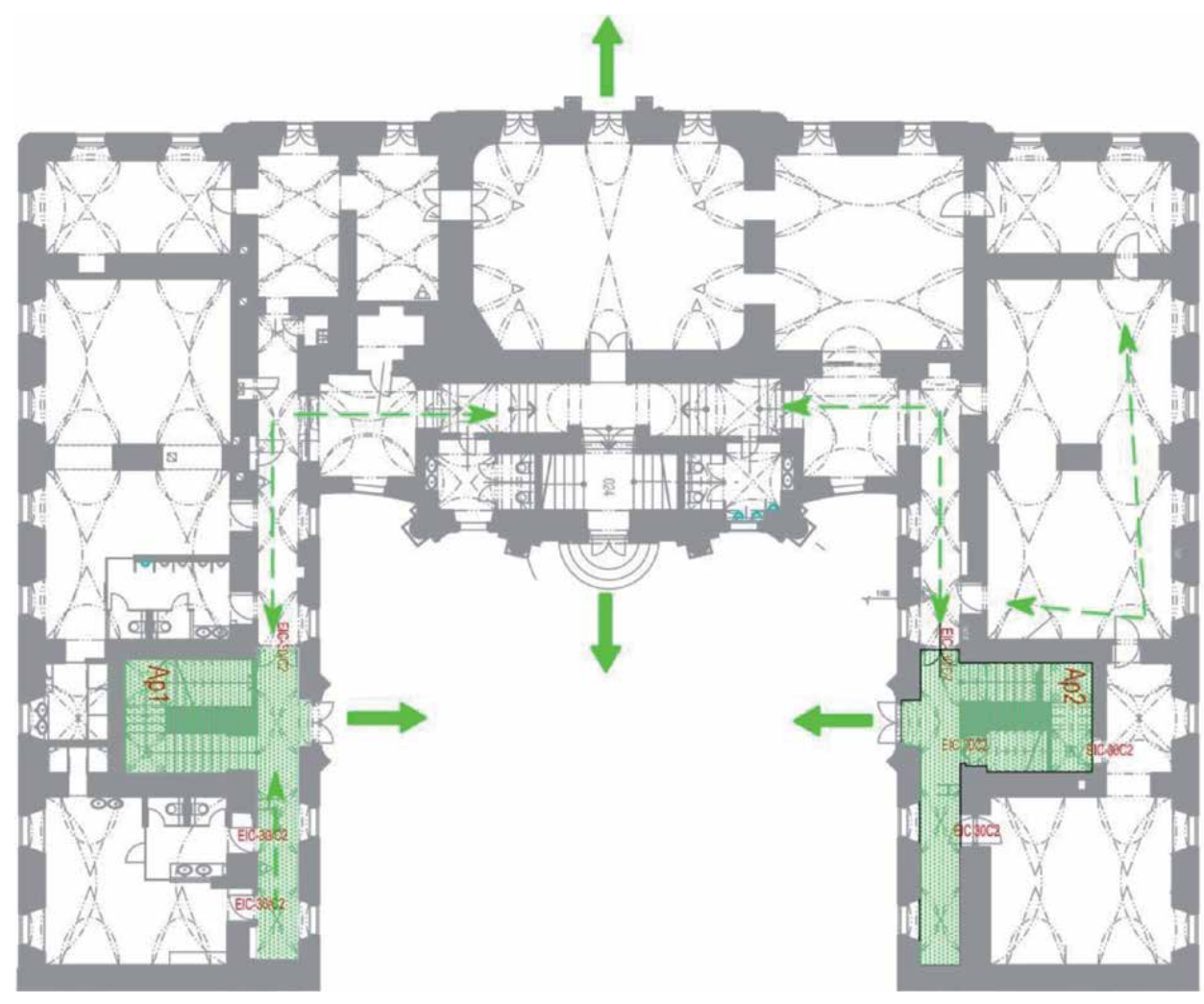

Figure 5.

Emergency routes on the first floor leading to an open area in a model solution of the restored manor house. 


\section{Conclusions}

To achieve higher fire safety in historic buildings whose functional use was changed, it is recommended to optimize the fire risk considering combustibility of building structures and building's fire height. Authors J. Li, H. Li, B. Zhou and $\mathrm{X}$. Wang in their work "Investigation and Statistical Analysis of Fire Load of 83 Historic Buildings in Beijing" analyzed the fire load in timber historic buildings where the primary requirement of the restoration was the optimization of accidental fire load [20].

The building should be divided into fire compartments if it is acceptable in terms of the building conservation. If it is possible, another emergency route with direct ventilation should be created. This route would also serve for firefighting intervention. The large roof spaces should be divided into smaller units using fireseparating walls overlapping the roof by at least $300 \mathrm{~mm}$. An accidental fire loads should be excluded from the attic space. All attic entrances should be provided with self-closing fire doors. Interventions into the original floors should be reduced.

Hidden cavities in the floors should be analyzed in the project documentation due to the load-bearing capacity during the fire intervention as well as in terms of the occurrence of hidden fire caused by short circuits in electrical installations. All cable entries, pipes and anchoring of heavy chandeliers through ceilings should be carefully fire-sealed. The copper roofing on wooden decking or wooden shingles should be replaced with non-combustible roofing made of burnt tiles or slate-see an example of the castle of Krásna Hôrka. The baroque buildings on the Svatá Hora near the town of Prríbram in the Czech Republic underwent a similar restoration after a large fire in 1798. The fire affected buildings' wooden roofs as in Krásna Hôrka. The original wooden shingles were replaced by ceramic tiles after fire. The roof spaces in buildings of significant historic importance should be equipped with an automatic fire alarm system, ideally supplemented with an automatic fire extinguishing system. An example of such solution is the protection of the supporting truss members in St. Vitus Cathedral in Prague, Czech Republic. There is an electrical fire alarm and automatic sprinkler fire extinguishing system installed in its roof space.

The spaces containing visible combustible load-bearing and fire-separating structures should be equipped with an automatic fire alarm system. Water sources that can be used for fire extinguishing should be sufficient and located near the building. Accessibility of water sources is often complicated in historic buildings. One of the possibilities is the use of water tanks with $10 \mathrm{~m}^{3}$ capacity equipped with a 50-m-long fire hose [21].

Access roads should be verified and optimized within natural possibilities. It is important for the building's operation and its fire safety to have functional firefighting equipment and fire-trained staff so that the risks associated with building's restoration and maintenance can be minimized [22-24].

The current fire documentation should be elaborated and updated so as to provide sufficient information on the evacuation plans for persons and exhibits, building's structural design, firefighting water sources and technical condition of access and emergency roads.

\section{Thanks}

The work is published with the financial support of the project VEGA 1/0248/19. The work presents knowledge from the author's design practice. 


\section{Author details}

Agnes Iringová

Faculty of Civil Engineering, University of Žilina, Žilina, Slovakia

*Address all correspondence to: agnes.iringova@fstav.uniza.sk

\section{IntechOpen}

(C) 2020 The Author(s). Licensee IntechOpen. This chapter is distributed under the terms of the Creative Commons Attribution License (http://creativecommons.org/licenses/ by/3.0), which permits unrestricted use, distribution, and reproduction in any medium, provided the original work is properly cited. (cc) BY 


\section{References}

[1] Stewart K, Haire S. Fire Safety Management in Traditional Buildings:

Part 1. Principles and Practise.

Edinburgh: Historic Scotland; 2010. ISBN 978-1-84917-035-2

[2] Egri J. Fire in the castle of Krásna Hôrka. In: PYROMEETING_Fire Protection of Historical Monuments. Brno. 2013

[3] Firenet: History of Fire Safety (online). 2009. Available from: http:// www.fire.org.uk/history-of-fire-safety. html

[4] STN 73 0834. Fire safety of buildings. In: Changes in Buildings. Bratislava: SUTN; 2010

[5] Svoboda P, Polatova E. Methodology for fire protection of accessible monuments. In: Proceedings of the Bridges to Fire Protection of Cultural Monuments, Prague. 2015. pp. 32-37

[6] Caston P. Historic roof trusses between 1500 and 1700 in German speaking Central Europe: Documentation, analysis, and development. In: Second International Congress on Construction History, Queens' College, Cambridge University, March 29 to April 04. 2006. pp. 579-597

[7] STN EN 1991-1-1. Eurocode 1. In: Load of Structures-Part 1-1. Bratislava: SUTN; 2007

[8] STN EN 1991-1-3. Eurocode 1. In: Load of Structures-Part 1-3. Bratislava: SUTN; 2007

[9] STN EN 1991-1-4. Eurocode 1: Load of Structures-Part 1-4. Bratislava: SUTN; 2007

[10] Wald F et al. Calculation of Fire Resistance of Building Structures.
Praha: ČVUT Publishing House; 2005. 336 p. ISBN 80-0103157-8

[11] Iringova A, Idunk R. Assessment and usability of historic trusses in terms of fire protection-A case study. International Wood Products Journal. 2017;8(2):80-87

[12] STN 730821. Fire protection of buildings. In: Fire Resistance of Engineering Structures. Praha: UNMZ; 1973

[13] STN EN 1995-1-1 + A1. Eurocode 5. Design of Wooden Structures-Part 1-1. Generally_General Rules and Rules for Buildings. Bratislava: SUTN; 2008

[14] STN EN 1995-1-2. Eurocode 5. In:

Design of Wooden Structures-Part 1-2. General Rules-Design of Structures for Fire Effect. Bratislava: SUTN; 2008

[15] Vassart O, Zhao B, Cajot LG, Robert F, Meyer U, Frangi A. Eurocodes: Background applications structural fire design. In: Report EUR26698 EN. European Union; 2014. ISSN 1831-9424

[16] Gašpercová S, Makovická L, Kostelanský T. Assessment of fire protection in the castle of Trenčín.

Available from: https://stavba.tzb-info. cz/historicke-stavby/17908

[17] STN EN 338. Constructional wood. In: Strength Classes. Bratislava: SUTN; 2010

[18] Emery S. Emergency Plans for Heritage Buildings and Collections. London: English Heritage; 2011

[19] STN 73 0802. Structural fire protection. In: Common Regulations. Bratislava: SUTN; 2010

[20] Li J, Li H, Zhou B, Wang X. Investigation and statistical analysis 
of fire load of 83 historic buildings in Beijing. International Journal of Architectural Heritage. 2018

[21] Karlsen E. Fire Protection of Norwegian Cultural Heritage. Norway: Directorate for Cultural Heritage (Riksantikvaren). Available from: http:// www.arcchip.cz/w04/w04_karlsen.pdf

[22] Ditlev J, Orrainen M. Managing fire safety in historical buildings. In: CFPA-E Guideline No. 30: 2013. F Copenhagen: CFPA Europe; 2013

[23] German Insurance Association. Brandschutz in historischen Gebäuden. Empfehlungen zur Schadenverhütung (VdS 2171). 2008-2012

[24] Jensen G, Cowi AS. Manual Fire Extinguishing Equipment for Protection of Heritage. Norway: Riksantikvaren the Norwegian Directorate for Cultural Heritage Historic Scotland: Technical Conservation, Research and Edication Group; 2006. ISBN: 82-7574-039-8 


\title{
BLEVE Fireball Effects in a Gas Industry: A Numerical Modeling Applied to the Case of an Algeria Gas Industry
}

\author{
Brady Manescau, Khaled Chetehouna, Ilyas Sellami, \\ Rachid Nait-Said and Fatiha Zidani
}

\begin{abstract}
This chapter presents the numerical modeling of the BLEVE (Boiling Liquid Expanding Vapor Explosion) thermal effects. The goal is to highlight the possibility to use numerical data in order to estimate the potential damage that would be caused by the BLEVE, based on quantitative risk analysis (QRA). The numerical modeling is carried out using the computational fluid dynamics (CFD) code Fire Dynamics Simulator (FDS) version 6. The BLEVE is defined as a fireball, and in this work, its source is modeled as a vertical release of hot fuel in a short time. Moreover, the fireball dynamics is based on a single-step combustion using an eddy dissipation concept (EDC) model coupled with the default large eddy simulation (LES) turbulence model. Fireball characteristics (diameter, height, heat flux and lifetime) issued from a large-scale experiment are used to demonstrate the ability of FDS to simulate the various steps of the BLEVE phenomenon from ignition up to total burnout. A comparison between BAM (Bundesanstalt für Materialforschung und -prüfung, Allemagne) experiment data and predictions highlights the ability of FDS to model BLEVE effects. From this, a numerical study of the thermal effects of BLEVE in the largest gas field in Algeria was carried out.
\end{abstract}

Keywords: BLEVE effects, CFD, FDS, fireball, LES, QRA

\section{Introduction}

After the industrial revolution of the nineteenth century, the world has experienced significant growth in new technologies embedded in the process industry such as gas processing, manufacture of transportation means, etc. In these installations, several fuel elements are present and require special attention in order to avoid accidents whose consequences have severe impacts on people, equipment, and environment. The most common accidents encountered in the chemical and petrochemical process industry are fires, explosions, and toxic releases. Considering the number of existing and future installations, the consequences of 
these types of accidents remain a major concern for decision-makers, industrial experts, and fire safety analysts.

In the context of defining an accurate assessment of the safety of industrial facilities, risk analysts often use quantitative risk analysis (QRA) [1]. It is an analysis method that makes it possible to understand and quantify the consequences of accidental phenomena (thermal radiation, overpressure, toxicity dose).

Among the accidental phenomena most observed in the process industry is the boiling liquid expanding vapor explosion (BLEVE). It corresponds to a violent vaporization of explosive nature following the rupture (loss of confinement) of a tank containing a liquid at a temperature significantly higher than its normal boiling point at atmospheric pressure [2]. Between 1940 and 2005, the different BLEVEs listed have cost more than 1000 lives and have injured more than 10,000 people in addition to harming property worth billions of dollars [3]. In addition to human lives and material goods, BLEVE has hazardous effects on the environment; it can release dangerous substances likely to attack the environment. Considering this, it is important to estimate the potential damage that would be caused by such an explosion. In this context, several studies have been conducted to analyze the BLEVE mechanisms. Thermal radiation hazards associated with liquefied petroleum gas (LPG) releases from pressurized storage were studied by Roberts [4]. He established correlations allowing to obtain the fireball characteristic parameters from the fuel mass (diameter, lifetime, and heat flux). From these mathematical laws, Crocker and Napier [5] evaluated fire and explosion hazards of LPG. They showed that these models overestimate the risks associated with jet fires, fireballs, and BLEVE blast effects. Prugh [6], in his part, studied the effects of fuel type and fuel quantity on fireball diameter, duration, and energy and the relationships between fireball energy, distance from the fireball, and consequences of personnel and property exposure.

Roberts et al. [7] presented results from a series of experimental tests performed by the Health and Safety Laboratory in the context of JIVE project (hazards consequences of jet fire interaction with vessels containing pressurized liquids). During these tests, several propane tanks were exposed to fires. They allowed to identify the conditions of temperature and rupture pressure, failure mode, as well as the fireball characteristics. In a study conducted by Abbasi et al. [3], the mechanism, the causes, the consequences, the hand calculation methods, and the preventive strategies associated with BLEVEs were presented in an excellent review. Based on medium-scale experimental tests, Birk et al. [8] concluded that the liquid part does not contribute to the generation of shock waves. They proposed a model based on the TNO model that uses the vapor part to calculate the expansion energy. Other works like Bubbico and Marchini [9] and Chen et al. [10] give information on the fact that BLEVE evolution process is characterized by two-phase flow with an overpressure effect.

In works cited above, there are empirical and semiempirical approaches which provide data highlighting the characteristics of BLEVE. However, these approaches are not very satisfactory because they usually include an experimentally adjusted reduction factor and mostly overestimate the BLEVE effects [11-13]. Furthermore, they do not consider the effect of buildings, obstructions, and topography for specific facilities. In addition, the data provided by these approaches may not ensure enough repertory for conducting an in-depth QRA.

In order to overcome the empirical approach limitations, it is necessary to use the computational fluid dynamics (CFD) modeling which appears as a powerful complementary tool for experimental and theoretical studies. Considering the complexity of the BLEVE phenomenon process, current published CFD simulation studies [14-19] focus only on certain BLEVE aspects, such as fireball formation, 
without considering vessel disintegration. Indeed, with a sufficiently fine numerical resolution, it is possible to carry out simulations of explosion phenomena considering turbulence, combustion process, heat transfer, and geometry.

Among the numerical studies on the BLEVE, Yakush and Makhviladze [14] compared the fireball lifetime predictions from two turbulence models (based on RANS and LES approach) and the fireball lifetime obtained by the experimental correlation of Roper et al. [15]. The simulations were performed by the CFD code FDS from NIST version 4. They showed that the simulation using LES model better predicts fireball dynamics than the simulation using RANS model. Other simulations were made using the CFD code FDS [16-18]. The FDS validation was carried out using the experimental data such as the BAM BLEVE experiment [19]. They evaluated the code capabilities to simulate the fireball characteristics (diameter, lifetime, flame dynamics, and structure). In addition to FDS, other CFD codes are used to simulate fireball characteristics such as OpenFOAM, Ansys CFX, etc. Indeed, Mishra et al. [20] performed a CFD investigation on a peroxy-fuel BLEVE using the CFD commercial code Ansys CFX, and Shelke et al. [21] used the OpenFOAM CFD code. They highlighted the abilities of these CFD codes to predict the reactive flows present in a fireball such as BLEVE.

In this chapter, in addition to evaluating the capability of the CFD code FDS to predict the BLEVE characteristics, an evaluation of the BLEVE thermal effects on a real gas processing plant is presented. The evaluation of the CFD code is made using data obtained from empirical correlations and large-scale experimental data issued from the literature. The calculations are carried out using the FDS code version 6.

In this context, an overview of the BLEVE phenomenon is presented in the second part of the chapter. In the third part, the capability of FDS to predict BLEVE characteristics is presented in comparison with experimental data. In the fourth part, the BLEVE thermal effects on a real case study are illustrated to finish with conclusions and perspectives in the last part.

\section{BLEVE presentation}

\subsection{BLEVE definition}

BLEVE is described as a violent explosive vaporization resulting from the rupture of a tank containing a liquid at a temperature significantly above its boiling point at atmospheric pressure.

BLEVE can occur with any liquid, flammable or not, when heated and pressurized into a closed container. Two types of BLEVE can be distinguished, cold BLEVE and hot BLEVE, depending on the temperature at which the rupture of the enclosure occurs.

In this illustration, the hot BLEVE with a flammable liquid is studied. The BLEVE explosion of hydrocarbon fuels (e.g., LPG, LNG, etc.) is characterized by the formation of fireball and the release of intense thermal radiation in a short time.

\subsection{Description of the different BLEVE tests}

In the focus to characterize the BLEVE phenomenon with enough accuracy, it is important to define an experimental setup with a fine and controlled 
instrumentation. However, the current measurement instruments do not allow the proper acquisition of results during a BLEVE test due to its magnitude. In addition, the high cost of this type of test and considering respect for the environment, there are few experimental tests that deal with this kind of phenomenon. In the literature $[19,22]$, there are large-scale experiment tests: the BAM test (Bundesanstalt für Materialforschung und -prüfung, Allemagne), the British Gas experiments, and the JIVE tests (hazards consequences of jet fire interaction with vessels containing pressurized liquids, 1994/1995).

In this chapter, only the BAM experiment is used to evaluate the capability of FDS to predict BLEVE characteristics.

By doing a little reminder on the BLEVE phenomenon, in 1998, the BAM conducted a BLEVE test with a road tank of $45 \mathrm{~m} 3$ of capacity, containing 5 tons of commercial propane (fill liquid level 22\%) [19, 22]. The wagon was exposed to a fuel pool fire. In this test, an instrumentation has been performed to obtain physical quantities such as heat flux, temperature, and pressure.

In the goal to make a comparison between empirical law and numerical modeling, the next sections will present the equations used for the empirical laws and the different models proposed to simulate the reactive flows inducted by the fireball.

\subsection{BLEVE modeling using empirical laws}

In order to predict the fireball effects, different authors proposed correlations to predict fireball diameter and lifetime based on fuel quantity [4, 23-30]. These correlations are given in the following equations:

$$
\begin{aligned}
& D_{F B}=a_{1} M^{b 1} \\
& t_{F B}=a_{2} M^{b_{2}}
\end{aligned}
$$

where $D_{F B}$ is the fireball diameter, $M$ is the fuel mass, $t_{F B}$ is the fireball lifetime, and $a_{1}, b_{1}, a_{2}$, and $b_{2}$ are empirical constants.

With the difficulty to choose good coefficients which give better correlation for the fireball characterization, a comparative analysis made by Satyanarayana et al. [31] to define the best correlations which describe the fireball diameter and lifetime is given as follows:

$$
\begin{aligned}
& D_{F B}=6.14 M^{0.325} \\
& t_{F B}=0.41 M^{0.340}
\end{aligned}
$$

Equations (3) and (4) are used in this study in order to compare with the experiment data and CFD predictions.

To estimate the incident radiation received by a target at a given distance, the solid-flame model may be used [23, 27]:

$$
\dot{q}_{r}^{n}=E_{p} \cdot F_{v} \cdot \tau_{a t m}
$$

where $\dot{q}_{r}^{\prime \prime}$ is the radiation received by target, $E_{p}$ is the surface emissive power, $F_{v}$ is the view factor, and $\tau_{\text {atm }}$ is the atmospheric attenuation factor (transmissivity). 


\section{Numerical modeling of BLEVE}

The numerical modelings were performed using the CFD code FDS 6.5.3 [32]. This one solves the Navier-Stokes equations based on an explicit finite difference scheme. Moreover, it models the thermally driven flow with an emphasis on smoke and heat transport. It is a LES model using a uniform mesh and has parallel computing capability using message-passing interface (MPI) [26, 33].

\subsection{Fire source modeling}

The modeling of the fire is based on a reaction rate considered as infinitely fast, and the combustion is modeled using the EDC of Magnussen and Hjertager [34-36]. The turbulent combustion processes are based on the governing equations for the mass fraction of the chemical species, such as $\mathrm{C}_{x} \mathrm{H}_{y}, \mathrm{O}_{2}, \mathrm{CO}_{2}, \mathrm{H}_{2} \mathrm{O}$, and $\mathrm{N}_{2}$ through a single step as follows [37]:

$$
C_{x} H_{y}+\left(x+\frac{y}{4}\right)\left(O_{2}+3.76 N_{2}\right) \rightarrow x C_{2}+\frac{y}{2} H_{2} \mathrm{O}+3.76\left(x+\frac{y}{4}\right) N_{2}
$$

Considering the complexity of the BLEVE phenomenon, only the fireball is modeled in this work. Indeed, as the published CFD studies say, the container disintegration is complicated to model and is not considered. For that, the present study is based on the BLEVE modeling by fuel release.

The fuel used is propane. Its heat of combustion is set to $46,334 \mathrm{~kJ} / \mathrm{kg}$. The ejection surface was calculated using the approach of Makhviladze et al. [38]. The fuel releases as a hot gas with a temperature equal to $700^{\circ} \mathrm{C}$. The ignition of the mixture air/fuel is ensured by an autoignition. The extinction model and turbulence model used in simulations are the default code models.

The numerical simulations are carried out in a rectangular 3D domain with dimensions of $200 \mathrm{~m} \times 200 \mathrm{~m} \times 300 \mathrm{~m}$ assimilated to an open ambient environment. These dimensions are obtained from the max-diameter and the max-height of the fireball calculated using the empirical correlations presented in the second section.

\subsection{Mesh sensitivity analysis}

In the mesh resolution, it is necessary to determine the fire characteristic diameter according to its heat release rate (HRR). This diameter, denoted $D^{*}$, is written as [32]:

$$
D^{*}=\left(\frac{\dot{Q}}{\rho_{\infty} c_{\infty} T_{\infty} \sqrt{g}}\right)
$$

where $D^{*}$ is the characteristic fire diameter, $Q$ is the heat release rate, and $c_{p}$ is the specific heat.

From obtaining the characteristic diameter, the optimal mesh size of the domain is given by the dimensionless ratio $\frac{D^{*}}{\delta_{x}}$, where $\delta_{x}$ is the nominal mesh size.

Based on several experiences, the US Nuclear Regulatory Commission recommends a $\frac{D^{*}}{\delta_{x}}$ ratio between 4 and 16 to produce accurate results at a moderate computational cost $[18,39]$.

In order to model a fireball using FDS, it is important to define the good mesh size. For that, a comparison between experiment data and numerical data using 
four mesh sizes is made in Figure 1(a) and (b). The different mesh sizes are obtained from the US Nuclear Regulatory Commission recommendation. The numerical simulations are carried out in a rectangular 3D domain with dimensions of $200 \mathrm{~m} \times 200 \mathrm{~m} \times 300 \mathrm{~m}$ as mentioned previously.

The comparisons between the experiment and the predictions for the four different meshes are made based on the evolution of the heat flux and the fireball height (cf. Figure 1). The heat flux was measured at $30 \mathrm{~m}$ over the ground from the projected center of the fireball on the ground under the fireball, and the height was obtained from the fireball center to the ground level. These figures show that the numerical results obtained from the mesh sizes of $0.5 \mathrm{~m}$ and $1 \mathrm{~m}$ converge with the experimental results, while the results from the mesh sizes of $2 \mathrm{~m}$ and $4 \mathrm{~m}$ diverge. Moreover, the mesh size of $0.5 \mathrm{~m}$ offers more precision than the results obtained with a mesh size of $1 \mathrm{~m}$ as shown by the root-mean-square Error (cf. Table 1).

From Figure 1(a) and (b), the numerical simulation with a mesh size of $0.5 \mathrm{~m}$ is more precise but requires a calculation time 50 times greater than the calculation carried out with a mesh size of $1 \mathrm{~m}$ (cf. Table 1 ). Thus, by wanting to conciliate precision and optimal calculation time, the mesh size of $1 \mathrm{~m}$ will be used for the rest of numerical simulations. This mesh size allows solving the Navier-Stokes equations with a good accuracy. Indeed, with the mesh size of $1 \mathrm{~m}$, the different numerical models such as the turbulence model based on the Deardorff model, the combustion model based on the EDC definition, and the extinction model based on the critical temperature flame are very well calculated for giving a very nice modeling of the fireball. Moreover, taking into account the mesh size
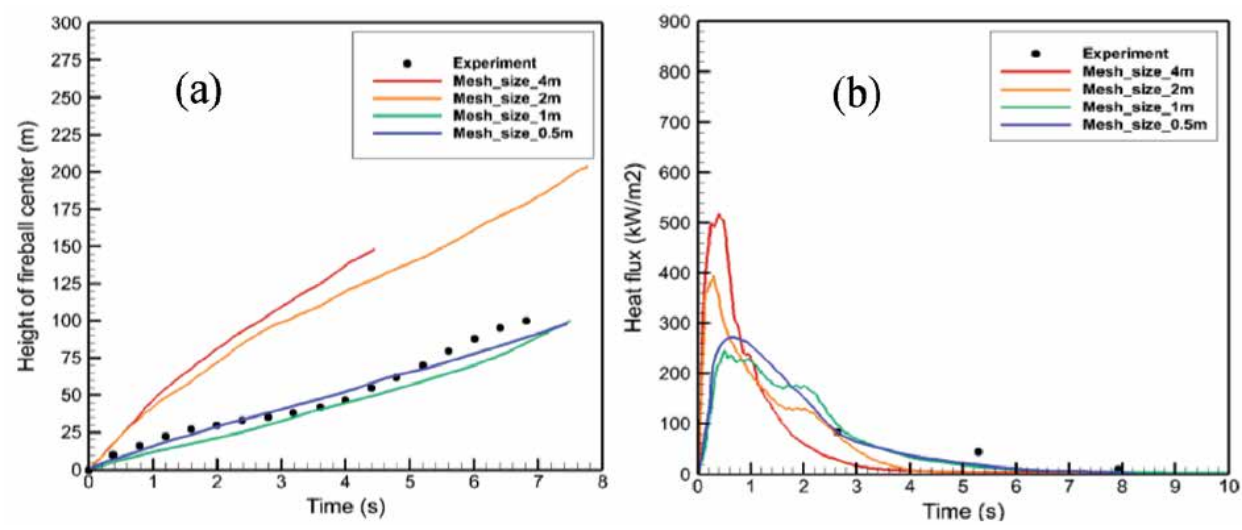

Figure 1.

Mesh resolution on (a) the height of fireball center and $(b)$ the heat flux at $30 \mathrm{~m}$ on ground level.

\begin{tabular}{ccccc}
\hline Numerical grid & \multirow{2}{*}{ Number of cells } & \multicolumn{2}{c}{ Root-mean-square error } & \multirow{2}{*}{ CPU time (min) } \\
\cline { 3 - 4 } & & Height $(\mathbf{m})$ & Heat flux $\left(\mathbf{k W} / \mathbf{m}^{2}\right)$ & \\
\hline Mesh size $4 \mathrm{~m}$ & 187,500 & 60.22 & 34.09 & 2 \\
\hline Mesh size $2 \mathrm{~m}$ & $1,500,000$ & 59.01 & 21.56 & 14 \\
\hline Mesh size $1 \mathrm{~m}$ & $12,000,000$ & 9.74 & 16.24 & 161 \\
\hline Mesh size $0.5 \mathrm{~m}$ & $96,000,000$ & 5.86 & 13.23 & 8000 \\
\hline
\end{tabular}

Table 1.

Results of mesh sensitivity analysis. 
BLEVE Fireball Effects in a Gas Industry: A Numerical Modeling Applied to the Case... DOI: http://dx.doi.org/10.5772/intechopen.92990
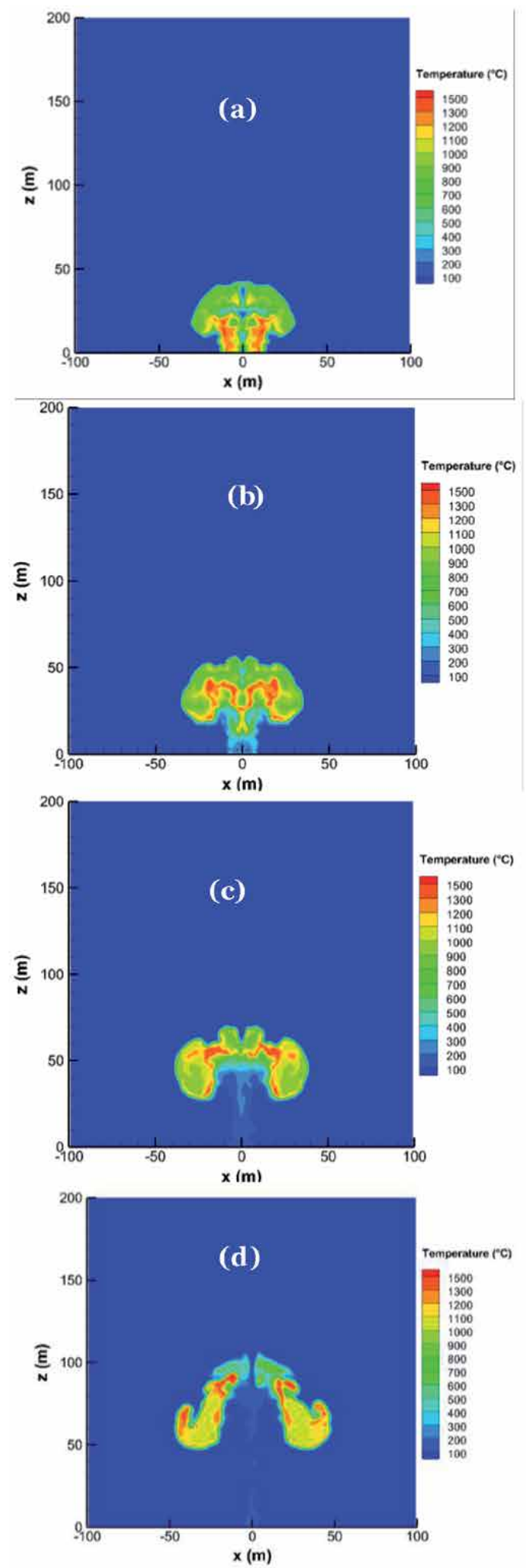

Figure 2.

Simulation of the fireball temperature field with mesh size $1 \mathrm{~m}$ in the cross-section at (a) $2 s,(b) 3 s,(c) 4 s$, and $(d) 6 s$. 


\begin{tabular}{lccccc}
\hline $\begin{array}{l}\text { Fireball } \\
\text { Characteristics }\end{array}$ & Experiment & Empirical & $\begin{array}{c}\text { Present } \\
\text { data }\end{array}$ & $\begin{array}{c}\text { RMSE } \\
\text { (Empirical) }\end{array}$ & $\begin{array}{c}\text { RMSE } \\
\text { (Present data) }\end{array}$ \\
\hline Max-diameter (m) & 100 & 98 & 101 & 1.41 & 0.71 \\
\hline Duration (s) & 7.2 & 7.4 & 7.8 & 0.14 & 0.42 \\
\hline Max-height (m) & 100 & 74 & 99 & 18.38 & 0.71 \\
\hline
\end{tabular}

Table 2.

Comparison between numerical data and BAM test.

of 2 and $4 \mathrm{~m}$, there is an important divergency on the solving of the previous numerical models.

Working with the mesh size of $1 \mathrm{~m}$, Figure 2(a)-(d) shows the evolution and the development of the fireball structure at different times $(2,3,4$, and $6 \mathrm{~s})$ after the fuel release to the atmosphere. From these pictures, the evolutions of the temperature field obtained from the numerical modeling highlight the same observations made by Hurley et al. [40]. It is observed that the diameter of the flame increases the height and the time, and Hurley et al. have observed that the diameter of the fireball reaches its maximum at about $6 \mathrm{~s}$ with a value of $100 \mathrm{~m}$ as diameter. And, by making a comparison with the numerical data, this one agrees with experimental results.

Moreover, considering that the flame temperature of a hydrocarbon fire can approach about $1300^{\circ} \mathrm{C}$, it is shown in Figure $2(\mathbf{a})-(\mathbf{d})$ that the predicted field temperature represents the diameter of the fireball during its evolution. In this context, the reactive flows modeled using this mesh resolution come close themselves to the flame dynamics of BLEVE phenomenon.

In conclusion, FDS can predict BLEVE characteristics after a good definition of the mesh size and the fuel release rate. For another case of validation, Table 2 illustrates the comparison between numerical data and BAM test. In this one, it is observed that the predictions of the parameters such as max-diameter, lifetime, and max-height of the fireball agree with experiment with a better precision than empirical estimates.

\section{BLEVE thermal effects: case study for a Hassi R'Mel gas processing plant}

From the previous analyses, it has been shown that FDS code is able to simulate the evolution and development of a fireball in comparison with experimental test, considering that it is possible to predict the evolution and thermal effects of a BLEVE in a real installation. In addition, from the numerical results obtained in the previous section, it is necessary to use a nice mesh size in order to make an accurate modeling of a fireball under FDS and a good knowledge of the mass and the release rate of the fuel. Moreover, the definition of a calculation domain that considers the recirculation and the reactive flows during the fireball expansion is very important to justify a good numerical calculation. So, respecting the previous numerical recommendations, it is possible to simulate thermal effects of BLEVE in a real installation such as in Hassi R'Mel Gas Processing Plant.

\subsection{Description of the gas processing plant and the ignition source}

The gas processing plant studied in this work is defined as the Module Processing Plant 3 (MPP3) of SONATRACH Company at Hassi R'Mel gas field 
(located about $550 \mathrm{~km}$ south of Algiers). This MPP3-plant consists of three identical gas processing trains that mainly produce natural gas (with a production capacity of 60 million $\mathrm{m}^{3} /$ day), LPG, and condensate. Figure 3 illustrates the configuration of the MPP3-plant. The origin of the explosion is taken at the level of a pressurized propane accumulator D108 located in the MPP3-plant as shown in Figure 3.

The choice of the accumulator D108 is based on the opinions of the risk analysts who consider it as one of the most critical systems in the MPP3-plant, which can generate catastrophic BLEVE accidents [41]. Table 3 summarizes the technical characteristics of the D108 vessel used in our calculation.

\subsection{Boundary conditions}

The numerical modeling of the MPP3-plant described above is carried out in an open calculation domain of $300 \mathrm{~m} \times 300 \mathrm{~m} \times 360 \mathrm{~m}$. The dimensions of this domain are chosen based on the fireball diameter and height calculated using empirical correlations. The calculations are carried out under atmospheric conditions with a relative humidity of $40 \%$ and an ambient temperature of $20^{\circ} \mathrm{C}$. The plant configuration is modeled as solid obstructions considering the real equipment dimensions of the three MPP3-plant trains.

The calculations were performed with a time step of $0.01 \mathrm{~s}$ and took 2729 minutes with a mesh size of $1 \mathrm{~m}$ (i.e., 32,400,000 meshes) using 90 CPUs. The simulation is performed using the default numerical models. The ejection surface was calculated using the approach of Makhviladze et al. [38] as mentioned in Section 3. The origin of the explosion is taken at the level of the D108 as mentioned previously. Using the

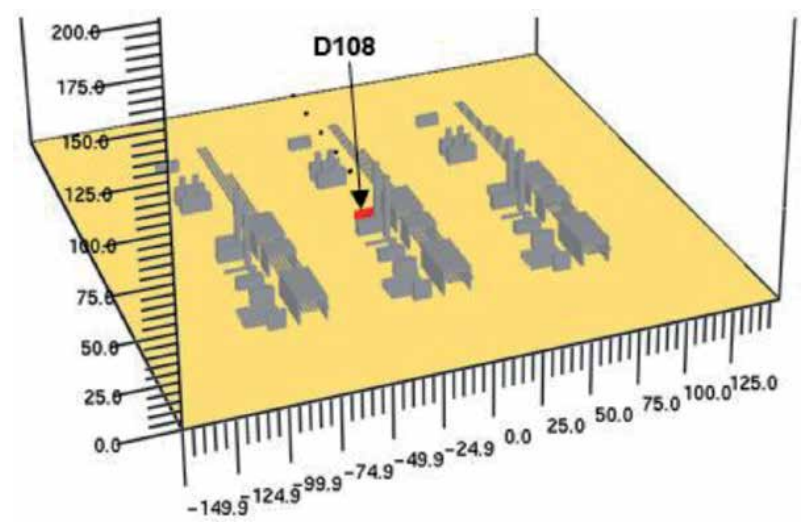

Figure 3.

Numerical MPP3-plant.

\begin{tabular}{lc}
\hline Characteristics & Values \\
\hline Operating temperature $\left({ }^{\circ} \mathrm{C}\right)$ & 40 \\
\hline Operating pressure $($ bar $)$ & 14.5 \\
\hline Volume $\left(\mathrm{m}^{3}\right)$ & 50 \\
\hline Propane density $\left(\mathrm{kg} / \mathrm{m}^{3}\right)$ & 483.6 \\
\hline
\end{tabular}

Table 3.

Technical characteristics of the accumulator D108. 
same modeling approach presented in Section 3, the BLEVE is modeled through the ejection of $24,180 \mathrm{~kg}$ of hot propane with a velocity of $100 \mathrm{~m} / \mathrm{s}$.

\section{Results and discussions}

In the previous section, it is shown that the comparison of the predicted fireball diameter and lifetime with the empirical values is similar to the experimental data. However, the predicted height is better than the empirical value in comparison with experiment data.

Considering the real installation, there are no experimental data and so no possibility to compare with empirical values and numerical data. In these conditions, the comparison is made only between the numerical and empirical data based on the evaluation of BLEVE characteristics. Moreover, considering the observations made in the previous section, the results issued from the BLEVE simulation in the MPP3-plant show similar observations. Indeed, in Table 4, the predicted fireball diameter and lifetime are like the empirical values, but the empirical height is underestimated by comparing to the predicted value.

Taking into account the comparisons obtained previously, it is possible to say that the evolution and the development of the fireball predicted by FDS in the MPP3-plant would be representative of reality. Figure 4 shows the simulation of the fireball at two different times in the studied plant. With this simulation, it is possible to follow the evolution of different physical parameters in a spatiotemporal manner such as heat flux, heat release rate, species concentrations, flame temperature, etc. In this paper, only the prediction of heat flux is studied.

Figure 5 presents the comparison between the prediction and the empirical approach based on the evolution of heat flux over time at 50 and $70 \mathrm{~m}$ at ground level. It is found that the prediction provides a temporal evolution of the heat flux representative of the reality in comparison with the empirical one which gives a constant value. Indeed, during the first moments, a maximum peak of the heat flux is observed. This maximum value represents the heat flux emitted by the fireball when the latter is near to the ground. With the fireball elevation in height, the heat flux received at ground level decreases. This is represented by the evolution of the heat flux predicted by FDS code. From these comparisons, it is justified that the data provided by the numerical simulation give a more realistic support during a QRA.

Indeed, as indicated in introduction, risk analysis requires knowledge of representative input data of the phenomenon to be studied. Thus, depending on the data, a risk analysis can be well estimated, underestimated, and overestimated. As a result, it is preferable to use the data obtained from numerical simulation in comparison with the data obtained from empirical laws.

\begin{tabular}{lcc}
\hline Fireball characteristics & Empirical & Present data \\
\hline Max-diameter $(\mathrm{m})$ & 163 & 174 \\
\hline Duration $(\mathrm{s})$ & 12.7 & 14 \\
\hline Max-height $(\mathrm{m})$ & 122 & 160 \\
\hline
\end{tabular}

Table 4.

Comparison between numerical and empirical data for MPP3-plant. 

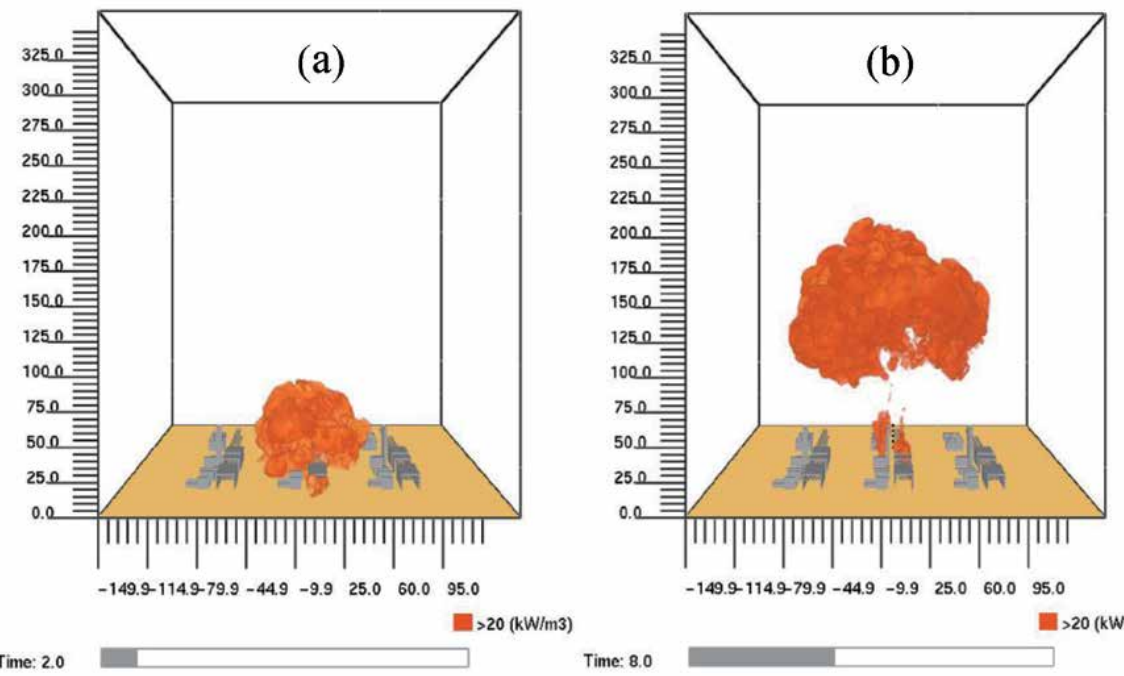

Time: 2.0

Time: 8.0

Figure 4.

Fireball simulation at (a) $2 \mathrm{~s}$ and $(b) 8 s$.
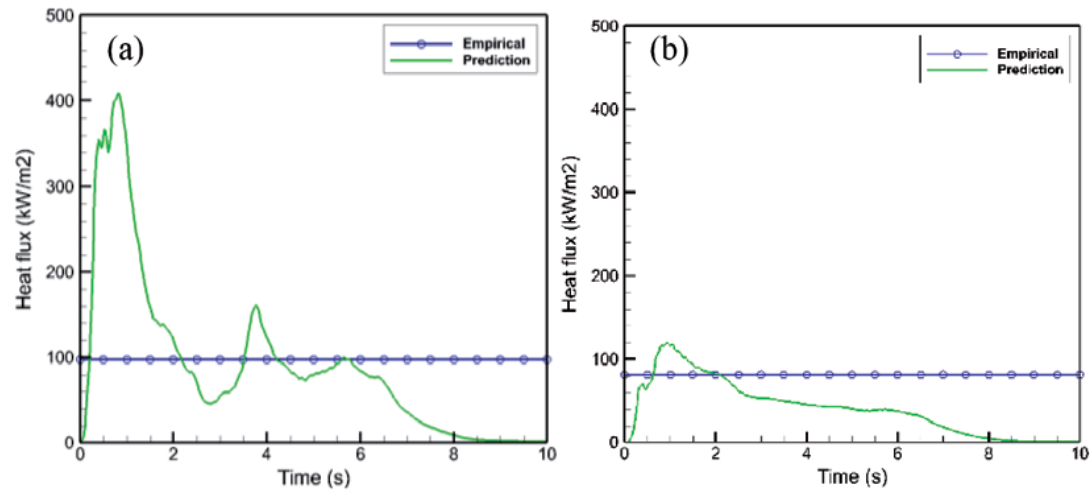

Figure 5.

Comparison between empirical and thermal flux prediction at the distance of (a) $50 \mathrm{~m}$ and $(b) 75 \mathrm{~m}$ on the ground level.

In addition to the evolutions of the heat flux presented in Figure 5, the same observation is found in Figure 6(a) and (b). These figures show the heat flux distribution at $1 \mathrm{~s}$ and $4 \mathrm{~s}$ in order to better observe the heat flux field over the entire MPP3-plant. With this illustration, it is shown that it is necessary to present the results during the first few seconds. Indeed, considering the heat flux distribution throughout the plant, it is observed during the first instants that the heat flux intensity is important at the explosion source and decreases in the remote zones.

In Figure 6, it is observed that the heat flux intensity decreases at the explosion origin and increases in the remote zones with the fireball evolution in terms of diameter and height. This observation is like the reality and is true only for a fireball height less than $70 \mathrm{~m}$.

In conclusion, the BLEVE thermal effects in Hassi R'Mel Gas Processing Plant are well predicted by FDS. In addition, the predictions of FDS give information which allows a better understanding on BLEVE phenomenon. It can be considered also a tool that can be used in a QRA. 

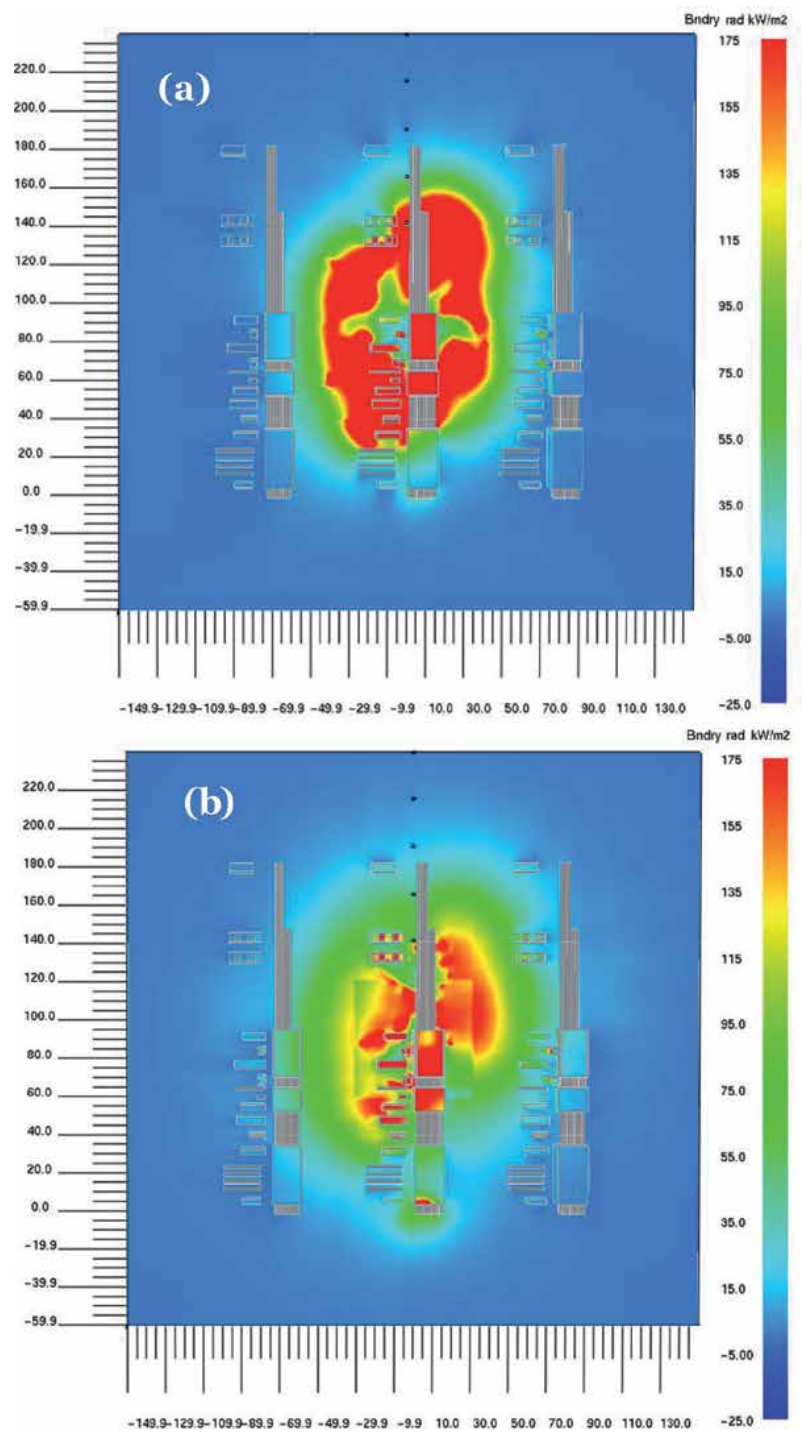

Figure 6.

Thermal radiation contour plot in the $x-y$ plane at $(a) 1 s$ and $(b) 4 s$.

\section{Conclusion}

In this chapter, a CFD evaluation of the thermal effects of the BLEVE phenomenon in a real installation is presented. This evaluation firstly required the code validation to correctly simulate the BLEVE characteristics in comparison with the data that come from literature experimental test. Numerical calculations were performed using the CFD FDS code version 6.5.3 with the default numerical models. The results show a good agreement between the predictions and the experiments, justifying a nice capability to FDS to simulate the fireball dynamics with a good accuracy.

After highlighting that FDS can predict the spatiotemporal evolution of a fireball in comparison with an experimental test, a simulation of the BLEVE is performed in a real installation. This involves studying the fireball thermal effects resulting from the explosion of a pressurized propane tank in an Algerian gas treatment unit. The results obtained showed great relevance of carrying out this type of study in 
BLEVE Fireball Effects in a Gas Industry: A Numerical Modeling Applied to the Case...

DOI: http://dx.doi.org/10.5772/intechopen.92990

this type of installation. From the numerical data, it is shown that the heat flux reaches a maximum value during the first moments at ground level and decreases with the elevation of the fireball. In addition, comparisons between prediction and empirical models, based on heat flux evolution, show that prediction is representative of reality compared to empirical models. Thus, for a risk analysis in this type of installation, it is preferable to use the numerical approach.

Moreover, the current results can be considered as a first step to make a modeling of the BLEVE phenomenon, and in order to improve the global description of this phenomenon, it will be necessary to consider, in a next work, the container disintegration in order to model the complete BLEVE process.

\section{Author details}

Brady Manescau ${ }^{1 *}$, Khaled Chetehouna ${ }^{1}$, Ilyas Sellami ${ }^{1,2,3}$, Rachid Nait-Said ${ }^{3}$ and Fatiha Zidani ${ }^{2}$

1 INSA Centre Val de Loire, Univ. Orléans, PRISME, Bourges, France

2 LRPI Laboratory, Institute of Health and Industrial Safety, University of Batna 2 - Mostefa Ben Boulaïd, Fesdis, Batna, Algeria

3 DIRE Laboratory, Department of Applied Engineering, Institute of Technology, Kasdi Merbah University - Ouargla, Ouargla, Algeria

*Address all correspondence to: brady.manescau@insa-cvl.fr

\section{IntechOpen}

(C) 2020 The Author(s). Licensee IntechOpen. This chapter is distributed under the terms of the Creative Commons Attribution License (http://creativecommons.org/licenses/ by/3.0), which permits unrestricted use, distribution, and reproduction in any medium, provided the original work is properly cited. (cc) BY 


\section{References}

[1] Sellami I, Nait-Said R. Analyse Quantitative des Risques Industriels: Apport des Techniques Floues et Possibilistes. Saarbrücken: Éditions Universitaires EuropÉennes; 2017

[2] CCPS. Guidelines for Vapor Cloud Explosion, Pressure Vessel Burst, BLEVE, and Flash Fire Hazards. 2nd ed. Hoboken, NJ, USA: John Wiley \& Sons, Inc.; 2010

[3] Abbasi T, Abbasi SA. The boiling liquid expanding vapour explosion (BLEVE): Mechanism, consequence assessment, management. Journal of Hazardous Materials. 2007;141(3):489-519

[4] Roberts AF. Thermal radiation hazards from releases of LPG from pressurised storage. Fire Safety Journal. 1981;4(3):197-212

[5] Crocker WP, Napier DH. Assessment of mathematical models for fire and explosion hazards of liquefied petroleum gases. Journal of Hazardous Materials. 1988;20(C):109-135

[6] Prugh RW. Quantitative evaluation of 'Bleve' hazards. Journal of Fire Protection Engineering. 1991;3(1):9-24

[7] Roberts T, Gosse A, Hawksworth S. Thermal radiation from fireballs on failure of liquefied petroleum gas storage vessels. Process Safety and Environment Protection. 2000;78(3):184-192

[8] Birk AM, Davison C, Cunningham M. Blast overpressures from medium scale BLEVE tests. Journal of Loss Prevention in the Process Industries. 2007;20(3):194-206

[9] Bubbico R, Marchini M. Assessment of an explosive LPG release accident: A case study. Journal of Hazardous Materials. 2008;155(3):558-565
[10] Chen S, Sun J, Wan W. Boiling liquid expanding vapor explosion: Experimental research in the evolution of the two-phase flow and over-pressure. Journal of Hazardous Materials. 2008;156(1-3):530-537

[11] Laboureur D, Heymes F, Lapebie E, Buchlin JM, Rambaud P.

BLEVE overpressure: Multiscale comparison of blast wave modeling. Process Safety Progress. 2014;33(3):274-284

[12] Laboureur D et al. A closer look at BLEVE overpressure. Process Safety and Environment Protection. May 2015;95:159-171

[13] Van Den Berg AC, Van Der Voort MM, Weerheijm J, Versloot NHA. Expansion-controlled evaporation: A safe approach to BLEVE blast. Journal of Loss Prevention in the Process Industries. 2004;17(6):397-405

[14] Yakush SE, Makhviladze GM. Large Eddy simulation of hydrocarbon fireballs Institute for Problems in mechanics. In: Proceedings of the European Combustion Meeting. 2005

[15] Roper F, Arno J, Jaggers HC. The effect of release velocity and geometry on burning times for non-premixed fuel gas clouds. Combustion Science and Technology. 1991;78(4-6):315-338

[16] Luther W, Müller WC. FDS simulation of the fuel fireball from a hypothetical commercial airliner crash on a generic nuclear power plant. Nuclear Engineering and Design. 2009;239(10):2056-2069

[17] Rajendram A, Khan F, Garaniya V. Modelling of fire risks in an offshore facility. Fire Safety Journal. 2015;71:79-85

[18] Sikanen T, Hostikka S. Numerical simulations of liquid spreading and 
fires following an aircraft impact. Nuclear Engineering and Design. 2017;318:147-162

[19] Balke C, Heller W, Konersmann R, Ludwig J. Study of the Failure Limits of a Railway Tank Car Filled with Liquefied Petroleum Gas Subjected to an Open Poolfire Test. Berlin: Germany; 1999

[20] Mishra KB, Wehrstedt KD, Krebs H. Boiling liquid expanding vapour explosion (BLEVE) of Peroxyfuels: Experiments and computational fluid dynamics (CFD) simulation. Physics Procedia. 2015;66(1):149-152

[21] Shelke A, Maheshwari NK, Gera B, Singh RK. CFD analysis of hydrocarbon fireballs. Combustion Science and Technology. 2017;189(8):1440-1466

[22] INERIS. OMEGA 5- Le BLEVE: phénoménologie et modélisation des effets thermiques. Institut National de l'Environnement Industriel et des Risques; 2002

[23] Casal J. Evaluation of the Effects and Consequences of Major Accidents in Industrial Plants. Vol. 8. Amsterdam: Elsevier; 2008

[24] CCPS. Guidelines for Chemical Process Quantitative Risk Analysis. 2nd ed. New York: American Institute of Chemical Engineers; 2000

[25] CCPS. Guidelines for Consequence Analysis of Chemical Releases. New York: American Institute of Chemical Engineers; 1999

[26] Chakrabarty A, Mannan S, Cagin T. Multiscale Modeling for Process Safety Applications. ButterworthHeinemann; 2016

[27] Mannan S. Lee's Loss Prevention in the Process Industries: Hazard Identification, Assessment, and Control. 4th ed. Amsterdam: ButterworthHeinemann Elsevier; 2012
[28] Papazoglou IA, Aneziris ON. Uncertainty quantification in the health consequences of the boiling liquid expanding vapour explosion phenomenon. Journal of Hazardous Materials. 1999;67(3):217-235

[29] TNO. Methods for the Calculation of Physical Effects (Yellow Book): CPR 14E. 3rd ed. The Hague: Committee for the Prevention of Disasters; 2005

[30] TNO. Guidelines for Quantitative Risk Assessment (Purple Book): CPR 18E. Den Haag: Sdu Uitgevers; 1999

[31] Satyanarayana K, Borah M, Rao PG. Prediction of thermal hazards from fireballs. Journal of Loss Prevention in the Process Industries. 1991;4(5):344-347

[32] McGrattan K, Hostikka S, McDermott R, Floyd J, Weinschenk C, Overholt K. Fire Dynamics Simulator, User's Guide. 2015

[33] Gropp W, Lusk E, Skjellum A. Using MPI: Portable Parallel Programming with the Message-Passing Interface. 2000

[34] Magnussen BF. The Eddy dissipation concept- a bridge between science and technology. In: ECCOMAS Thematic Conference on Computational Combustion. 2005. pp. 21-24

[35] Magnussen BF, Hjertager BH. On mathematical modeling of turbulent combustion with special emphasis on soot formation and combustion. Symposium on Combustion. 1977;16(1):719-729

[36] Poinsot T, Veynante D. Theoretical and Numerical Combustion. 2nd ed. Edwards; 2005

[37] McGrattan K, Hostikka S, McDermott R, Floyd J, Weinschenk C, Overholt K. Fire Dynamics Simulator Technical Reference Guide Volume 1: Mathematical Model. 2017 
[38] Makhviladze GM, Roberts JP, Yakush SE. Formation and combustion of gas clouds in accidental discharge to the atmosphere. Combustion, Explosion, and Shock Waves. 1997;33(2):144-156

[39] Magnognou B, Garo JP, Coudour B, Wang HY. Risk analysis of unburnt gas ignition in an exhaust system connected to a confined and mechanically ventilated enclosure fire. Fire Safety Journal. July 2017;91:291-302

[40] Hurley MJ et al. SFPE Handbook of Fire Protection Engineering. Fifth ed. 2016

[41] SONATRACH. Risk Assessment Study of Industrial Units, Report $\mathrm{N}^{\circ}$ EP002715. Hassi R'Mel; 2010 



\section{Edited by Fahmina Zafar and Anujit Ghosal}

To ensure a healthy lifestyle, fire safety and protocols are essential. The population boom, economic crunches, and excessive exploitation of nature have enhanced the possibilities of destruction due to an event of a fire. Computational simulations enacting case studies and incorporation of fire safety protocols in daily routines can help in avoiding such mishaps. 